\title{
Adoption of resource -conserving agricultural technologies: An economic and *policy analysis for South Africa
}

\author{
Daniel Vusanani Dlamini \\ West Virginia University
}

Follow this and additional works at: https://researchrepository.wvu.edu/etd

\section{Recommended Citation}

Dlamini, Daniel Vusanani, "Adoption of resource -conserving agricultural technologies: An economic and *policy analysis for South Africa" (2005). Graduate Theses, Dissertations, and Problem Reports. 2324. https://researchrepository.wvu.edu/etd/2324

This Dissertation is protected by copyright and/or related rights. It has been brought to you by the The Research Repository @ WVU with permission from the rights-holder(s). You are free to use this Dissertation in any way that is permitted by the copyright and related rights legislation that applies to your use. For other uses you must obtain permission from the rights-holder(s) directly, unless additional rights are indicated by a Creative Commons license in the record and/ or on the work itself. This Dissertation has been accepted for inclusion in WVU Graduate Theses, Dissertations, and Problem Reports collection by an authorized administrator of The Research Repository @ WVU. For more information, please contact researchrepository@mail.wvu.edu. 


\title{
Adoption of Resource Conserving Agricultural Technologies: An Economic and Policy Analysis for South Africa
}

\author{
Daniel Vusanani Dlamini
}

\author{
Dissertation submitted to the \\ Davis College of Agriculture, Forestry, and Consumer Sciences \\ at West Virginia University \\ in partial fulfillment of the requirements \\ for the degree of \\ Doctor of Philosophy \\ in \\ Natural Resource Economics
}

Tim T. Phipps, PhD, Chair
Gerard E. D’Souza, PhD
Mark Sperow, PhD
Dale Colyer, PhD
Stratford M. Douglas, PhD

Department of Agricultural and Resource Economics

Morgantown, West Virginia

2005

Key Words: Logit Model, Resource Degradation, Land Quality, Policy, Off-Farm Damage, Best Management Practices, South Africa

Copyright 2005 Daniel Vusanani Dlamini 


\section{ABSTRACT \\ Adoption of Resource Conserving Agricultural Technologies: An Economic and Policy Analysis for South Africa}

\section{Daniel Vusanani Dlamini}

Land degradation continues to be a threat to the agricultural sector of South Africa. Land degradation induced by agricultural production activities is considered to be among the major factors responsible for a decline in land productivity. Conservation efforts through government intervention and voluntary efforts have produced minimal success compared to the desired targets. The purpose of this study is to understand the factors that influence the adoption decisions of resource conserving technologies in the context of commercial farmers in South Africa.

Adoption of conservation-oriented agricultural technologies in South Africa is influenced by a wide range of economic and social factors, and land characteristics. It is important to understand the role of these factors to ensure the development of appropriate technologies and the design of successful conservation programs. This study examines the impact of such factors on the adoption of resource conserving technologies in commercial farms of South Africa.

Models to evaluate the probability of adoption are specified for given Best Management Practice technologies and are estimated using a logit maximum likelihood procedure using a nine-province survey data set. The findings suggest that while government financial assistance to farmers, the level of farmer education, farmers' income, and farm size have a significant positive effect on the marginal probability of technology adoption. On the other hand tenure insecurity (measured by land rent) and age of farmer have significant negative effects on the adoption. Availability of credit to farmers, off-farm employment opportunities, and perception of the resource degradation problem has a positive influence on the probability of adoption; however, their magnitude was not found to be statistically significant. An important conclusion to be drawn from this study is that differences in farmers' socio-economic conditions, institutional settings, and their complementarities with policy programs need to be factored into land conservation-oriented intervention programs. 


\section{TABLE OF CONTENTS}

CHAPTER 1 Introduction.......................................................................1

1.1 BACKGROUND ......................................................................

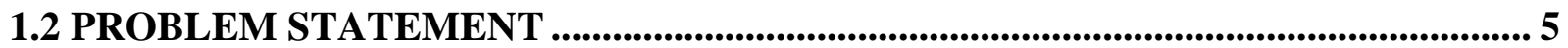

1.3. OBJECTIVES OF THE STUDY ........................................................................................ 8

1.4. RESEARCH HYPOTHESES .............................................................................................. 9

1.5 SCOPE AND LIMITATIONS OF THE STUDY ...................................................... 9

1.6. METHOD AND ORGANIZATION .................................................................. 10

CHAPTER 2 Literature Review on Technology Adoption and Resource Conservation Policy in Agriculture..................................................................................................................... 12

2.1. INTRODUCTION.............................................................................................................. 12

2.2. THE ECONOMIC MEANING OF TECHNOLOGY ADOPTION AND ITS

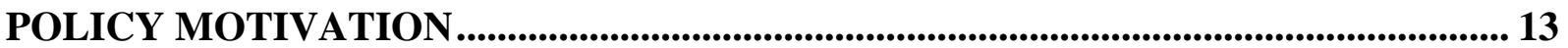

2.3. REVIEW OF EMPIRICAL STUDIES ON TECHNOLOGY ADOPTION IN

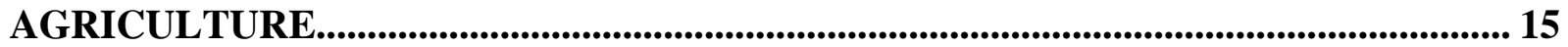

2.4 OVERVIEW OF AGRICULTURAL RESOURCES IN SOUTH AFRICA................. 25

2.5. RESOURCE CONSERVATION TECHNOLOGIES ................................................. 30

2.6 PUBLIC POLICY, RESOURCE DEGRADATION, AND RATIONALE FOR

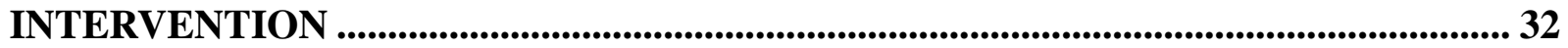

2.7. FACTORS AFFECTING AGRICULTURAL TECHNOLOGY ADOPTION ............ 35 2.8. SOUTH AFRICAN AGRICULTURAL SECTOR IN PERSPECTIVE AND ITS ENVIRONMENTAL POLICY ........................................................................................ 37

2.8.1.a The Resource Poor Farmers ......................................................................... 38

2.8.1.b Commercial Farmers............................................................................................... 39

2.8.2. Environmental Policy and Agriculture .......................................................................... 40

Chapter 3 Theoretical Model of Adoption of Resource Conservation Technologies ............ 44

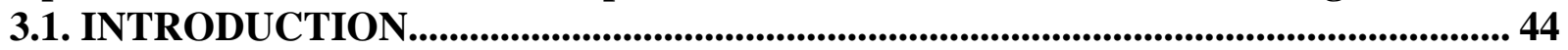

3.2. TECHNOLOGY ADOPTION THE ABSENCE OF GOVERNMENT POLICY

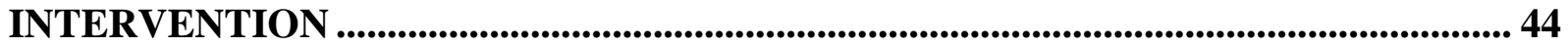

3.3. CONTROLLING OF OFF-FARM RESOURCE DEGRADATION .......................... 47

3.4 A RANDOM UTILITY MODEL ................................................................................. 49

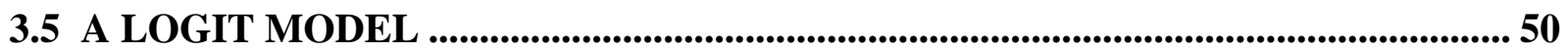

3.6 ESTIMATION OF THE LOGIT MODEL ..................................................................... 51

3.7 RANDOM UTILITY AND THE MULTINOMIAL LOGIT MODEL ......................... 54

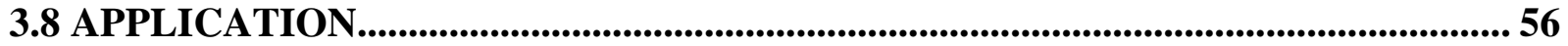

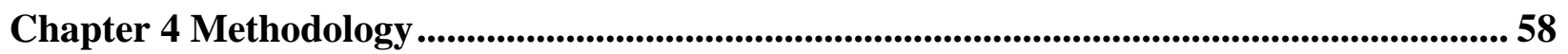

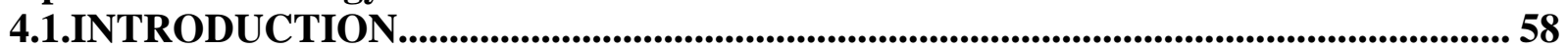

4.2. MODEL SPECIFICATION AND DESCRIPTION OF THE VARIABLES

INCLUDED IN THE MODEL ...............................................................................58

4.2.1. Model Selection ..................................................................................................59

4.2.2. Empirical Logit Models...........................................................................................................6 61

4.2.3. Description of the Explanatory Variables ........................................................................ 65

4.2.3.a Household Social Characteristics (S) ....................................................................... 65

4.2.3b. Land and Farm Characteristics $(\mathrm{L})$.................................................................... 67

4.2.3c. Economic Characteristics...................................................................................... 69 
4.2.3d. Institutional Characteristics ................................................................... 70

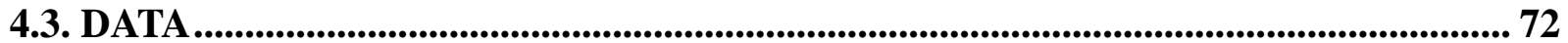

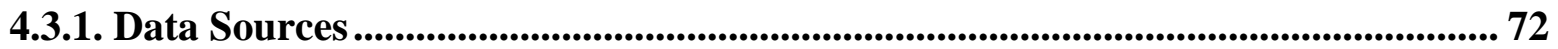

4.3.2. Survey Design ............................................................................................. 73

4.3.3. Determining the Sample Size ......................................................................... 74

4.3.4. The Sampling Procedure ....................................................................................... 75

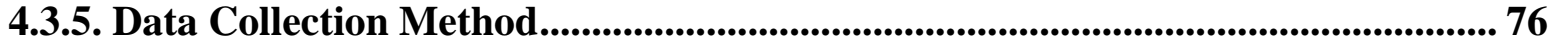

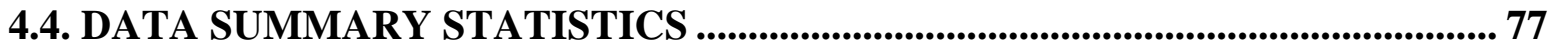

Chapter 5 Econometric Model Results and Analysis .................................................................. 78

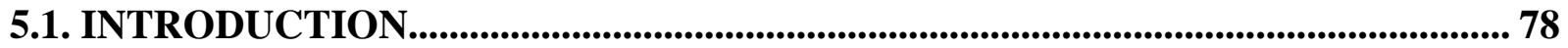

5.2. MEASUREMENT AND INTERPRETATION OF LIKELIHOOD ESTIMATORS78

5.2.1. Hypothesis Testing and Goodness of Fit Tests............................................... 78

5.2.2. Marginal Effects Estimation and Economic Interpretation ............................. 80

5.3. EMPIRICAL LOGIT MODEL RESULTS AND ANALYSIS OF ADOPTION....... 81

5.3.1 Adoption of Best Management Practices (BMP) Model 1.................................... 81

The Binary choice Explanatory variable Model (Model 2).......................................... 89

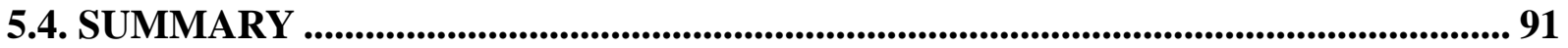

Chapter 6 Summary Policy Implications and Conclusion ................................................. 92

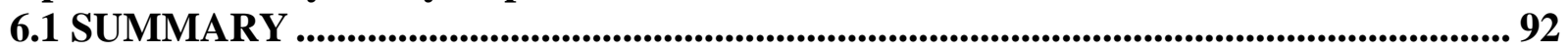

6.2. POLICY IMPLICATIONS AND RECOMMENDATIONS ................................... 95

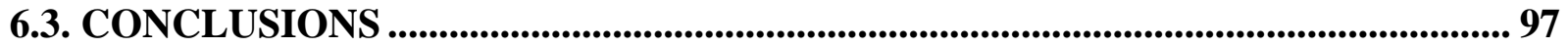

6.3.1. Contribution of the Study.................................................................................................. 98

6.3.2. Suggestions for Future Research and Development ........................................... 99

References.................................................................................................................... 100

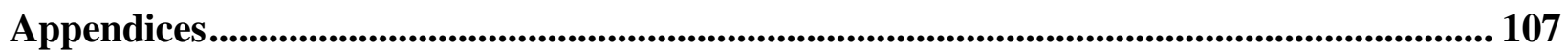

Appendix A. SURVEY QUESTIONNAIRE ................................................................. 108

Appendix B. SELECTED CONSERVATION AND ENVIRONMENTALLY-FOCUSED

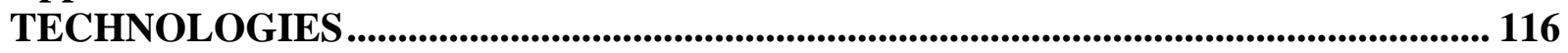

Appendix C DESCRIPTIVE STATISTICS.......................................................... 118

Appendix D DESCRIPTIVE STATISTICS BY PROVINCE ...................................... 119

Appendix E NUMBER OF ADOPTERS AND NON -ADOPTERS BY PROVINCE.... 137

Appendix F DATA USED IN THE LOGIT MODEL ......................................................... 138 


\section{LIST OF TABLES}

Table 2.1: Land Area by Province............................................................................................. 25

Table 4.1: Definition Of Variables Used In The Decision Of Adopting Resource-Conserving Technologies (Model 1)...................................................................................................................... 63

Table 4.2: Definition of Variables (Binary) Used in the Decision to Adopt Resource-

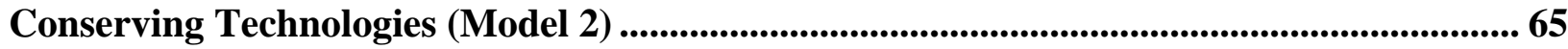

Table 4.3: Expected Signs for the Explanatory Variables .............................................. 72 Table 4.4: Number of commercial farming units in South Africa by land use and province

Table 4.5: Sampling Quotas by Land Use Category and by Province ..................................... 75

Table 4.6: Summary Statistics of the Data Set ........................................................................ 77

Table 5.1: Estimation Results for Model 1.............................................................................. 82

Table 5.2: Logit Model Results for Binary Explanatory Variables (Model 2)..................... 89 


\section{LIST OF FIGURES}

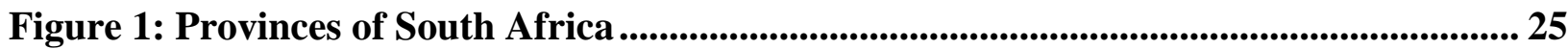

Figure 2: Agricultural Regional of South Africa ............................................................ 27

Figure 3: Rainfall Distribution ..................................................................................... 28

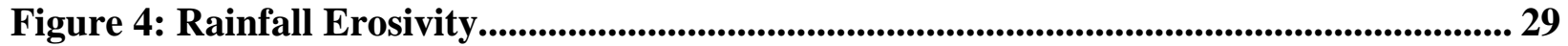

Figure 5: Predicted Soil Loss ....................................................................................................... 30 


\section{CHAPTER 1}

\section{INTRODUCTION}

\subsection{BACKGROUND}

Renewable natural resources, which comprise the environmental base for agriculture and most other economic activities in both urban and rural areas, are under threat from degradation throughout the developing world. Agricultural land is eroding and water is being over used, mismanaged, and polluted on a large scale (FAO, 1999). The problem is, in general more, severe where farmers are forced by population pressures to farm on marginal land (Hugo et al., 1997; Steiner, 1998). In some communities, the long-term viability of agricultural production is threatened by land degradation because of irreparable damage to land resources. Reduction of the land degradation problem requires action, but the development of relevant environmentally focused programs requires better knowledge of the factors that prevent the use of conservation practices by land owners and operators.

A review of the world-wide impact of soil degradation found that 1.2 billion ha have undergone moderate or worse degradation from human activities over the last 45 years (World Bank, 1992). Some $55 \%$ of the world's cultivated land is affected by resource degradation (GLASOD, 1990). In Africa, it is estimated that 321 million ha (14.4\% of the total vegetated land) have been degraded moderately or worse and another 174 million ha lightly degraded (Oldeman et al, 1991).

According to Staatz and Eicher (1998) and Funes et al. (2002), acid rain, pollution, environmental degradation, and sustainable ${ }^{1}$ agriculture emerged as central issues in the 1980 's

\footnotetext{
${ }^{1}$ The Bruntland (1985) definition of sustainable development is the one that is generally acceptable. That is, "development which meets the needs of the present generation without compromising the ability of future generations to meet their own needs."
} 
and 1990's, especially following the release of the influential Bruntland report Our Common Future (World Commission on Environment and Development, 1987) and the UN conference on the Environment and Development (Earth Summit) in Rio de Janeiro, Brazil in 1992. This was followed by the Rio +10 Conference which was held in Johannesburg, South Africa in 2002 (The World Summit on Sustainable Development). The "Earth Summit" was established to monitor the progress of sustainable development using its standards or indicators. The latter summit sparked an increased awareness, both to the public and policy makers that issues pertaining to environment and agricultural development cannot be separated and as such need to be addressed jointly. In line with this statement, if Southern Africa is to achieve meaningful levels of economic development and social progress, then issues of agricultural and natural resource management can no longer be divorced from issues of politics, democracy and good governance (Rukuni, 2002). There has been sound support for sustainable agriculture from both politicians and policy makers in recent times in most parts of the world, particularly in the developed countries.

South Africa is endowed with wide range of natural resources, though agricultural resources are limited and characterised by skewed and uneven rainfall distribution. South Africa is a semi-arid country and crippling droughts are common (Zimmerman, 2000). There is an obvious need to improve and secure land productivity as well as labour productivity (Perret and Mercoiret, 2003). Given continuous degradation of natural resources in South Africa, the consequences for food security, nutrition and sustainable agricultural development are enormous unless appropriate farming systems are practiced. The major challenge for South Africa, as pointed out by Kleynhans (2003), is how to use the limited arable land in an ecologically sustainable manner. 
As far as agricultural development in South Africa is concerned, the government is confronted with the challenge of addressing past injustices through land reform and other related programmes. Simultaneously, it is concerned about agricultural production that is dependent on farming practices. One of the broad principles governing policy towards the agricultural use of natural resources in South Africa is that the government is responsible for promoting the sustainable use of natural resources in agriculture. This principle requires that resources be used at a rate that does not exceed the rate of renewal while maintaining and enhancing the ecological integrity of natural systems, and minimizing or avoiding risks that would lead to irreversible damage. Second, the primary custodian of the environment is the resource user who bears the responsibility for conservation, sustainability and maintenance of biodiversity. Thus, the government should design policies and enact legislation that will strengthen the right of land users and facilitate their assumption of responsibility for conserving natural resources (Green paper on RSA Agriculture, 1998).

In recent years, many governments, including the government of South Africa, have attempted to address the problems of land degradation arising from agricultural production. Alternative policies to address these problems can be categorized into three areas: 1) regulation or command and control, that includes mandatory types of management practices; 2) incentives, such as soil erosion reduction subsidies, or taxes on inputs; and 3) voluntary programs that create environmental awareness and provide technical assistance to induce farmers to adopt best management practices.

Historically, the government of South Africa has made numerous attempts to correct some of the environmental problems associated with agricultural production through various conservation programs to encourage farmers to adopt best land management practices. For 
example, soil conservation has been part of agricultural policy in South Africa since 1946. A unit staffed with natural agricultural resources inspectors was established to manage and monitor the utilization of resources. The Government also has adopted several other programs that included soil conservation goals. Among these programs is the Soil Conservation Act 43 of 1946, which provided for financial assistance to farmers for soil conservation works and established soil conservation institutions at regional levels. Soil Conservation Act 76 of 1969 amended this program with emphasis on the command and control approach to soil conservation. It authorizes the government to regulate land use by setting standards and enforcing compliance by farmers, including enforcing grazing systems. The Conservation of Agricultural Resources Act 43 of 1983 allows the government to supply subsidies to individual farmers for soil conservation activities based on the extent of soil erosion levels on the farm. Recently, the policy direction is shifting focus to voluntary programs such as the Land Care program (South African Department of Agriculture 2002). Despite the role that these programs played, little is known about how farmers have responded to such programs.

Land degradation continues to be a problem that threatens South Africa's sustainable agricultural development (Van Zyl etal., 1996). For South Africa's agriculture to continue along a sustainable path of economic development, further production increases must be generated by technologies that are both profitable and environmentally friendly (South African Department of Agriculture, 2003). The high expectation placed on agriculture as a basis to overcome unemployment and poverty has meant increased pressure for land with intensive agricultural practices, making achieving this goal difficult. The agricultural development strategy has become one of expanding agricultural production through increased land utilization and other intensification policies with the goal of maintaining a high agricultural contribution to economic 
growth and food security. Currently, agriculture accounts for 5\% of the GDP of South Africa (South African Department of Agriculture, 2002). The expansion may create pressure on marginal land and steeper slopes, thus inducing intensive-land use practices that may cause land degradation.

To achieve sustainable agricultural production, the Agricultural Research Council (ARC) undertook a study to identify Eco-technologies, which provide farmers with economic and environmental benefits under the Land Care Program. The results of this study indicated that there were substantial benefits to farmers and society as a whole when farmers replaced conventional cultivation systems with eco-technologies such as conservation farming and water harvesting. These findings are in line with the Sectoral Strategic Plan of the Department of Agriculture in South Africa, which encourages farmers to adopt farming practices that will result in short-term economic benefits for the farmers and contribute to long-term environmental objectives (NDA, 2002). The proposed technologies are seen to be technologies that may reduce degradation of the land.

\subsection{PROBLEM STATEMENT}

There is great concern around the world for the environmental problems resulting from the industrial agriculture model, which has induced erosion, salinity, and infertility in a large portion of our agricultural soils and has led to loss of biodiversity, growing deforestation, and socioeconomic problems in rural regions, including mass migration to cities (Funes et al., 2002). This has influenced agricultural production systems. Changes in agricultural practices were also sparked by, inter alia, the stringent environmental care requirements (Kleynhans, 2003), increased awareness of the environment and the importance of safe food. Many retail 
supermarkets in Europe, which is one of South Africa's major markets, have strict regulations regarding pesticide residue on fruits and vegetables. Consequently, organic farming and other alternative technologies and techniques are being adopted by farmers in developing countries as a means of improving food production (Onduru et al., 1998) and complying with the requirements imposed by certain institutions such as the European Union.

The South African Government's interventions to address the issue of sustainable utilisation of resources in agriculture over the years have not produced the desired results. Degradation of land and water resources still poses a threat to agriculture and other sectors of the South African economy (South Africa National Department of Agriculture, 2002). The ecotechnologies made available to farm operators have not been adopted by a substantial number of farmers. Experience with technologies such as conservation farming and rainwater harvesting demonstrates that even when technologies are profitable, barriers to adopting new practices can limit their effectiveness.

Recently, there has been a policy shift by the government of South Africa to focus on voluntary programs for farmers to adopt best management practices as opposed to a command and control strategy. In the course of voluntary resource conservation programs, the usual policy objective is to induce farmers to adopt a specific technology using a mix of information, technical and financial assistance. A farmer's willingness to adopt land degradation reducing technologies is likely to depend upon a number of factors. These factors include changes in profitability due to adoption, changes in on-farm environmental quality, socio-economic, information and policy factors, and utility derived by the farmer from improved environmental quality. Therefore, it is important to empirically determine the specific role these factors play in the willingness to adopt decisions of the farmer. 
More recently, increased concerns about water quality degradation from non-point source pollution and the implementation of the natural agricultural resource regulations have generated interest in a variety of policies for environmental improvements in agriculture and mechanisms to encourage the adoption of conservation practices such as conservation farming methods (FAO, 2001). For these technologies to be attractive to farmers, they must provide short-term payoffs as well as improve the long-term sustainability of the natural resource base on which agriculture depends (NDA, 2003). Understanding the impact of such technologies must become more pronounced as the economic development strategy, rather than ingrained only in the environmental strategy. The destruction of soil productivity is of special importance for an economic evaluation.

Economic analysis of the efficiency of these technologies requires an understanding of the costs of achieving gains in environmental quality due to the adoption of conservation practices. In addition, we need to understand how farmers respond to new technologies. Adopting conservation practices does not always lead to reduction in profit for farmers. In fact, even without any government subsidy, on average some of South Africa's (S.A.) farmers on privately owned land practice conservation farming. Nevertheless, to the extent that an individual farmer ignores the social benefits of conservation practices, the adoption rate is likely to be lower than socially optimal. Further, even when conservation practices can raise farmers' expected profit, they may be reluctant to adopt because the practices may be riskier. Numerous studies have shown, however, that profit is not always sufficient to guarantee adoption of a conservation technology (Sanders, Southgate and Lee, 1995). Furthermore, failure to adopt does not necessarily imply that the cost of adoption exceeds the benefits, since many other factors influence technology adoption decisions. 
Although technical studies from the Agricultural Research Council (ARC) and Consortium for Sustainable Soil Systems (CS3) have clearly indicated benefits of adopting conservation agriculture and sustainable soil systems (ARC, 2001; CS3, 2003), no study has analyzed the extent of their adoption and the influence of various interrelated factors that will affect the willingness to adopt decision. The question remains open as to whether there are any factors that may accelerate the rate farmers can adopt and make use of these technologies. These are important policy questions to enable the government to design policy instruments that may change the behavior of the farmers. The absence of empirical findings on this issue justifies further investigation.

\subsection{OBJECTIVES OF THE STUDY}

The main objective of this study is to examine a farmer's decision making to adopt environmentally focused production technologies as a means to control land and water degradation and improve agricultural productivity in South Africa. Specifically, the tasks to meet this objective are to:

1. Develop a theoretical model for determining the factors that influence a farmer's decision to adopt resource-conserving production technologies with and without government policy intervention.

2. Analyze the socio-economic and policy factors that affect technology adoption decisions.

3. Determine the resulting policy implications for future support measures to encourage adoption of the technologies. 


\subsection{RESEARCH HYPOTHESES}

It is hypothesized that:

1 The willingness to adopt land degradation reducing technologies increases as the farmer is more integrated with farmers' organizations.

2 Awareness of land degradation problems increases the chances of adopting technologies.

3 Adoption increases with access to income from off-farm employment.

$4 \quad$ Farmers are more likely to adopt resource conserving production practices if they own the land.

5 Farmers are more likely to adopt resource conserving farming practices if they have access to credit.

6 Adoption increases with the number of years of experience in farming.

7 Adoption of best management practices in agricultures increases with government assistance.

8 Farmers with large farms are more likely to adopt best management practices than small farms.

\subsection{SCOPE AND LIMITATIONS OF THE STUDY}

This study is based on micro level economic analysis of farmers' BMP adoption behaviors in South Africa. The findings could represent the national perspective of adoption of environmentally focused technologies in agriculture, with a certain level of adjustment. Generalization of the results, however, requires caution and supplementation of the results with further studies because of the rapidly reforming agricultural sector. The agricultural sector 
constitutes both commercial and emerging farmers. This may make a difference in adoption behavior. Only the commercial economic sector aspects are dealt with in this study. Neoclassical theory states that institutional factors and market structure play an important role in determining long-term investment for sustainable resource management. This study deals with those institutional and market factors that apply to commercial farmers.

The market and institutional environment in which these two groups operate are different. This implies the need for extended time devoted to research activities to collect information and analyze the adoption behavior differences. The time and resources required to achieve this is beyond the scope available for this study. Therefore, the results need to be understood in this context and can only be taken as indicative, rather than being considered as definitive.

\subsection{METHOD AND ORGANIZATION}

Chapter 2 of this dissertation is a review of literature on technology adoption in agriculture, especially technologies devised to reduce soil erosion and conserve water resources. Soil conservation practices are similar to pollution-reducing technologies in that the private costs of adoption may outweigh the private benefits. It also reviews literature on structure of agriculture and land degradation in South Africa, the concept of best management practices, and public policy. It concludes with a review of previous studies on technology adoption.

The theoretical model explaining the individual farmer's adoption decision is presented in Chapter 3. This model incorporates the level of on-farm quality into the farmer's optimization processes. It discusses theoretical model development relevant for studying technology adoption decisions based on established economic theories. It presents the model for technology selection with and without government policy intervention. Analysis of the model determines the optimal 
on-farm environmental quality level and its trade-off with profit. The model also presents the potential effects of off-farm resource quality incorporation and discusses the effect of policy intervention in the form subsidy or tax.

The random utility model and its linkage to logit model are discussed in this chapter. The theoretical logit model is also discussed and finally, the maximum likelihood estimation of the logit model and applications of the theoretical model are discussed.

Logit models are specified to predict the farmer's decision to adopt as a function of the factors discussed in presented in chapter 3 . The corresponding discrete dependent variable econometric model is described. The chapter concludes with a description of the survey data set. The statistical methods used are discussed in chapter 4.

Chapter 5 presents the estimation and analysis of the econometric results. A summary of descriptive statistics is discussed and the estimation of the logit models is presented. Chapter 6 presents the summary, policy implications and conclusions. 


\section{CHAPTER 2}

\section{LITERATURE REVIEW ON TECHNOLOGY ADOPTION AND RESOURCE CONSERVATION POLICY IN AGRICULTURE}

\subsection{INTRODUCTION}

This chapter reviews the previous literature and studies on technology adoption decisions, economic motivation for adoption, and a methodological approach used in modelling technology adoption decisions in the agricultural sector. It also provides a review of the agricultural sector and resources in South Africa. This chapter is, thus, subdivided into six sections. Section one (2.1) addresses the policy motivation of the public sector to pursue resource conserving production technologies in agriculture. The second section (2.2) extensively reviews empirical studies and literature in agricultural adoption decisions of farmers. Section three (2.3) provides an overview of agricultural resources in South Africa. The fourth section (2.4) reviews feasible technologies that may reduce resource degradation and why one technology may be preferred against the other depending on socio-economic factors associated with a farming region. Section 2.5 discusses public policy for environmentally conscious agricultural production and the economic rationale for public sector intervention. Section 2.6 primarily focuses on the factors that are identified as affecting the decision of farmers to adopt a new technology, ranging from psychological to economic factors. Finally, section (2.7) provides a broad review of the agricultural sector in South Africa, legislation dealing with best farming practices, and discussion of the concept of best management practices in agriculture vis-à-vis environmental and resource conservation goals. 


\subsection{THE ECONOMIC MEANING OF TECHNOLOGY ADOPTION AND ITS POLICY MOTIVATION}

Voluntary adoption of a new technology refers to the integration of a different technology than the one that was previously in use, which presumably puts the adopter at a higher utility or economic welfare level. From this simple definition, two important elements of a technology adoption process may be identified: that of availability of an alternative viable technology to adopt; and that of ensuring the adopted technology will meet a pre-stated expectation of higher economic welfare. Though the question of whether a given better technology or technical improvement will be adopted or not may depend on the perception of its marginal costs and benefits to the adopter, the extent of technology adoption itself in the long-run will also depend on myriad of socio-economic factors.

Adoption is defined as the degree of new technology use in a long-run equilibrium when a farmer has full information about the new technology and its potential (Feder, Just, and Zilberman, 1985). Adoption at the farm level describes the realization of the farmer's decision to apply a new technology in the production process. On the other hand, aggregate adoption is the process by which a new technology spreads or diffuses within a region. For this reason, a distinction exists between adoption at the individual farm level and aggregate adoption within a targeted region. In industries where technological progress and technical change are rapid and volatile, the achievement of an equilibrium level of adoption at any particular time becomes difficult. However, if technological change has a phased process, then before the next wave of new innovations arrive, the current best available practice may diffuse and become standard, hence at equilibrium. 
Research on the inter-temporal link between investment in technological innovation and a country's productivity and economic growth indicates a significant and positive relationship between the two. For instance, (Solow, 1994 and Griliches, 1995), argue that technological change is a critical component of productivity and economic growth. The rate of technology adoption and resulting productivity growth is also linked with increased competitiveness of countries in the international market (Stoneman, 1995), and may also provide a balance of payments macroeconomic incentive. This provides the policy motivation for countries to pursue the adoption of new technologies in productive sectors of their economy. In the agricultural sector, the rapid diffusion and adoption of agricultural technologies is credited for sustained agricultural productivity growth that ensured abundance of food (Huffman and Evenson, 1993; Alston and Pardey, 1996; Ball et al, 1997).

Past studies focused on understanding the impact of new technology adoption on farm productivity and profitability, and the importance of farmer attributes on the rate of adoption without due attention on the environmental and resource degradation impacts of new technologies. For instance, the works of (Rahm and Huffman, 1984) and (Caswell and Zilberman, 1985) focus on farmers' characteristics determining technology adoption. Recent technology policy debates have surfaced during discussions about the appropriate role of public sector in fostering new innovations and promoting their adoption (Feder and Umali, 1993). This may have provided the motivation for recent studies in agricultural technology adoption to focus on the adoption decision of farmers given full information on the environmental and resource impacts of new alternative agricultural technologies. 


\subsection{REVIEW OF EMPIRICAL STUDIES ON TECHNOLOGY ADOPTION IN}

\section{AGRICULTURE ${ }^{2}$}

The literature on farmers' environmentally preferred technology decisions has succeeded in highlighting the complexity of factors involved in adoption. Each study adds to the body of knowledge in the area by identifying new variables to be considered in the behavioral function. The problem is that most of the studies are location specific and acknowledge that farmer's circumstances are diverse; hence it is difficult to draw reasonable generalizations. These differences emanate from the variation in agro-ecological, socio-economic and institutional factors among countries and regions. The commonly used econometric models in adoption studies use qualitative response variables such as used in logit and probit models. Both probit and logit analyses are well-established approaches in studies focusing on adoption of technologies (Burton et al, 1999). However, a greater number of studies use the logit analysis.

The adoption decision can be considered from a static or dynamic perspective. Static adoption models seek to explain how socio-economic factors influence technology adoption decisions at a particular time of reference. Dynamic models explain the diffusion of technology use over time due to changes in farmers' financial conditions, expected costs and benefits associated with a particular technology, information and prices. Most of the theoretical studies of individual farm behavior use static analyses but may still shed light on and the dynamic properties of technology adoption (Feder, Just and Zilberman, 1985).

Most technology adoption studies examine a farmer's decision about whether or not to use a new technology. The primary reason to consider a new technology is because it has the

\footnotetext{
${ }^{2}$ Section 2.3 from the beginning until the first full paragraph on page 20 is based closely on Norton, 1994 . Note that the focus of the current study is different in that Norton focussed more on adoption of technologies that improve water quality while this study focuses primarily on adoption of soil conservation practices. This study also uses primary survey data collected in South Africa while Norton's study dealt with a region of the U.S.
} 
potential to increase profits either by increasing yields or reducing costs. Adoption rates depend on a variety of factors. These include constraints on credit, land and labor, risk aversion coupled with uncertainty about the effects of the new technology on yields and prices, limited information, absence of markets for farmers' produce, and tenure arrangements (Feder, Just and Zilberman, 1985). Other adoption determinants include education, experience and other socioeconomic characteristics plus physical characteristics of the farm such as soil quality and climate.

Over a long period of time before and after the Green Revolution, the focus of agricultural technologies was on productivity increases in agriculture. With growing awareness about environmental and resource conservation, attention is shifting from increasing output to maintaining the productivity of the earth's land resources. As the concern over land degradation grew, so did studies on resource and environmental conservation.

The factors that explain adoption of yield-increasing technologies are not sufficient to explain the resource conservation decisions of farmers (Samann, et al, 1999). This is primarily because farmers may not capture all the benefits of adoption of resource conservation technologies plus the net benefits from adoption generally are not realized for many years.

One study (Ervin and Ervin, 1982) looked at the effects of economic, institutional, and farmer characteristics, plus the physical factors of the land, to model the decision-making process for the use of soil conservation techniques. They hypothesized that a farmer's perception of the degree of the erosion problem and its impact on farm returns and land values should be closely linked with his willingness to pay for conservation measures. The existence of cost sharing programs should also positively influence the adoption decision. In their empirical model they found five variables to be significantly linked with the adoption decision:: a farmer's 
perception of the degree of the erosion problem (positive); a measure of actual erosion potential (positive); education level (positive); commercial farmers (negative, because of their emphasis on short-run profits); and percent of the farmers' cropland that received cost-sharing payments (positive). The shortcoming of their study is that farmers' behaviour was not linked directly with microeconomic theory, i.e., they did not base their model on profit-maximizing or utilitymaximizing behavioural assumptions.

Another study by (Purvis et al., 1989) looked at farmers' willingness to participate in a filter strip program. Unlike Ervin and Ervin, their model was based on utility-maximizing behavior. In their model farmers decide whether or not to accept a yearly payment to participate in a ten-year filter strip program according to their preferences, characteristics and constraints. Adoption was hypothesized to be determined by cost, the size of the annual subsidy payment, farm-level benefits from reduced soil erosion, non-market benefits, the opportunity cost of investment, and expected future commodity prices. Data were derived from a contingent valuation survey that offered respondents an option to accept or reject a yearly payment to participate in the ten-year filter-strip program. The survey gave information on the filter-strip technology and gave the rules for participation in the program. Respondents could accept or reject the offer. If they accepted they then indicated how many acres they would enroll. They used a Tobit model to relate adoption to the proportion of eligible acres enrolled the yearly payment, and economic factors representing opportunity costs, expectations, costs, and preferences. Significant explanatory factors included the yearly payment, concern about the environment, and household income (all positive) and the average yield on the filter strip land and the opinion that the 10-year filter strip contract was too long (negative factors). 
McConnell, (1983) developed a dynamic theoretical model that described a farmer's soil conservation investment decisions purely in terms of the impact on the present value of the firm. This study has been criticized because it neglected the farmer's preferences and other socioeconomic characteristics that influence adoption. Lynne et al., (1988) attempted to explain conservation behavior in a model that linked psychological processes to economic decisions. They formulated an indirect utility function based on farmers' income, prices paid for conservation effort, attitudes, and farm features. The survey elicited the farmers' attitudes about farming, their economic future, and the responsibility of farmers toward the environment and future generations. The responses were coded from 1 to 5 , representing responses from strongly disagree to strongly agree. Other independent variables included land tenure, income, percentage of capital borrowed (financial constraints), and an erosion index. For the dependent variable, the authors used the number of conservation practices to represent the amount of effort undertaken by farmers.

The estimated coefficients on five explanatory variables were statistically significant. These variables were: 1) farmers have a responsibility to conserve soil resources (positive); 2) farmers should bear the cost of reducing the off-farm effects of soil erosion (positive); 3 ) technical advances in chemicals and seed can offset the adverse effects of soil erosion on productivity (negative); 4) profit maximization takes precedence over soil conservation (negative); and 5) willingness to invest $\$ 50,000$ in successively riskier farm ventures (positive). In addition, the coefficients of dummy variables for tenure and the erosion index were both positive and significant.

Rahm and Huffman, (1984), studied the adoption of reduced tillage techniques. They found that the probability of adoption by corn farmers varied across Iowa, depending on soil 
characteristics, cropping systems and the size of the farm. They also used a utility maximization model where utility depends on the distribution of the net returns for each technology, and on other characteristics of the technology. They argued that these variables were unobserved and unavailable, so they postulated utility to be a linear function of characteristics of the farm. When utility from the new technology is higher than the old technology farmers adopt the new technology. They used probit to estimate the adoption decision and found the following factors to significantly and positively affect the adoption decision: corn acreage, the ratio of soybean to corn acreage, and several of the 19 soil association dummy variables which represented the rolling, lighter, and better drained soils. The authors then constructed an efficiency index based on the estimated probabilities of their adoption model. This efficiency index was high when the model predicted the adopt/not adopt decision correctly and was low when the model predicted incorrectly. They then linke their efficiency index to "human capital" variables such as education, experience, and use of information sources. They then statistically related the efficiency index to the human capital variables. Education, attending short courses, and use of media sources of information were positive and significantly related to the efficiency index.

Nielsen et al., (1989) examined investment in soil conservation and other land improvements. Their analysis dealt with the economic factors influencing adoption, including the macro-economic and international effects. They argued that past studies indicated that cost sharing and other conservation are not be efficient and are sometime contradictory. The authors analyzed investment in soil conservation practices at the aggregate level using time-series (198086) and cross-sectional analysis. Soil conserving investments were hypothesized to a function of expected income, the long-term interest rate, acreage idled in government programs, ratio of the price of land improvements to price of land, the value of the previous period's capital stock, the 
government subsidy, and acreage in conservation tillage. Using four different models they found income, acres idled, the price ratio, and capital stock variables to be significantly related to the level of investment. The interest rate was significant and of the expected sign in 3 out of the 4 models. Government assistance was represented by cost-share expenditures under the Acreage Conservation Program (ACP) and related programs and technical assistance under the conservation programs. ACP (government subsidies) had a significant influence on investment in one model, but technical assistance was not significantly associated with investment. The authors concluded that their study showed that farmers do respond to economic factors when making soil conserving investment decisions

Perret (2003) looked at factors that affect the adoption of water conservation in South Africa. Perret acknowledged that a number of technologies have been developed to address water mismanagement problems, but farmers just do not adopt them. The author identified two categories of factors that affect adoption of water conservation technologies; first, household context which includes wealth, labor, and diversity of farmers, and second, external environment which includes information, environmental and price risk, collective action, farmers' organization, social and cultural factors, rural finance and infrastructure. This study was a qualitative analysis. The author used a flow chart to demonstrate the decision process to adopt technologies. The study was not based on economic theory and did not quantify the impact of the factors on farmers' willingness to adopt.

Paudel et al (2004) conducted a study of the factors influencing the adoption of land management practices in mountain watersheds of Nepal. The study used data collected from 300 households. A multivariate correlation analysis was used to determine the collinearity of the independent variables. Regression analyses on 10 independent variables with high degree of 
correlation with the dependent variable and low degree of correlation with each other were included in the model. Results indicate that ten variables were significantly influencing the adoption of land management technologies. Extension services were revealed as the strongest factor that significantly influenced the adoption of land management technologies.

Harbtemariam and Düvel (2003) used a multiple regression to identify the determinants of technology adoption. They considered personal, environmental and intervention factors on the adoption behavior and production efficiency of maize growers in Shashemene district in Ethiopia. Unlike the study conducted by Paudel et al (2004), this study added another component of variables, namely mediating variables. The mediating variables gave the highest and significant prediction value.

Marasas (1998) conducted a study of adoption of the Russian wheat aphid integrated control program in Central and Eastern Free State of South Africa. Data were collected from established and new commercial wheat farmers in the study area by means of personal interviews. A standard pretested questionnaire was used. The impact of Russian Wheat Aphid integrated control was assessed in a comprehensive manner. The study was confined to the dry land wheat production areas of the Central Free Sate (CFS) and Eastern Free State (EFS), where the Russian Wheat Aphid had the highest concentrations.

Within the CFS and EFS, both established commercial (EC) and new commercial (NC) farmers could further be distinguished and were surveyed separately. A random sample of EC farmers representing the relatively homogenous farming area in the CFS and EFS were selected. Address lists, obtained from various co-operatives, were used as the sampling frame. It was not, however, possible to draw a random sample of the NC farmers at the time. It was found that the wheat production systems varied between the various farming groups. This emphasized the 
importance of adoption and impact studies as tools to measure the outcomes of research

programs at the farm level. The benefits of the Russian Wheat Aphid integrated control program contributed (RWA - ICP) to a yield gain of the resistant cultivars and a reduction in the chemical control of these cultivars.

The social gains of private sector research were not measured, and the impact of the research program was assessed in a comprehensive manner according to the framework ${ }^{3}$ suggested by Anandajayasekeram, et al, (1996). The RWA - ICP was found to be a very profitable investment to society. It was recommended that given the constant decline in resources available to agricultural research in South Africa, the findings should be increasingly used as a source of information.

Bembridge (1992) conducted a study on the adoption of avocado growing practices by small-scale growers in Thohoyandou District of Venda situated in the Northern part of Limpopo Province, South Africa. The study was carried out in the high rainfall (circa $1000-1500 \mathrm{~mm}$ ) sub-tropical area of Thohoyandou District, using a sample of 53 fully active avocado farmers. Farmers identified were interviewed and scales were constructed to measure farm management practices. The management scale was adapted from the scale devised by Burger (1966), using a 3-point scale for each of the variables, i.e., budgeting, expenditure and income records, production records, administrative facilities and maintenance of farm buildings, implements and improvements.

This area is not well suited to livestock production; this factor, together with the shortage of grazing land, accounts for the low proportion of producers owning cattle and goats. The

\footnotetext{
3 The framework suggested by Anandajayasekeram for analysing a project or a research programme includes the following: inter - related elements: Technical, Institutional - Organizational - Managerial, Social, Commercial and Business, Financial, Economic, and Environmental aspects. This list is used to identify analytical elements for each stage in the project cycle, i.e. during preparation, analysis, and subsequent evaluation, and impact assessment. A more detailed description of these elements can also be found in van Rooyen et al. (Eds.) Agricultural Project Planning and Analysis: A source book for course work in agricultural development project planning and appraisal; and for the planning, appraisal and monitoring of agricultural research investments.
} 
adoption of critical avocado growing cultural and management practices, as well as knowledge levels of avocado growing was considerably below optimum. The majority of the sample drawn (88\%) had begun establishing avocado orchards at least three years prior to the study. Males, of whom $60 \%$ were employed, headed all avocado producer households. Most of them $(80 \%)$ had no previous experience with avocado growing. In terms of education, the majority (84\%) had received 5 or more years of education and therefore was considered to be literate (Koshy, 1977). The level of education was considerably higher than progressive farmers in Transkei and Gazankulu, South Africa, respectively. The average family size was 8.12 person, which is larger than Venda, South Africa, as a whole (circa 5.6 persons) (Bembridge ,1988).

All items used in the scale correlated significantly with each other, suggesting that the scale gave a valid measurement of adoption of management practices. Practice adoption was measured according to the degree of adoption of soil sampling, phytophthera control, spraying against diseases, weed control and fertilizer application. However, the study found that a weakness in the knowledge base was not the only factor affecting the development of avocado growing. Other important factors were transport, and in some cases, development finances and funds for annual production inputs. It was recommended that producer organizations could play an important role in creating awareness, leadership development, horizontal communication, and other group reinforcing attributes, which will enhance the ability of avocado growers to solve their own problems.

The above mentioned studies on the adoption of conservation practices are helpful in identifying factors affecting the adoption of technologies that may not provide immediate and full benefits to farm operators. However, the conceptual framework of these studies was not grounded in economic theory and proper extension of these studies by incorporating economic 
modeling is important to make future studies relevant for policy and technology adoption management programs.

Ervin and Ervin ( 1982) and Saliba and Bromley (1986) were among the first to model the farm-level conservation adoption process based on a complex combination of diverse factors including physical and economic factors, farmer perceptions and attitudes about soil erosion, and management. Neither study, though, was explicitly grounded in microeconomic theory. Purvis et al. (1989) assumed utility-maximizing behavior, but did not develop a formal theoretical model. Studies that have used micronomic models have usually chosen either a utility maximization or a profit maximization viewpoint. As argued by Norton (1994, p. 19), "the farmer's decision to adopt soil conservation or pollution-reducing technologies can be shown to be result of both processes." Perret (2003) identified the factors that affect adoption of technology in South Africa, but his study also failed to relate these factors to the optimization behavior of farmers. In addition, it failed to quantify the impact of these factors to farmers' decisions to adopt. The studies conducted by Paudel et al. (2004); Harbtemariam and Düvel,(2003), Marasas,(1998) and Bembridge, (1992) in South Africa were not based on economic theory and all were regionally based studies.

The conceptual model and empirical analysis in this study builds on previous studies by overcoming the limitations discussed above. The contribution of this study to the existing literature comes through its modeling of technology adoption decisions based on fundamental economic principles and theory as well as building an empirical model that will enable a quantitative analysis of technology adoption in the agricultural sector of South Africa. It also contributes by incorporating a national study that tries to aggregate and produce policy information that can be useful for agricultural sector policy and management. Particularly, 
information generated from the model on the economic motivations of adoption decisions might be relevant for developing effective environmental and resource conservation conscious production schemes in the country. Furthermore, it has broader implication as it was conducted in an emerging economy where institutional and market forces respond differently from developed economies where most previous studies have been conducted.

\subsection{OVERVIEW OF AGRICULTURAL RESOURCES IN SOUTH AFRICA}

South Africa is divided into nine provinces with distinct agricultural natural resources. The type of technology used depends on the agricultural resource endowments of those particular provinces. Figure 1 indicates location of the nine provinces of South Africa.

The Land area per province and the proportion of the total area of South Africa the province constitutes are shown in Table 2.1

Table 2.1: Land Area by Province

\begin{tabular}{|l|c|c|}
\hline Province & Area (ha) & \% of Total Land Area \\
\hline Eastern Cape & 16986732 & 13.9 \\
\hline Free State & 12979852 & 10.6 \\
\hline Gauteng & 1699323 & 1.4 \\
\hline Kwazulu- Natal & 9230821 & 7.6 \\
\hline Limpopo & 12281861 & 10.1 \\
\hline Mpumalanga & 7936897 & 6.5 \\
\hline North West & 11616341 & 9.5 \\
\hline Northern Cape & 36273925 & 29.7 \\
\hline Western Cape & 12950863 & 10.6 \\
\hline Republic of South Africa & 121956615 & 100 \\
\hline
\end{tabular}

Source; Department of Agriculture 2004

\section{Figure 1: Provinces of South Africa}




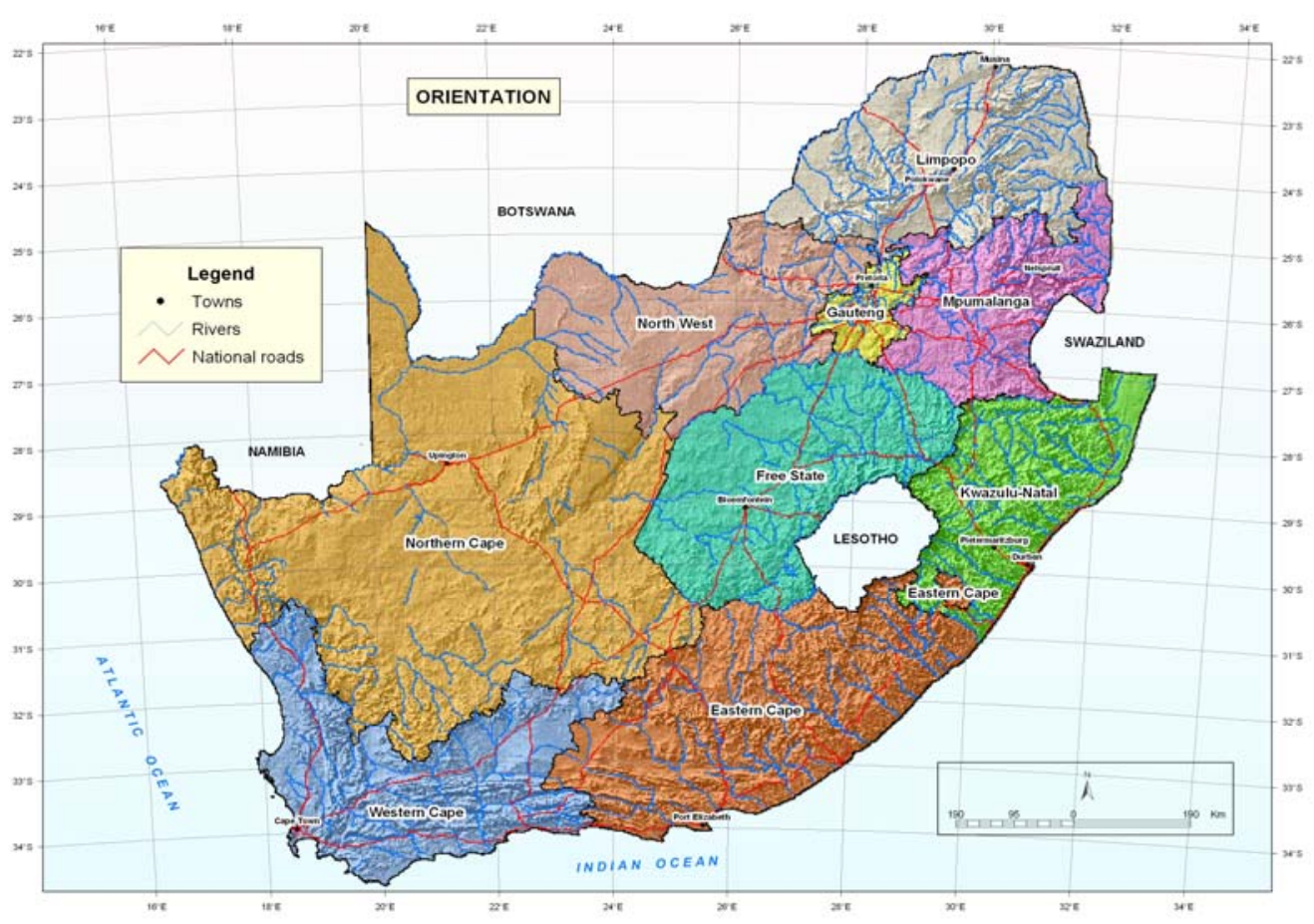

Source: Department of Agriculture 2004

South Africa is divided into different agricultural regions. The agricultural regions are based on agricultural potential which is defined by the Department of Agriculture (1990) as a measure of possible productivity per unit area and unit time achieved with specified management inputs. For a given farming enterprise and level of management, agricultural potential is determined by the interaction of climate, soil and terrain. The agricultural regions of South Africa are indicated in figure 2. It shows that the bulk of subsistence crop land in the Limpopo and North West provinces are suited to cattle farming areas with marginal or lower capability. Therefore, the types of resource conserving technologies used will differ with the agricultural region. 
Figure 2: Agricultural Regions of South Africa

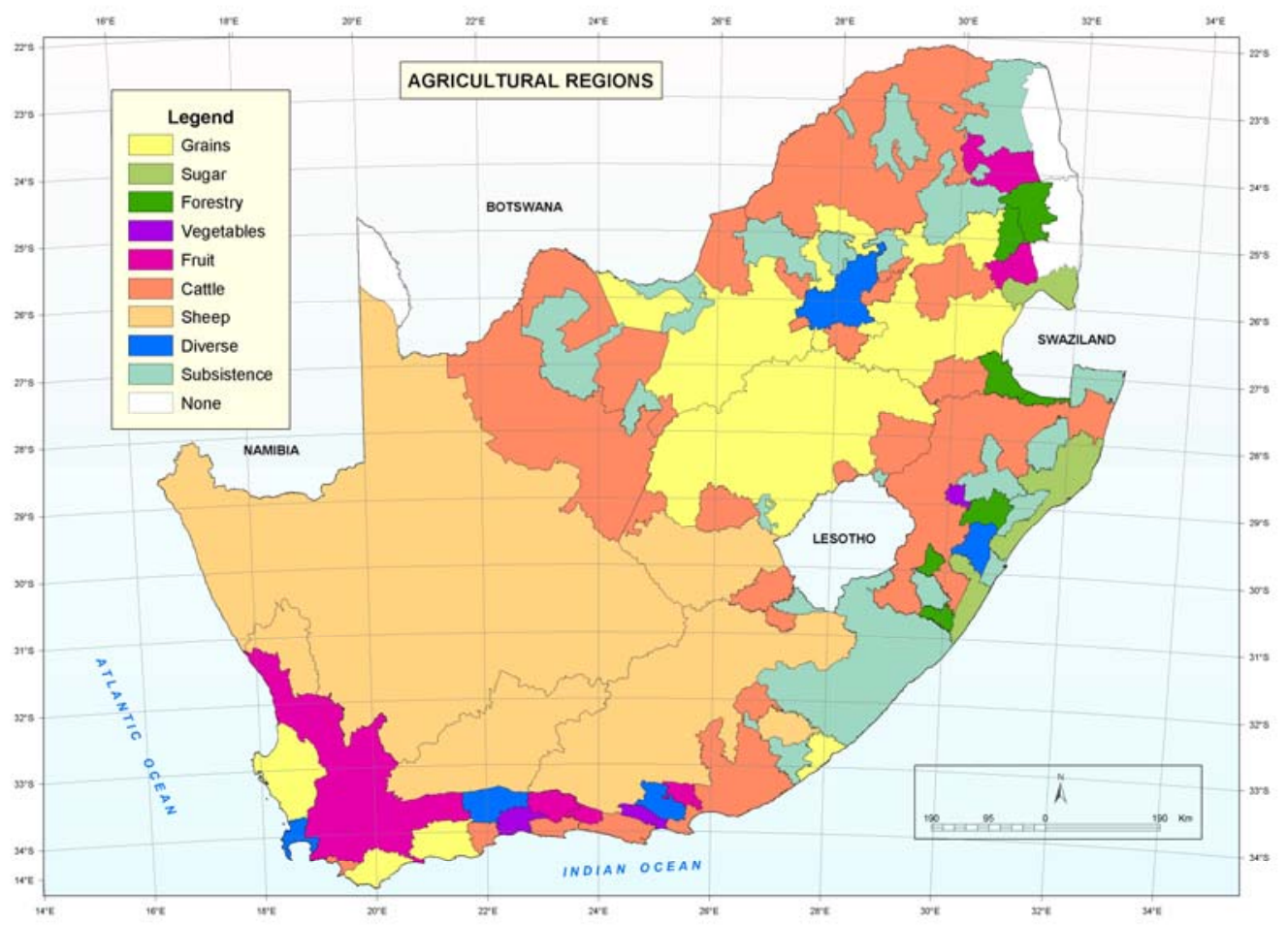

Source: Department of Agriculture 2004

Rainfall, both total and seasonal distribution, plays a major role in determining the types of resource conserving technologies that are commonly found in the different regions. There three main rainfall areas, include: a winter rainfall area in the south-western part of the region, all year-round rainfall area along the South coast and a summer rainfall which covers the reminder of the region. Figure 3 indicates the distribution of rain in South Africa. 


\section{Figure 3: Rainfall Distribution}

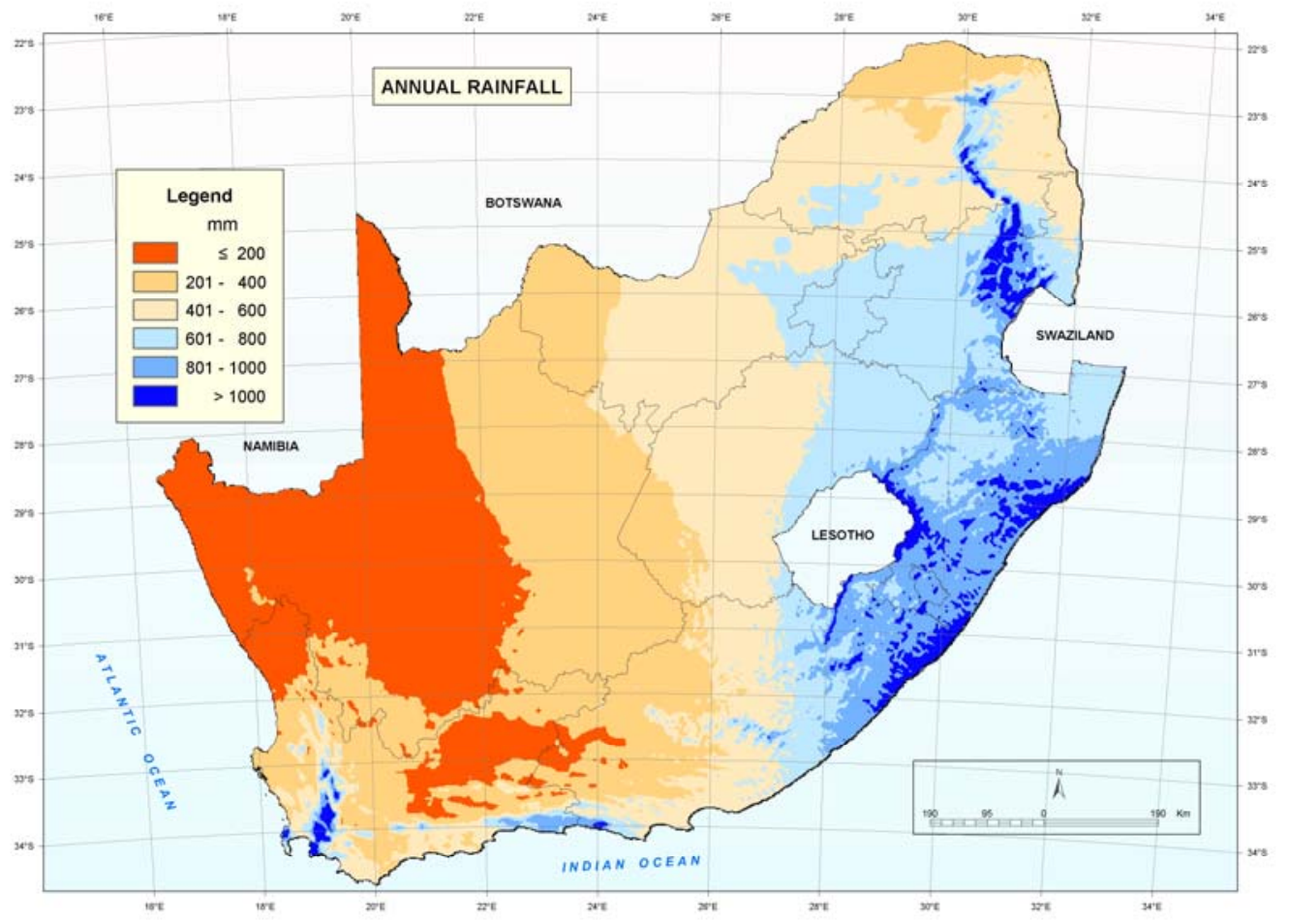

Source: ARC- Institute for Soil, Climate and Water 2004

Rainfall erosivity has a direct influence on what type of technologies are likely to be adopted in a particular region. Rainfall erosivity is defined as the ability of rainfall to increase soil loss. Figure 4 illustrates the distribution of rainfall erosivity in South Africa. 
Figure 4: Rainfall Erosivity

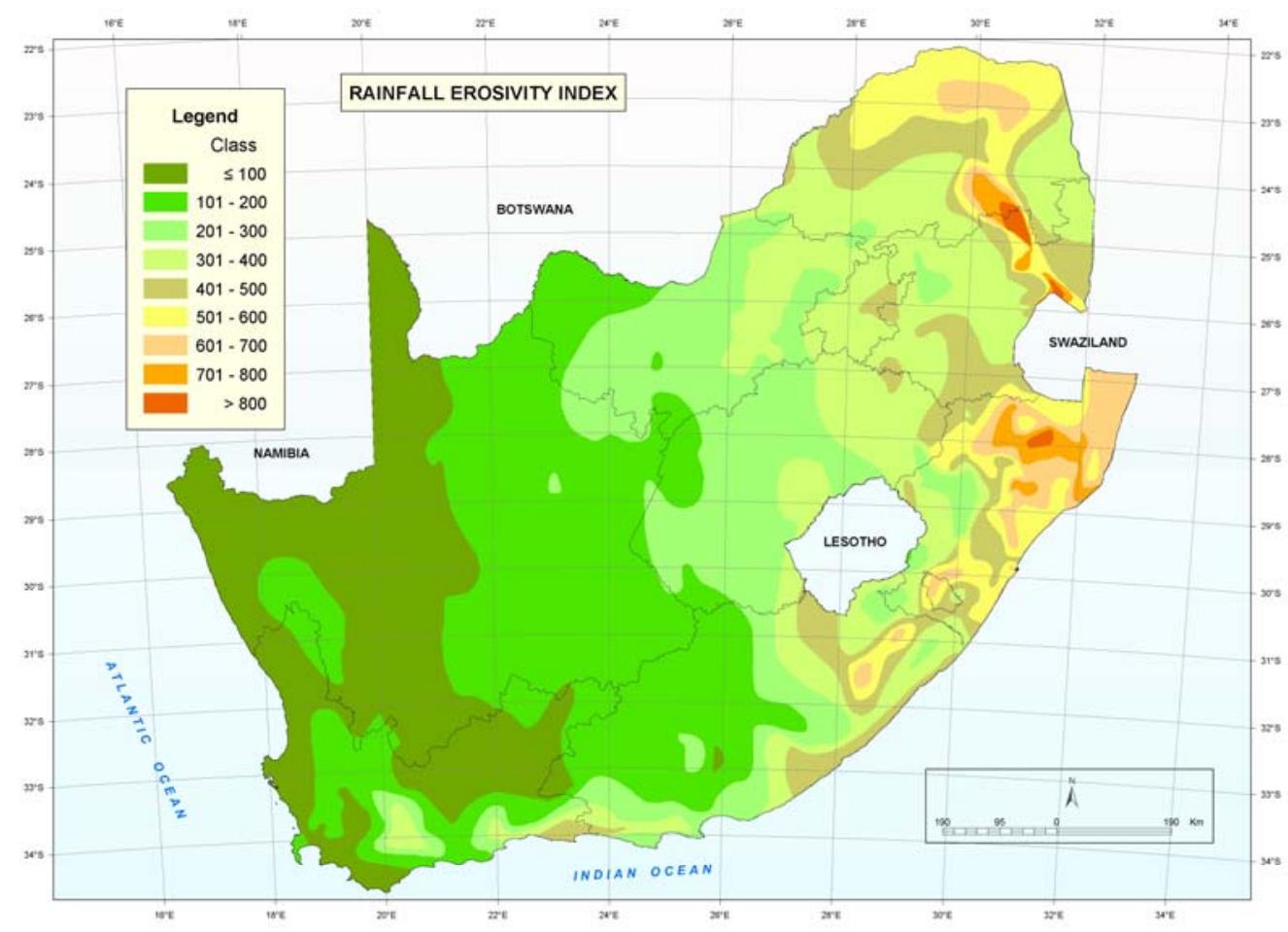

Source: Department of Agriculture 2004

Resource conserving technologies become more important where there is likelihood of soil loss.

Figure 5 indicates the distribution of predicted soil loss 
Figure 5: Predicted Soil Loss

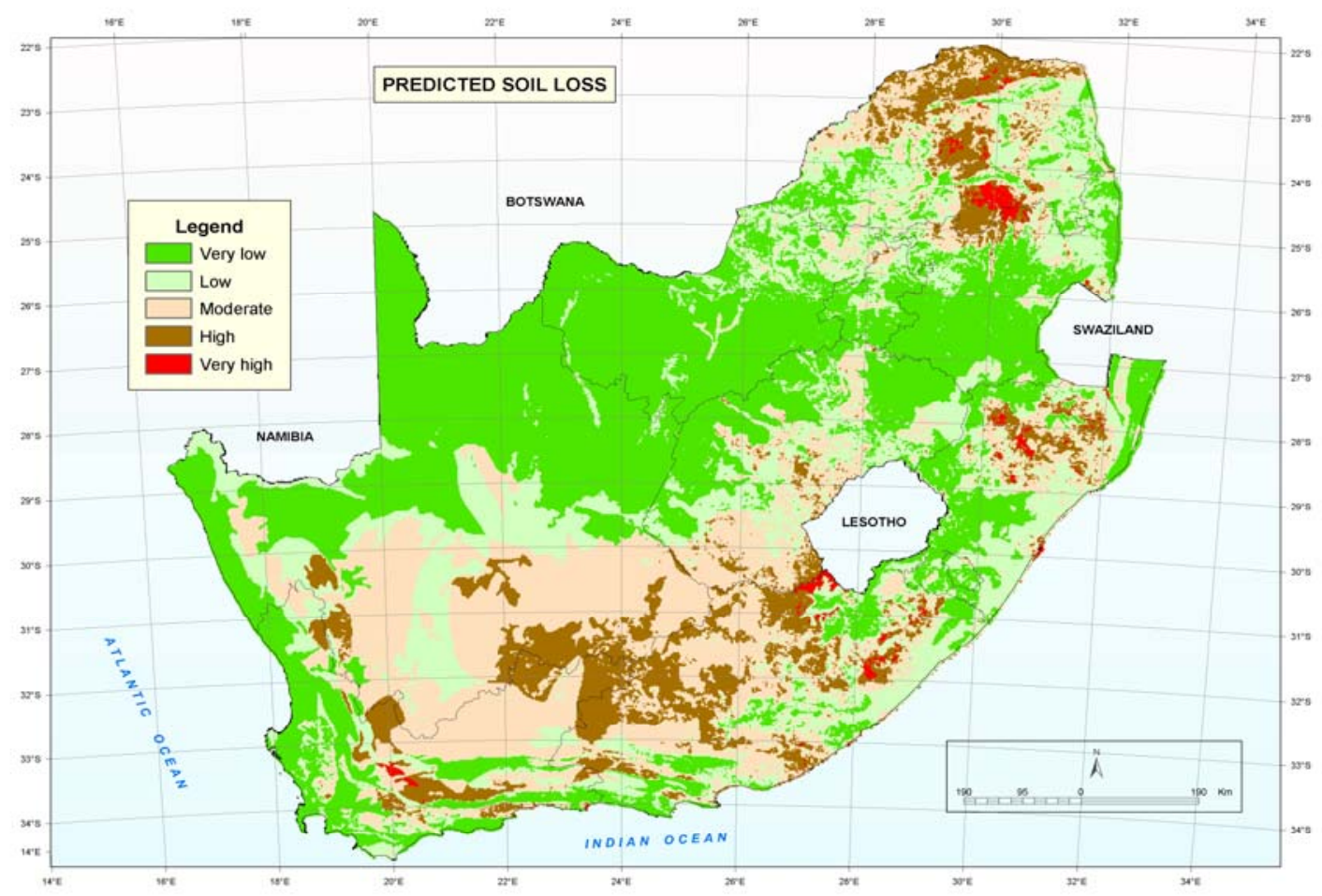

Source: Department of Agriculture 2004

\subsection{RESOURCE CONSERVATION TECHNOLOGIES}

There are a number of available technologies that reduce soil erosion and improve resource conservation. The relative preference of farmers for one technology against the other depends on many factors, including the relative costs of each technology which varies from place to place, the socio-economic characteristics of a farming unit, the risk involve in adopting that particular technology and other relevant variables. This section reviews some of the available soil conserving technologies.

One such technology is increased surface crop residue, which reduces soil displacement and transport during rainfall events thereby decreasing erosion rates. However, increasing crop 
surface residue may involve added costs to the farm operation. In many areas, crop residues provide an important feed for livestock. In other areas, an increase in crop residue may cause an increase in pest populations and result in added crop damage or loss.

Associated with crop-residue management, changes in cropping systems and tillage practices can help reduce soil erosion rates. The adoption of no-till and reduced tillage systems that leave more residues on the soil surface can decrease soil loss. The effectiveness of crop rotations to reduce wind and water erosion will depend not only on the crops produced, but also on the timing of erosion events.

For example, a farm demonstration, which was conducted by the ARC (Agricultural Research Council) at Mlondozi Project in Mpumalanga Province, South Africa, indicates that notillage can greatly reduce soil loss and increase yield. In the case of wind erosion, orienting furrows perpendicular to the prevailing wind generally results in lower rates of loss. Contour tillage on rolling hills has also been shown to reduce water-erosion rates and risk reducing . Tied ridging or furrow digging is another tillage technology that can reduce surface runoff velocities, decrease erosion, and increase infiltration, thereby making more water available to crops. That in turn reduces draught risk.

Other farm-level adjustments to reduce soil erosion include structural measures. Benchterracing of sloped soils is one structural practice which can reduce water erosion. The establishment of vegetative buffers and windbreaks is another structural practice that can be adopted to decrease wind-erosion susceptibility. These types of practices often involve taking some land out of crop production. If farmers perceive that the benefits of these structural practices are greater than the cost of establishment and foregone crop revenues, they will be adopted. 
A summary description of alternative resource-conserving technologies is presented in Appendix B.

\subsection{PUBLIC POLICY, RESOURCE DEGRADATION, AND RATIONALE FOR INTERVENTION}

In the face of resource and environmental degradation, the response of many environmental activists and public officials has been to meet resource depletion with state intervention. Versed in the economic literature of dealing with externalities, many economists have reservations in relying on market forces to correct resource and environmental degradation problems. However, unlike many economists, activists and government officials feel that government intervention is the ultimate proper policy course that is capable of correcting the excesses that are characteristic of the marketplace.

Dealing with market failure is a legitimate enterprise for any government. Anti-trust laws are applied so that monopolization will be limited and prices will be driven toward competitive levels. The public sector also involves itself in the supply of goods and services that are non-rival and nonexclusive (public goods) in consumption (Randall, 1987), since private-sector production of those same commodities is always sub-optimal (Samuelson, 1954).

Environmental deterioration, including soil degradation, has a great deal to do with market failure. However, conceptual and practical difficulties always arise when policies for dealing with market failure are being designed and implemented. It is rare for the impacts of any single failure (be it weak property rights or a lack of competition) to be confined to just one market. Rather, inefficiency is apt to reverberate through many markets, counteracting or amplifying other inefficiencies along the way. However, even where suitable interventions in the 
marketplace can be identified, there is no assurance that they will be implemented successfully. Government capacity to enforce laws and regulations are not limitless.

The caution that governments need to exercise when dealing with market failure has been expressed in a primer on the economics of environmental degradation in poor countries:

"Market failure ... is a necessary but not a sufficient condition for intervention. To be truly worthwhile, a government intervention must meet two other conditions. First, the intervention must outperform the market or improve its function. Second, the benefits from such intervention must exceed the costs of planning, implementation, and enforcement, as well as any indirect and unintended costs of distortions introduced to other sectors of the economy by such intervention (Panayotou, 1992, p. 57).”

Where government has interfered greatly with private property rights and market forces, as is the case in virtually the entire developing world, one should hesitate before recommending new interventions for environmental or any other purpose. Instead, the most effective contribution a government can make to the wise use and management of natural resources may be to reform the policies that diminish incentives for conservation. Remedying policy failures can lead to simultaneous improvements in economic performance and environmental quality (Panayotou 1992; Southgate, 1994).

Over time, the belief that the state could successfully intervene to offset breakdowns in the market system, especially those of various types of pollution such as the off-site effects of erosion, has decreased. Many resource economists emphasize improving markets and legal systems rather than state intervention. These principal arguments are the need for the improvement of incentives for farmers, for bargaining among parties affected by off-farm erosion, and a decreased role of government in direct regulatory functions. 
The general case for government intervention is based on theory of market failures (Kahn, 1997). The existence of market failure provides, in principle, an economic justification for government intervention on behalf of the society when markets produce outcomes that diverge from those sought by the society as a whole. Land use would be socially efficient if all markets were perfectly competitive so that prices reflected the social scarcity of all resources. But real markets are not perfectly competitive in South Africa or any where else: Although the underlying factors behind land degradation in South Africa need detailed investigation (which is not the objective of this study), the difference between private and social costs of land use, which has led to high externality cost, is obvious. Hence, government may justify use of policy instruments to address the difference between the two costs.

On the contrary, (Shiferaw and Holden, 1997) argue that the existence of market failure is not a sufficient condition for government intervention into the market process. The efficient level of soil conservation that equates marginal benefits and costs of abating degradation can result in a soil erosion level, either lower or higher than natural rate of regeneration. Kahn (1997) supports Shiferaw and Holden (1997). The probability of policy failure and a net social welfare loss due to inappropriate policy measures further strengthens this point.

The extent of market failure must be determined and a cost- benefit analysis must be undertaken to justify action and intervention. This will avoid providing wrong incentives to farmers. There is a strong belief that the South African agricultural sector is riddled with distorting policy failures introduced by the apartheid regime (Department of Agriculture, 1998). These include protectionist and farm support policies. Over capitalization and excessive use of irrigation water and chemicals are some of the examples of government policy failure in the South African agricultural sector. The high level of assistance to commercial farmers, led to 
under-pricing of these agricultural inputs, which encourages their excessive use. The South African government policies gave farmers incentives to increase output of physical products, but not the supply of environmental goods. Hence, these policies focused on removing impediments to more intensive resource use, and not on balancing environmental and agricultural growth objectives.

\subsection{FACTORS AFFECTING AGRICULTURAL TECHNOLOGY ADOPTION}

Economists and sociologists have made extensive contributions to the literature on the adoption and diffusion of technological innovation in agriculture (e.g. Feder et al., 1985; Rogers, 1995). Such research typically focuses on the long-term rate of adoption and the factors that influence the adoption decision.

The characteristics of new innovations are widely known to influence the adoption decision (Rogers, 1995; Batz et al. 1999). Rogers (1995) hypothesized that five technology attributes affect the rate of adoption: relative advantage; compatibility; complexity; triability; and observabibilty. Using this characterization, environmentally focused technologies have attributes that would be expected to affect their adoption rates. A basic hypotheses regarding technology transfer is that the adoption of an innovation will tend to take place earlier on larger farms than on small farms. Just, Zilbeman, and Rausser (1980) note that given the uncertainty, and the fixed transaction and information costs associated with innovations, farm size becomes critical. It follows that innovations with large fixed transaction and/or information costs are less likely to be adopted by smaller farms.

Disentangling farm size from other factors hypothesized to influence technology adoption has been problematic. For example, Feder et al. (1985) caution that farm size may be a proxy for 
other factors, such as wealth, access to credit, scarce inputs, or information. Moreover, access to credit is related to farm size and land tenure because both factors determine the potential collateral availability to obtain credit. Also farm size is affected positively by the amount and quality of management labor and profitability and credit considerations (Gould et al., 1989).

The ability to adapt new technologies for use on the farm clearly influences the adoption decision. Most adoption studies attempt to measure this trait through operator age, formal education, or years of farming experience (Fernandez-Cornejo et al., 1994). More years of education and/or experience are often hypothesized to increase the probability of adoption whereas increasing age reduces the probability. Factors inherent in the aging process or the lowered likelihood of payoff from a shortened planning horizon over where expected benefits can accrue would be deterrents of adoption (Barry et al., 1995; Batte and Johnson, 1993). Younger farmers tend to have more education and are often hypothesized to be more willing to innovate.

Land ownership is widely believed to encourage adoption of technologies. While several empirical studies support this hypothesis, the results are not unanimous and the subject has been widely debated (e.g., Feder et al., 1985). For example, Bultena and Hoiberg (1983) find no support for the hypothesis that land tenure had a significant influence on adoption of conservation tillage. The apparent inconsistencies in the empirical results are due to the nature of innovation. Land ownership is likely to influence adoption if the innovation requires investments tied to the land. Presumably, tenants are less likely to adopt these types of innovations because they perceive that benefits of adoption will not necessary accrue to them. Because the use of environmentally focused technologies requires land-tied investments, land tenure affects adoption of these technologies (Mkhize, 2001; Rukuni, 2002). 
Given the high level of interdependency between the household and farm business, the combined labor supply of operator and family members indicates the total amount of time available for farming and non-farming activities. Operator and/or spouse off-farm employment may constrain adoption of management-intensive technologies because it competes for farm managerial time (McNamara et al., 1991). Conversely, adoption by households with off-farm employment may be encouraged if technology is operator labor-saving, as may be the case with environmental focused technologies in agriculture.

Any fixed investment requires the use of equity or borrowed capital. The adoption of a non-divisible conservation technology, which requires a large initial investment, may be hampered by lack of borrowing capacity (El-Osta and Morehart, 1999). Similarly, a credit or capital constraint should have an adverse impact on adoption of environmentally focused technologies.

Uncertainty is another factor that farmers that influence the adoption of technology. The use of some technologies for a risk adverse farmer may different under uncertainty than under certainty. There are a number of studies which address the issue of risk in using a technology e.g. (Zilberman, Just and Barshira (1997) and Leathers and Ouggin (1991)). A summary description of the technologies in relation to farm-operator risk is presented in Appendix B.

\subsection{SOUTH AFRICAN AGRICULTURAL SECTOR IN PERSPECTIVE AND ITS ENVIRONMENTAL POLICY}

The importance of agriculture in South Africa may be measured by the fact that, although it only covers $4 \%$ of the African continent, it produces $30 \%$ of the continent's maize production, $28 \%$ of its sugarcane, $20 \%$ of the beef, and $30 \%$ of its wheat, as well as being one of the world's seven 
leading net exporters of food products (Department of Agriculture (DoA), South Africa, 2004). In a year of average rainfall, $25 \%$ of the total value of commercial agriculture leaves the country as exports, generating a significant portion of the country's foreign earnings. This is in spite of the fact that the proportion of GDP from the agricultural sector declined to $4.1 \%$ in 2002 (DOA, South Africa, 2004).

South Africa has a semi-arid climate. The eastern arable areas receive annual rainfall ranging from 600 to $800 \mathrm{~mm}$; northern areas average 400 to $600 \mathrm{~mm}$, concentrated in the midsummer, while in the west the rainfall averages 200 to $400 \mathrm{~mm}$ and falls later. The area under intensive irrigation at 1.5 million hectares is modest by world standards.

The agricultural sector of South Africa is comprised by both large and small scale farmers with varying degrees of capital investment, farming methods, agro-ecological conditions, and land tenure patterns. The degree of the land degradation problem also varies from region to region and from one kind of farm practice to another.

\subsection{1.a The Resource Poor Farmers}

This group consists of small farms, which are sometimes called subsistence farmers. They have different levels of income and are not a homogenous group. They constitute a pyramid of small-scale producers, rising from the subsistence at the base to the progressive smallscale commercial producers at the apex. As the biggest category of producers, in terms of numbers, they are characterized by low productivity due to inadequate land, communal tenure, lack of capacity in terms of management and technical skills, lack of capital, and a weak physical infrastructure. 
In addition to individual arable holdings, most resource poor farmers have access to communal grazing, which makes livestock production difficult due to overgrazing. The open access nature of the grazing lands encourages individual farmers to act according to rational self-interest and thus encourages the "free rider" phenomenon. However, McKean (1992) argues that collective management of resources is the most efficient way in villages, because the transaction costs of private property is avoided. McKean acknowledges the need of developing some rules as a form of regulatory system and that the community must enforce these rules.

\subsection{1.b Commercial Farmers}

Commercial farmers are the mainstay of the agricultural sector. They own large farms and have well defined property rights for these lands. They produce most of the food and raw material for local use and export. Through its many linkages, commercial farming creates employment throughout the economy.

In the past, white commercial farmers were not only organized, but also received considerable support from government, even when environmentally hostile technologies were sometimes used. By contrast, black commercial farmers, few in number, unorganized and confined to specific areas by law, received little or no support from the government. Land tenure in this group is freehold.

Land degradation in this sector arises mainly due to use of environmentally unfriendly technologies and policy failures. The high level of assistance given to the large-scale farming group has increased land use pressure through the over-intensive use of agricultural land. This has encouraged encroachment of farming into fragile habitats. Furthermore, some government 
policies led to under-pricing of agricultural inputs, which encouraged excessive use of inputs and resulted in environmental pollution.

\subsubsection{Environmental Policy and Agriculture}

Although the apartheid government excluded certain states in South Africa called homelands (which still reflect that legacy), it seems that there is continuity between the policies of the old apartheid government and the new dispensation. The sustainable utilization of agricultural resources and environmental quality in agriculture is guided by a number of government policies including the Conservation of Agricultural Resources Act of 1983, the Sustainable Utilization of Agricultural Resources Bill of 2004, the Discussion White Paper on Agriculture of 1998, the National Land Care Implementation Framework of 1997, the Strategic Plan for South African Agriculture of 2001, the National Water Act of 1998, the White Paper on Disaster Management of 2001, the National Environmental Management Act 107 of 1998, and the National Environmental Management Act of 2004. A description of these policies is outlined below.

The Conservation of Agricultural Resources Act, 1983 (Act 43 of 1983), allows the Department of Agriculture to exercise control over utilization of South Africa's natural agricultural resources. The Act provides for the conservation of these resources by maintaining the land's production potential, combating and preventing erosion, protecting vegetation and combating weeds and invaders. The Sustainable Utilization of Agricultural Resources Bill, once approved, will replace this Act.

The Sustainable Utilization of Agricultural Resources Bill of 2004 provides for the development of various incentive programmes and also prescribes standards, control measures and law enforcement mechanisms aimed at assisting farmers and natural agricultural resource 
users to promote conservation practices that will improve the quality of the soil, water, and agroecosystems in their farming activities.

The 1998 National Policy for Agriculture outlines the three broad principles that govern policy on the agricultural use of natural resources. The first principle emphasizes the government's responsibility in promoting the sustainable use of natural resource in agriculture, and enhancing the ecological integrity of natural systems while minimizing or avoiding risks that will lead to irreversible damage.

The National Land Care Programme (1997) is a community-based and government initiative which seeks to improve the ability of land users and community farmers to manage their natural resources in a sustainable and self-reliant manner. The programme offers provincial support, technical assistance and education awareness programmes to community groups who identify, implement, and monitor conservation and management activities necessary to deal with land degradation problems while improving their livelihoods.

The Strategic Plan for South African Agriculture (2001) reflects a commitment to the realization of sustainable use of agricultural natural resources. One of its three core strategies is sustainable resource management, which aims to enhance farmers' capacities to use resources in a sustainable manner and to ensure the wise use and management of natural resources. Central to this strategy is the preservation of agricultural biodiversity and promotion of sustainable use of soil and water through the enhancement of crop and livestock productivity and more sustainable farming systems.

Section 29(1) of the National Water Act 36 of 1998 deals with the adverse effects of agriculture on water quality. It confers responsibility for the Department of Agriculture (DOA) to attach conditions to water management by specifying management practices and general 
requirements for any water use including water conservation measures. This led to the development of guidelines and control measures on how intensive-farming systems should handle the problem.

The White Paper on Disaster Management (2001) emphasizes a developmental approach with a focus on risk reduction, prevention and mitigation strategies, creation of permanent structures, and delineation of accountability and responsibility. The DoA is one of the national departments that have dedicated financial resources towards disaster management strategies. In fact, the DoA has made provisions for disaster relief before. Section 8 of the Conservation of Agricultural Resources Act 43 of 1983 allows the department to provide financial assistance for relief during agriculture-related disasters. The DoA has integrated disaster planning with its overall development strategy.

The National Environmental Management Act 107 of 1998 seeks to promote cooperative environmental governance and integrated environmental management of activities by establishing principles and an implementation framework for decision-making affecting the environment and sustainable development. National departments are required to prepare consolidated environmental implementation and managerial plans.

The National Environmental Management Biodiversity Act of 2003 provides for the management and conservation of biodiversity within the framework of the National Environmental Management Act of 1998, the protection of species and ecosystems, the sustainable use of indigenous biological resources, the fair and equitable sharing of benefits arising from bio-prospecting of genetic material derived from indigenous biological resources and regulation of activities relating to components of biodiversity. 
The current government programs aimed at protecting the natural resource base are successful but insufficient. In the absence of well-defined markets for pollution, some form of intervention is necessary to minimize pollution impacts. Policy instruments for natural resource conservation and environmental policy vary widely, with programs that range from voluntary to regulatory. Economic incentives have many desirable characteristics; they offset the cost of carrying out conservation practices, thereby stimulating adoption and reduction of the impacts of pollution. Incentives include any activity that may motivate farmers to adopt and implement measures that improve resource utilization practices in order to conserve biodiversity and environment. These activities are generally referred to as best management practices in agriculture. 


\section{CHAPTER 3}

\section{THEORETICAL MODEL OF ADOPTION OF RESOURCE CONSERVATION TECHNOLOGIES}

\subsection{INTRODUCTION}

This chapter presents a theoretical model for the adoption of resource conserving technologies by farmers. It discusses theoretical model development relevant for studying technology adoption decisions based on established economic theories. Section 3.2 presents the model for technology selection in the absence of government intervention (incentive payments). Section 3.3 presents the potential effect of off-farm environmental quality incorporation. Section 3.4 presents a theoretical logit model. The maximum likelihood estimation of the logit model is discussed in section 3.5. Finally, the random utility and multinomial logit model is discussed in section 3.6.

\subsection{TECHNOLOGY ADOPTION THE ABSENCE OF GOVERNMENT POLICY INTERVENTION ${ }^{4}$}

Following Ervin and Ervin (1982), McConnell (1983), Rahn and Huffman (1994) and Norton

1994, let farmers adoption of resource conservation be based on the underlying profit and utility maximization behavior. A farmer evaluates and uses information to make production and technology adoption decisions. Assume that a farmer maximizes profit subject to an environmental quality constraint:

\footnotetext{
${ }^{4}$ This section closely follows the development of the theoretical model in Norton, Ch.4, 1994.
} 


$$
\begin{aligned}
& \operatorname{Max} \pi=\operatorname{Pf}(x, t ; L)-w X-C(t) \\
& \text { Subject to: } f(x, t, L)=q
\end{aligned}
$$

where $\mathrm{f}(\mathrm{x}, \mathrm{t} ; \mathrm{L})$ is the twice-differentiable production function where $\mathrm{x}$ is a vector of variable inputs, $\mathrm{t}$ is a vector of conservation technologies and $\mathrm{L}$ is land area. On-farm resource quality is given by the function $\mathrm{q}(\mathrm{x}, \mathrm{t}, \mathrm{L})$. The function is assumed to be non-increasing in $\mathrm{x}$, the vector of input levels, non-decreasing in $t$, the vector of resource conservation technologies or Best Management Practices, and twice differentiable. This production function is introduced to the profit maximization equation as a constraint on output. The farmer chooses $\mathrm{x}$ and $\mathrm{t}$ optimally. The technology impacts on yield are reflected in the parameters of the production function. The technology set includes all resource quality focusing technologies/Best Management Practices that are relevant to the farmer's operation. Some are effective at reducing runoff of sediment and others at reducing infiltration of chemicals. It is assumed that $t$ is continuous of one or more technologies that are increasingly more effective at achieving on-farm resource quality. For structural practices, the values of $t$ also relate to the relevant scale attributes of a particular technology, such as the size of scale attributes of a particular technology.

The resource quality in (3.1) is determined by $\mathrm{x}, \mathrm{t}$, and $\mathrm{L}$ through the functional relationship q. Generally, q could be a vector of resource quality characteristics but is considered here to be a single variable. Profit-maximizing levels of $\mathrm{x}$ and $\mathrm{t}$ are functions of input and output prices, the level of on-farm resource quality (q), and the vector of farmland characteristics (L). Optimal solutions of the system can be represented as:

$$
\mathrm{x}^{*}=\mathrm{x}^{*}(\mathrm{p}, \mathrm{w}, \mathrm{q} ; \mathrm{L}) \quad \mathrm{t}^{*}=\mathrm{t}^{*}(\mathrm{p}, \mathrm{w}, \mathrm{q} ; \mathrm{L})
$$

Where $\mathrm{x}^{*}$ and $\mathrm{t}^{*}$ are optimal input levels, $\mathrm{w}$ and $\mathrm{p}$ are input and output prices, respectively. The optimal quantities of $\mathrm{x}$ and $\mathrm{t}$ for all levels of $\mathrm{q}$ can be obtained by varying $\mathrm{q}$ and 
holding $\mathrm{p}, \mathrm{w}$, and $\mathrm{L}$ fixed. Substituting these optimal quantities into the profit equation yields the restricted profit function as a function of input and output prices, on-farm resource quality, and L:

$$
\pi=\pi(\mathrm{p}, \mathrm{w}, \mathrm{q}, \mathrm{L})
$$

The Equation $\pi=\pi(\mathrm{p}, \mathrm{w}, \mathrm{q}, \mathrm{L})$ represents the maximum attainable profit for different levels of $q$, given prices, and $L$. The optimal values of $x$ and $t$ in (3.2) represent the least cost method of achieving any given q. Therefore, the first stage optimization process determines the farmer's choice set, which represents the required technical trade off between $\pi$ and q, given the available technology set, the functional relation for $\mathrm{q}, \mathrm{L}$, and prices.

In the second stage the farmer determines the optimal level of on-farm resource quality to provide by accounting for the desired trade off between $\pi$ and $\mathrm{q}$. This can be achieved by maximizing the utility of the farmer subject to the expenditures constraint on $\mathrm{q}$ and all other goods, $\mathrm{k}$, and setting it equal to income using the restricted profit function in (3.3). Therefore, the farmers' utility maximization problem is:

$$
\begin{aligned}
& \operatorname{Max} \mathrm{U}(\mathrm{k}, \mathrm{q} ; \mathrm{s}) \\
& \text { subject to } \pi=\pi(\mathrm{p}, \mathrm{w}, \mathrm{q}, \mathrm{L})=\mathrm{k}
\end{aligned}
$$

Utility is a function of all other goods represented by $\mathrm{k}$ and on-farm resource quality. The vector of socioeconomic characteristics of the farmer that influence the farmer's resource quality preferences is represented by s. To ensure that the indifference curve is convex, it is assumed that $\frac{\partial U(k, q: s)}{\partial k} \geq 0$ and $\frac{\partial U(k, q: s)}{\partial q} \geq 0$. It is also assumed that the profit function is strictly concave $\left(\frac{\partial^{2} \pi}{\partial q^{2}} \leq 0\right)$. The utility function is quasi-concave, twice differentiable, increasing in $\mathrm{k}$, and nondecreasing in $\mathrm{q}$. The solution to the utility maximization problem is: 


$$
\begin{aligned}
& q^{*}=q^{*}(p, w, s, L) \\
& k^{*}=k^{*}(p, w, s, L)
\end{aligned}
$$

where $\mathrm{q}^{*}$ is the optimal level of on-farm resource quality and $\mathrm{k}^{*}$ is the optimal level of other goods for the farmer. The optimal point of the restricted profit function and the highest attainable indifference curve represents this optimality condition. Therefore, any level of q other that $\mathrm{q}^{*}$ would lower the utility of the farmer.

This indicates that, farm profits and resource quality can be positively related over some range. However, improving on-farm quality beyond a certain point, may not increase profits. The farmer's preferences for resource quality such as clean water, land value or less silting of the water reservoir may influence choosing level of q, such that it is greater that of the maximum point $\left(\mathrm{q}^{*}\right)$. If a farmer's resource degradation problem is entirely onfarm, then $\mathrm{q}^{*}$ is socially optimal. However, if the farming operation uses technologies that have off-site damages such as runoff to surrounding surface waters, then $\mathrm{q}^{*}$ will not generally be socially optimal.

\subsection{CONTROLLING OF OFF-FARM RESOURCE DEGRADATION}

Policy intervention variables are introduced to the profit and utility functions in order to force the farmer to internalize the costs imposed upon society. The policy intervention in the form of a subsidy or tax eliminates the divergence between the social optimum resource quality and private quality $\mathrm{q}^{*}$. The farmer would then produce the socially preferred resources quality level. Achieving these efficient levels of resource quality and related agricultural nonpoint-source pollution is the objective of the social planner. 
In this case, off-farm resource quality (Q) becomes endogenous to the farmers profit function. The profit maximization becomes:

$$
\pi^{*}(\mathrm{p}, \mathrm{w}, \mathrm{r}, \mathrm{Q})
$$

Where $r$ represents the policy variable that forces the farmer to internalize the off-farm resource quality $\frac{\partial Q}{\partial r} \geq 0$, technology used and the environmental characteristics of the farm affects adoption of Best Management Practices by the farmer. Therefore, society is concerned about the effect of a farmer's action on the off-farm resource quality. Farmers, in response to subsidy or tax may adopt a technology that increases $\mathrm{Q}$ when the tax or subsidy is equal or greater than the marginal social cost. Q has a direct effect on the farmers profit and indirect effect on farmer's utility function. The farmer chooses the desired level of profit and on-farm quality, denoted by q. The level Q is determined by the government tax or subsidy. Therefore, the farmer now operates under:

$$
\begin{aligned}
& t=t(p, w, q: L) \\
& x=x(p, w, q: L) \\
& \text { where } \quad q=q(p, w: s, e, L)
\end{aligned}
$$

profit is given by $\pi=\pi(p, w, q() ; L$.

The indirect utility function is given by

$$
U(\pi(.), q(.): s)
$$




$$
\begin{aligned}
& Q=Q(x, \alpha: L) \\
& \pi_{Q}=\pi_{Q}(p, w, Q(x, \alpha: L): L)
\end{aligned}
$$

where $\alpha$ represents a vector of resource-conserving technologies. The indirect utility after government policy intervention is given by:

$$
U\left(\pi_{Q}(.), Q(.) ; s\right)
$$

The farmer will only adopt off-farm damage measures if

$$
U\left(\pi_{Q}, Q(.) ; s\right)-U(\pi(.), q(.) ; s) \geq 0
$$

\subsection{A RANDOM UTILITY MODEL}

Random utility models assume, as in neoclassical economic theory, that a farmer has perfect discrimination capability. The analyst, however, is assumed to have incomplete information and, therefore, uncertainty must be taken into account. Manski (1997) identifies four different sources of uncertainty: unobserved alternative attributes, unobserved individual attributes (called "unobserved taste variations" by Manski, 1997), measurement errors, and proxy, or instrumental, variables.

The utility is modeled as a random variable in order to reflect this uncertainty. More specifically, the utility that individual $i$ is associated with the alternative technology $t$ is given by:

$$
\begin{aligned}
& U\left(\pi^{0}(.), q^{0}(.): s\right)=V(\pi q ; S)+\varepsilon \\
& U\left(\pi_{Q}(.)+I, Q(.) ; s\right)=V(\pi+I, Q ; S)+\varepsilon
\end{aligned}
$$

where $\mathrm{V}$ is the deterministic part of the utility, and $\varepsilon$ is the stochastic part, capturing the uncertainty (Norton 1994). Similar to the neoclassical economic theory, the alternative with the highest utility is expected to be chosen. Therefore, technology $t$ is adopted by the farmer if:

$$
V(\pi+I, Q ; S)+\varepsilon \geq V(\pi, q ; S)+\varepsilon
$$


Random utility models are the most widely used discrete choice models for technology adoption applications (e.g., Hanemann, 1984). The derivation of random utility models is based on a specification of the utility as defined above.

\subsection{A LOGIT MODEL}

A logit model may be used when the dependent variable is binary, i.e., takes values of either one or zero. The decision to adopt a given conservation technology takes a binary format, as farmers have decisions of either to adopt the technology or not. If a given economic problem has such binary decisions as dependent variables, one econometric approach to study the economics behind such decisions making patterns is to use a logit probability model. The probability of adoption of a resource conserving technologies can similarly be represented as:

$$
\begin{aligned}
P_{\alpha}=\operatorname{Pr}(Y=1) & =\operatorname{Pr}\left(\mu_{1}\right)\left(U\left(\pi_{Q}(.)+\mathrm{I}, Q(.) ; s\right)+\varepsilon_{1}-\left(\mu_{2}\right) U(\pi(.), q(.) ; s)+\varepsilon_{2} \geq 0\right) \\
& =\operatorname{Pr}\left(\varepsilon_{1}-\varepsilon_{2}\right) \geq U(\pi(.), q(.) ; s)\left(\mu_{2}-\mu_{1}\right) \\
& =F(X, B) \text { or } Y(X, B)
\end{aligned}
$$

where $\mathrm{X}_{\mathrm{i}}=\mathrm{n} \times \mathrm{K}$ matrix of explanatory variables in $\mathrm{B}=\mathrm{k} \times 1$ vector of parameters to be estimated, $\varepsilon=$ random error term, and $\mathrm{Y}(\mathrm{X}, \mathrm{B})$ is the cumulative distribution function estimated at $(\mathrm{X}, \mathrm{B})$. The probabilities that a farmer will adopt Best Management Practices are, thus, a function of the explanatory variables and the unknown error term. If the error term is assumed to follow a logistic distribution, then Y (.) can be estimated using a logit model, which also assumes a logistic distribution. 


\subsection{ESTIMATION OF THE LOGIT MODEL}

Estimation of the Logit model is based on the method of Maximum Likelihood. If data are available at the micro level, non-linear in parameter estimation procedures are called for (Gujarati, 2003).

Let $\left(\mathrm{Y}_{1}, \mathrm{X}_{1}\right) \ldots .\left(\mathrm{Y}_{\mathrm{n}}, \mathrm{X}_{\mathrm{n}}\right)$ be a random sample from the conditional Logit distribution. Then, the conditional logit distribution of $\mathrm{Y} / \mathrm{X}_{\mathrm{i}}$ can be given by:

$$
\begin{aligned}
& P\left[Y_{j}=1 \mid X_{j}\right]=\frac{1}{1+\exp \left(\alpha_{0-} \beta_{0} X_{j}\right)} \\
& P\left[Y_{j}=0 \mid X_{j}\right]=\frac{\exp \left(\alpha_{0-} \beta_{0} X_{j}\right)}{1+\exp \left(\alpha_{0-} \beta_{0} X_{j}\right)} \\
& P\left[Y_{j}=1 \mid X_{j}\right]=\frac{1}{1+\exp \left(\alpha_{0-} \beta_{0} X_{j}\right)} \\
& P\left[Y_{j}=0 \mid X_{j}\right]=\frac{\exp \left(\alpha_{0-} \beta_{0} X_{j}\right)}{1+\exp \left(\alpha_{0-} \beta_{0} X_{j}\right)}
\end{aligned}
$$

where $\alpha_{0}$ and $\beta_{0}$ are unknown parameters to be estimated( Madala, 1992). This model is called a Logit model, because:

$$
P\left[Y_{j}=1 \mid X_{j}\right]=F\left(\alpha_{0}+\beta_{0} X_{j}\right)
$$

where : $F(x)=\frac{1}{1+\exp (-x)}$ is the distribution function of the logistic (Logit) distribution. 
Following Bierens (2004), the conditional probability function can further be expressed as:

$$
\begin{aligned}
& f\left(y \mid X_{j,} \alpha_{0}, \beta_{0}\right) \\
& =F\left(\alpha_{0}+\beta_{0} X_{j}\right)^{y}\left(1-F\left(\alpha_{0}+\beta_{0} X_{j}\right)\right)^{1-y} \\
& = \begin{cases}F\left(\alpha_{0}+\beta_{0} X_{j}\right) & \text { if } y=1, \\
1-F\left(\alpha_{0}+\beta_{0} X_{j}\right) & \text { if } y=0 .\end{cases}
\end{aligned}
$$

The likelihood function is for the above stated logistic distribution functions are:

$$
\sum_{j=1}^{n} \ln \left(f\left(Y_{j} \mid X_{j}, \alpha, \beta\right)\right)+\sum_{j=1}^{n}\left(1-Y_{j}\right) \ln \left(1-F\left(\alpha+\beta X_{j}\right)\right)
$$

The conditional log-likelihood function is for equation (3.21) can mathematically be expressed as:

$$
\begin{aligned}
& \ln \left(L_{n}(\alpha, \beta)\right)=\sum_{j=1}^{n} \ln \left(f\left(Y_{j} \mid X_{j}, \alpha, \beta\right)\right) \\
& =\sum_{j=1}^{n} \ln \left(f\left(Y_{j} \mid X_{j}, \alpha, \beta\right)\right)+\sum_{j=1}^{n}\left(1-Y_{j}\right) \ln \left(1-F\left(\alpha+\beta X_{j}\right)\right) \\
& =-\sum_{j=1}^{n} Y_{j} \ln \left(1+\exp \left(-\alpha-\beta X_{j}\right)\right)-\sum_{j=1}^{n}\left(1-Y_{j}\right) \ln \left(1+\exp \left(-\alpha-\beta X_{j}\right)\right)+\sum_{j=1}^{n}\left(1-Y_{j}\right) \ln \left(1+\exp \left(-\alpha-\beta X_{j}\right)\right) \\
& =\sum_{j=1}^{n}\left(1-Y_{j}\right)\left(\alpha+\beta X_{j}\right)-\sum_{i=1}^{n} \ln \left(1+\exp \left(-\alpha-\beta X_{j}\right)\right)
\end{aligned}
$$

Taking expected values and rearranging (Bierens (2004): 


$$
\begin{aligned}
& =\frac{f\left(1 \mid X_{j,},{ }^{\alpha \beta}\right)}{f\left(1 \mid X_{j,} \alpha_{\left.0, \beta_{0}\right)}\right)} P\left[Y_{j}=1 \mid X_{j}\right]+\frac{f\left(0 \mid X_{j}, \alpha, \beta\right)}{f\left(0 \mid X_{j,} \alpha_{0,} \beta_{0}\right)} P\left[Y_{j}=0 \mid X_{j}\right]-1
\end{aligned}
$$

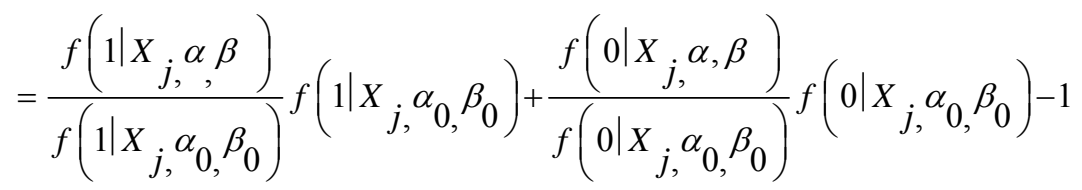

$$
\begin{aligned}
& =f\left(y \mid X_{j,}, \beta\right)+f\left(0 \mid X_{j,}, \beta\right)-1 \\
& =\frac{1}{1+\exp \left(-\alpha-\beta X_{j}\right)}+\frac{\exp \left(-\alpha-\beta X_{j}\right)}{1+\exp \left(-\alpha-\beta X_{j}\right)}
\end{aligned}
$$

Following the mathematical derivations, it can be inferred that:

$$
E\left[\ln \left(L_{n}(\alpha, \beta)\right) \mid X_{1}, \ldots . X_{n}\right] \leq E\left[\ln \left(L_{n}\left(\alpha_{0}, \beta_{0}\right)\right) \mid X_{1}, \ldots . X_{n}\right]
$$

The estimation of equation (3.24) requires determining the values of $\alpha_{0}$ and $\beta_{0}$ by maximizing the $\log$ likelihood of the function $\ln \left(L_{n}\left(\alpha_{0}, \beta_{0}\right)\right)$. Mathematically, this would mean that:

$$
\ln \left(L_{n}(\hat{\alpha}, \hat{\beta})\right)=\max _{\alpha, \beta} \ln \left(L_{n}(\hat{\alpha}, \hat{\beta})\right)
$$

The first order conditions for maximizing the log-likelihood function are:

$$
\begin{aligned}
& 0=\frac{\delta \ln \left(L_{n}(\hat{\alpha}, \hat{\beta})\right)}{\delta \hat{\alpha}}=-\sum_{j=1}^{n}\left(1-Y_{j}\right)+\sum_{j=1}^{n} \frac{\exp \left(-\hat{\alpha}-\hat{\beta} X_{j}\right)}{1+\exp \left(-\hat{\alpha}-\hat{\beta} X_{j}\right)}, \\
& 0=\frac{\delta \ln \left(L_{n}(\hat{\alpha}, \hat{\beta})\right)}{\delta \hat{\beta}}=-\sum_{j=1}^{n}\left(1-Y_{j}\right) X_{j}+\sum_{j=1}^{n} \frac{\exp \left(-\hat{\alpha}-\hat{\beta} X_{j}\right)}{1+\exp \left(-\hat{\alpha}-\hat{\beta} X_{j}\right)_{i}}
\end{aligned}
$$


There is no explicit solution for $\hat{\alpha}$ and $\hat{\beta}$. The maximum likelihood estimators have to be solved from the first order conditions numerically, which is done by many econometric software packages.

\subsection{RANDOM UTILITY AND THE MULTINOMIAL LOGIT MODEL}

When the dependent variable involve a choice of more than two categories (i.e., is no longer binary) a multinomial model may be required. When the categories are unordered and greater than two, a multinomial Logistic model is the appropriate discrete choice modeling framework ( Madala 1983). Multinomial logit may be used to produce estimates of the parameters of a random utility model ${ }^{5}$. Random utility models assume that while individuals maximize their expected utility, these utilities are not known to researchers and must be assumed to be random variables. In this case each farmer will be indexed by (i) for each choice of alternative resource conserving technologies. A farmer (i) adopting resource conserving technology $\mathrm{j}$ is assumed to obtain utility equal to $\bigcup_{i j}=\bigcup\left(Q_{i j}\right)$, where $Q_{i j}$ is a vector of technology $\mathrm{j}$ characteristics of the individual as opposed to characteristics of the alternative. The utility of adopting technology $\mathrm{j}$ by i can be portioned into an observed component an unobserved portion, say $V_{i j}=V_{i j}\left(Q_{i j}\right)$, and a component that is not observable by the researcher, $e_{i j}$. Therefore,

$$
\bigcup_{i j}=V_{i j}\left(Q_{i j}\right)+e_{i j}
$$

Following (Adams and Berrens 1996), the estimation of the model proceeds by specifying a functional form for the systematic component part of the utility and assuming a distribution for the random component to all the population. This specification can be used to

\footnotetext{
${ }^{5}$ There are at least three ways in which discrete choice models can be motivated: from a random utility maximization framework, from direct probabilistic model, or threshold models (King 1989). The focus of this section is on the random utility maximization approach.
} 
estimate the probability that an individual farmer with a given observed utility level of $\mathrm{V}($.$) will$ adopt technology j. The choice probabilities are estimated based on the hypothesis of utility maximization. It is for this reason that on any given choice occasion, farmer i will adopt technology $\mathrm{j}$ if the utility of technology $\mathrm{j}$ is larger than the utility of adopting any other technology alternative. Then each individual farmer

$$
\operatorname{Pr} o b(t e c h n o=j)=\operatorname{Pr} o b\left(\bigcup_{i j} \geq \bigcup_{i m}, \forall m \in T_{i}, m \neq j\right)
$$

With

$\bigcup_{i j}=V_{i j}\left(Q_{i j}\right)+e_{i j}$, then we have

$$
\operatorname{Pr} o b(t e c h n o=j)=\operatorname{Pr} o b\left(V_{i j}+e_{i j}>V_{i m}+e_{i m}\right)
$$

A multinomial logit model will be assumed if the e's are independently and identically distributed with a type extreme value variate (McFadden 1973). The alternatives must also be truly nomial and mutually exclusive (Maddala). If the observed component of the utility function is linear, then the probability that an individual farmer chooses to adopt technology will follow the standard multinomial logit model (MNLM).

Consider such a model:

$$
P_{i j}=\frac{\exp \left(V_{i j}\right)}{\Sigma_{m} \exp \left(V_{i m}\right)}, m=1, \ldots ., J
$$

$V_{i j}=\beta^{\prime} Q_{i j}$, where $Q_{i j}$ is the vector of the characteristics of the individual farmer and $\beta$ is a vector of parameters.

There are five technologies in the choice set: Crop rotation, IPM (integrated pest management), organic practices, rotation grazing and water harvesting. The probability of a farmer i choosing a certain technology based on the characteristics of the individual is: 


$$
\operatorname{Pr} o b(\text { farmeri, site } j)=\frac{\exp \left(V_{i j}\right)}{\sum_{m=1}^{5} \exp \left(V_{i m}\right)}=\frac{\exp \left(\beta^{\prime} Q_{i j}\right)}{\sum_{m=1}^{5} \exp \left(\beta^{\prime} Q_{i m}\right)},
$$

Where $\mathrm{j}=1$, if crop rotation is chosen by farmer $\mathrm{i}$

$\mathrm{j}=2$ if organic practices is chosen by farmer $\mathrm{i}$

$\mathrm{j}=3$ if rotational grazing is chosen by farmer $\mathrm{i}$

$\mathrm{j}=4 \quad$ if $I P M$ is chosen by farmer $\mathrm{i}$

$\mathrm{j}=5$ if water harvesting is chosen by $\mathrm{i}$.

A multinomial logit approach was considered for this study. However, the data collected did not meet the mutual exclusiveness condition specified by Maddala for a multinomial logit model since the technologies considered in this study were not mutually exclusive. Indeed, many of the farmers in the data set had adopted more than one of the alternative technologies. Therefore, the random component cannot be independent in this case. It is for this reason that a multinomial logit model is not estimated in this study. The multinomial probit model relaxes the assumption of mutual exclusiveness and may be considered in future work.

\subsection{APPLICATION}

This study is primarily focused on econometrically investigating farmers' resource conservation technology adoption decisions given their socio-economic and institutional settings. The factors that may affect the adoption of conservation-oriented agricultural technologies have already been discussed. The interest of this chapter is on building the theoretical basis to model conservationbased technology adoption decisions using survey data from South Africa.

Since the dependent variable in this study involves whether farmers will adopt a given technology or not given their individual characteristics, the appropriate econometric modeling 
choice is a discrete choice model. A logit model with maximum likelihood estimation procedure is followed for modeling technology adoption decision.

A complete empirical specification of the theoretical model is provided in Chapter 4. The empirical model introduces an array of economic, social, institutional, and other relevant factors in econometrically determining the parameters that provide information on the characteristics of technology adoption in South Africa. 


\section{CHAPTER 4 \\ METHODOLOGY}

\subsection{INTRODUCTION}

In Chapter three, the theoretical model for technology adoption and the theoretical logit model were presented. Some useful insights regarding the adoption of resource conservation technologies, also known as best management practices, and the socio-economic variables involved in the adoption decision have been gained from this framework. This chapter presents two empirical logit models of the adoption decisions. The models will focus on decisions to adopt a package of preferred resource conservation technologies in South Africa.

This chapter is organized as follows: section 4.2 discusses the specification of the empirical models and description of the variables included in the models. Section 4.3 discusses the data used to estimate the empirical model.

\subsection{MODEL SPECIFICATION AND DESCRIPTION OF THE VARIABLES INCLUDED IN THE MODEL}

In order to estimate the potential adoption of resource conservation technologies by farmers given their past adoption decisions, data have been collected on a number of socioeconomic variables that might affect adoption decisions of farmers in South Africa.

One objective of this dissertation is to determine the factors that affect the adoption decisions of commercial farmers in South Africa with or without intervention policy. From a policy perspective, the main interest is on the likelihood of future adoption of resource 
conservation technologies. This information may be relevant for future technology adoption and conservation-oriented government programs.

To determine the relationship between technology adoption decisions and farmers' socioeconomic, land and institutional characteristics variables, a logit model is estimated. By their very nature, adoption decisions are binary choices, i.e., a farmer has the choice of either adopting a technology or not. Hence, a logit econometric model is an appropriate tool to capture the relationships between a binary dependent variable and the above-mentioned variables. It is assumed that the decision to adopt any particular technology is independent of the decision to adopt any other technology. This assumption is supported by the data on South Africa because we have instances of farmers adopting no technologies, single technologies, and various combinations of the proposed technologies. Also, the technologies do not have to be adopted in any particular order, i.e., none of the specified technologies require the prior adoption of any of the other specified technologies. As discussed in Chapter 3, the technologies are also not mutually exclusive, i.e., adoption of one does not exclude any of the others from consideration. Adoption rates by Province are given in Appendix E.

\subsubsection{Model Selection}

The model used to determine the association between adoption and the factors that affect adoption involves a mixed set of qualitative and quantitative analyses. Qualitative models have been used extensively in adoption studies although they have been criticized for their inability to account for partial adoption (Feder et al., 1985; Norton, 1994: Cypers et al.,1984; Bennert et al., 2003 ). Alternative specifications of qualitative choice models include the linear probability models, the Probit model and the Logit model. These are the two most frequently used 
applications in explaining the socio-economic phenomena, especially for analyzing the relationship between dependent discrete variables (adoption) and explanatory variables. Both the Probit and Logit models yield similar parameter estimates and it is difficult to distinguish them statistically (Gujarati, 2003). Of these two models, the binomial Logit model is easier to estimate and simpler to interpret (Abebaw and Belay, 2001).

To measure an outcome of such discrete output, a variety of multivariate statistical techniques can be used to predict a binary dependent variable from a set of independent variables. The logit model is appropriate for this study, because it is applicable to a broader range of research situations and is able to predict the presence or absence of a characteristic or outcome based on values of a set of predictor variables. It is similar to a non-linear regression model but is suited to models where the dependent variable is dichotomous. There is flexibility in the model where independent variables can be interval level or categorical; if categorical, they should be dummy or indicator. Therefore, the binomial logit model was used in this study, given the limitations of the linear probability model (Madala, 2001, Pindyck and Rubinfield, 1990). The probit model would give the same results as the logit model but for its simplicity, the logit model was selected for this study.

In the logit model, the relationship between the independent variable and the probability of adoption is non-linear. The probability estimate will always be between 0 and 1 , regardless of the value of the independent variables. The parameters of the model were estimated using the maximum-likelihood method. That is, the coefficients that make the observed results most likely are selected. Since the logit regression model is nonlinear, an iterative algorithm is necessary for parameter estimation. 


\subsubsection{Empirical Logit Models}

Following the theoretical model in chapter three, the econometric model for the adoption decision for the specified Best Management Practices (BMP's) can be specified as:

$$
y_{i}^{*}=\beta^{\prime} x_{i}+\varepsilon_{i}
$$

In practice $\mathrm{y}^{*}$ is not observed, but is estimated through the discrete variable, $\mathrm{Y}_{\mathrm{i}}$, such that;

$$
\begin{array}{ll}
Y_{\mathrm{i}}=1 & \text { if } y^{*}{ }_{i} \geq 0 \\
\mathrm{Y}_{\mathrm{i}}=0 & \text { otherwise }
\end{array}
$$

$\varepsilon_{\mathrm{i}}$ is assumed to be distributed according to a logistic distribution (with mean of zero and standard deviation of $\pi^{2} / \sqrt{ } 3$ ). This assumption allows for the use of logit estimations in the econometric model. Therefore, the general logit model for the adoption decision is:

$$
Y_{i}=\alpha+\sum_{k} \beta \kappa X_{\kappa i}+\varepsilon_{i}
$$

where $\mathrm{Y}_{\mathrm{i}}$ is the indirect utility difference and is underlying latent variable that indexes the adoption of BMP practices on a given parcel. $\mathrm{X}_{\mathrm{k}}$ is the vector of explanatory variables (social, economic, land characteristics, and government policy variables determining adoption decision). $\beta$ is a column vector of parameters to be estimated and the stochastic error term, $\varepsilon_{\mathrm{i}}$ is distributed logistically with mean zero and variance normalized to $\pi^{2} / \sqrt{ } 3$. The variable $Y_{i}$ is not observed but the adoption decision is observed, such that: 


$$
\begin{array}{ll}
A D P T_{i}=1 & \text { if } \alpha+\sum_{k} \beta \kappa X_{\kappa i}+\varepsilon_{i} \geq 0 \\
A D P T_{i}=0 & \text { if } \alpha+\sum_{k} \beta \kappa X_{\kappa i}+\varepsilon_{i}<0
\end{array}
$$

The logit model is estimated by a maximum likelihood method using LIMDEP 8.0 econometric software. In the empirical logit model, it is assumed that social, economic, land characteristics and government policy vectors influence farmers' adoption behavior. The empirical specification of model 1 , thus, may be specified as:

$$
\begin{aligned}
& A D P T_{\mathrm{i}}=\phi_{0}+\Omega_{1} G F A_{\mathrm{i}}+\Omega_{2} A G E_{35 \mathrm{i}}+\Omega_{3} A G E_{3645 \mathrm{i}}+\Omega_{4} A G E_{45 \mathrm{i}}+\Omega_{5} R E N T_{\mathrm{i}}+\Omega_{6} P L A N D C_{\mathrm{i}} \\
& +\Omega_{7} \text { LEDUCH }_{\mathrm{i}}+\Omega_{8} \text { LEDUC }_{\mathrm{i}}+\Omega_{9} \text { LEDUU }_{\mathrm{i}}+\Omega_{10} L A B I_{\mathrm{i}}+\Omega_{11} \text { FHUOM }_{i} \\
& +\Omega_{12} \text { FHUOL }_{i}+\Omega_{13} F E X_{5 i}+\Omega_{14} \text { FEXP }_{610 i}+\Omega_{15} \text { FEXP }_{20 i}+\Omega_{16} C D T_{i}+\Omega_{17} \text { FIN }_{100 i} \\
& +\Omega_{18} \text { FIN }_{100250 i}+\Omega_{19} \text { FIN }_{250500 i}+\Omega_{20} \text { FLC }_{i}+\Omega_{21} \text { ENTFCROP }_{i}+\Omega_{22} \text { ENTHORT }_{i} \\
& +\Omega_{23} \text { ENTLVST }+\varepsilon_{i}
\end{aligned}
$$

The definition of the variables is presented in table 4.1. 
Table 4.1: Definition Of Variables Used In The Decision Of Adopting Resource-Conserving Technologies (Model 1)

\begin{tabular}{|c|c|}
\hline Variable/Parameter & Definition \\
\hline ADPT & $\begin{array}{l}\text { A binary variable; a value of } 1 \text { if the farmer adopted } \\
\text { and maintain at least one technology of BMP over the } \\
\text { last five years; } 0 \text { otherwise. }\end{array}$ \\
\hline GFA & $\begin{array}{l}1 \text { if the farmer received assistance from government } \\
\text { during the last five years; } 0 \text { otherwise }\end{array}$ \\
\hline RENT & Size of rented land in ha \\
\hline LABI & $\begin{array}{l}1 \text { if the farmer or a member of the family has off- farm } \\
\text { employment; } 0 \text { otherwise }\end{array}$ \\
\hline PLANDC & $\begin{array}{l}1 \text { if the farmer participated in the National Land Care } \\
\text { Program, } 0 \text { otherwise }\end{array}$ \\
\hline CDT & $\begin{array}{l}\text { A value of } 1, \text { if the farmer had credit access; } 0 \\
\text { otherwise }\end{array}$ \\
\hline FIN100 & 1 if the farmer's income is less than R100, 000 (base) \\
\hline FIN100250 & $\begin{array}{l}1 \text { if the farmer's income is between R100, 000- } \\
250,000\end{array}$ \\
\hline FIN250500 & $\begin{array}{l}1 \text { if the farmer's income is between R } 250,000- \\
500,000\end{array}$ \\
\hline FIN500 & 1 if the farmer's income is above $\mathrm{R} 500,000$ \\
\hline AGE35 & 1 if younger than 35,0 otherwise (base) \\
\hline AGE 3645 & 1 if between the age of 36 and 45,0 otherwise \\
\hline AGE46 & 1 if over the age of 46,0 otherwise \\
\hline LEDULH & 1 if less than high school, 0 otherwise (base) \\
\hline LEDUCH & 1 if completed high school, 0 otherwise \\
\hline LEDUC & 1 if have some college, 0 otherwise \\
\hline LEDUU & 1 if completed university, 0 otherwise \\
\hline FHUO & Farm size (the number of total hectares operated) \\
\hline FHUOS & 1 if the farm size is less than 500 ha \\
\hline FHUOM & 1 if the farm is between 500 and 5000 ha \\
\hline FHUOL & 1 if the farm is larger than 5000 ha \\
\hline FLC & 1 if there is soil erosion problem; 0 otherwise \\
\hline FEXP5 & 1 if farming for less than 5 years, 0 otherwise (base) \\
\hline FEXP610 & 1 if farming for between 6 and 10 years, 0 otherwise \\
\hline FEXP20 & 1 if farming for over 20 years, 0 otherwise \\
\hline ENTHORT & 1 if the type of enterprise is Horticulture; 0 otherwise \\
\hline ENTFCROP & $\begin{array}{l}\text { A value of } 1 \text {, if the type enterprise is Field crops ; } 0 \\
\text { otherwise }\end{array}$ \\
\hline ENTLVST & $\begin{array}{l}1 \text { if the type of enterprise is live stock production, } 0 \\
\text { otherwise }\end{array}$ \\
\hline ENTMXFAR & $\begin{array}{l}1 \text { if the type of enterprise is mix farming, } 0 \text { otherwise } \\
\text { (base) }\end{array}$ \\
\hline
\end{tabular}


Most variables reported in table 4.1 are used in the econometric model estimation procedure. Only variables that are theoretically considered to influence adoption were left in the model even if there were not significant. Otherwise all variables which were found to be not significant and have no compelling theoretical reason to keep were left out. However, base dummy variables, i.e., dummy variable categories used as base of comparison, are dropped from the model in order to avoid perfect multicollinearity. The influence of the dropped variables for each group of dummies is picked up by the constant term. Coefficients of every dummy variable reflect the change in the intercept from the base case.

The variables in the two models are divided into the following categories:

1) Household characteristics (the $S$ vector),

2) Economic characteristics of the farm operator (the $E$ vector),

3) Land and farm characteristics (the L vector), and

4) Institutional factors (the I vector).

Model 1 provided econometric estimates for a model with multiple categorical and dummy variables. A second model (2) was estimated using the same variables as in model 1, except that all multiple categorical explanatory variables were constrained to binary choice variables. The major goal of this approach is to test the robustness of the models and to generate alternative analyses of the data. In order to measure the robustness of the estimated model, the category explanatory variables used in model 1 were constrained to be binary choice variables. The reclassified variables are redefined in table 4.2. The second model estimation includes all the other variables in model 1. 
Table 4.2: Definition of Variables (Binary) Used in the Decision to Adopt ResourceConserving Technologies (Model 2))

\begin{tabular}{ll}
\hline Variable & Definition \\
\hline ADPT & $\begin{array}{l}\text { A binary variable; a value of } 1 \text { if the farmer adopted and maintain } \\
\text { at least one technology of BMP over the last five years; } 0 \\
\text { otherwise. }\end{array}$ \\
& 1 if the farmer received assistance from government during the \\
last five years; 0 otherwise \\
GFA & Size of rented land in ha \\
RENT & 1 if the farmer or a member of the family has off- farm \\
LABI & employment; 0 otherwise \\
PLANDC & 1 if the farmer participated in the National Land Care Program, 0 \\
otherwise & A value of 1, if the farmer had credit access; 0 otherwise \\
CDT & 1 if the farmer's income is R 250,000 and above; 0 otherwise \\
FIN250 & 1 if over the age of 36,0 otherwise \\
AGE36 & 1 if have some college and higher, 0 otherwise \\
LEDC & 1 if the farm size is 500 ha and above; 0 otherwise \\
FHUOLA & 1 if there is soil erosion problem; 0 otherwise \\
FLC & 1 if farming for 11 years and more, 0 otherwise \\
FEXP 11 & 1 if the type of enterprise is Horticulture; 0 otherwise \\
ENTHORT & A value of 1, if the type enterprise is Field crops; 0 otherwise \\
ENTFCROP & 1 if the type of enterprise is live stock production, 0 otherwise \\
ENTLVST & 1 if the type of enterprise is mix farming, 0 otherwise (base) \\
ENTMXFAR &
\end{tabular}

\subsubsection{Description of the Explanatory Variables}

\subsection{3.a Household Social Characteristics (S)}

Studies of farmers' adoption of soil conservation technologies have shown importance of farmers' social characteristics in influencing adoption decisions. Evidence from studies in Africa can be found in Adesina et al. (2000) and Atta-Kra and Francis (1987). Evidence from studies outside of Africa can be found in Lynne et. al. (1988) and Lohr and Park (1994). The S vector is 
proxy for possible differences in attitudes among farmers. From the econometric model above, the S vector comprised of: LEDU, FEXP, AGE, FLC and PLANDC.

In order for a market system to operate competitively and allocate resources efficiently, the role of information is critical. Farmers evaluate and use information to make production and management decisions. Therefore, a farmer's education level and experience are proxies for a farmer's ability to acquire and effectively use information about new technologies.

The level of education is a measure of the degree of human capital accumulation. It can be expected that education will positively influence technology adoption through making information available to farmers and providing the ability to take a calculated risk. Education is one of the popular ways of inducing technology adoption and diffusion.

On the other hand, the impact of a farmers' experience on their adoption decision is not clear a priori. Studies in the past have reported conflicting results. In this study, no a priori sign is fixed for this relationship and is rather left to be concluded based on the empirical results.

The farmer's participation in the National Land Care program provides awareness of environmental problems and they are expected to increase an individual's awareness of the true private and social costs of agricultural activities. Participation in the National Land Care program (PLANDC) may also indicate the willingness of farmers to participate in conservation programs. Once such decisions to participate are made, there is a flow of information and assistance that might further encourage adoption of conservation-oriented farming practices. Hence, it is expected that farmers who participate in the national Land Care program would have a higher rate of adoption.

Age of farmers in the survey do no have any specified sign a priori as the impact of age on adoption is not theoretically clear and uniform. Different studies have concluded different 
results depending on where the study is conducted and the types of farming activity considered. The relationship of age with adoption will be left to be empirically determined.

Perception of the degree of the resource and environmental degradation problem by farmers may make a significant difference in their technology adoption behavior. To test this hypothesis, the degree of soil erosion (FLC) variable is introduced. It is expected that as the resource degradation problem intensifies and its perception by farmers is more apparent, adoption of technologies to mitigate these local natural resource problem is likely to increase. Hence, a positive relationship between adoption and degree of resource degradation is expected.

The above discussed social factors are introduced in the empirical logit model to capture variations in the adoption decision that are attributable to differences in social factors experienced by each surveyed farmer.

\subsection{3b. Land and Farm Characteristics (L)}

With the exception of the type of farming operation, the effect of a change in a characteristic of the farm and/or soil has an undetermined effect on the adoption decision. The components of vector L for this model are: farm size (FHUO) and perception of resource degradation problem (FLC). The three types of farming operations, field crop farming enterprise (ENTFCROP), livestock enterprise (ENTLVST), horticulture enterprise (ENTHORT), and mixed farming enterprise (ENTMXFAR) are also part of the vector L component. It is assumed that these variables influence the adoption decision of a farmer through technical effects on the production and on-farm resource quality functions.

Farm size (FHUO) represents the fixed land resources for the farm in this static model and indicates the size of the farming operation. There is ambiguity in the effect of an increase in 
farm size on the likelihood of adoption due to the conflicting effects of farm size on the costs of adoption and the impact on the environment. The ambiguity emanates from: 1) Larger farms may have lower costs of adoption due to economies of scale and technology advancement. Just et al. (1980) show that given the uncertainty and the fixed transaction and information costs associated with innovations, there may be a critical lower limit on farm size, which prevents smaller farms from adopting. It follows that innovations with large fixed transaction and information costs are less likely to be adopted by small farms. 2) The output losses or gains due to degradation will vary from field to field and the average potential decrease in farm revenues may have an inverse relationship to farm size, since the risk of adoption is spread over a larger area. In contrast, the extent and amount of damage both on and off the farm may be greater the larger the farm size.

The types of farm production activities influence the likelihood of adopting different technologies. A set of farming activity variables are introduced to test which agricultural activity or enterprise is more likely to adopt new technologies. Livestock, crop farm, horticulture and mixed farming are introduced. There is no reason to believe that one enterprise may adopt more than the other in South Africa. Hence, the direction of influence is left to be empirically determined.

The farms characterized by highly vulnerable soils are more likely to have resource quality problems. These farmers, assuming they have knowledge of their potential soil erosion, are hypothesized to have a greater level of concern for soil quality. Therefore, it is expected that as the resource degradation problem intensifies and its perception by farmers is more apparent, adoption of technologies to mitigate these local natural resource problem is likely to increase. Hence, a positive relationship between adoption and degree of resource degradation is expected. 
The locations of the farmer and the soil characteristics have an effect on technology adoption decisions. Location factors such as topography, climate, soil type, and availability or access to information can influence the profitability of different technologies across different farms. In the case of soil conservation technologies, the physical environment of the farm may encourage the farmer to adopt such technologies. Heterogeneity of the resource base has been shown to influence technology adoption (Green et al., 1996).

\subsection{3c. Economic Characteristics}

Farmers may adopt profitable soil conservation measures if they have sufficient funds of their own or if they have access to credit facilities. High initial investment and maintenance cost of structures is often more than affordable by farmers, therefore, the adoption of a non-divisible technology, which requires a large investment, may be prevented by lack of borrowing capacity (El-Osta and Morehart, 1999). Hence, for many technology options, there is a degree of capital investment needed to sustain the adoption. This would mean that adoption of a technology may not be free to the farmer and any sustainable adoption may require some degree of capital investment. In this case, the availability of credit to farmers can facilitate the rate of technology adoption as well as diffusion. Therefore, the expected sign on availability of credit is positive.

The variable $\mathrm{LABI}_{\mathrm{i}}$ is a proxy for additional income to the farmer and also an indication of managerial time for the farm. The influence of this variable is ambiguous. Additional income is expected to increase the probability of technology adoption. Generally, with off-farm employment and income, a farmer's financial resources increase. This may increase the financial capacity of farmers that may help adopt technologies which are otherwise unaffordable and uneconomical at lower incomes. Off-farm employment and income may also improve the ability 
to have access to credit due to a collateral guarantee and better income. Hence, these effects may dominate to influence a farmer to adopt better technologies. In contrast, given the high level of interdependency between the household and farm business, the occupation of the operator is an indication of the total time available for farming activities. Best Management Practices can require a substantial amount of managerial time. Operators with off-farm employment may present constrain to adoption because it competes for on farm managerial time (McNamara et al., 1991). The coefficient sign will be left to be empirically determined.

Farm income (FIN) is also expected to positively influence adoption. For the same reason that access to credit may affect adoption rates and diffusion of technologies in agriculture, the ability of farmers to generate a higher return per hectare may also affect adoption and sustenance of technologies. Income can also affect the perception of risk. Low income farmers may tend to be risk averse to sustain their basic needs, while high income farmers may tend to take some level of risk.

\subsection{3d. Institutional Characteristics}

The Rent variable is used as a proxy to measure land tenure. Resource conservation from an economic perspective implies saving resources for the future, in this case redistribution of land use rates into the future. Land degradation by using degrading practices, on the other hand, implies redistribution of land use rates to the present. Therefore, the absence of long-term tenure security to the renters is more likely to induce short planning horizons so that long-term effects of land productivity will have less influence on land use decisions. For this reason they may tend to employ land degrading agricultural practices that will degrade more land at present at the expense of the future. Farmers in South Africa have two land use choices for farming: to own 
farm-land or to rent farmland. Renting farmland would entail that tenure security is not guaranteed and investment in land improvement would become risky and the beneficiary of such investments will be mainly the owner of the natural resource. This result would hold even more strongly as land rent increases and tenure security decreases. Hence, it is expected that RENT will have a negative association with farm technology adoption.

The variable government financial assistance $\left(\mathrm{GFA}_{\mathrm{i}}\right)$ is a policy instrument that the government uses as an incentive for adopting Best Management Practices (environmentally preferred technologies). All government programs designed to induce farmers to adopt Best Management Practices are expected to show a positive sign in the model. Government financial assistance to farmers is one way of providing positive incentives to farmers to adopt a certain agricultural technology. In the presence of government financial intervention, the opportunity cost of not adopting a given technology to farmers now changes. It is, hence, expected that if the government financial assistance (GFA) is a significant amount and if it is related to a particular environmentally friendly production method, then the probability that the technology is adopted by a given farmer increases, hence a positive expected sign.

The expected signs of the effects of the variables discussed above on the likelihood of farmers' adoption decision are summarized in table 4.3. 
Table 4.3: Expected Signs for the Explanatory Variables

\begin{tabular}{ll}
\hline Variable & Expected Sign \\
\hline GFA & + \\
RENT & - \\
LABI & + - \\
PLANDC & + \\
CDT & + \\
FIN100 & + \\
FIN100250 & + \\
FIN250500 & + \\
FIN500 & + \\
AGE35 & $+/-$ \\
AGE 3645 & $+/-$ \\
AGE4655 & $+/-$ \\
AGE55 & +- \\
PROXYAGE & + \\
LEDULH & + \\
LEDUCH & + \\
LEDUC & + \\
LEDUU & + \\
FHUO & $+/-$ \\
FLC & + \\
FEXP5 & +- \\
FEXP610 & $+/-$ \\
FEXP20 & $+/-$ \\
ENTHORT & $+/-$ \\
ENTFCROP & $+/-$ \\
ENTLVST & $+/-$ \\
ENTMXFAR & $+/-$ \\
\hline
\end{tabular}

\subsection{DATA}

\subsubsection{Data Sources}

Data to estimate the model were obtained through a field survey, which was conducted by the author in collaboration with the University of Pretoria between October 2004 and March 2005. Six hundred commercial farmers were expected to be surveyed in all nine provinces of South Africa. Unfortunately, a lower than anticipated budget and lack of cooperation by some farmers 
led to only 337 farmers actually being surveyed. While the sample size is lower than prior expectations it is still felt that the sample is representative of the population. The survey was structured to elicit information from farmers on agricultural activities, including adoption of various soil conservation technologies. In particular, the survey contains information on socioeconomic characteristics, land and farm characteristics, farm production characteristics, and institutional characteristics and Best Management Practices. The definition of commercial farmers in this survey is the existence of any farming business operated on private land.

\subsubsection{Survey Design}

There are approximately 60,000 commercial farming units in South Africa, covering a wide range of land uses and enterprises. The register of farmers from the commercial farmers union (AGRISA) was used as a sampling frame. The farmers' list was stratified and the stratification variable was location (province). The farmers were further stratified according to dominant land use categories and the information on the break down according to land use time was obtained from the Agricultural Census 1993 which was the last census. The next census was conducted in 2003 and its results were not available at the time of designing this study. Table 4.4 presents a breakdown of these farming units according to five dominant land use categories and by province.

Table 4.4: Number of commercial farming units in South Africa by land use and province

\begin{tabular}{lllllllllll}
\hline & W Cape & N Cape & $\begin{array}{l}\text { Free } \\
\text { State }\end{array}$ & E Cape & KZN & Mpu & Limpopo & Gauteng & NW & Total \\
\hline Total 1993 & 8352 & 6593 & 10252 & 6106 & 6080 & 5406 & 5053 & 2500 & 7638 & 57980 \\
Field crops & 1051 & 922 & 3055 & 238 & 1819 & 1703 & 545 & 492 & 2167 & 11992 \\
Horticulture & 3336 & 565 & 214 & 616 & 708 & 560 & 1067 & 423 & 550 & 8039 \\
Forestry & 76 & - & - & 33 & 286 & 256 & 137 & 3 & 5 & 796 \\
Animal & 3114 & 4705 & 6065 & 4640 & 2611 & 2336 & 2644 & 1192 & 4135 & 31442 \\
Mixed & 775 & 401 & 918 & 579 & 656 & 551 & 660 & 390 & 781 & 5711 \\
\hline
\end{tabular}

Source: Abstract Agricultural statistics Department of Agriculture 2003. 


\subsubsection{Determining the Sample Size}

There were many alternative methods considered to determine the sample size for this survey. This included using census data, imitating sample size of similar studies, using published tables, and applying statistical formulas to calculate sample size. The latter approach was finally selected to determine the sample size for this survey. The census approach was dropped because some important variables for this study were missing. The formula approach was found to be more efficient, given that there is software available to calculate the sample size.

For this survey, we chose the basic formula that has been developed to yield a representative sample for a large population:

$$
n_{0}=\frac{Z^{2} p q}{e^{2}}
$$

Where $n_{0}$ is the sample size, $Z^{2}$ is the distribution of normal curve that cuts off an area at the tails $(1-\mathrm{e})$ equals the desired confidence level, which in this survey was $95 \%)$, so e is the desired level of precision. Five percent was considered to be an adequate level of precision for the study. $\mathrm{P}$ is the estimated proportion of an attribute that is present in the population. Since commercial farmers comprise a large percentage of the population of South Africa, it is difficult to estimate the variability in the proportion that will adopt the technologies. Therefore, $\mathrm{P}=0.5$, implying maximum variability was assumed, and $q$ is $1-p$. The value for $Z$ is found in statistical tables which contain the area under normal curve. Therefore, the ideal sample size for the survey was,

$$
n_{0}=\frac{(1.96)^{2}(.5)(.5)}{(0.05)^{2}}=384
$$

The figure was raised to 600 to allow for non- responses. 
The ideal sample size was not achieved, since only 337 observations were made due to budget and time constraints. It was felt that this level of response was still adequate to obtain a representative sample of the commercial farmers' population in South Africa.

\subsubsection{The Sampling Procedure}

A proportionate stratified random sampling procedure was employed in this survey. It was necessary to use this approach to ensure national representation of the key farming categories in South Africa. Within each stratum, a systematic sample was selected. Therefore, based on the known proportions of the various land-use types per province, the sampling quotas were allocated accordingly by land use type and then by province. The resulting sampling proportion is presented in Table 4.5 .

Table 4.5: Sampling Quotas by Land Use Category and by Province

\begin{tabular}{|c|c|c|c|c|c|c|c|c|c|c|}
\hline $\begin{array}{l}\text { Land use } \\
\text { category* }\end{array}$ & W Cape & N Cape & $\begin{array}{l}\text { Free } \\
\text { State }\end{array}$ & E Cape & KZN & $\mathrm{Mpu}$ & Limpopo & Gauteng & $\begin{array}{l}\mathrm{N} \\
\mathrm{W}\end{array}$ & Total \\
\hline Field crops & 11 & 10 & 32 & 2 & 19 & 18 & 6 & 5 & 23 & 126 \\
\hline Horticulture & 36 & 6 & 2 & 6 & 7 & 6 & 11 & 4 & 6 & 84 \\
\hline Animal & 33 & 49 & 64 & 49 & 27 & 25 & 28 & 13 & 43 & 330 \\
\hline Mixed & 8 & 4 & 10 & 6 & 7 & 6 & 7 & 4 & 8 & 60 \\
\hline Total & 87 & 69 & 108 & 64 & 61 & 54 & 52 & 26 & 80 & 600 \\
\hline
\end{tabular}

Note: Since the category "forestry" was nearly insignificant in terms of prevalence, it was excluded in the survey. 


\subsubsection{Data Collection Method}

A survey questionnaire was developed and used as an instrument for data collection (the survey instrument is given in Appendix A). The survey instrument contains a total of 43 questions focusing on the variables of interest: namely socio-economic, farm production, and institutional variables. Most of the questions are limited responses (yes/no or selection from a list), although some questions have a free-response data format.

A face-to-face interview technique was preferred, given that most farmers cannot write and read English ${ }^{6}$. The personal interviewing was also preferred in this survey because it builds rapport and confidence, given that there is mistrust of the government in the farming community due to the political economic environment in South Africa.

\footnotetext{
${ }^{6}$ Most commercial farmers in South Africa are Afrikaans speakers.
} 


\subsection{DATA SUMMARY STATISTICS}

The minimum, maximum and averages are given for the data in Table 4.6 and in Appendix C along with the standard deviations. Appendix D contains descriptive statistics of the data by Province. The raw data are presented in Appendix F.

Table 4.6: Summary Statistics of the Data Set

\begin{tabular}{llll}
\hline Variable/Parameter & Maximum & Minimum & Average \\
\hline ADPT & 1.0 & 0 & 0.57 \\
GFA & & & \\
RENT & 1.0 & 0 & 0.26 \\
LABI & $15,000.0$ & 0 & 524.08 \\
PLANDC & 1.0 & 0 & 0.54 \\
CDT & 1.0 & 0 & 0.1 \\
FIN100 & 1.0 & 0 & 0.6 \\
FIN100250 & 1.0 & 0 & 0.17 \\
FIN250500 & 1.0 & 0 & 0.20 \\
FIN500 & 1.0 & 0 & 0.30 \\
AGE35 & 1.0 & 0 & 0.31 \\
AGE 3645 & 1.0 & 0 & 0.16 \\
AGE46 & 1.0 & 0 & 0.3 \\
LEDULH & 1.0 & 0 & 0.65 \\
LEDUCH & 1.0 & 0 & 0.22 \\
LEDUC & 1.0 & 0 & 0.21 \\
LEDUU & 1.0 & 0 & 0.24 \\
FHUO & 1.0 & 0 & 0.33 \\
FHUOS & $12,500.0$ & 2.6 & 2342.6 \\
FHUOM & 1.0 & 0 & 0.33 \\
FHUOL & 1.0 & 0 & 0.49 \\
FLC & 1.0 & 0 & 0.18 \\
FEXP5 & 1.0 & 0 & 0.68 \\
FEXP610 & 1.0 & 0 & 0.22 \\
FEXP20 & 1.0 & 0 & 0.30 \\
ENTHORT & 1.0 & 0 & 0.23 \\
ENTFCROP & 1.0 & 0 & 0.27 \\
ENTLVST & 1.0 & 0 & 0.21 \\
ENTMXFAR & 1.0 & 0 & 0.15 \\
\hline
\end{tabular}




\section{CHAPTER 5}

\section{ECONOMETRIC MODEL RESULTS AND ANALYSIS}

\subsection{INTRODUCTION}

Chapter four presented empirical model specification and description of the variables and data used in this study. Some theoretical determinants of decisions to adopt resource conserving technologies, also known as best management practices (BMP), were identified. The discussion, however, revealed only qualitative theoretical measures of adoption decisions. Further analysis of the factors that determine adoption of agricultural technologies in South Africa requires econometric estimation and analysis. This chapter presents a single logit model of adoption decisions and discusses the estimated results. The estimations are for the single equation logit models for the adoption decisions on a package of Best Management Practices (BMP). The organization of this chapter is as follows: Section 5.2 is focused on the measurement and interpretation of the maximum likelihood estimators. Section 5.3 presents the empirical logit model results and analysis of adoption. Section 5.4 provides a summary of this chapter.

\subsection{MEASUREMENT AND INTERPRETATION OF LIKELIHOOD ESTIMATORS}

\subsubsection{Hypothesis Testing and Goodness of Fit Tests}

Specific hypothesis testing was conducted on the logit results obtained from the two models. This was necessary to test the statistical significance of the parameter estimates and the overall significances of the model. The following specific hypothesis tests were conducted:

1. The null hypotheses for all explanatory variables are: 


$$
H_{0}: \Omega_{i}=0 i=1, \ldots \ldots . k
$$

The alterative hypotheses for coefficients with an expected sign as discussed in chapter four are:

$$
H_{A}: \Omega_{i}>0 \text { or } H_{A}: \Omega_{i}<0 \text {. }
$$

The alternative hypothesis $H_{0}: \Omega_{\uparrow} \neq 0$ was used for the coefficients with uncertain sign. The Limdep estimation results list the $\mathrm{p}$ values and $\mathrm{t}$ statistics. The statistical significance of a result is an estimated measure of the degree to which it is "true" (in the sense of "representative of the population"). The value of the p-level represents a decreasing index of the reliability of a result. The higher the p-level, the less we can believe that the observed relation between variables in the sample is a reliable indicator of the relation among the respective variables in the farmer's population. Specifically, the p-level represents the probability of error that is involved in accepting our observed result as valid, that is, as "representative of the population." For example, the $p$-level of .05 (i.e., $1 / 20$ ) indicates that there is a $5 \%$ probability that the relation between the variables found in our sample is a "coincidence."

To test the null hypothesis that all slope coefficients are zero: $\Omega_{0}=\Omega_{1}=\ldots=\Omega_{k}=0$. The likelihood ratio (LR) test is used to measure if the model explain farmers' adoption behavior. It is calculated as follows:

$$
L R=2\left(\log L_{\max }-\log L_{o}\right)
$$

where $L_{\max }$ is the maximum of the likelihood function when maximized under certain parameter restrictions and $L_{o}$ denote the value of the restricted log-likelihood when all slope coefficients are zero (Log-Likelihood (O)). Given the null hypothesis, the LR statistic follows the $\chi^{2}$ distribution with 23 degrees of freedom. The null hypothesis can be rejected if the LR P value $<0.05$ (95\% critical value for $\chi^{2}$ with 23 degrees of freedom). The LR value and its $\mathrm{P}$ 
value are already calculated in the Limdep output. In addition to the LR measure, the pseudo $R^{2}$ is also used to measure the model fit. The pseudo $R^{2}$ is similar to the $R^{2}$ from maximum likelihood estimation of the standard linear regression; it lies between 0 and 1.

\subsubsection{Marginal Effects Estimation and Economic Interpretation}

For the logit models, the estimated coefficients do not have a direct economic interpretation as most of economic analysis deals with marginal changes, marginal effects, and marginal decisions. Measures that are familiar to economists are marginal effects and elasticities. To enable meaningful economic analysis, marginal effects are computed for agricultural technology adoption decision analysis in this study. The marginal effect of an explanatory variable on the probability of adoption in a logit model is not equal to the estimated coefficient. The marginal effect, MPk, of the kth variable is calculated as follows:

$$
\begin{gathered}
M P_{K}=\frac{\partial P_{i}}{\partial x_{i k}}=\beta_{k} P_{i}\left(1-P_{i}\right) \quad \frac{\partial p[y=1 \mid x]}{\partial x_{i}}=F^{\prime}\left(\beta^{\prime} X\right) \beta_{i}>0 \\
\text { Where: } P_{i}=\frac{1}{1+\exp (-\beta X i)}
\end{gathered}
$$

Unlike the estimated marginal effects from a linear model, the partial derivatives of the nonlinear logit model vary with the values of the x's. Studies with logit and probit models often present the estimated marginal probabilities calculated at the means of the explanatory variables. In this study, the marginal probabilities can be interpreted as the marginal effect of each explanatory variable, which approximates the change in probability of adoption at the explanatory variables' means. The marginal probability values are used in interpretation of the results for continuous variables and are presented in the Limdep output. 
However, the marginal effect formulas do not apply to determining the magnitude of partial effect from changing a dummy variable from zero to one. The calculation of marginal effects for dummy variable is different and is given by: $P\left(Y=1 \mid X_{k}, X_{*}\right)=1-P\left(Y=1 \mid X_{k}, X_{*}\right)$. The Limdep output reports marginal effects for all dummy explanatory variables by computing $p \mid 1-$ $\mathrm{p} \mid 0$.

\subsection{EMPIRICAL LOGIT MODEL RESULTS AND ANALYSIS OF ADOPTION}

Economic and land characteristic data differ significantly in magnitudes and distributions over the farms, hence heteroskedasticity problems may arise. Maximum likelihood estimation provides consistent parameter estimates in the presence of heteroskedasticity, but the maximum likelihood standard errors will be biased and should not be used for inference. A heteroskedasticity test is conducted in the econometric application and the result indicates that for the survey data, there was no significant heteroskedasticity problem.

There was no reason to suspect multicollinearity in the analysis, given that most the signs of the coefficient were as expected and over $50 \%$ were significant. A more formal test using variable correlation matrix reveals that the highest correlation coefficient is 0.65 , hence it is below a serious level of multicollinearity, which is around 0.8 (Studenmund, 2001).

\subsubsection{Adoption of Best Management Practices (BMP) Model 1}

The empirical results of factors that affect the likelihood of farmers to adopt or maintain at least one best management practice in the last five years are reported in Table 5.1. The model was able to explain 70 percent of the relationship between the variables and the adoption probability. 
Table 5.1: Estimation Results for Model 1

\begin{tabular}{|l|l|l|l|l|}
\hline Variable & $\begin{array}{l}\text { Coefficient } \\
\text { Estimate }\end{array}$ & P Value & $\begin{array}{l}\text { Marginal } \\
\text { Probability }\end{array}$ & P Value \\
\hline Constant & -1.20 & 0.1184 & -0.50 & 0.1180 \\
\hline RENT & $-0.01^{* * *}$ & 0.0042 & $-0.47^{* * *}$ & 0.0035 \\
\hline GFA & $1.20^{* *}$ & 0.0353 & $0.29^{* *}$ & 0.0218 \\
\hline CDT & 0.86 & 0.1653 & 0.21 & 0.1530 \\
\hline LABI & 0.47 & 0.4518 & 0.12 & 0.4471 \\
\hline FHUOM & $1.44^{* * *}$ & 0.0090 & $0.35^{* * *}$ & 0.0045 \\
\hline FHUOL & 0.81 & 0.2618 & 0.20 & 0.2361 \\
\hline FLC & 0.54 & 0.2784 & 0.12 & 0.2688 \\
\hline PLANDC & -0.82 & 0.3409 & -0.20 & 0.2987 \\
\hline LEDUCH & $1.29^{* *}$ & 0.0728 & $0.31^{* *}$ & 0.0454 \\
\hline LEDUC & $2.72^{* * *}$ & 0.0002 & $0.55^{* * *}$ & 0.0001 \\
\hline LEDUU & $2.68^{* * *}$ & 0.0001 & $0.57^{* * *}$ & 0.0001 \\
\hline AGE2645 & $-2.60^{* * *}$ & 0.0027 & $-0.54^{* * *}$ & 0.0001 \\
\hline AGE4655 & $-2.65^{* * *}$ & 0.0012 & $-0.55^{* * *}$ & 0.0001 \\
\hline AGE55 & $-2.25^{* * *}$ & 0.0094 & $-0.46^{* * *}$ & 0.0006 \\
\hline FEXP610 & $1.27^{* *}$ & 0.0624 & $0.30^{* *}$ & 0.0412 \\
\hline FEXP1120 & -1.10 & 0.1701 & -0.26 & 0.1328 \\
\hline FEXP20 & 0.25 & 0.7464 & 0.63 & 0.7456 \\
\hline ENTLVST & $-1.38^{* *}$ & 0.0414 & $-0.33^{* *}$ & 0.0248 \\
\hline ENTHORT & 0.59 & 0.4326 & 0.15 & 0.4223 \\
\hline ENTFCROP & $-1.07^{*}$ & 0.1452 & $-0.25^{*}$ & 0.1063 \\
\hline FIN1025 & 0.26 & 0.7532 & 0.65 & 0.7523 \\
\hline FIN2550 & $2.55^{* * *}$ & 0.0020 & $0.54^{* * *}$ & 0.0001 \\
\hline FIN500 & $1.89^{* * *}$ & 0.0214 & $0.43^{* * *}$ & 0.0063 \\
\hline Psuedo R & 0.665 & & & \\
\hline Likelihood Ratio & 322.15 with 23 DF $(\mathrm{p}=0.000)$ & \\
\hline \% of Correct Prediction & $91 \%$ & & & \\
\hline N & 336 & & & \\
\hline Adopt BMP & $138(\mathrm{no}), 198(\mathrm{yes})$ & & \\
\hline & & & & \\
\hline
\end{tabular}

$* * *=$ Significant at $1 \%$ significant level

$* * *=$ Significant at $5 \%$ significant level

$*=$ significant at $10 \%$ significant level

The adoption decision of farmers is estimated using data ranging from farmers' income and education to participation in land care program, farm size, experience of farmers, and type of agricultural production activity. All variables with a P value of less than 0.5 with the expected 
sign supported by theory were retained in the model. Those variables with a P value of more than 0.5 were discarded from the model.

The signs of most of the estimated parameters conform to prior expectations (with the exception of participation in the Land Care Program (PLANDC) which was used as a proxy for information). The likelihood statistic goodness of fit shows a good fit for the model (significant at $\mathrm{P}<0.001$ level). The vector of variables that were found to be positive and have significant effects on the probability of adopting BMP (table 5.1) are: i) Social attributes (including level of education (LEUDC, LEDUU) and farmers experience (FEXP610) ii) farm characteristics (including farm size (FHUOM)), iii) Economic attributes (including farmers income (FIN2550, FIN500)). Among the vector of institutional variables only RENT was found to be negative and have significant effect on the probability of adopting a BMP. Government policy (GFA) was found to be positive and significant in affecting the probability of adopting BMP. The other policy variable (PLANDC) was found to be negative and not significant.

The LR test indicates that the hypothesis that all coefficients are equal to zero can be rejected at the $99 \%$ confidence level for the logit model. The percentage of correct prediction is 91.9\%. Hence the model has good explanatory power for the adoption behavior of farmers in South Africa.

The result on the impact of education on adoption decision was tested by using categorical educational attainment data. By stratifying educational attainment in to uneducated, high school (LEDUCH), college (LEDUC), and university (LEDUU) levels, uneducated farmers are compared against the rest of the sample group. The education parameter was positive and significant for each category, which implies that the adoption increases with the increase in years of schooling. Education as a measure of human capital development enables an individual 
farmer to access information and makes informed decisions about resource management. In order for a market system to operate competitively and allocate resources efficiently, the role of education is crucial in processing information. Hence, the likelihood of farmers who have higher education to adopt best management practices is higher compared to those with less education. The result significantly indicates that for all education attainment groups, the marginal probability of adoption of best farming practice technologies was significantly higher for any level of educational attainment as compared to the base uneducated farmers group. This may indicate that exposure to education or expansion of educational opportunities to farmers is one way to increase their likelihood of adopting environmentally conscious farming practices. The marginal probability for LEDUCH implies that farmers who have completed high school will increase the likelihood of adoption by $30 \%$ above the mean to compare to farmers who have less than high school. Similarly, farmers with college education (LEDUC) are 55\% above the mean likely to adopt compared to those with less than high school. The marginal probability for LEDUU implies that farmers with University education $56 \%$ above the mean likely to adopt compare to the base category. The findings in South Africa are similar with that of Ervin and Ervin (1982), and Rahm and Huffman (1993) in the United States of America.

Farmers' income was another economic variable that was hypothesized to positively affect the marginal probability of adoption. Farm income data from the survey is divided in to four categories, each of them entering the model as dummy variables through category transformation. The low income group (FIN10) is held as the base, and the impact of income on adoption for all other income groups (FIN1025, FIN550, and FIN500) is compared against this base group. The econometric result indicates that farmers with annual farm income of 100,000- 
250,000 $\operatorname{Rand}^{7}$ (FIN1025) showed no significant difference in terms of adoption, however, all the other income groups (FIN2550 and FIN500) have a higher and significant marginal probability of adoption. This result reinforces similar findings in previous studies that farm income is one critical component in shaping the behavior of farmers in terms of adopting conservation-oriented farming. On assumption that the technology is a normal good, it is not surprising that, other things equal, that farmer's income and the demand for technology is positively correlated.

To measure the impact of government financial assistance on the adoption decision, a government financial support variable (GFA) is introduced in the empirical logit model. It is hypothesized that government financial assistance decreases risk aversion behavior and increases the rate of adoption. The computed result indicates that government support programs significantly improve the marginal probability of adopting environmentally-conscious farming technologies. This result may validate the motivation of the public sector intervention in the farming sector through government transfer programs to generate social positive externalities that are associated with adoption of conservation technologies. This finding is consistent with previous findings (Norton, 1994).

The positive coefficient of credit (CDT) was as expected. It implies that the availability of credit encourages farmers to adopt BMPs. Given that some of the practices require a high initial investment, it is consistent with previous studies that a technology which requires a large initial investment may be hampered by lack of borrowing capacity (El-Osta and Morehart, 1999). However, this variable was not statistically significant.

The positive and significant coefficient of farm size (FHUO) indicates the positive relationship between FHUO and BMP. To investigate the impact of farm size on adoption decision, farmland is classified into small (FHUOS), medium (FHUOM) and large (FHUOL)

${ }^{7}$ Exchange rate $=\mathrm{R} 6 / \$$ in 2005 
farms. The computed marginal probability of medium size farms was found to be 0.35 , indicating the incremental change of adoption probability BMP due to a unit increase in medium farm size as compared to small farms. The probability of adoption is $36 \%$ for a 100 ha increase from the mean when compared to small farms. This could be attributed to the fact that small farms are highly risk averse concerning new technologies due to limited size and uncertain outcomes from the technology. This finding is consistent with previous studies (Zilberman and Rausser, 1980).

The variable Rent is used as proxy for land tenure. It was included as an indicator of the strength of soil conservation incentives, since renters operating under short-term contracts are widely believed to have an incentive to over exploit soil; hence the negative sign was expected. Best management practices from the economic perspective imply saving the resource for the future use, i.e., redistribution of resource use rates into the future. Land degradation by erosive agricultural practices, on the other hand, implies redistribution of resource use rate to the present. When there is no tenure security over important assets such as land, farmers are more likely to have short planning horizons so that long-term effects of their farming practices on productivity will have less influence on land use decisions. The negative sign on Rent confirms that the probability of renters operating under short-term contracts adopting Best Management Practices in South Africa is low. The probability of adoption decreases by about $1.9 \%$ for every 1000 hectare increase in rented land from the mean of 524 hectares. This finding is not consistent with Norton's (1994) findings in the United States. This may confirm that farmers in developed countries behave differently from those in developing countries like South Africa. This shows that land tenure security played an important role in determining the farmers planning horizon, 
hence, it appears to play a more important role in the actual decision about whether or not to adopt BMP in South Africa.

Farm experience was used as an indicator of human capital. The sign was negative though not significant, for experience ranging from $11-20$ years, confirming that experienced farmers are not as likely to adopt BMP technologies possibly due to their being closer to the end of their operating horizons, leaving less time to earn returns from investments. It can also mean that the risk aversion factors increase with an increase in experience and age. A converse result would presumably be found for less experienced farmers more willing to experiment.

Farm experience (FEXP610) was found to be positive and significant. This implies that moderately experienced farmers are more likely to adopt compared to farmers with less than five years of experience.

Another proxy for experience is perhaps age of farmers. Age in the data was categorized in four groups. All AGE variables are negative and significant in the model. The results confirm findings of previous studies (Norris and Batie, 1987; Gould et al., 1989) that older farmers are more likely to reject conservation practices.

To measure the impact of availability of more financial resources to the farmer to his/her adoption of conservation technologies, an off-farm income variable is introduced as a proxy. The off-farm income variable (LABI) was found positive but not statistically significant. This suggests that off-farm income does not play a major role in influencing a farmer's decision to adopt. The results are not consistent with previous technology adoption studies where off-farm employment reduces the likelihood of adoption (Norton 1994, Daberkow and McBride, 1998, Cyphers, 1993). In some previous studies (Gould et al., 1989) the effect was undetermined on 
theoretical grounds. The results in South Africa could be attributed to the fact that agricultural labor is in abundance as opposed to developed countries.

Enrollment in such programs such as the National Land Care Program (PLANDC) was introduced as a proxy to farmers' awareness of environmentally-focused farming,. This variable is negatively related with adoption, but its magnitude is not statistically significant in the model. This may imply that participation in the program is not necessary for the farmer to enhance the rate of adoption. It appears not to affect the likelihood of BMP adoption. Although the Land Care program is designed to provide the necessary information, knowledge and skills in order to enable farmers to make decision on practicing best management practices, the coefficient was not found to be significant. This finding is not in conformity with other studies (Rahm and Huffman, Perret) where extension services were reported to increase the likelihood to adopt technology. Although, in this study Land Care was used as a proxy for information, the program is not popular among commercial farmers.

Overall, the analysis reveals that most of the factors associated with environmentally focused technology adoption in other studies also apply to South Africa. Farm income was the most pervasive influence on technology adoption. It was positive and significantly associated with adoption of BMP technologies. Farmers' experience was negatively and statistically associated with both technologies. This later finding hints a link between adoption rate and the less experience farmers who still want to explore new production practices.

Variables that were not statistically significant sometimes exhibited positive effects on the likelihood of adopting both technologies. For example, access to credit and off-farm income showed a positive relationship with the adoption of BMP technologies. This finding is interesting because it implies that farmers' credit and off-farm income in South Africa is not a 
determining factor for adopting Best Management Practices. This is in contrast with the theory and similar studies in other countries.

\subsubsection{The Binary choice Explanatory variable Model (Model 2)}

The logit results for adopting BMPs after the explanatory variables were constrained into binary choice variables are presented in Table 5.2. Most of the regressors used in the model had signs that comply with prior expectations and are similar to the ones in the first model.

Table 5.2: $\quad$ Logit Model Results for Binary Explanatory Variables (Model 2)

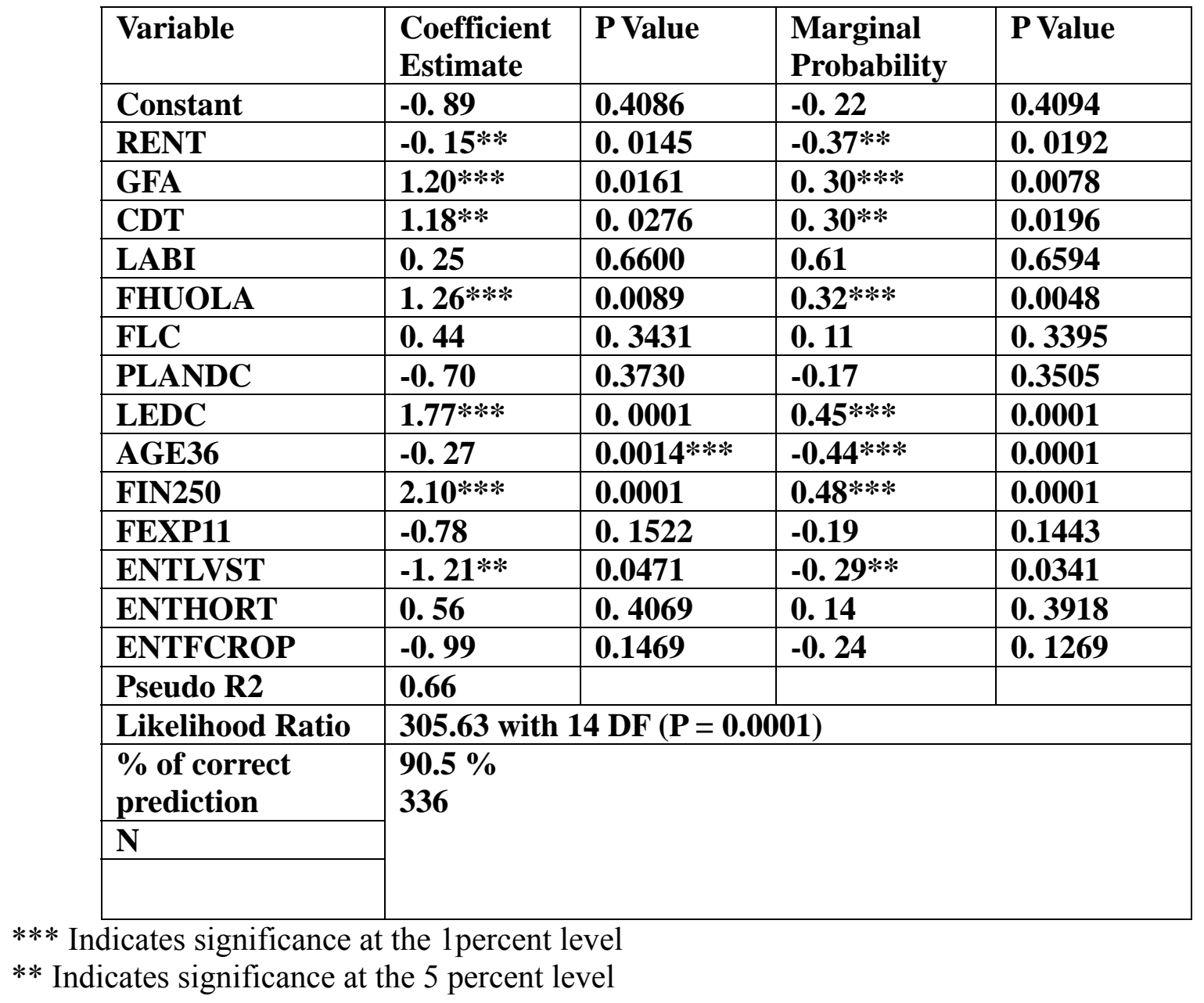


However, the results of model 2 show marginal differences in significance. The variable CDT is highly significant. In the context of the adoption model, this suggests a positive relationship between credit access and the probability of adoption. The log marginal probability for farmers with access to credit to adopt the environmentally desired technology is 0.30 . This indicates that holding other variable fixed, there is a higher probability for farmers with access to credit to adopt the desired environmental focused technologies. This is consistent with previous studies that a technology that requires a large initial investment may be hampered by lack of borrowing capacity (El-Osta and Morehart, 1999; Rahm and Huffman, 1984).

Constraining of the explanatory variables AGE, FEXP and FIN into binary choice did not result in a better econometric fit than in model 1. To give some evidence that this model is not giving a better fit, the likelihood statistic value is lower than the value reported for the first model. However, considering the BIC-BIC (no model) statistics and the fact that there was improvement in significant variables, model 2 is considered to be superior to model $1 .^{8}$

The LR test indicates that the hypothesis that all coefficients are equal to zero can be rejected at the $99 \%$ confidence level for model 2 . The percentage of correct prediction is 90.5 Hence the model has good explanatory power for the adoption behavior of farmers.

Overall, the logit model confirms that the variables with positively significant coefficients enhance the adoption of BMP's. The model was able to explain 66 percent of the variation in the dependent variable, compared to 67 percent in model 1 . However, it can generally be concluded that model 2 reaffirms the robustness of the data and the underlying relationship among the variables in the model. This relationship tends to hold irrespective of alternative modeling approaches, suggesting the robustness of the results in this study. The

\footnotetext{
${ }^{8} \mathrm{BIC}-\mathrm{BIC}$ (no model) statistics measure the strength of the model. If the BIC - BIC statistics is small the better the model. Model2 has lower BIC-BIC (no model) than model 1; hence model 2 is a better model.
} 
significance of variables and the direction of sign are similar in the two models discussed. From economic analysis perspective, though the marginal effects magnitudes are slightly different in the two models, the interpretation and information generated by the two models remains similar.

\subsection{SUMMARY}

Using the national survey data from South Africa, a single logit model is estimated employing the procedure of maxim likelihood to determine the characteristics associated with adoption of environmentally focused technologies. The BMP model is the case where a farmer adopts and maintains a minimum package of technologies over a period of time. Empirical results suggest that the likelihood estimates of the BMP appear to work best for the South African model application.

Examination of the empirical Logit estimate results confirms the importance of the influence of the social (represented by LEDUM, AGE3645, AGE4655, AGE55 and FEXP610), economic (represented by FIN2550 AND FIN 500), land characteristics (represented by FUHOM) and institutional (represented by RENT, GFA) factors to farmers' adoption decision.

For example, the results show that increase in access to financial assistance increases the probability of adopting BMPs in South Africa. Similarly, farmer's experience may have a negative impact on adopting these technologies. The results suggest that adoption of environmentally focused technologies increase in South Africa if the necessary conditions hold. It also suggests that long-term investment on soil conservation can not take place under high tenure insecurity. 


\section{CHAPTER 6}

\section{SUMMARY, POLICY IMPLICATIONS, AND CONCLUSION}

\subsection{SUMMARY}

Renewable natural resources, which comprise the environmental base for agriculture and most other economic activities in both urban and rural areas, are under threat from degradation throughout the developing world. Empirical and theoretical studies show that environmental problems emanating from agricultural activities produce great concerns around the world, which require attention. The South African Government interventions to address these concerns over the years have not produced the desired results. Reduction of the land degradation problem requires action, but the development of relevant resource conservation programs also requires better knowledge of the factors that prevent the use of conservation practices by land operators.

The main objective of this study was to examine the farmers' decision to adopt environmentally focused production technologies as a means to control land and water degradation, and improve agricultural productivity in South Africa. The selected technologies include those which have been proved to be effective in addressing the environmental concerns and improve resource quality, and where the government has taken position on these technologies.

The working hypotheses are to test the effects of a vector of social, economic, land operation and institutional factors on adoption of the identified Best Management Practices. Two models are estimated in order to develop conclusions about the effectiveness of the mentioned factors. The first model uses a binary choice response variable and the explanatory variables age, 
experience education and income are split into three groups and one is used as a base in the analysis. The second model used the same variables, but was constrained into binary categories. This study provides a review of previous literature and studies on technology adoption decisions, economic motivation for adoption, and methodological approaches used in modeling technology adoption decisions in the agricultural sector, and a review of the agricultural sector in South Africa. Previous literature on adoption models indicate that the decision to adopt agricultural conservation technology is often based on a combination of factors including financial and non-financial factors. A review of previous studies also shows that there are four categories of factors that influence the farmer to adopt or not to adopt a given technology. These include social, economic, land and institutional factors.

These past studies are helpful in identifying factors affecting the adoption of technologies that may not provide immediate and full benefits to farm operators. However, most of these studies were conducted with applications in developed economies where the market response may be different than for developing economies. Many of the conceptual frameworks of these studies (especially those from outside developed countries) were not grounded in economic theory and proper extension of these studies by incorporating economic behavior modeling becomes appropriate for policy information and technology adoption management programs.

A theoretical model for the adoption of resource conservation technologies by farmers was developed for hypothesis testing. The model deals with the difficult decision farmers face to maximize profit and at the same time optimize environmental quality. The model was extended to observe the farmers' behavior in considering off-farm damages. The choices of technology approach are used to model decisions on whether or not to adopt environmental technologies in South Africa. The model led to decision rules that emphasize certain characteristics as the key 
determinates of underlying adoption decisions. The model emphasizes the indicators of the social, economic, land and institutional factors in adoption decisions. Given the previous studies, the model captures the important aspects of the adoption decision.

Considering that the response variable is dichotomous, an empirical logit model was set up. The model was estimated using data obtained from a survey conducted in the nine provinces of South Africa during October 2004 to March 2005.

Overall, the logit model confirms that the variables with positively significant coefficients enhance the adoption of BMP technologies. Absence of any of these variables could hamper the adoption decision.

The major findings of this study can be summarized as follows:

- Holding everything else constant, the probability of renters operating under short-term contracts adopting Best Management Practices in South Africa is low. This result may be due to tenure insecurity that may reduce investment in technology adoption.

- Farmers who receive government financial assistance are more likely to adopt BMPs than those who do not receive financial assistance. This suggests that there is a role for government-sponsored efforts to encourage adoption of best management practices in South Africa.

- Other prominent determinants of best management practices in South Africa are the level of education, age of the farmer, experience of the farmer, type of enterprise and farmers' income. The results indicate that the probabilities of older farmers not to adopt the desired practices are higher than those who are younger than 35 years old. Similarly, higher levels of education increase the probability of adopting BMP as opposed to those 
with lower educational level. For instance, a farmer with collage education is more likely to adopt BMP than one who has not completed high school.

- Off-farm income was found to positively affect adoption, but was not statistically significant; which may imply that it widens the possibility of adopting BMP by mitigating the shortage of capital input. However, it does not play a major role in South Africa. The estimated influence of farm income shows that a farmer's perception of the effect of the technologies on the farm income is a significant factor in the decision of technology adoption.

- The positively significant coefficient of farm size may also indicate its positive influence on BMP technologies adoption.

- Access to credit positively affects the probability of technology adoption. Credit opportunity determines the extent of available investment capital to farmers that influences the adoption decision of BMPs.

\subsection{POLICY IMPLICATIONS AND RECOMMENDATIONS}

The empirical econometric model and the empirical results are important to South Africa for technology development and design of policies and targeting strategies that promote resource conservation. The study is useful in identifying practices whose adoption is likely to be responsive to any form of financial assistance. The results presented in Chapter 5 suggest that adoption of the given technologies should be quite responsive to a number of incentive programs.

Other policy implications that may arise from the empirical study results can be summarized as follows: 
- Farmers' participation on the Land Care program, off-farm income and farmers' location are not associated with commercial farmers' adoption decisions of BMPs in South Africa. This may call for a review of the Land Care program to be receptive and generate high net benefits. The positive relationship between off-farm income and adoption may call for the government to help stimulate non-farm employments in rural areas.

- If the current resource management programs, such as the land Care programs and resource inspections services are not successful at achieving significant increases in controlling resource degradation in South Africa, then targeting assistance to responsive factors may achieve the highest net program benefits and improve performance. The findings of this study may be helpful in developing and targeting strategies. For example, targeting the factors that yield high response to adoption decisions.

- Older and more experienced farmers may require efficient support services to make information available on improve technologies and improve their capacity for resource management. The public sector should play an essential role in providing public good information about resource-conserving technologies.

- Provision of financial assistance for soil conservation purposes for young and less experienced farmers may be desirable in order to attain socially optimal levels of resource conservation.

- Promotion of large farms and private ownership may be important intervention strategies to increase adoption of BMPs. However, this needs to be weighed against the welfare impacts to emerging and small-scale farmers. 
- Provision of renters with incentives to promote stewardship of land use by introducing land improvement rebate by land owners is another is another strategy to address the problem of tenure security problem.

- Policies affecting the use and management of land should be co-coordinated across departments to facilitate appropriate decision-making by farmers. For example a farmer's income has a significant influence on adoption decision behavior. Therefore, support services to increase a farmer's income through entrepreneurship development programs would be an appropriate policy intervention to increase adoption of BMPs in South Africa.

- The positive relationship between off-farm income and adoption suggest that it might be worthwhile for the government to help stimulate nonfarm employment in rural areas.

\subsection{CONCLUSIONS}

Literature on the economics of technology adoption in agriculture, particularity technologies that focus on creating harmony between the environment and agriculture have been expanding. However, most of the literature is focused on developed economies and may not be directly applicable to developing countries. The need for greater knowledge in this area is acknowledged and it gives an indication of issues that require attention and more investigations under different scenarios. This is necessary because of the complexity of the issues that surround resource degradation in agriculture that are linked to different physical, social, economic, and institutional and management systems. One problem with the existing literature was that most studies are site specific and could not be accurately extrapolated to deferent levels. This dissertation contributes 
to the body of literature in this area, and the results also help in assisting BMP policy decisions and identifying potential research gaps in South Africa.

Furthermore, evidence from this study indicates that the link between tenure insecurity and adoption decision behavior is complex and varies according to ecological, economic and institutional setting. It is also confirmed that it is difficult to generalize about factors affecting adoption of BMP in different parts of the world because of differences in agro-ecological and socio-economic settings under which farmers operate. While the principal economic rationality assumption, i.e., the utility maximization objective of individual farmers, might be the same for farmers everywhere, specific attributes influencing the utility of farmers and adoption decisions are far from being uniform. Hence, these differences need to be accounted for in studies and policy applications of technology adoption problems.

\subsubsection{Contribution of the Study}

There have not been a significant number of economic, theory-based quantitative technology adoption studies in South Africa. This study contributes in this area through its modeling of technology adoption decisions based on fundamental economic principles and theory as well as building an empirical model that will enable a quantitative analysis of technology adoption in the agricultural sector of South Africa. It also contributes by incorporating a national study that tries to aggregate and produce policy information that can be useful for agricultural sector policy and management. Particularly, information generated from the model on the economic motivations of adoption decisions might be relevant for developing effective environmental and resource conservation conscious production schemes in the country. Furthermore, it has broader 
implications as it was conducted in an emerging economy where institutional and market forces respond differently from developed economies.

\subsubsection{Suggestions for Future Research and Development}

This study is primarily focused on understanding technology adoption decisions of commercial farmers, as such, little emphasis is given to emerging and subsistence farmers. This does not, however, imply that the land degradation in emerging agriculture sector in South Africa is insignificant. Therefore, it is necessary that the study be extended to the emerging agricultural sector as well. Analysis of the decision for emerging farmers to adopt best management practices remains an area that requires attention of researchers and policy-makers in the immediate future.

Another area for research and development in understanding specific farm circumstances is incentive mechanisms to promote sustainable use of land and water resources in order to combat resources degradation. It is generally accepted that farmers use unsustainable methods of farming in South Africa that is exposing land resources to degradation. It is unquestionable that some of the practices contribute to resource degradation; however, there is a general lack of quantified research information to show the magnitude of the effect in order to induce policy interventions that foster sustainable resource utilization. Therefore, research to evaluate the current programs and services to farmers and national economy, as well as the incentive mechanisms for farmers to promote sustainable methods of farming, is another area for future research in South Africa.

The environmental effects of using BMPs, like runoff-reducing practices, likely vary according to the kind of conservation method used. A study to measure the extent to which these technologies are used in South Africa will be helpful. 


\section{REFERENCES}

Abebaw, D. and K. Belay. (2001). "Factors Influencing Adoption of High Yielding Maize Varieties in South Western Ethiopia: An Application of Logit." Quarterly Journal of International Agriculture, 40: 2.

Adams, R.M and R. Berrens (1996). "Welfare Effects of Fishery Policies" Journal of Agricultural and Resource Economics, 21: 2, 263- 276

Adesina, A., D. Mila, G. B. Nkamleu and D. Endamara. (2000). "Economic Analysis of The Determinants of Adoption of Alley Farming by Farmers in the Forest Zone of Southwest Cameron." Agriculture, Ecosystems and Environment, 80: 255 -265.

Alson, J., and P. G. Pardey. (1996). Making Science Pay: The Economics of Agricultural R \& D Policy. Washington DC: AEI Press.

Atta-Krah, A. N. and P. A. Francis. (1987). "The role of on-farm trails in the evaluation of composite technologies: The case of alley farming in Southern Nigeria." Agricultural Systems, 23: 133-152.

Ball, V. E., J. C. Bureau, R. Nehring, and A. Somwaru. (1997). "Agricultural Productivity Revisited." American Journal of Agricultural Economics, 70: 1045-1063.

Barry, P.J., Ellinger, J.A. Hopkins, and C.B. Baker. (1995). "Financial Management in Agriculture." $5^{\text {th }}$ Edition Intestate Publishers, Inc. Danville, IL.

Batte, M. and R. Johnson. (1993). "Technology and its Impact on American Agriculture" in Size, Structure, and the Changing Face of American Agriculture, A. Hallum, ed., Westview Press Inc.

Bar-Shira, Z., R.E. Just, and Zilberman.(1997) “Estimation of Farmer’s Risk Attitude: An Economrtric Approach" Agricultural Economics, 17: 211-22

Batz, F., K. Petres, and W. Janssen. (1999). "The Influence of Technology Characteristics on the Rate and Speed of Adoption." Agricultural Economics, 21: 121-130.

Bishop, J. and J. Allen. (1989). "The On-site Costs of Soil Erosion in Mali.” World Bank Environment Working Paper No. 21. Washington DC.

Bojo, J. (1991). “Economics and Land Degradation.” Ambio, 20(2): 75-79.

Bulttena, G. L. and E. O. Hoiberg. (1983). "Factors Affecting Farmers' Adoption of Conservation Tillage." Journal of Soil and Water Conservation. 
Burton, M., D. Rigby and T. Young. (1999). "Analysis of the Determinants of Adoption of Organic Horticultural Technique in UK." Journal of Agricultural Economics, 50(1): 4763

Caswell, M. and D. Zilberman. (1985). "The Choices of Irrigation Technologies in California". Economic Development and Cultural Change, 33(2): 255-297.

Department of Agriculture. "Working Paper on Agricultural Policy in South Africa." Available [Online] at www.nda.agric.za; accessed on November 2004.

El Serafy, S. (1992). “The Environment as Capital.” In R. Costanza, ed. Ecological Economics: the Science and Management of Sustainability. New York, Columbia University Press.

El-Osta, H. and M. Morehart. (1999). "Technology Adoption Decisions in Dairy Production and the Role of Herd Expansion." Agricultural and Resource Economics Review, 28(1): 8495 .

Erenstein, O. (1999). "The Economics of Soil Conservation in Developing Countries: The Case of Crop Residue Mulching." Wageningen, the Netherlands, Wageningen University.

Ervin, C. A. and D. E. Ervin. (1982). "Factors Affecting the Use of Soil Conservation Practices: Hypothesis, Evidence, and Policy Implications." Land Economics, 58: 277-292.

FAO. (1999). Erosion-Induced Loss in Soil Productivity and its Impacts on Agricultural Production and Food Security." by M. Stocking and A. Tenberg in H. Nabhan, A.M. Mashali and A.R. Mermut, eds. Integrated Soil Management for Sustainable Agriculture and Food Security in Southern and Eastern Africa. Proceedings of the Expert Consultation, Harare, Zimbabwe, 8-12 December 1997, AGL/MISC/23, Rome.

Feder, G., and D.L. Umali. (1984). "The Adoption of Agricultural Innovations: A Review." Technological Forecasting and Social Change, 43: 215-239.

Feder, G., R., J. Just and D. Zilberman. (1985). "Adoption of Agricultural Innovations in Developing Countries: A survey". Economic Development and Cultural Change, 33(2): 255-98.

Fernandez- Cornejo, J., E. D. Beach, and W-Y. Huang. (1994). “The Adoption of IPM Techniques by Vegetable Growers in Florida, Michigan, and Texas." Journal of Agricultural and Applied Economics, 26: 158-172.

Funes, F., L. Garcia, M. Bourque, N. Perez, and P. Rosset. (2002). Sustainable Agriculture and Resistance: Transforming Food Production in Cuba. Oakland: Food First Books.

GLASODA. (1990). "World Maps, Global Assessment of Soil Degradation." ISRIC, UNEP; Wageningen, Niederlande. 
Gould, B. W., W. E. Saupe, and R.M Klemme (1989). "Conservation Tillage: The Role of Farm and Operator Characteristics and the Perception of Soil Erosion." Land Economics, 65(2): 167-82.

Gould, B. W., W. E. Saupe, and R. M. Klemme. (1989). “Conservation Tillage: The role of Operator Characteristics and Perception of Soil Erosion.” Land Economics, 65:167-182.

Ministry of Agriculture and Land Affairs, South Africa. (1998). "Green Paper on Agriculture." Section 4: Conserving Agricultural Natural Resources.

Green, G., D. Sunding, D. Zilberman, and D. Parker. (1996). "Explaining Irrigation Technology Choices: A Microparameter Approach.” American Journal of Agricultural Economics, 78: 1064-1072.

Griliches, Z. (1995). "R\&D and Productivity: Econometric Results and Measurement Issues." Handbook of the Economics of Innovation and Technological Change. P. Stoneman, ed., Blackwell Publishers Inc., Cambridge, Ma.

Halstead, J. M., S. S. Batie, and R. A. Kramer. (1988). “Agricultural Practices and Environmental Attitudes of Rockingham County, Virginia Dairy Farmer: Results of a Survey." Agricultural Economics Staff Paper No. 88-1, Virginia Polytechnic Institute and State University.

Huffman, W. E, and R. E. Eveson. (1993). Science for Agriculture. Ames, IA: Iowa Sate University Press.

Hugo, M. L., A. T. Viljoen, L. M. Meeuwis. (1997). The Ecology of Natural Resource Management: The Quest for Sustainable Living. A Text for South African Students. Pretoria: Kagiso.

Just, R., D. Ziberman, and G. Rauser. (1980). “A Putty- Clay Approach to Distributional Effects of New Technology Under Risk" in Operations Research in Agriculture and Water Resources, D. Yaron and C. Tapero, eds., New York: North Holland Publishing Company.

Kahn, R. J. (1998). The Economic Approach to Environmental and Natural Resources. 2nd Ed. The Dryden Press Harcourt Brace Collage Publishers, Fort Worth.

King, G.., (1989). Unifying Polititical Methodology. New York: Cambridge University Press.

Kleynhans, T. E. (2003). "Environment Module South Africa: Environmental Externalities.” Roles of Agriculture Project, International Conference: Rome, Italy.

Krueger, A., M. Schiff, and A. Valdes. (1988). "Agricultural Incentives in Developing Countries: Measuring the Effects of Sectoral and Economy-Wide Policies." World Bank Economics Review, 2(1): 255-271. 
Lal, R. (1987). "Effects of Soil Erosion on Crop Productivity." CRC Critical Reviews in Plant Sciences, 5(4): 303-67.

Lal, R. (1990). Soil Erosion in the Tropics: Principles and Management. New York, McGraw Hill.

Lal, R. (1994). "Methods and Guidelines for Assessing Sustainable Use of Soil and Water Resources in the Tropics." USDA Soil Conservation Service Technical Monograph No. 21, Washington, DC.

Lal, R. and B. A. Stewart. (1995). "Managing Soils for Enhancing and Sustaining Agricultural Production." In R. Lal and B.A. Stewart. Soil Management Experimental Basis for Sustainability and Environmental Quality. CRC Press: Boca Raton, FL, USA.

Leather, H.D., and J.D. Quiggin (1991). "Interactions between Agricultural and Resource Policy: Importance of Attitudes Toward Risk." American Journal of Agricultural Economics, 73: 757-64

Lohr, L. and T. A. Park. (1994). "Discrete? Continuous Choices in Contingent Valuation Surveys: Soil Conservation Decisions in Michigan." Review of Agricultural Economics, 16: 1-15.

Lynne, G. D., J. S. Shonkwiler and L. R. Rola. (988). “Attitudes and Farmers Conservation Behavior." American J. Agricultural Economics, 12-19.

McFadden, D. (1973). “Conditional Logit Analysis of Qualitative Choice Behavior.” In Frontiers in Econometrics, ed . P. Zarembka. New York: Academic Press.

MacNamara, K. T., M. E. Wetzstein and G. K. Dounce. (1991). "Factors Affecting Peanut Producer Adoption of Integrated Pest Management." Review of Agricultural Economics, 13:129-139.

Madala, G. S.: Introduction to Econometrics, John Wiley \& Sons, 3d ed., New York, 2001.

Madala, G..S., (1983). Limited-Dependent and Qualitative Variables in Econometrics. New York: Cambridge University Press.

McConnell, K. E. (1983). “An Economic Model of Soil Conservation.” American Journal of Agricultural Economics, 65: 83-89.

McNamara, K. T., M. E. Wetzstein, and G. K. Dounce. (1991). "Factors Affecting Peanut Producer Adoption of Integrated Pest Management." Review of Agricultural Economics, 13: $129-39$.

Mkhize, S. F. M. (2001). Rural Poverty and Land Degradation: A Determinant Study for Natural Resource Management in Marginal Lands of South Africa. Ph.D Thesis, University of Pretoria. 
Nielsen, E. G., J. A. Miranowski, and M. J. Morehart. (1989). "Investments in Soil Conservation and Land Improvements: Factors Explaining Farmers' Decisions.” Agricultural Economic Report No. 601, USD, ERS.

Norris, P. E. and S. S. Batie. (1987). "Virginia Farmers' Soil Conservation Decisions: An Application of Tobit Analysis." Southern Journal of Agricultural Economics, 19: 79-90.

Norse, D. and R. Saigal. (1992). "National Economic Costs of Soil Erosion: The Case of Zimbabwe." Paper prepared for the CIDIE Workshop on Environmental and Natural Resource Management in Developing Countries, C. 22-24 and Washington, DC, World Bank.

Norton, N. A. (1994). An Economic Analysis of Factors Affecting the Adoption of Non- Point Source Pollution- Reducing Technologies. A Ph.D Dissertation, West Virginia University, Morgantown, WV.

Oldeman, L. R., R. T. A. Hakkeling, and W. G. Sombroek. (1991). "World Map of the Status of Human-Induced Soil Degradation: An Explanatory Note." $2^{\text {nd }}$ ed. Wageningen, The Netherlands.

Oldeman, R., R. Hakkeling and W. Sombroeck. (1990). "World Map of the Status of Human Induced Soil Degradation: An Explanatory Note.” International Soil Reference and Information Centre, Wageningen, the Netherlands, and UNEP, Nairobi, Kenya.

Onduru, D. D., J. Kariuku, J. Diop, and E. van Der Werf. (1998). In: Volume 2, Rural Livelihood, Empowerment and the Environment: Going Beyond the Farm Boundary Proceeding. $15^{\text {th }}$ International Symposium, AFSRE, Pretoria, South Africa.

Panayotou, T. (1992). Green Markets: The Economics of Sustainable Development. San Francisco, CA: Institute of Contemporary Studies Press.

Pearce, D. W. and J. J. Warford. (1994). "World without End Economics, Environment, and Sustainable Development.” Washington, DC. World Bank.

Perret, S. and M. Mercoiret. (2003). Supporting Small-Scale Farmers and Rural Organisations: Learning from Experiences in West Africa. a Handbook for Development Operators and Local Managers. Pretoria: Protea Book House; France: CIRAD.

Pindyck, R.S., and D.L. Rubinfield . Econometric Models and Econometric Forecasts, $4^{\text {th }}$ ed., McGraw-Hill, New York, 1990

Purvis, A., J. P. Hoehn, V. L. Sorenson, and F. J. Piercie. (1989). "Farmers' Response to a Fiter Strip Program. Results from contingent Valuation Survey." Journal of Soil and Water Conservation, 44: 501-504. 
Rahm, M. R., and E. Huffman. (1984). "Adoption of Reduced Tillage: The Role of Human Capital and Other Variables.” American Journal of Agricultural Economics, 66:405-13.

Randall, A. (1987). Resource Economics: An Economic Approach to Natural Resource and Environmental Policy. ${ }^{\text {nd }}$ Ed. New York: John Willey and Sons.

Repetto, R., and M. Gillis. (1988). Public Policies and Misuse of Forest Resources. New York Cambridge University Press.

Rogers, E. (1995). Diffusion of Innovations. Free Press, New York.

Rukuni, M. (2002). "Why Land Tenure Security in Africa is Central to Land Reform and Community Based Governance, Economic and Social Progress." Paper prepared for a seminar session for graduate students, Department of Agricultural Economics, University of Pretoria, South Africa.

Samuelson, P. (1954). "The Pure Theory of Public Expenditure." Review Economics \& Statistics, 36: $387-389$.

Sanders, J., D. Southgate, and J. G. Lee. (1995). "The Economics of Soil Degradation: Technological Change and Policy Alternatives." USAID Soil Management Support Service Technical Monograph No.22. Washington, DC: World Soil Resources.

Scherr, S. (1999). "Soil Degradation: A Threat to Developing-Country Food Security by 2020?" Food, Agriculture and the Environment Discussion Paper 27. Washington, D.C., IFPRI.

Shiferaw, B. and Holden, T. (1997). "Analysis of Economic Incentives for Soil Conservation: The case of Highland Peasant Households in Ethiopia." A Discussion Paper No. D09/1997, Dep. of Economics and Social Sciences, NLH, AS.

Solow, R. M. (1994). "Perspectives on Growth Theory." Journal of Economic Perspectives, 8(1): 45-54.

South African National Department of Agriculture. "Agricultural Strategic plan.” Available [Online] at www.nda.agric.co.za; accessed in October, 2004.

Southgate, and M. Whitaker. (1994). Economic Progress and the Environment: One Developing Country's Policy Crisis. New York: Oxford University Press.

Staatz, J. M., and C. K. Eicher. (1998). Agriculture Development Ideas in Historical Perspective. In: Staatz, J. M., and C. K. Eicher (Eds). International Agricultural Development. $3^{\text {rd }}$ Edition. Baltimore and London: The Johns Hopkins University Press.

Steiner, K. G. (1998). Conserving Natural Resources and Enhancing Food Security by Adopting No- Tillage. Deutsche Gesellschaft fur, Eschborn. 
Stoneman, P. (1995). Introduction, Handbook of the Economics of Innovation and Technological Change. P.Stoneman. Ed., Blackwell Publishers Inc., Cambridge, MA.

Studenmund, A. H. (2001). Using Econometrics: A Practical Guide. Addison Ewsley Longman, Inc., New York.

UNEP. (1991). "Status of Desertification and Implementation of the United Nations Plan of Action to Combat Desertification." Draft Report. United Nations Environment Programme, Nairobi, Kenya.

University of Natal. (2003). Proceedings of the Soil Health and Radiation Workshop, University of Natal, Pietermaritzburg.

Van Zyl, J., J. Kristen, and C. McKenze. (1996). "Natural Resource Management Issues in Rural South Africa. In: Van Zyl, J. Kristen, J. and Binswanger, H., Eds., Agricultural Land Reform In South Africa; Policies, Markets and Mechanisms. Oxford University Press, Cape Town, 237-257.

World Bank. (1992). "Development and Environment.” World Bank Development Report 1992. Washington, D.C.: World Bank.

Yadav, S. and S. Scherr. (1995). "Land Degradation in the Developing World: Is it a Threat for Food Production to the Year 2020?" Draft paper for workshop on: Land Degradation in the Developing World: Implications for Food, Agriculture and Environment to the Year 2020, 4-6 April, Annapolis, IFPRI.

Zimmerman, F. J. (2000). "Barriers to Participation of the Poor in South Africa's Land Redistribution." World Development, 28(8): 1439-1460. 
APPENDICES 
Appendix A. Survey Questionnaire

CONFIDENTIAL QUESTIONNAIRE - “AGRICULTURAL PRACTICES IN SOUTH

AFRICA"

Data Reported In This Questionnaire Will Be Used For Research Purposes Only

Results Will Be Reported In A Combined Form With No Individuals Identified

1. Surname and name of principal farmer/farm operator (OPTIONAL)

2. Province:

$\begin{array}{lll}\text { Eastern Cape Province } & (1) & \text { Mpumalanga } \\ \text { Free State } & (2) & \text { Northern Cape } \\ \text { Gauteng } & (3) & \text { North - West } \\ & & \\ \text { Kwazulu - Natal } & (4) & \text { Western Cape } \\ \text { Limpopo } & (5) & \end{array}$

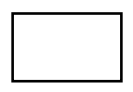

3. Nearest Town.

4. Name of the magisterial district in which most of the farming activities covered by this questionnaire, take place.

5. Name of the municipality in which most of the farming activities covered by this questionnaire, take place.

6. Gender of the principal farmer/farm operator:

Male (1) Female

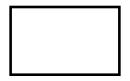

7. Present Age of the Farm operator

$$
\begin{array}{lll}
>35 \mathrm{yrs} & \text { (1) } & 36-45 \mathrm{yrs} \\
46-55 \mathrm{yrs} & \text { (3) } & >55 \mathrm{yrs}
\end{array}
$$

8. What is the highest level of education that you (farm operator) have completed?

No Formal Education

Some Grade/High School

Completed high School
(1) Some College/University

(4)

(2) Enrolled for/Completed Degree/Diploma (5)

(3) Enrolled in/Completed postgraduate studies (6) 
9. Please indicate the ownership of the farm. Is this farm owned by:

Individual (1) Close corporation (6)

Family

(2) Co-operative society (7)

Partnership

(3) Government Enterprise

(8)

Public company

(4) Trust

Private company

(5) Public corporation

Other (specify)

10. Are you member of any farmers' organization(s) in South Africa?

Yes (1) No

If yes, please give the name(s) of that/those organization(s):

11. Is the principal farmer/farm operator operating the farm on a full-time or part-time basis?

Full - time

Part - time

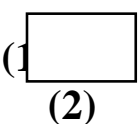

12. Does the principal farmer/farm operator and his/her family resides on the farm?

Yes

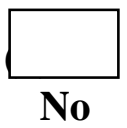

(2)

13. Does the principal farmers/farm operator have off-farm employment?

Yes

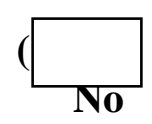

(2)

14. What type of an enterprise is your farm?

1. Extensive Animal production

2. Intensive Animal production

3. Horticulture

4.

Field crops production (e.g. Maize, wheat, sorghum etc.)

5. Mixed farming 
15. Over the past five years, have you increased, decreased or kept constant your use of (where applicable):

Crop rotation

Tillage for seedbed preparation

Cultivation for weed control

Integrated pest management

Organic practices

Rotational grazing

Rainwater harvesting techniques

\begin{tabular}{|l|l|l|l|}
\hline INCREASED & DECREASED & CONSTANT & $\begin{array}{c}\text { DO NOT } \\
\text { USE }\end{array}$ \\
\hline & & & \\
\hline & & & \\
\hline & & & \\
\hline & & & \\
\hline & & & \\
\hline & & & \\
\hline & & & \\
\hline
\end{tabular}

16. What (if any) soil and/or water conservation practices have you implemented or are you considering implementing? (Check all that apply)

\begin{tabular}{l|l|l|l|}
\cline { 2 - 2 } $\begin{array}{l}\text { Tile } \\
\text { Drainage } \\
\text { No till } \\
\text { planting } \\
\text { Cover crop } \\
\text { None }\end{array}$ & $\begin{array}{l}\text { Crop rotations } \\
\text { None }\end{array}$ & $\begin{array}{l}\text { Ridge - till } \\
\text { planting } \\
\text { Terraces } \\
\text { Other (specify) }\end{array}$ &
\end{tabular}

17. What (if any) soil and/or water conservation practices have your neighbors implemented? (Check all that apply)

\begin{tabular}{|c|c|}
\hline Tile & Crop rotations \\
\hline No till & Ridge - till \\
\hline Cover crop & Terraces \\
\hline None & Other (specify) \\
\hline
\end{tabular}

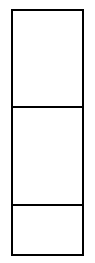

Diversion ditches

Reduced - till planting

Strip cropping

18. Do you feel that soil erosion is a major problem on your cropland?
Yes (1)
No
(2)
Not Sure

(3)

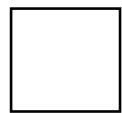

19. Do you think that water pollution by agricultural production activities is a problem:

On your farm

In your community
Yes

Yes

(1)
(1)

No

(2)

No

(2)
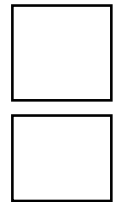
20. On a scale of 1 to 5 , rank the factors that you consider before implementing a new farming practice or enterprise: ( 1 being the most important; 5 being the least important)

$$
\begin{aligned}
& \text { Cost } \\
& \text { Effect on the land } \\
& \text { quality } \\
& \text { Other (Specify) }
\end{aligned}
$$

Potential for profit Effect on Health

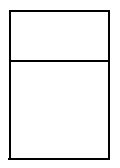

21. On a scale of 1 to 5 , rank (1 being the most limiting) what you would consider to be the major obstacles limiting the adoption of a new technology (examples: no-tillage, rainwater harvesting techniques):

Limited availability of money

Insufficient knowledge of profitability

Insufficient knowledge of potential effects on the

technology

Inadequate skills to operate and

New techniques not compatible with existing system

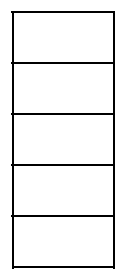

environment

maintain the new

of production

Other (specify)

22. Are you currently producing produce that is classified as organic grown or pesticide free?

$\begin{array}{llll}\text { Yes (1) No } & \text { (2) }\end{array}$

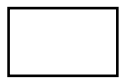

23. Did you receive any financial assistance to implement the technology in 22 above?

Y es

(1)

No

(2)

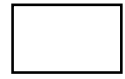

If yes, how much was it $R$ and from where

24. If the answer to question 22 above is yes, how did your income change since you started using the new technology?
Increased
(1) Decreased
(2)
Same (3)
(3)
Not sure

(4)

25. If the answer to question 22 above is no, do you plan to produce any products that could be classified as organically grown or pesticide free?
Yes
(1)
No
(2)
Not sure

(3)

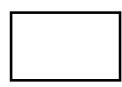

26. If YES, what are those products? 
27. Which one of the following best describes your farming goals? (select one)

I farm to maximize the personal enjoyment that i receive from farming (1)

I farm to maximize profits

(2)

I farm to get enough food for my family

28. What influences your decisions relating to what you produce: (Rank the three most important sources; 1 Most important, 2 important, 3 Fairly important)

My personal

preferences

Consumer needs

Land available

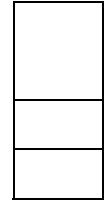

Potential for profit

Trends

Other (specify)

29. Where do you get most of your information related to farming? (Rank the three most important sources; 1 Most important, 2 Important, 3 Fairly important)

Agri-News

Neighbors/friends/family

Universities

Department of agriculture

Other (specify)
Landcare Group

Agricultural extension officer

Your framers union

Farm supply/equipment

dealers

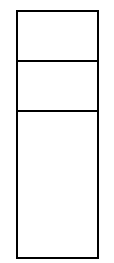

30. If the information you get is not sufficient, what is the major constraint to access to agricultural information. (Mark all that apply)

Distance to extension
office
No time to attend
workshops
Other (Please specify

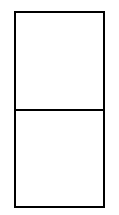

Low level of literacy

Location of the farm

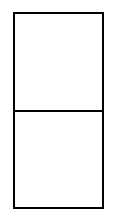

31. What role should government play in agricultural production? (Check all that apply)

Price support

Food safety regulation

Environmental quality

regulation

Other (specify)
Cost sharing

Technical assistance/education

No role 
32. Did you participate in the national LandCare program in 2003?

Yes (Specify the type of activity)

No

33. Approximately how many DAYS PER YEAR (if any) were spent working off the farm in 2003?
1. Operator
2. Spouse

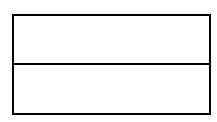

34. What is the approximate amount of credit you received in 2003? R

35. In 2003, what was your approximate proportion of farm debt to farm assets? (TOTAL FARM DEBT DIVIDED BY TOTAL FARM ASSETS)

36. Is the availability of infrastructure a problem?
On your farm
Yes
(1) No
In your community Yes
(1) No
(2)

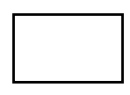

37. Please indicate the type(s) and average amount(s) of crops and livestock, and the amount of pasture that you normally produce.

\begin{tabular}{|l|}
\hline LIVESTOCK \\
\hline \\
\hline \\
\hline \\
\hline
\end{tabular}
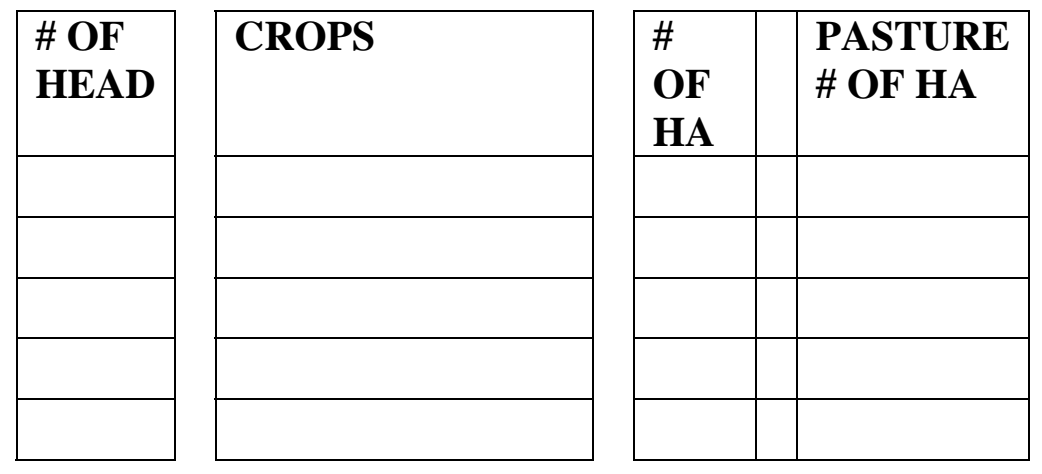

38. Please indicate the total amount of land cultivated during the following years:

Year

Land Available (ha)

Land Cultivated (ha)

2002

2003

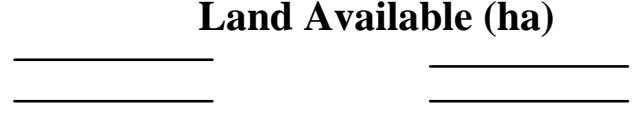

Rent Or Lease

39. How many hectares do you: Own Rent Or Lease

40. Please indicate the major land and soil characteristics of your farm (Tick all that apply) 


\begin{tabular}{|l|l|l|l|l|}
\hline \multicolumn{2}{|l|}{ LAND CHARACTERISTICS } & \multicolumn{2}{l|}{ SOIL } \\
CHARACTERITICS
\end{tabular}

41. Do you use any hired labor in your farming operation?

Yes (1) No (2)

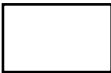

42. What is your system of record keeping?

1. Manual/record book

2. Personal computer

3. No organized system
4. Professional consultant

5. Checkbook

6. Other (please specify.

43. Given the current and future state of land quality, what do you think should be done concerning the adoption of environmentally friendly technologies? (Select one only)

Tax on land degrading technologies

Pay farmers to stop degrading the land

Maintain standards of control of production technologies

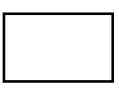

44. If Payment, how much should be paid per HA in Rand

45. Please indicate the approximate amount received from farm sales in 2002:

Less than R100, 000

R250, 000 - R500, 000
R100, 000 - R250, 000

(3) Over R500, 000
(2)

(4)

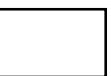

46. Please indicate the approximate amount of total farm costs in 2003:

Less than R100, 000

R250, 000 - R500, 000
R100, 000 - R250, 000

(3) Over R500, 000
(2)

(4)

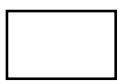

47. What was the approximate amount of total farm income in 2003;

Less than R100, 000

R250, 000 - R500, 000
(1)

R100, 000 - R250, 000

(3) Over R500, 000
(2)

(4) 
48. How many years have you been farming?

Less than 5 yrs

11 - 20 yrs
(1) 6 - 10 yrs

(3) Over 20 yrs

49. What is the date of establishment of your farm?......(dd/mm/yyyy)

Any Additional comments you would like to make concerning the questionnaire, the study, South African Agriculture, or the Agricultural sector in general.

Thank you very much for your time and we assure you all the information received will be treated with confidentiality! 


\section{Appendix B. SELECTED CONSERVATION AND ENVRONMENTALLY-FOCUSED}

\section{TECHNOLOGIES}

\section{Best Management Practices}

\begin{tabular}{|c|c|c|}
\hline Practice & Description & Risk Status \\
\hline Crop rotation & $\begin{array}{l}\text { Crop rotation is a planned order of } \\
\text { specific crops planted on the same } \\
\text { field. Crop rotation also means that } \\
\text { succeeding crops are of a different } \\
\text { genus, species, subspecies, or variety } \\
\text { than the previous crop. Examples } \\
\text { would be barley after wheat, row } \\
\text { crops after small grains, grain crops } \\
\text { after legumes, etc. The planned } \\
\text { rotation sequence may be for a two- } \\
\text { or three-year or longer period. Some } \\
\text { of the general purposes of rotations } \\
\text { are to improve or maintain soil } \\
\text { fertility, reduce erosion, reduce the } \\
\text { build-up of pests, spread the } \\
\text { workload, reduce risk of weather } \\
\text { damage, reduce reliance on } \\
\text { agricultural chemicals, and increase } \\
\text { net profits. }\end{array}$ & $\begin{array}{l}\text { Crop rotation is risk } \\
\text { reducing technology as } \\
\text { it reduces the chance of } \\
\text { drought and pest } \\
\text { infestation }\end{array}$ \\
\hline IPM & $\begin{array}{l}\text { Refers to a management strategy that } \\
\text { includes an understanding of the } \\
\text { target pest and use of a combination } \\
\text { of physical, chemical, biological and } \\
\text { cultural controls. Proper storage, } \\
\text { mixing and handling of pesticides are } \\
\text { also essential in minimizing risk to } \\
\text { the environment. }\end{array}$ & $\begin{array}{l}\text { IMP is risk increasing } \\
\text { in the short term. } \\
\text { Implementation of this } \\
\text { technology during the } \\
\text { introduction stage may } \\
\text { increase the risk of pest } \\
\text { infestations. However, } \\
\text { with time it will stabilize } \\
\text { and reduce the risk of } \\
\text { environmental damage } \\
\text { by chemicals. }\end{array}$ \\
\hline Organic practices & $\begin{array}{l}\text { Organic practices in agriculture are } \\
\text { an ecological production } \\
\text { management system that promotes } \\
\text { and enhances biodiversity, biological } \\
\text { cycles and soil biological activity. It } \\
\text { is based on minimal use of off-farm } \\
\text { inputs and on management practices } \\
\text { that restore, maintain and enhance } \\
\text { ecological harmony. }\end{array}$ & $\begin{array}{l}\text { Organic practices are } \\
\text { risk neutral. }\end{array}$ \\
\hline Rotational Grazing & Rotational grazing is periodically & Rotational grazing \\
\hline
\end{tabular}




\begin{tabular}{|c|c|c|}
\hline & $\begin{array}{l}\text { moving livestock to fresh paddocks, } \\
\text { to allow pastures to regrow. } \\
\text { Rotational grazing requires skillful } \\
\text { decisions and close monitoring of } \\
\text { their consequences. Modern electric } \\
\text { fencing and innovative water- } \\
\text { delivery devices are important tools. } \\
\text { Feed costs decline and animal health } \\
\text { improves when animals harvest their } \\
\text { own feed in a well-managed } \\
\text { rotational grazing system. }\end{array}$ & $\begin{array}{l}\text { practices is risk } \\
\text { decreasing. The practice } \\
\text { of rotational grazing } \\
\text { reduces the risk of } \\
\text { draught, diseases } \\
\text { infection and resource } \\
\text { degradation. }\end{array}$ \\
\hline Water harvesting & $\begin{array}{l}\text { The process of collecting and } \\
\text { concentrating runoff water from a } \\
\text { runoff area into a run-on area, where } \\
\text { the collected water is either directly } \\
\text { applied to the cropping area and } \\
\text { stored in the soil profile for } \\
\text { immediate use by the crop, i.e. runoff } \\
\text { farming, or stored in an on-farm } \\
\text { water reservoir for future productive } \\
\text { uses, i.e. domestic use, livestock } \\
\text { watering, aquaculture irrigation. The } \\
\text { collected water can also be used for } \\
\text { groundwater recharge and storage } \\
\text { into the aquifer, i.e. recharge } \\
\text { enhancement. }\end{array}$ & $\begin{array}{l}\text { Water harvesting can be } \\
\text { both risk increasing and } \\
\text { risk reducing. It will be } \\
\text { risking increasing } \\
\text { because it may increase } \\
\text { underground water } \\
\text { pollution and will be } \\
\text { risk decreasing as it } \\
\text { reduces the risk of } \\
\text { draught, especially in } \\
\text { rainfed agriculture }\end{array}$ \\
\hline
\end{tabular}




\section{Appendix C DESCRIPTIVE STATISTICS}

Descriptive Statistics

\begin{tabular}{|c|c|c|c|c|c|}
\hline Variable & Mean & Std.Dev. & Minimum & Maximum & \\
\hline \multicolumn{6}{|c|}{ All observations in current sample } \\
\hline BMP & .568452381 & .496030798 & .000000000 & 1.00000000 & 336 \\
\hline RENT & 524.078869 & 1328.69342 & .000000000 & 15000.0000 & 336 \\
\hline PLANDC & $.982142857 \mathrm{E}-01$ & .298048021 & .000000000 & 1.00000000 & 336 \\
\hline FHUO & 2342.62292 & 2724.53756 & 2.60000000 & 12500.0000 & 33 \\
\hline LABI & .541666667 & .499003983 & .000000000 & 1.00000000 & 33 \\
\hline CDT & .595238095 & .491577968 & .000000000 & 1.00000000 & 33 \\
\hline GFA & .264880952 & .441927918 & .000000000 & 1.00000000 & 33 \\
\hline FLC & .684523810 & .465398317 & .000000000 & 1.00000000 & 33 \\
\hline LEDUH & .199404762 & .400148782 & .000000000 & 1.00000000 & 336 \\
\hline LEDUCH & .214285714 & .410937874 & .000000000 & 1.00000000 & 336 \\
\hline LEDUC & .238095238 & .426552934 & .000000000 & 1.00000000 & 336 \\
\hline LEDUU & .330357143 & .471043165 & .000000000 & 1.00000000 & 336 \\
\hline AGE35 & .163690476 & .370546284 & .000000000 & 1.00000000 & 336 \\
\hline AGE3645 & .309523810 & .462986811 & .000000000 & 1.00000000 & 336 \\
\hline FEXP5 & .223214286 & .417021881 & .000000000 & 1.00000000 & 33 \\
\hline FEXP610 & .300595238 & .459200736 & .000000000 & 1.00000000 & 336 \\
\hline FEXP1120 & .250000000 & .433658508 & .000000000 & 1.00000000 & 336 \\
\hline FEXP20 & .226190476 & .418987849 & .000000000 & 1.00000000 & 336 \\
\hline ENTLVST & .366071429 & .482447783 & .000000000 & 1.00000000 & 336 \\
\hline ENTHORT & .264880952 & .441927918 & .000000000 & 1.00000000 & 336 \\
\hline ENTFCROP & .211309524 & .408846297 & .000000000 & 1.00000000 & 336 \\
\hline ENTMXFAR & .151785714 & .359348202 & .000000000 & 1.00000000 & 33 \\
\hline FIN100 & .181547619 & .386046147 & .000000000 & 1.00000000 & 336 \\
\hline FIN1025 & .205357143 & .404564838 & .000000000 & 1.00000000 & 336 \\
\hline FIN2550 & .300595238 & .459200736 & .000000000 & 1.00000000 & 336 \\
\hline FIN500 & .312500000 & .464203699 & .000000000 & 1.00000000 & 336 \\
\hline AGE46 & .651785714 & .477114863 & .000000000 & & \\
\hline
\end{tabular}




\section{Appendix D DESCRIPTIVE STATISTICS BY PROVINCE}

Descriptive Statistics for the Eastern Cape Province

All results based on nonmissing observations.

\begin{tabular}{|c|c|c|c|c|c|}
\hline Variable & Mean & Std.Dev. & Minimum & Maximum & \\
\hline \multicolumn{6}{|c|}{ All observations in current sample } \\
\hline LEDUU & .486486486 & .506711710 & .000000000 & 1.00000000 & 37 \\
\hline AGE35 & .135135135 & .346583497 & .000000000 & 1.00000000 & 37 \\
\hline AGE3645 & .243243243 & .434958836 & .000000000 & 1.00000000 & 37 \\
\hline FEXP5 & .108108108 & .314800094 & .000000000 & 1.00000000 & 37 \\
\hline FEXP610 & .135135135 & .346583497 & .000000000 & 1.00000000 & 37 \\
\hline FEXP1120 & .243243243 & .434958836 & .000000000 & 1.00000000 & 37 \\
\hline FEXP20 & .513513514 & .506711710 & .000000000 & 1.00000000 & 37 \\
\hline ENTLVST & .432432432 & .502247202 & .000000000 & 1.00000000 & 37 \\
\hline ENTHORT & $.810810811 \mathrm{E}-01$ & .276724731 & .000000000 & 1.00000000 & 37 \\
\hline ENTFCROP & .216216216 & .417341795 & .000000000 & 1.00000000 & 37 \\
\hline ENTMXFAR & .270270270 & .450225169 & .000000000 & 1.00000000 & 37 \\
\hline FIN100 & .216216216 & .417341795 & .000000000 & 1.00000000 & 37 \\
\hline FIN1025 & .108108108 & .314800094 & .000000000 & 1.00000000 & 37 \\
\hline FIN2550 & .243243243 & .434958836 & .000000000 & 1.00000000 & 37 \\
\hline FIN500 & .405405405 & .497742652 & .000000000 & 1.00000000 & 37 \\
\hline AGE46 & .756756757 & .434958836 & .000000000 & 1.00000000 & 37 \\
\hline FHUOS & .486486486 & .506711710 & .000000000 & 1.00000000 & 37 \\
\hline FHUOM & .324324324 & .474578998 & .000000000 & 1.00000000 & 37 \\
\hline FHUOL & .189189189 & .397061277 & .000000000 & 1.00000000 & 37 \\
\hline RESIDUAL & $-.540540541 \mathrm{E}-01$ & .404553660 & -1.00000000 & 1.00000000 & 37 \\
\hline FIN250 & .648648649 & .483977514 & .000000000 & 1.00000000 & 37 \\
\hline FEXP11 & .756756757 & .434958836 & .000000000 & 1.00000000 & 37 \\
\hline AGE36 & .945945946 & .229243435 & .000000000 & 1.00000000 & 37 \\
\hline LEDC & .594594595 & .497742652 & .000000000 & 1.00000000 & 37 \\
\hline FHUOLA & .513513514 & .506711710 & .000000000 & 1.00000000 & 37 \\
\hline CROPR & .270270270 & .450225169 & .000000000 & 1.00000000 & 37 \\
\hline PROV & 1.00000000 & .000000000 & 1.00000000 & 1.00000000 & 37 \\
\hline ENTERP & 2.75675676 & 1.75444523 & 1.00000000 & 5.00000000 & 37 \\
\hline NOTILL & .216216216 & .417341795 & .000000000 & 1.00000000 & 37 \\
\hline ROTGRAI & .216216216 & .417341795 & .000000000 & 1.00000000 & 37 \\
\hline IPM & .135135135 & .346583497 & .000000000 & 1.00000000 & 37 \\
\hline WH & .135135135 & .346583497 & .000000000 & 1.00000000 & 37 \\
\hline BMP & .459459459 & .505227924 & .000000000 & 1.00000000 & 37 \\
\hline ORGANIC & .108108108 & .314800094 & .000000000 & 1.00000000 & 37 \\
\hline COVERCR & .378378378 & 491672393 & .000000000 & 1.00000000 & 37 \\
\hline
\end{tabular}




$\begin{array}{llllll}\text { TERR } & .810810811 \mathrm{E}-01 & .276724731 & .000000000 & 1.00000000 & 37 \\ \text { STRIPCRO } & .945945946 & .229243435 & .000000000 & 1.00000000 & 37 \\ \text { DIVESION } & .216216216 & .417341795 & .000000000 & 1.00000000 & 37 \\ \text { RTILPLA } & .270270270 \mathrm{E}-01 & .164398987 & .000000000 & 1.00000000 & 37 \\ \text { RTILL } & .540540541 & .505227924 & .000000000 & 1.00000000 & 37 \\ \text { RENT } & 705.959459 & 2615.82764 & .000000000 & 15000.0000 & 37 \\ \text { FEXP } & 3.16216216 & 1.04119359 & 1.00000000 & 4.00000000 & 37 \\ \text { FIN } & 3.00000000 & 1.24721913 & 1.00000000 & 4.00000000 & 37 \\ \text { PLANDC } & .810810811 \mathrm{E}-01 & .276724731 & .000000000 & 1.00000000 & 37 \\ \text { FHUO } & 2558.23243 & 3926.15429 & 2.60000000 & 12500.0000 & 37 \\ \text { LABI } & .270270270 & .450225169 & .000000000 & 1.00000000 & 37 \\ \text { RESFA } & .837837838 & .373683877 & .000000000 & 1.00000000 & 37 \\ \text { LEDU } & 4.32432432 & 1.22597023 & 1.00000000 & 6.00000000 & 37 \\ \text { CDT } & .486486486 & .506711710 & .000000000 & 1.00000000 & 37 \\ \text { GFA } & .243243243 & .434958836 & .000000000 & 1.00000000 & 37 \\ \text { OWN } & 4.56756757 & 3.46041536 & 1.00000000 & 9.00000000 & 37 \\ \text { FLC } & .675675676 & .474578998 & .000000000 & 1.00000000 & 37 \\ \text { LEDUH } & .243243243 & .434958836 & .000000000 & 1.00000000 & 37 \\ \text { LEDUCH } & .108108108 & .314800094 & .000000000 & 1.00000000 & 37 \\ \text { LEDUC } & .108108108 & .314800094 & .000000000 & 1.00000000 & 37\end{array}$


Descriptive Statistics for the Free State Province

All results based on nonmissing observations.

\begin{tabular}{|c|c|c|c|c|c|}
\hline Variable & Mean & Std.Dev. & Minimum & Maximum & Cases \\
\hline \multicolumn{6}{|c|}{ All observations in current sample } \\
\hline PROV & 2.00000000 & .000000000 & 2.00000000 & 2.00000000 & 63 \\
\hline ENTERP & 2.68253968 & 1.57424223 & 1.00000000 & 5.00000000 & 63 \\
\hline NOTILL & 396825397 & .493168902 & .000000000 & 1.00000000 & 63 \\
\hline CROPR & 285714286 & .455382556 & .000000000 & 1.00000000 & 63 \\
\hline ROTGRAI & .206349206 & .407934615 & .000000000 & 1.00000000 & 63 \\
\hline IPM & .158730159 & .368359450 & .000000000 & 1.00000000 & 63 \\
\hline WH & .142857143 & .352737811 & .000000000 & 1.00000000 & 63 \\
\hline BMP & .492063492 & .503952631 & .000000000 & 1.00000000 & 63 \\
\hline ORGANIC & 142857143 & .352737811 & .000000000 & 1.00000000 & 63 \\
\hline COVERCR & .555555556 & .500895256 & .000000000 & 1.00000000 & 63 \\
\hline TERR & $.476190476 \mathrm{E}-01$ & .214669395 & .000000000 & 1.00000000 & 63 \\
\hline STRIPCRO & .904761905 & .295901341 & .000000000 & 1.00000000 & 63 \\
\hline DIVESION & .571428571 & .498846596 & .000000000 & 1.00000000 & 63 \\
\hline RTILPLA & $.793650794 \mathrm{E}-01$ & .272478901 & .000000000 & 1.00000000 & 63 \\
\hline RTILL & .290322581 & .457616662 & .000000000 & 1.00000000 & 62 \\
\hline RENT & 856.587302 & 1465.32469 & .000000000 & 6500.00000 & 63 \\
\hline FEXP & 2.44444444 & 1.11843465 & 1.00000000 & 4.00000000 & 63 \\
\hline FIN & 2.60317460 & 1.07072003 & 1.00000000 & 4.00000000 & 63 \\
\hline PLANDC & .111111111 & .316793976 & .000000000 & 1.00000000 & 63 \\
\hline FHUO & 2473.30159 & 2989.37068 & 10.0000000 & 9005.00000 & 63 \\
\hline LABI & .587301587 & .496273878 & .000000000 & 1.00000000 & 63 \\
\hline RESFA & .507936508 & .503952631 & .000000000 & 1.00000000 & 63 \\
\hline LEDU & 3.73015873 & 1.32234334 & 1.00000000 & 6.00000000 & 63 \\
\hline CDT & .539682540 & .502426269 & .000000000 & 1.00000000 & 63 \\
\hline GFA & .222222222 & .419079038 & .000000000 & 1.00000000 & 63 \\
\hline OWN & 4.50793651 & 3.15141042 & 1.00000000 & 10.0000000 & 63 \\
\hline FLC & .634920635 & .485319559 & .000000000 & 1.00000000 & 63 \\
\hline LEDUH & .301587302 & .462633438 & .000000000 & 1.00000000 & 63 \\
\hline LEDUCH & .190476190 & .395830807 & .000000000 & 1.00000000 & 63 \\
\hline LEDUC & 190476190 & .395830807 & .000000000 & 1.00000000 & 63 \\
\hline LEDUU & .317460317 & .469227121 & .000000000 & 1.00000000 & 63 \\
\hline AGE35 & $.952380952 \mathrm{E}-01$ & .295901341 & .000000000 & 1.00000000 & 63 \\
\hline AGE3645 & .444444444 & .500895256 & .000000000 & 1.00000000 & 63 \\
\hline FEXP5 & .253968254 & .438775935 & .000000000 & 1.00000000 & 63 \\
\hline FEXP610 & 285714286 & .455382556 & .000000000 & 1.00000000 & 63 \\
\hline FEXP1120 & .222222222 & .419079038 & .000000000 & 1.00000000 & 63 \\
\hline FEXP20 & 238095238 & .429338791 & .000000000 & 1.00000000 & 63 \\
\hline ENTLVST & .428571429 & .498846596 & .000000000 & 1.00000000 & 63 \\
\hline
\end{tabular}




$\begin{array}{llllll}\text { ENTHORT } & .158730159 & .368359450 & .000000000 & 1.00000000 & 63 \\ \text { ENTFCROP } & .222222222 & .419079038 & .000000000 & 1.00000000 & 63 \\ \text { ENTMXFAR } & .174603175 & .382676590 & .000000000 & 1.00000000 & 63 \\ \text { FIN100 } & .206349206 & .407934615 & .000000000 & 1.00000000 & 63 \\ \text { FIN1025 } & .22222222 & .419079038 & .000000000 & 1.00000000 & 63 \\ \text { FIN2550 } & .285714286 & .455382556 & .000000000 & 1.00000000 & 63 \\ \text { FIN500 } & .269841270 & .447442525 & .000000000 & 1.00000000 & 63 \\ \text { AGE46 } & .476190476 & .503444358 & .000000000 & 1.00000000 & 63 \\ \text { FHUOS } & .412698413 & .496273878 & .000000000 & 1.00000000 & 63 \\ \text { FHUOM } & 365079365 & .485319559 & .000000000 & 1.00000000 & 63 \\ \text { FHUOL } & .222222222 & .419079038 & .000000000 & 1.00000000 & 63 \\ \text { RESIDUAL } & .317460317 \mathrm{E}-01 & .309435176 & -1.00000000 & 1.00000000 & 63 \\ \text { FIN250 } & .555555556 & .500895256 & .000000000 & 1.00000000 & 63 \\ \text { FEXP11 } & .460317460 & .502426269 & .000000000 & 1.00000000 & 63 \\ \text { AGE36 } & .873015873 & .335629572 & .000000000 & 1.00000000 & 63 \\ \text { LEDC } & .507936508 & .503952631 & .000000000 & 1.00000000 & 63 \\ \text { FHUOLA } & 587301587 & .496273878 & .000000000 & 1.00000000 & 63\end{array}$


Descriptive Statistics for the Gauteng Province

All results based on nonmissing observations.

$=========================================================$
Variable $\quad$ Mean
$===========================================================$

All observations in current sample

\begin{tabular}{|c|c|c|c|c|}
\hline PROV & 3.00000000 & .000000000 & 3.00000000 & 3.00000000 \\
\hline ENTERP & 2.92000000 & 1.15181017 & 1.00000000 & 5.00000000 \\
\hline NOTILL & .480000000 & .509901951 & .000000000 & 1.00000000 \\
\hline CROPR & .120000000 & .331662479 & .000000000 & 1.00000000 \\
\hline ROTGRAI & .240000000 & .435889894 & .000000000 & 1.00000000 \\
\hline IPM & $.400000000 \mathrm{E}-01$ & .200000000 & .000000000 & 1.00000000 \\
\hline WH & .160000000 & .374165739 & .000000000 & 1.00000000 \\
\hline BMP & .520000000 & .509901951 & .000000000 & 1.00000000 \\
\hline ORGANIC & .120000000 & .331662479 & .000000000 & 1.00000000 \\
\hline COVERCR & .600000000 & .500000000 & .000000000 & 1.00000000 \\
\hline TERR & .000000000 & .000000000 & .000000000 & .000000000 \\
\hline STRIPCRO & .920000000 & .276887462 & .000000000 & 1.00000000 \\
\hline DIVESION & .720000000 & .458257569 & .000000000 & 1.00000000 \\
\hline RTILPLA & $.400000000 \mathrm{E}-01$ & .200000000 & .000000000 & 1.00000000 \\
\hline RTILL & .320000000 & .476095229 & .000000000 & 1.00000000 \\
\hline RENT & 487.200000 & 965.257867 & .000000000 & 4000.00000 \\
\hline FEXP & 2.56000000 & 1.00332780 & 1.00000000 & 4.00000000 \\
\hline FIN & 2.56000000 & 1.08320512 & 1.00000000 & 4.00000000 \\
\hline PLANDC & $.800000000 \mathrm{E}-01$ & .276887462 & .000000000 & 1.00000000 \\
\hline FHUO & 2014.52000 & 2161.97770 & 123.000000 & 6400.00000 \\
\hline LABI & .480000000 & .509901951 & .000000000 & 1.00000000 \\
\hline RESFA & .480000000 & .509901951 & .000000000 & 1.00000000 \\
\hline LEDU & 3.60000000 & 1.19023807 & 2.00000000 & 6.00000000 \\
\hline CDT & .440000000 & .506622805 & .000000000 & 1.00000000 \\
\hline GFA & .240000000 & .435889894 & .000000000 & 1.00000000 \\
\hline OWN & 4.68000000 & 2.42761886 & 1.00000000 & 10.0000000 \\
\hline FLC & .600000000 & .500000000 & .000000000 & 1.00000000 \\
\hline LEDUH & .280000000 & .458257569 & .000000000 & 1.00000000 \\
\hline LEDUCH & 240000000 & .435889894 & .000000000 & 1.00000000 \\
\hline LEDUC & .240000000 & .435889894 & .000000000 & 1.00000000 \\
\hline LEDUU & .240000000 & .435889894 & .000000000 & 1.00000000 \\
\hline AGE35 & .200000000 & 408248290 & .000000000 & 1.00000000 \\
\hline AGE3645 & .480000000 & .509901951 & .000000000 & 1.00000000 \\
\hline FEXP5 & .160000000 & .374165739 & .000000000 & 1.00000000 \\
\hline FEXP610 & .320000000 & .476095229 & .000000000 & 1.00000000 \\
\hline FEXP1120 & .320000000 & .476095229 & .000000000 & 1.00000000 \\
\hline FEXP20 & .200000000 & .408248290 & .000000000 & 1.00000000 \\
\hline ENTLVST & .280000000 & .458257569 & .000000000 & 1.00000000 \\
\hline
\end{tabular}




$\begin{array}{llllll}\text { ENTHORT } & .440000000 & .506622805 & .000000000 & 1.00000000 & 25 \\ \text { ENTFCROP } & .160000000 & .374165739 & .000000000 & 1.00000000 & 25 \\ \text { ENTMXFAR } & .120000000 & .331662479 & .000000000 & 1.00000000 & 25 \\ \text { FIN100 } & .200000000 & .408248290 & .000000000 & 1.00000000 & 25 \\ \text { FIN1025 } & .280000000 & .458257569 & .000000000 & 1.00000000 & 25 \\ \text { FIN2550 } & .280000000 & .458257569 & .000000000 & 1.00000000 & 25 \\ \text { FIN500 } & .240000000 & .435889894 & .000000000 & 1.00000000 & 25 \\ \text { AGE46 } & .440000000 & .506622805 & .000000000 & 1.00000000 & 25 \\ \text { FHUOS } & .240000000 & .435889894 & .000000000 & 1.00000000 & 25 \\ \text { FHUOM } & .520000000 & .509901951 & .000000000 & 1.00000000 & 25 \\ \text { FHUOL } & .240000000 & .435889894 & .000000000 & 1.00000000 & 25 \\ \text { RESIDUAL } & .400000000 \mathrm{E}-01 & .200000000 & .000000000 & 1.00000000 & 25 \\ \text { FIN250 } & .520000000 & .509901951 & .000000000 & 1.00000000 & 25 \\ \text { FEXP11 } & .520000000 & .509901951 & .000000000 & 1.00000000 & 25 \\ \text { AGE36 } & .800000000 & .408248290 & .000000000 & 1.00000000 & 25 \\ \text { LEDC } & .480000000 & .509901951 & .000000000 & 1.00000000 & 25 \\ \text { FHUOLA } & .760000000 & .435889894 & .000000000 & 1.00000000 & 25\end{array}$


Descriptive Statistics for the Kwazulu Natal Province

All results based on nonmissing observations.

$=========================================================$
Variable $\quad$ Mean
$============================================================$

All observations in current sample

\begin{tabular}{|c|c|c|c|c|}
\hline PROV & 4.00000000 & .000000000 & 4.00000000 & 4.00000000 \\
\hline ENTERP & 3.11627907 & 1.29484881 & 1.00000000 & 5.00000000 \\
\hline NOTILL & .581395349 & .499168744 & .000000000 & 1.00000000 \\
\hline CROPR & .302325581 & .464700811 & .000000000 & 1.00000000 \\
\hline ROTGRAI & .162790698 & .373543684 & .000000000 & 1.00000000 \\
\hline IPM & $.930232558 \mathrm{E}-01$ & .293902599 & .000000000 & 1.00000000 \\
\hline WH & .279069767 & .453850269 & .000000000 & 1.00000000 \\
\hline BMP & .674418605 & .474137324 & .000000000 & 1.00000000 \\
\hline ORGANIC & .139534884 & .350604604 & .000000000 & 1.00000000 \\
\hline COVERCR & .674418605 & .474137324 & .000000000 & 1.00000000 \\
\hline TERR & $.465116279 \mathrm{E}-01$ & .213082632 & .000000000 & 1.00000000 \\
\hline STRIPCRO & .883720930 & .324353006 & .000000000 & 1.00000000 \\
\hline DIVESION & .395348837 & .494711791 & .000000000 & 1.00000000 \\
\hline RTILPLA & $.465116279 \mathrm{E}-01$ & .213082632 & .000000000 & 1.00000000 \\
\hline RTILL & .279069767 & .453850269 & .000000000 & 1.00000000 \\
\hline RENT & 321.883721 & 846.566292 & .000000000 & 5000.00000 \\
\hline FEXP & 2.09302326 & .995560466 & 1.00000000 & 4.00000000 \\
\hline FIN & 2.90697674 & 1.01919561 & 1.00000000 & 4.00000000 \\
\hline PLANDC & $.697674419 \mathrm{E}-01$ & .257769631 & .000000000 & 1.00000000 \\
\hline FHUO & 3195.93023 & 2875.88356 & 20.0000000 & 9654.00000 \\
\hline LABI & .581395349 & .499168744 & .000000000 & 1.00000000 \\
\hline RESFA & 697674419 & .464700811 & .000000000 & 1.00000000 \\
\hline LEDU & 4.13953488 & 1.16662712 & 1.00000000 & 6.00000000 \\
\hline CDT & 697674419 & .464700811 & .000000000 & 1.00000000 \\
\hline GFA & .418604651 & .499168744 & .000000000 & 1.00000000 \\
\hline OWN & 6.74418605 & 2.30003130 & 1.00000000 & 10.0000000 \\
\hline FLC & .651162791 & .482242822 & .000000000 & 1.00000000 \\
\hline LEDUH & .139534884 & .350604604 & .000000000 & 1.00000000 \\
\hline LEDUCH & .116279070 & .324353006 & .000000000 & 1.00000000 \\
\hline LEDUC & .302325581 & .464700811 & .000000000 & 1.00000000 \\
\hline LEDUU & .441860465 & .502485517 & .000000000 & 1.00000000 \\
\hline AGE35 & .232558140 & .427462574 & .000000000 & 1.00000000 \\
\hline AGE3645 & .255813953 & .441481448 & .000000000 & 1.00000000 \\
\hline FEXP5 & .325581395 & .474137324 & .000000000 & 1.00000000 \\
\hline FEXP610 & .372093023 & .489083488 & .000000000 & 1.00000000 \\
\hline FEXP1120 & .186046512 & .393749615 & .000000000 & 1.00000000 \\
\hline FEXP20 & .116279070 & .324353006 & .000000000 & 1.00000000 \\
\hline ENTLVST & .255813953 & .441481448 & .000000000 & 1.00000000 \\
\hline
\end{tabular}




$\begin{array}{llllll}\text { ENTHORT } & .395348837 & .494711791 & .000000000 & 1.00000000 & 43 \\ \text { ENTFCROP } & .232558140 & .427462574 & .000000000 & 1.00000000 & 43 \\ \text { ENTMXFAR } & .930232558 \mathrm{E}-01 & .293902599 & .000000000 & 1.00000000 & 43 \\ \text { FIN100 } & .116279070 & .324353006 & .000000000 & 1.00000000 & 43 \\ \text { FIN1025 } & .209302326 & .411625091 & .000000000 & 1.00000000 & 43 \\ \text { FIN2550 } & .325581395 & .474137324 & .000000000 & 1.00000000 & 43 \\ \text { FIN500 } & .348837209 & .482242822 & .000000000 & 1.00000000 & 43 \\ \text { AGE46 } & .651162791 & .482242822 & .000000000 & 1.00000000 & 43 \\ \text { FHUOS } & .232558140 & .427462574 & .000000000 & 1.00000000 & 43 \\ \text { FHUOM } & .511627907 & .505780539 & .000000000 & 1.00000000 & 43 \\ \text { FHUOL } & .255813953 & .441481448 & .000000000 & 1.00000000 & 43 \\ \text { RESIDUAL } & -.232558140 \mathrm{E}-01 & .266223330 & -1.00000000 & 1.00000000 & 43 \\ \text { FIN250 } & .674418605 & .474137324 & .000000000 & 1.00000000 & 43 \\ \text { FEXP11 } & .302325581 & .464700811 & .000000000 & 1.00000000 & 43 \\ \text { AGE36 } & .744186047 & .441481448 & .000000000 & 1.00000000 & 43 \\ \text { LEDC } & .744186047 & .441481448 & .000000000 & 1.00000000 & 43 \\ \text { FHUOLA } & .767441860 & .427462574 & .000000000 & 1.00000000 & 43\end{array}$


Descriptive Statistics for the Limpopo Province All results based on nonmissing observations.

\begin{tabular}{|c|c|c|c|c|c|}
\hline Variable & Mean & Std.Dev. & Minimum & Maximum & Cases \\
\hline
\end{tabular}

All observations in current sample

\begin{tabular}{|c|c|c|c|c|}
\hline PROV & 5.00000000 & .000000000 & 5.00000000 & 5.00000000 \\
\hline ENTERP & 2.68000000 & 1.60000000 & 1.00000000 & 5.00000000 \\
\hline NOTILL & .720000000 & .458257569 & .000000000 & 1.00000000 \\
\hline CROPR & .400000000 & .500000000 & .000000000 & 1.00000000 \\
\hline ROTGRAI & .280000000 & .458257569 & .000000000 & 1.00000000 \\
\hline IPM & .000000000 & .000000000 & .000000000 & .000000000 \\
\hline WH & .160000000 & .374165739 & .000000000 & 1.00000000 \\
\hline BMP & .760000000 & .435889894 & .000000000 & 1.00000000 \\
\hline ORGANIC & .160000000 & .374165739 & .000000000 & 1.00000000 \\
\hline COVERCR & .840000000 & .374165739 & 000 & 1.00000000 \\
\hline TERR & .120000000 & .331662479 & .000000000 & 1.00000000 \\
\hline STRIPCRO & .960000000 & .200000000 & .000000000 & 1.00000000 \\
\hline DIVESION & .360000000 & 489897949 & .000000000 & 1.00000000 \\
\hline RTILPLA & $.800000000 \mathrm{E}-01$ & .276887 & 00 & 1.00000000 \\
\hline RTILL & .440000000 & .506622805 & .000000000 & 1.00000000 \\
\hline RENT & 456.200000 & 1371. & 000 & 5900.00000 \\
\hline FEXP & 2.04000000 & .840634681 & 000 & 4.00000000 \\
\hline FIN & 3.04000000 & & & 4.00000000 \\
\hline PLANDC & $.800000000 \mathrm{E}-01$ & .276887462 & .00 & 1.00000000 \\
\hline FHUO & 3279.92000 & 2568.12079 & 00000 & 9010.00000 \\
\hline LABI & 920000000 & 7462 & 0000 & 1.00000000 \\
\hline RESFA & .800000000 & .408248290 & 0000 & 1.00000000 \\
\hline LEDU & 3.68000000 & 900000000 & 2.00000000 & 5.00000000 \\
\hline CDT & .800000000 & .408248290 & .00 & 00000 \\
\hline GFA & $.800000000 \mathrm{E}-01$ & .276887462 & 000 & 1.00000000 \\
\hline OWN & 3.80000000 & 2.12132034 & & 9.00000000 \\
\hline FLC & .840000000 & .374165739 & 000000 & 1.00000000 \\
\hline LEDUH & .120000000 & .331662479 & .000000000 & 1.00000000 \\
\hline LEDUCH & .240000000 & .435889894 & .000000000 & 1.00000000 \\
\hline LEDUC & .480000000 & .509901951 & .000000000 & 1.00000000 \\
\hline LEDUU & .160000000 & .374165739 & .000000000 & 1.00000000 \\
\hline AGE35 & $.800000000 \mathrm{E}-01$ & .276887462 & .000000000 & 1.00000000 \\
\hline AGE3645 & .200000000 & .408248290 & .000000000 & 1.00000000 \\
\hline FEXP5 & .280000000 & .458257569 & & 1.00000000 \\
\hline FEXP610 & .440000000 & .506622805 & .000000000 & 1.00000000 \\
\hline FEXP1120 & .240000000 & .435889894 & .000000000 & 1.00000000 \\
\hline FEXP20 & $.400000000 \mathrm{E}-01$ & .200000000 & .000000000 & 1.00000000 \\
\hline ENTLVST & .360000000 & 489897949 & .000000000 & 1.00000000 \\
\hline
\end{tabular}




$\begin{array}{llllll}\text { ENTHORT } & .280000000 & .458257569 & .000000000 & 1.00000000 & 25 \\ \text { ENTFCROP } & .200000000 & .408248290 & .000000000 & 1.00000000 & 25 \\ \text { ENTMXFAR } & .200000000 & .408248290 & .000000000 & 1.00000000 & 25 \\ \text { FIN100 } & .800000000 \mathrm{E}-01 & .276887462 & .000000000 & 1.00000000 & 25 \\ \text { FIN1025 } & .160000000 & .374165739 & .000000000 & 1.00000000 & 25 \\ \text { FIN2550 } & .400000000 & .500000000 & .000000000 & 1.00000000 & 25 \\ \text { FIN500 } & .360000000 & .489897949 & .000000000 & 1.00000000 & 25 \\ \text { AGE46 } & .880000000 & .331662479 & .000000000 & 1.00000000 & 25 \\ \text { FHUOS } & .800000000 \mathrm{E}-01 & .276887462 & .000000000 & 1.00000000 & 25 \\ \text { FHUOM } & .720000000 & .458257569 & .000000000 & 1.00000000 & 25 \\ \text { FHUOL } & .200000000 & .408248290 & .000000000 & 1.00000000 & 25 \\ \text { RESIDUAL } & -.800000000 \mathrm{E}-01 & .276887462 & -1.00000000 & .000000000 & 25 \\ \text { FIN250 } & .760000000 & .435889894 & .000000000 & 1.00000000 & 25 \\ \text { FEXP11 } & .280000000 & .458257569 & .000000000 & 1.00000000 & 25 \\ \text { AGE36 } & 1.00000000 & .000000000 & 1.00000000 & 1.00000000 & 25 \\ \text { LEDC } & .640000000 & .489897949 & .000000000 & 1.00000000 & 25 \\ \text { FHUOLA } & .920000000 & .276887462 & .000000000 & 1.00000000 & 25\end{array}$


Descriptive Statistics for Mpumalanga Province

All results based on nonmissing observations.

\begin{tabular}{|c|c|c|c|c|}
\hline Variable & Mean & Std.Dev. & Minimum & Maximum Cases \\
\hline
\end{tabular}

All observations in current sample

\begin{tabular}{|c|c|c|c|c|}
\hline PROV & 6.00000000 & .000000000 & 6.00000000 & 6.00000000 \\
\hline ENTERP & 3.06451613 & 1.36468516 & 1.00000000 & 5.00000000 \\
\hline NOTILL & .548387097 & .505879411 & .000000000 & 1.00000000 \\
\hline CROPR & .225806452 & .425023719 & .000000000 & 1.00000000 \\
\hline ROTGRAI & .161290323 & .373878251 & .000000000 & 1.00000000 \\
\hline IPM & .129032258 & .340777101 & .000000000 & 1.00000000 \\
\hline WH & .193548387 & .401609664 & .000000000 & 1.00000000 \\
\hline BMP & .612903226 & .495137648 & .000000000 & 1.00000000 \\
\hline ORGANIC & .129032258 & .340777101 & .000000000 & 1.00000000 \\
\hline COVERCR & .612903226 & .495137648 & .000000000 & 1.00000000 \\
\hline TERR & $.322580645 \mathrm{E}-01$ & .179605302 & .000000000 & 1.00000000 \\
\hline STRIPCRO & .967741935 & & .000000000 & 1.00000000 \\
\hline DIVESION & .903225806 & .300537154 & .000000000 & 1.00000000 \\
\hline RTILPLA & $.645161290 \mathrm{E}-01$ & 1038 & .000000000 & 1.00000000 \\
\hline RTILL & .387096774 & .495137648 & .000000000 & 1.00000000 \\
\hline RENT & 440.70 & & .000000000 & 3400.00000 \\
\hline FEXP & 2.25806452 & .929793595 & 1.00000000 & 4.00000000 \\
\hline FIN & 2.70967742 & 1.10131886 & 1.00000000 & 00000 \\
\hline PLANDC & $.645161290 \mathrm{E}-01$ & .24973 & .000000000 & 00000 \\
\hline FHUO & 2436.35484 & 2577.23025 & 25.0000000 & 8213.00000 \\
\hline LABI & .645161290 & 457 & .000000000 & 00000 \\
\hline RESFA & .645161290 & 3457 & .000000000 & 00000 \\
\hline LEDU & 4.12903226 & 1.0244 & 2.00000000 & 6.00000000 \\
\hline CDT & .580645161 & .5016 & .000000000 & 1.00000000 \\
\hline GFA & .129032258 & .340777101 & .000000000 & 00000 \\
\hline OWN & 5.66666667 & 2.13885779 & .000000000 & 00000 \\
\hline FLC & & & .000000000 & 1.00000000 \\
\hline LEDUH & $.967741935 \mathrm{E}-01$ & .300537154 & .000000000 & 1.00000000 \\
\hline LEDUCH & .193548387 & .401609664 & .000000000 & 1.00000000 \\
\hline LEDUC & .354838710 & .486373457 & .000000000 & 1.00000000 \\
\hline LEDUU & .354838710 & .486373457 & .000000000 & 1.00000000 \\
\hline AGE35 & .225806452 & .425023719 & .000000000 & 1.00000000 \\
\hline AGE3645 & .387096774 & .495137648 & .000000000 & 1.00000000 \\
\hline FEXP5 & .225806452 & .425023719 & .000000000 & 1.00000000 \\
\hline FEXP610 & .387096774 & .495137648 & .000000000 & 1.00000000 \\
\hline FEXP1120 & .290322581 & .461414375 & .000000000 & 1.00000000 \\
\hline FEXP20 & $.967741935 \mathrm{E}-01$ & .300537154 & .000000000 & 1.00000000 \\
\hline ENTLVST & .290322581 & .461414375 & .000000000 & 1.00000000 \\
\hline
\end{tabular}




$\begin{array}{llllll}\text { ENTHORT } & .354838710 & .486373457 & .000000000 & 1.00000000 & 31 \\ \text { ENTFCROP } & .161290323 & .373878251 & .000000000 & 1.00000000 & 31 \\ \text { ENTMXFAR } & .161290323 & .373878251 & .000000000 & 1.00000000 & 31 \\ \text { FIN100 } & .193548387 & .401609664 & .000000000 & 1.00000000 & 31 \\ \text { FIN1025 } & .193548387 & .401609664 & .000000000 & 1.00000000 & 31 \\ \text { FIN2550 } & .322580645 & .475190963 & .000000000 & 1.00000000 & 31 \\ \text { FIN500 } & .290322581 & .461414375 & .000000000 & 1.00000000 & 31 \\ \text { AGE46 } & .677419355 & .475190963 & .000000000 & 1.00000000 & 31 \\ \text { FHUOS } & .193548387 & .401609664 & .000000000 & 1.00000000 & 31 \\ \text { FHUOM } & .580645161 & .501610310 & .000000000 & 1.00000000 & 31 \\ \text { FHUOL } & .225806452 & .425023719 & .000000000 & 1.00000000 & 31 \\ \text { RESIDUAL } & -.322580645 E-01 & .179605302 & -1.00000000 & .000000000 & 31 \\ \text { FIN250 } & .612903226 & .495137648 & .000000000 & 1.00000000 & 31 \\ \text { FEXP11 } & .387096774 & .495137648 & .000000000 & 1.00000000 & 31 \\ \text { AGE36 } & .935483871 & .249731038 & .000000000 & 1.00000000 & 31 \\ \text { LEDC } & .709677419 & .461414375 & .000000000 & 1.00000000 & 31 \\ \text { FHUOLA } & .806451613 & .401609664 & .000000000 & 1.00000000 & 31\end{array}$


Descriptive Statistics for Northen Cape Province

All results based on nonmissing observations.

$===========================================================$
Variable Mean $\quad$ Std.Dev. Minimum Maximum Cases
$===========================================================$

All observations in current sample

\begin{tabular}{|c|c|c|c|c|}
\hline PROV & 7.00000000 & .000000000 & 7.00000000 & 7.00000000 \\
\hline ENTERP & 2.74418605 & 1.49750623 & 1.00000000 & 5.00000000 \\
\hline NOTILL & .395348837 & .494711791 & .000000000 & 1.00000000 \\
\hline CROPR & .232558140 & .427462574 & .000000000 & 1.00000000 \\
\hline ROTGRAI & .162790698 & .373543684 & .000000000 & 1.00000000 \\
\hline IPM & $.697674419 \mathrm{E}-01$ & .257769631 & .000000000 & 1.00000000 \\
\hline WH & .186046512 & .393749615 & .000000000 & 1.00000000 \\
\hline BMP & .511627907 & .505780539 & .000000000 & 1.00000000 \\
\hline ORGANIC & .139534884 & .350604604 & .000000000 & 1.00000000 \\
\hline COVERCR & .465116279 & .504684588 & .000000000 & 1.00000000 \\
\hline TERR & $.930232558 \mathrm{E}-01$ & .293902599 & .000000000 & 1.00000000 \\
\hline STRIPCRO & .930232558 & .257769631 & .000000000 & 1.00000000 \\
\hline DIVESION & .325581395 & .474137324 & .000000000 & 1.00000000 \\
\hline RTILPLA & $.465116279 \mathrm{E}-01$ & .213082632 & .000000000 & 1.00000000 \\
\hline RTILL & .372093023 & .489083488 & .000000000 & 1.00000000 \\
\hline RENT & 609.697674 & 1116.85171 & .000000000 & 5520.00000 \\
\hline FEXP & 2.39534884 & .929401622 & 1.00000000 & 4.00000000 \\
\hline FIN & 2.58139535 & 1.05181381 & 1.00000000 & 4.00000000 \\
\hline PLANDC & .116279070 & .324353006 & .000000000 & 1.00000000 \\
\hline FHUO & 2343.72093 & 2588.37061 & 32.0000000 & 8640.00000 \\
\hline LABI & .465116279 & .504684588 & .000000000 & 1.00000000 \\
\hline RESFA & .534883721 & .504684588 & .000000000 & 1.00000000 \\
\hline LEDU & 3.44186047 & 1.22089595 & 1.00000000 & 5.00000000 \\
\hline CDT & .558139535 & .502485517 & .000000000 & 1.00000000 \\
\hline GFA & .209302326 & .411625091 & .000000000 & 1.00000000 \\
\hline OWN & 6.27906977 & 2.38373038 & 1.00000000 & 10.0000000 \\
\hline FLC & .767441860 & .427462574 & .000000000 & 1.00000000 \\
\hline LEDUH & .209302326 & .411625091 & .000000000 & 1.00000000 \\
\hline LEDUCH & .255813953 & .441481448 & .000000000 & 1.00000000 \\
\hline LEDUC & .232558140 & .427462574 & .000000000 & 1.00000000 \\
\hline LEDUU & .255813953 & .441481448 & .000000000 & 1.00000000 \\
\hline AGE35 & .186046512 & .393749615 & .000000000 & 1.00000000 \\
\hline AGE3645 & .232558140 & .427462574 & .000000000 & 1.00000000 \\
\hline FEXP5 & .186046512 & .393749615 & .000000000 & 1.00000000 \\
\hline FEXP610 & .348837209 & .482242822 & .000000000 & 1.00000000 \\
\hline FEXP1120 & .348837209 & .482242822 & .000000000 & 1.00000000 \\
\hline FEXP20 & .116279070 & .324353006 & .000000000 & 1.00000000 \\
\hline ENTLVST & .418604651 & .499168744 & .000000000 & 1.00000000 \\
\hline
\end{tabular}




$\begin{array}{llllll}\text { ENTHORT } & .209302326 & .411625091 & .000000000 & 1.00000000 & 43 \\ \text { ENTFCROP } & .209302326 & .411625091 & .000000000 & 1.00000000 & 43 \\ \text { ENTMXFAR } & .162790698 & .373543684 & .000000000 & 1.00000000 & 43 \\ \text { FIN100 } & .186046512 & .393749615 & .000000000 & 1.00000000 & 43 \\ \text { FIN1025 } & .279069767 & .453850269 & .000000000 & 1.00000000 & 43 \\ \text { FIN2550 } & .302325581 & .464700811 & .000000000 & 1.00000000 & 43 \\ \text { FIN500 } & .232558140 & .427462574 & .000000000 & 1.00000000 & 43 \\ \text { AGE46 } & .651162791 & .482242822 & .000000000 & 1.00000000 & 43 \\ \text { FHUOS } & .302325581 & .464700811 & .000000000 & 1.00000000 & 43 \\ \text { FHUOM } & .465116279 & .504684588 & .000000000 & 1.00000000 & 43 \\ \text { FHUOL } & .232558140 & .427462574 & .000000000 & 1.00000000 & 43 \\ \text { RESIDUAL } & -.232558140 \mathrm{E}-01 & .152498570 & -1.00000000 & .000000000 & 43 \\ \text { FIN250 } & .534883721 & .504684588 & .000000000 & 1.00000000 & 43 \\ \text { FEXP11 } & .465116279 & .504684588 & .000000000 & 1.00000000 & 43 \\ \text { AGE36 } & .837209302 & .373543684 & .000000000 & 1.00000000 & 43 \\ \text { LEDC } & .488372093 & .505780539 & .000000000 & 1.00000000 & 43 \\ \text { FHUOLA } & .697674419 & .464700811 & .000000000 & 1.00000000 & 43\end{array}$


Descriptive Statistics for North West Province

All results based on nonmissing observations.

$==========================================================$
Variable $\quad$ Mean
$================================================================$

All observations in current sample

\begin{tabular}{|c|c|c|c|c|}
\hline PROV & 8.00000000 & .000000000 & 8.00000000 & 8.00000000 \\
\hline ENTERP & 2.67647059 & 1.45061300 & 1.00000000 & 5.00000000 \\
\hline NOTILL & .500000000 & .507519219 & .000000000 & 1.00000000 \\
\hline CROPR & .352941176 & .485071250 & .000000000 & 1.00000000 \\
\hline ROTGRAI & $.882352941 \mathrm{E}-01$ & .287902241 & .000000000 & 1.00000000 \\
\hline IPM & .147058824 & .359490628 & .000000000 & 1.00000000 \\
\hline WH & .294117647 & .462497290 & .000000000 & 1.00000000 \\
\hline BMP & .588235294 & .499554168 & .000000000 & 1.00000000 \\
\hline ORGANIC & $.882352941 \mathrm{E}-01$ & .287902241 & .000000000 & 1.00000000 \\
\hline COVERCR & .676470588 & .474858080 & .000000000 & 1.00000000 \\
\hline TERR & $.294117647 \mathrm{E}-01$ & .171498585 & .000000000 & 1.00000000 \\
\hline STRIPCRO & .970588235 & .171498585 & .000000000 & 1.00000000 \\
\hline DIVESION & .823529412 & .386952995 & .000000000 & 1.00000000 \\
\hline RTILPLA & $.294117647 \mathrm{E}-01$ & .171498585 & .000000000 & 1.00000000 \\
\hline RTILL & .411764706 & .499554168 & .000000000 & 1.00000000 \\
\hline RENT & 435.735294 & 830.802945 & .000000000 & 3500.00000 \\
\hline FEXP & 2.20588235 & 1.03804629 & 1.00000000 & 4.00000000 \\
\hline FIN & 2.91176471 & 1.05507854 & 1.00000000 & 4.00000000 \\
\hline PLANDC & .117647059 & .327034970 & .000000000 & 1.00000000 \\
\hline FHUO & 1868.44118 & 1631.69442 & 48.0000000 & 6200.00000 \\
\hline LABI & .558823529 & .503994737 & .000000000 & 1.00000000 \\
\hline RESFA & .705882353 & .462497290 & .000000000 & 1.00000000 \\
\hline LEDU & 3.67647059 & 1.03632767 & 2.00000000 & 5.00000000 \\
\hline CDT & .764705882 & .430561545 & .000000000 & 1.00000000 \\
\hline GFA & .235294118 & .430561545 & .000000000 & 1.00000000 \\
\hline OWN & 5.94117647 & 1.96855856 & 3.00000000 & 9.00000000 \\
\hline FLC & .676470588 & .474858080 & .000000000 & 1.00000000 \\
\hline LEDUH & .176470588 & .386952995 & .000000000 & 1.00000000 \\
\hline LEDUCH & .294117647 & .462497290 & .000000000 & 1.00000000 \\
\hline LEDUC & .264705882 & .447811076 & .000000000 & 1.00000000 \\
\hline LEDUU & .235294118 & .430561545 & .000000000 & 1.00000000 \\
\hline AGE35 & $.882352941 \mathrm{E}-01$ & .287902241 & .000000000 & 1.00000000 \\
\hline AGE3645 & .294117647 & .462497290 & .000000000 & 1.00000000 \\
\hline FEXP5 & .294117647 & .462497290 & .000000000 & 1.00000000 \\
\hline FEXP610 & .352941176 & .485071250 & .000000000 & 1.00000000 \\
\hline FEXP1120 & .205882353 & .410425630 & .000000000 & 1.00000000 \\
\hline FEXP20 & .147058824 & .359490628 & .000000000 & 1.00000000 \\
\hline ENTLVST & .411764706 & .499554168 & .000000000 & 1.00000000 \\
\hline
\end{tabular}




$\begin{array}{llllll}\text { ENTHORT } & .323529412 & .474858080 & .000000000 & 1.00000000 & 34 \\ \text { ENTFCROP } & .147058824 & .359490628 & .000000000 & 1.00000000 & 34 \\ \text { ENTMXFAR } & .117647059 & .327034970 & .000000000 & 1.00000000 & 34 \\ \text { FIN100 } & .147058824 & .359490628 & .000000000 & 1.00000000 & 34 \\ \text { FIN1025 } & .147058824 & .359490628 & .000000000 & 1.00000000 & 34 \\ \text { FIN2550 } & .352941176 & .485071250 & .000000000 & 1.00000000 & 34 \\ \text { FIN500 } & .352941176 & .485071250 & .000000000 & 1.00000000 & 34 \\ \text { AGE46 } & .735294118 & .447811076 & .000000000 & 1.00000000 & 34 \\ \text { FHUOS } & .294117647 & .462497290 & .000000000 & 1.00000000 & 34 \\ \text { FHUOM } & .676470588 & .474858080 & .000000000 & 1.00000000 & 34 \\ \text { FHUOL } & .294117647 \mathrm{E}-01 & .171498585 & .000000000 & 1.00000000 & 34 \\ \text { RESIDUAL } & -.588235294 \mathrm{E}-01 & .238832574 & -1.00000000 & .000000000 & 34 \\ \text { FIN250 } & .705882353 & .462497290 & .000000000 & 1.00000000 & 34 \\ \text { FEXP11 } & .352941176 & .485071250 & .000000000 & 1.00000000 & 34 \\ \text { AGE36 } & .970588235 & .171498585 & .000000000 & 1.00000000 & 34 \\ \text { LEDC } & .500000000 & .507519219 & .000000000 & 1.00000000 & 34 \\ \text { FHUOLA } & .705882353 & .462497290 & .000000000 & 1.00000000 & 34\end{array}$


Descriptive Statistics for Western Cape Province

All results based on nonmissing observations.

$===========================================================$
Variable $\quad$ Mean
$================================================================$

All observations in current sample

\begin{tabular}{|c|c|c|c|c|}
\hline PROV & 9.00000000 & .000000000 & 9.00000000 & 9.00000000 \\
\hline ENTERP & 2.54285714 & 1.44187087 & 1.00000000 & 5.00000000 \\
\hline NOTILL & .600000000 & .497050122 & .000000000 & 1.00000000 \\
\hline CROPR & .285714286 & .458349249 & .000000000 & 1.00000000 \\
\hline ROTGRAI & $.857142857 \mathrm{E}-01$ & .284028641 & .000000000 & 1.00000000 \\
\hline IPM & .142857143 & .355035801 & .000000000 & 1.00000000 \\
\hline WH & .285714286 & .458349249 & .000000000 & 1.00000000 \\
\hline BMP & .600000000 & .497050122 & .000000000 & 1.00000000 \\
\hline ORGANIC & .142857143 & .355035801 & .000000000 & 1.00000000 \\
\hline COVERCR & .600000000 & .497050122 & .000000000 & 1.00000000 \\
\hline TERR & .171428571 & .382385260 & .000000000 & 1.00000000 \\
\hline STRIPCRO & .971428571 & .169030851 & .000000000 & 1.00000000 \\
\hline DIVESION & .342857143 & .481593992 & .000000000 & 1.00000000 \\
\hline RTILPLA & .114285714 & .322802851 & .000000000 & 1.00000000 \\
\hline RTILL & .485714286 & .507092553 & .000000000 & 1.00000000 \\
\hline RENT & 111.000000 & 195.823300 & .000000000 & 605.000000 \\
\hline FEXP & 3.11428571 & 1.10537267 & 1.00000000 & 4.00000000 \\
\hline FIN & 2.88571429 & 1.13166791 & 1.00000000 & 4.00000000 \\
\hline PLANDC & .142857143 & .355035801 & .000000000 & 1.00000000 \\
\hline FHUO & 772.248571 & 1063.07137 & 10.0000000 & 5120.00000 \\
\hline LABI & .457142857 & .505432671 & .000000000 & 1.00000000 \\
\hline RESFA & .852941176 & .359490628 & .000000000 & 1.00000000 \\
\hline LEDU & 3.74285714 & 1.40048011 & 1.00000000 & 6.00000000 \\
\hline CDT & .542857143 & .505432671 & .000000000 & 1.00000000 \\
\hline GFA & .542857143 & .505432671 & .000000000 & 1.00000000 \\
\hline OWN & 6.85714286 & 2.15765201 & 3.00000000 & 9.00000000 \\
\hline FLC & .657142857 & .481593992 & .000000000 & 1.00000000 \\
\hline LEDUH & .142857143 & .355035801 & .000000000 & 1.00000000 \\
\hline LEDUCH & .342857143 & .481593992 & .000000000 & 1.00000000 \\
\hline LEDUC & $.857142857 \mathrm{E}-01$ & .284028641 & .000000000 & 1.00000000 \\
\hline LEDUU & .400000000 & .497050122 & .000000000 & 1.00000000 \\
\hline AGE35 & .257142857 & .443439574 & .000000000 & 1.00000000 \\
\hline AGE3645 & .200000000 & .405839725 & .000000000 & 1.00000000 \\
\hline FEXP5 & .142857143 & .355035801 & .000000000 & 1.00000000 \\
\hline FEXP610 & .114285714 & .322802851 & .000000000 & 1.00000000 \\
\hline FEXP1120 & .228571429 & .426042961 & .000000000 & 1.00000000 \\
\hline FEXP20 & .514285714 & .507092553 & .000000000 & 1.00000000 \\
\hline ENTLVST & .342857143 & .481593992 & .000000000 & 1.00000000 \\
\hline
\end{tabular}




$\begin{array}{llllll}\text { ENTHORT } & .285714286 & .458349249 & .000000000 & 1.00000000 & 35 \\ \text { ENTFCROP } & .314285714 & .471008216 & .000000000 & 1.00000000 & 35 \\ \text { ENTMXFAR } & .571428571 \mathrm{E}-01 & .235504108 & .000000000 & 1.00000000 & 35 \\ \text { FIN100 } & .171428571 & .382385260 & .000000000 & 1.00000000 & 35 \\ \text { FIN1025 } & .171428571 & .382385260 & .000000000 & 1.00000000 & 35 \\ \text { FIN2550 } & .228571429 & .426042961 & .000000000 & 1.00000000 & 35 \\ \text { FIN500 } & .342857143 & .481593992 & .000000000 & 1.00000000 & 35 \\ \text { AGE46 } & .742857143 & .443439574 & .000000000 & 1.00000000 & 35 \\ \text { FHUOS } & .571428571 & .502096445 & .000000000 & 1.00000000 & 35 \\ \text { FHUOM } & .400000000 & .497050122 & .000000000 & 1.00000000 & 35 \\ \text { FHUOL } & .285714286 \mathrm{E}-01 & .169030851 & .000000000 & 1.00000000 & 35 \\ \text { RESIDUAL } & .000000000 & .242535625 & -1.00000000 & 1.00000000 & 35 \\ \text { FIN250 } & .571428571 & .502096445 & .000000000 & 1.00000000 & 35 \\ \text { FEXP11 } & .742857143 & .443439574 & .000000000 & 1.00000000 & 35 \\ \text { AGE36 } & .885714286 & .322802851 & .000000000 & 1.00000000 & 35 \\ \text { LEDC } & .485714286 & .507092553 & .000000000 & 1.00000000 & 35 \\ \text { FHUOLA } & .428571429 & .502096445 & .000000000 & 1.00000000 & 35\end{array}$




\section{Appendix E NUMBER OF ADOPTERS AND NON -ADOPTERS BY PROVINCE}

\begin{tabular}{|l|l|l|}
\hline Province & No of Adopters & No of Non- Adopters \\
\hline Eastern Cape & 17 & 10 \\
\hline Free State & 31 & 32 \\
\hline Gauteng & 13 & 12 \\
\hline Kwazulu- Natal & 29 & 14 \\
\hline Limpopo & 19 & 6 \\
\hline Mpumalanga & 19 & 12 \\
\hline Northen Cape & 22 & 21 \\
\hline North West & 19 & 15 \\
\hline Western Cape & 21 & 14 \\
\hline
\end{tabular}


Appendix F DATA USED IN THE LOGIT MODEL

Table F.1

\begin{tabular}{|c|c|c|c|c|c|c|c|c|c|c|c|c|c|}
\hline PROV & BMP & RENT & FEXP & FIN & PLANDC & LABI & CDT & GFA & FLC & LEDUH & LEDUCH & LEDUC & LEDUU \\
\hline 1 & 0 & 20 & 4 & 4 & 0 & 0 & 0 & 0 & 0 & 0 & 0 & 1 & 0 \\
\hline 1 & 0 & 150 & 2 & 4 & 0 & 1 & 1 & 1 & 0 & 1 & 0 & 0 & 0 \\
\hline 1 & 1 & 0 & 4 & 1 & 0 & 0 & 0 & 0 & 1 & 0 & 0 & 0 & 1 \\
\hline 1 & 1 & 0 & 2 & 4 & 0 & 0 & 0 & 1 & 1 & 0 & 0 & 0 & 1 \\
\hline 1 & 1 & 1.5 & 4 & 1 & 0 & 0 & 1 & 0 & 1 & 0 & 0 & 0 & 1 \\
\hline 1 & 1 & 0 & 1 & 1 & 0 & 1 & 0 & 0 & 1 & 0 & 0 & 1 & 0 \\
\hline 1 & 1 & 1 & 1 & 1 & 0 & 0 & 0 & 1 & 0 & 1 & 0 & 0 & 0 \\
\hline 1 & 1 & 0 & 2 & 4 & 0 & 1 & 1 & 1 & 0 & 0 & 0 & 0 & 1 \\
\hline 1 & 0 & 500 & 3 & 1 & 1 & 0 & 0 & 0 & 0 & 0 & 1 & 0 & 0 \\
\hline 1 & 0 & 5000 & 4 & 2 & 0 & 0 & 0 & 0 & 0 & 0 & 0 & 0 & 1 \\
\hline 1 & 0 & 1000 & 3 & 3 & 0 & 0 & 0 & 0 & 1 & 0 & 0 & 0 & 1 \\
\hline 1 & 1 & 0 & 1 & 4 & 0 & 0 & 1 & 0 & 1 & 0 & 0 & 1 & 0 \\
\hline 1 & 0 & 3400 & 3 & 1 & 0 & 0 & 0 & 0 & 1 & 1 & 0 & 0 & 0 \\
\hline 1 & 0 & 500 & 4 & 2 & 0 & 0 & 0 & 0 & 1 & 0 & 1 & 0 & 0 \\
\hline 1 & 0 & 612 & 4 & 2 & 0 & 0 & 0 & 0 & 1 & 1 & 0 & 0 & 0 \\
\hline 1 & 0 & 1500 & 3 & 1 & 0 & 0 & 0 & 0 & 0 & 0 & 1 & 0 & 0 \\
\hline 1 & 0 & 1000 & 3 & 3 & 0 & 0 & 0 & 0 & 0 & 0 & 1 & 0 & 0 \\
\hline 1 & 0 & 100 & 3 & 2 & 0 & 0 & 0 & 0 & 0 & 1 & 0 & 0 & 0 \\
\hline 1 & 1 & 0 & 1 & 4 & 0 & 1 & 1 & 0 & 0 & 0 & 0 & 1 & 0 \\
\hline 1 & 1 & 0 & 2 & 4 & 0 & 1 & 1 & 0 & 1 & 0 & 0 & 1 & 0 \\
\hline 1 & 1 & 550 & 2 & 4 & 0 & 0 & 1 & 1 & 1 & 0 & 0 & 1 & 0 \\
\hline 1 & 0 & 100 & 3 & 2 & 0 & 0 & 0 & 0 & 1 & 0 & 1 & 0 & 0 \\
\hline 1 & 1 & 0 & 2 & 3 & 0 & 1 & 1 & 0 & 1 & 0 & 0 & 1 & 0 \\
\hline 1 & 0 & 500 & 3 & 2 & 0 & 0 & 0 & 0 & 1 & 1 & 0 & 0 & 0 \\
\hline 1 & 0 & 500 & 4 & 2 & 0 & 0 & 0 & 0 & 1 & 0 & 1 & 0 & 0 \\
\hline 1 & 1 & 0 & 2 & 4 & 0 & 1 & 1 & 0 & 1 & 0 & 0 & 1 & 0 \\
\hline 1 & 0 & 0 & 1 & 3 & 0 & 1 & 1 & 0 & 1 & 0 & 0 & 0 & 1 \\
\hline
\end{tabular}




\begin{tabular}{|c|c|c|c|c|c|c|c|c|c|c|c|c|c|}
\hline PROV & BMP & RENT & FEXP & FIN & PLANDC & LABI & CDT & GFA & FLC & LEDUH & LEDUCH & LEDUC & LEDUU \\
\hline 1 & 1 & 0 & 2 & 3 & 0 & 0 & 1 & 0 & 1 & 0 & 1 & 0 & 0 \\
\hline 1 & 0 & 0 & 3 & 1 & 0 & 0 & 0 & 0 & 0 & 1 & 0 & 0 & 0 \\
\hline 1 & 0 & 2000 & 4 & 2 & 0 & 0 & 0 & 0 & 0 & 0 & 1 & 0 & 0 \\
\hline 1 & 0 & 2500 & 3 & 1 & 0 & 1 & 0 & 0 & 1 & 0 & 1 & 0 & 0 \\
\hline 1 & 0 & 850 & 3 & 1 & 0 & 1 & 0 & 1 & 1 & 0 & 0 & 0 & 1 \\
\hline 1 & 0 & 1000 & 3 & 2 & 0 & 0 & 1 & 0 & 1 & 0 & 1 & 0 & 0 \\
\hline 1 & 1 & 0 & 2 & 3 & 0 & 1 & 1 & 0 & 1 & 0 & 0 & 0 & 1 \\
\hline 1 & 1 & 0 & 1 & 4 & 0 & 1 & 1 & 0 & 1 & 0 & 0 & 1 & 0 \\
\hline 1 & 0 & 0 & 1 & 1 & 1 & 1 & 0 & 1 & 0 & 1 & 0 & 0 & 0 \\
\hline 1 & 0 & 0 & 4 & 1 & 0 & 0 & 0 & 0 & 0 & 0 & 1 & 0 & 0 \\
\hline 2 & 1 & 0 & 1 & 3 & 0 & 1 & 1 & 0 & 1 & 0 & 0 & 0 & 1 \\
\hline 2 & 1 & 0 & 2 & 4 & 0 & 1 & 1 & 0 & 1 & 0 & 0 & 1 & 0 \\
\hline 2 & 0 & 0 & 2 & 4 & 0 & 1 & 0 & 0 & 1 & 0 & 0 & 1 & 0 \\
\hline 2 & 1 & 0 & 1 & 3 & 0 & 1 & 1 & 0 & 1 & 0 & 0 & 0 & 1 \\
\hline 2 & 0 & 6500 & 4 & 2 & 1 & 0 & 0 & 0 & 1 & 0 & 1 & 0 & 0 \\
\hline 2 & 0 & 1860 & 3 & 2 & 1 & 0 & 0 & 0 & 1 & 1 & 0 & 0 & 0 \\
\hline 2 & 0 & 2400 & 3 & 1 & 0 & 0 & 1 & 0 & 0 & 1 & 0 & 0 & 0 \\
\hline 2 & 1 & 0 & 1 & 3 & 0 & 1 & 1 & 1 & 1 & 0 & 0 & 1 & 0 \\
\hline 2 & 1 & 0 & 2 & 4 & 0 & 1 & 1 & 1 & 0 & 0 & 0 & 0 & 1 \\
\hline 2 & 0 & 1450 & 3 & 2 & 0 & 1 & 0 & 1 & 1 & 1 & 0 & 0 & 0 \\
\hline 2 & 0 & 2700 & 4 & 1 & 0 & 0 & 0 & 0 & 0 & 0 & 1 & 0 & 0 \\
\hline 2 & 0 & 1600 & 2 & 2 & 0 & 0 & 0 & 0 & 0 & 0 & 1 & 0 & 0 \\
\hline 2 & 1 & 0 & 2 & 3 & 0 & 1 & 1 & 0 & 1 & 0 & 0 & 0 & 1 \\
\hline 2 & 0 & 0 & 1 & 3 & 0 & 1 & 1 & 0 & 1 & 1 & 0 & 0 & 0 \\
\hline 2 & 1 & 0 & 1 & 4 & 0 & 1 & 1 & 0 & 0 & 0 & 0 & 1 & 0 \\
\hline 2 & 0 & 100 & 3 & 1 & 0 & 0 & 0 & 0 & 1 & 0 & 1 & 0 & 0 \\
\hline 2 & 0 & 360 & 4 & 2 & 0 & 0 & 0 & 0 & 1 & 0 & 1 & 0 & 0 \\
\hline 2 & 0 & 200 & 3 & 3 & 0 & 0 & 1 & 0 & 0 & 1 & 0 & 0 & 0 \\
\hline 2 & 0 & 3000 & 4 & 1 & 0 & 1 & 0 & 0 & 0 & 1 & 0 & 0 & 0 \\
\hline 2 & 0 & 300 & 3 & 2 & 0 & 0 & 0 & 0 & 1 & 1 & 0 & 0 & 0 \\
\hline 2 & 1 & 0 & 2 & 2 & 0 & 0 & 1 & 1 & 1 & 0 & 0 & 1 & 0 \\
\hline
\end{tabular}


Table F.1

\begin{tabular}{|c|c|c|c|c|c|c|c|c|c|c|c|c|c|}
\hline PROV & BMP & RENT & FEXP & FIN & PLANDC & LABI & CDT & GFA & FLC & LEDUH & LEDUCH & LEDUC & LEDUU \\
\hline 2 & 0 & 0 & 2 & 4 & 0 & 0 & 1 & 0 & 1 & 0 & 0 & 0 & 1 \\
\hline 2 & 1 & 0 & 1 & 4 & 0 & 0 & 1 & 1 & 1 & 0 & 0 & 1 & 0 \\
\hline 2 & 0 & 0 & 4 & 2 & 0 & 0 & 0 & 1 & 0 & 1 & 0 & 0 & 0 \\
\hline 2 & 0 & 860 & 4 & 2 & 0 & 0 & 0 & 0 & 0 & 1 & 0 & 0 & 0 \\
\hline 2 & 0 & 645 & 3 & 1 & 0 & 0 & 0 & 1 & 1 & 1 & 0 & 0 & 0 \\
\hline 2 & 1 & 10 & 2 & 4 & 0 & 1 & 1 & 1 & 1 & 0 & 1 & 0 & 0 \\
\hline 2 & 1 & 0 & 1 & 3 & 0 & 1 & 1 & 1 & 1 & 0 & 0 & 1 & 0 \\
\hline 2 & 1 & 0 & 1 & 4 & 0 & 1 & 1 & 0 & 0 & 0 & 0 & 1 & 0 \\
\hline 2 & 1 & 0 & 1 & 3 & 0 & 1 & 1 & 1 & 0 & 0 & 0 & 1 & 0 \\
\hline 2 & 1 & 0 & 2 & 3 & 0 & 1 & 1 & 1 & 1 & 0 & 0 & 0 & 1 \\
\hline 2 & 1 & 0 & 1 & 4 & 0 & 1 & 1 & 0 & 1 & 0 & 0 & 1 & 0 \\
\hline 2 & 1 & 0 & 2 & 3 & 0 & 1 & 1 & 0 & 0 & 0 & 0 & 0 & 1 \\
\hline 2 & 1 & 0 & 2 & 4 & 0 & 1 & 1 & 0 & 1 & 0 & 0 & 1 & 0 \\
\hline 2 & 0 & 2500 & 3 & 1 & 0 & 1 & 0 & 0 & 1 & 0 & 1 & 0 & 0 \\
\hline 2 & 1 & 20 & 2 & 3 & 0 & 1 & 1 & 0 & 1 & 1 & 0 & 0 & 0 \\
\hline 2 & 0 & 800 & 3 & 1 & 0 & 0 & 0 & 0 & 1 & 1 & 0 & 0 & 0 \\
\hline 2 & 0 & 650 & 3 & 2 & 0 & 0 & 0 & 0 & 1 & 1 & 0 & 0 & 0 \\
\hline 2 & 1 & 0 & 1 & 4 & 0 & 1 & 1 & 0 & 1 & 0 & 1 & 0 & 0 \\
\hline 2 & 1 & 12 & 2 & 3 & 0 & 1 & 1 & 0 & 1 & 0 & 0 & 1 & 0 \\
\hline 2 & 1 & 0 & 2 & 4 & 0 & 1 & 1 & 0 & 1 & 0 & 0 & 0 & 1 \\
\hline 2 & 0 & 1300 & 4 & 1 & 0 & 0 & 0 & 0 & 1 & 0 & 1 & 0 & 0 \\
\hline 2 & 0 & 290 & 3 & 2 & 1 & 0 & 0 & 0 & 1 & 0 & 1 & 0 & 0 \\
\hline 2 & 0 & 150 & 3 & 2 & 0 & 0 & 1 & 0 & 1 & 1 & 0 & 0 & 0 \\
\hline 2 & 0 & 200 & 4 & 1 & 0 & 0 & 0 & 0 & 1 & 0 & 0 & 0 & 0 \\
\hline 2 & 0 & 4000 & 3 & 1 & 0 & 0 & 0 & 0 & 1 & 0 & 1 & 0 & 0 \\
\hline 2 & 1 & 600 & 2 & 3 & 0 & 0 & 1 & 1 & 1 & 0 & 0 & 0 & 1 \\
\hline 2 & 1 & 0 & 2 & 4 & 0 & 1 & 1 & 0 & 1 & 1 & 0 & 0 & 0 \\
\hline 2 & 1 & 0 & 1 & 3 & 0 & 0 & 1 & 1 & 0 & 0 & 0 & 0 & 1 \\
\hline 2 & 1 & 0 & 2 & 4 & 0 & 1 & 1 & 0 & 0 & 0 & 0 & 0 & 1 \\
\hline 2 & 1 & 125 & 2 & 4 & 0 & 1 & 1 & 1 & 1 & 0 & 0 & 1 & 0 \\
\hline 2 & 1 & 0 & 1 & 3 & 0 & 0 & 1 & 1 & 1 & 0 & 0 & 0 & 1 \\
\hline
\end{tabular}


Table F.1

\begin{tabular}{|c|c|c|c|c|c|c|c|c|c|c|c|c|c|}
\hline PROV & BMP & RENT & FEXP & FIN & PLANDC & LABI & CDT & GFA & FLC & LEDUH & LEDUCH & LEDUC & LEDUU \\
\hline 2 & 1 & 0 & 2 & 4 & 0 & 1 & 1 & 1 & 1 & 0 & 0 & 1 & 0 \\
\hline 2 & 1 & 0 & 1 & 3 & 0 & 1 & 1 & 0 & 0 & 0 & 0 & 0 & 1 \\
\hline 2 & 0 & 100 & 3 & 1 & 0 & 0 & 0 & 0 & 0 & 0 & 1 & 0 & 0 \\
\hline 2 & 0 & 1050 & 3 & 4 & 1 & 0 & 0 & 0 & 1 & 0 & 1 & 0 & 0 \\
\hline 2 & 1 & 10 & 2 & 3 & 0 & 1 & 1 & 0 & 1 & 1 & 0 & 0 & 0 \\
\hline 2 & 1 & 0 & 1 & 3 & 0 & 0 & 1 & 0 & 0 & 0 & 1 & 0 & 0 \\
\hline 2 & 1 & 0 & 1 & 4 & 0 & 1 & 0 & 1 & 1 & 1 & 0 & 0 & 0 \\
\hline 2 & 0 & 600 & 4 & 2 & 0 & 0 & 0 & 0 & 1 & 1 & 0 & 0 & 0 \\
\hline 2 & 1 & 0 & 3 & 3 & 0 & 1 & 1 & 1 & 1 & 0 & 1 & 0 & 0 \\
\hline 2 & 0 & 300 & 4 & 4 & 0 & 0 & 1 & 0 & 0 & 0 & 1 & 0 & 0 \\
\hline 2 & 0 & 580 & 4 & 4 & 0 & 0 & 0 & 0 & 0 & 0 & 0 & 0 & 1 \\
\hline 3 & 0 & 5300 & 4 & 1 & 0 & 0 & 0 & 0 & 1 & 0 & 1 & 0 & 0 \\
\hline 3 & 1 & 0 & 1 & 3 & 0 & 0 & 1 & 0 & 1 & 0 & 0 & 0 & 1 \\
\hline 3 & 0 & 0 & 2 & 3 & 0 & 1 & 0 & 0 & 0 & 1 & 0 & 0 & 0 \\
\hline 3 & 0 & 0 & 2 & 4 & 1 & 1 & 1 & 0 & 0 & 0 & 0 & 0 & 1 \\
\hline 3 & 1 & 0 & 1 & 4 & 1 & 1 & 1 & 0 & 1 & 0 & 0 & 0 & 1 \\
\hline 3 & 0 & 500 & 4 & 1 & 0 & 0 & 0 & 0 & 1 & 1 & 0 & 0 & 0 \\
\hline 3 & 1 & 400 & 3 & 1 & 0 & 0 & 1 & 0 & 1 & 0 & 0 & 1 & 0 \\
\hline 3 & 0 & 360 & 1 & 3 & 0 & 1 & 0 & 0 & 0 & 1 & 0 & 0 & 0 \\
\hline 3 & 1 & 0 & 2 & 3 & 0 & 1 & 1 & 0 & 0 & 0 & 0 & 1 & 0 \\
\hline 3 & 0 & 2500 & 4 & 1 & 0 & 0 & 0 & 0 & 1 & 0 & 1 & 0 & 0 \\
\hline 3 & 1 & 0 & 2 & 4 & 1 & 1 & 1 & 1 & 1 & 0 & 0 & 0 & 1 \\
\hline 3 & 1 & 0 & 1 & 4 & 1 & 1 & 1 & 0 & 1 & 0 & 0 & 1 & 0 \\
\hline 3 & 1 & 0 & 2 & 3 & 0 & 1 & 1 & 0 & 1 & 0 & 0 & 0 & 1 \\
\hline 3 & 1 & 0 & 2 & 4 & 0 & 0 & 1 & 1 & 0 & 0 & 0 & 0 & 1 \\
\hline 3 & 1 & 0 & 2 & 3 & 0 & 1 & 1 & 0 & 0 & 0 & 0 & 0 & 1 \\
\hline 3 & 1 & 0 & 1 & 4 & 0 & 1 & 1 & 0 & 0 & 0 & 0 & 1 & 0 \\
\hline 3 & 1 & 0 & 1 & 3 & 0 & 0 & 1 & 1 & 1 & 0 & 0 & 0 & 1 \\
\hline 3 & 0 & 1500 & 3 & 1 & 0 & 0 & 0 & 0 & 1 & 0 & 1 & 0 & 0 \\
\hline 3 & 0 & 1000 & 3 & 1 & 1 & 0 & 0 & 0 & 0 & 0 & 1 & 0 & 0 \\
\hline 3 & 1 & 0 & 2 & 3 & 1 & 1 & 1 & 0 & 0 & 0 & 0 & 1 & 0 \\
\hline
\end{tabular}


Table F.1

\begin{tabular}{|c|c|c|c|c|c|c|c|c|c|c|c|c|c|}
\hline PROV & BMP & RENT & FEXP & FIN & PLANDC & LABI & CDT & GFA & FLC & LEDUH & LEDUCH & LEDUC & LEDUU \\
\hline 3 & 1 & 0 & 1 & 4 & 0 & 1 & 1 & 1 & 0 & 0 & 0 & 0 & 1 \\
\hline 3 & 1 & 0 & 2 & 3 & 0 & 0 & 1 & 1 & 0 & 0 & 0 & 1 & 0 \\
\hline 3 & 1 & 0 & 1 & 4 & 0 & 1 & 1 & 1 & 1 & 0 & 0 & 1 & 0 \\
\hline 3 & 0 & 900 & 4 & 2 & 0 & 0 & 1 & 0 & 0 & 0 & 1 & 0 & 0 \\
\hline 3 & 0 & 3500 & 4 & 2 & 0 & 0 & 1 & 0 & 0 & 1 & 0 & 0 & 0 \\
\hline 4 & 0 & 0 & 1 & 4 & 0 & 1 & 1 & 1 & 1 & 0 & 1 & 0 & 0 \\
\hline 4 & 0 & 100 & 4 & 4 & 0 & 0 & 0 & 0 & 1 & 0 & 0 & 1 & 0 \\
\hline 4 & 0 & 260 & 3 & 4 & 0 & 0 & 0 & 0 & 0 & 0 & 0 & 0 & 1 \\
\hline 4 & 0 & 0 & 3 & 4 & 0 & 0 & 0 & 0 & 1 & 0 & 1 & 0 & 0 \\
\hline 4 & 1 & 0 & 4 & 4 & 0 & 1 & 1 & 0 & 1 & 0 & 0 & 0 & 1 \\
\hline 4 & 1 & 0 & 4 & 4 & 0 & 0 & 0 & 0 & 1 & 0 & 0 & 0 & 1 \\
\hline 4 & 0 & 0 & 4 & 1 & 1 & 1 & 1 & 1 & 0 & 0 & 0 & 0 & 1 \\
\hline 4 & 0 & 140 & 1 & 4 & 0 & 0 & 0 & 0 & 1 & 1 & 0 & 0 & 0 \\
\hline 4 & 1 & 100 & 4 & 4 & 0 & 0 & 1 & 0 & 1 & 0 & 0 & 0 & 1 \\
\hline 4 & 0 & 0 & 3 & 4 & 0 & 0 & 0 & 0 & 1 & 1 & 0 & 0 & 0 \\
\hline 4 & 1 & 0 & 4 & 4 & 0 & 1 & 1 & 0 & 1 & 0 & 0 & 0 & 1 \\
\hline 4 & 0 & 0 & 3 & 4 & 0 & 0 & 1 & 1 & 0 & 0 & 0 & 0 & 1 \\
\hline 4 & 0 & 0 & 3 & 1 & 0 & 0 & 0 & 0 & 0 & 0 & 0 & 0 & 1 \\
\hline 4 & 1 & 0 & 3 & 1 & 0 & 0 & 0 & 0 & 1 & 0 & 0 & 0 & 1 \\
\hline 4 & 0 & 258 & 4 & 4 & 0 & 1 & 1 & 1 & 1 & 0 & 0 & 0 & 0 \\
\hline 4 & 1 & 0 & 2 & 4 & 0 & 1 & 1 & 1 & 0 & 0 & 0 & 0 & 1 \\
\hline 4 & 1 & 0 & 1 & 4 & 0 & 1 & 1 & 0 & 1 & 0 & 0 & 0 & 1 \\
\hline 4 & 1 & 0 & 1 & 4 & 0 & 1 & 1 & 0 & 1 & 0 & 0 & 1 & 0 \\
\hline 4 & 1 & 0 & 3 & 3 & 0 & 1 & 1 & 0 & 0 & 0 & 0 & 0 & 1 \\
\hline 4 & 1 & 0 & 2 & 3 & 0 & 1 & 1 & 0 & 1 & 0 & 0 & 0 & 1 \\
\hline 4 & 1 & 0 & 1 & 3 & 0 & 1 & 1 & 1 & 0 & 0 & 0 & 1 & 0 \\
\hline 4 & 1 & 0 & 2 & 4 & 0 & 1 & 1 & 1 & 1 & 0 & 0 & 0 & 1 \\
\hline 4 & 1 & 0 & 2 & 3 & 0 & 1 & 1 & 1 & 1 & 0 & 0 & 0 & 1 \\
\hline 4 & 0 & 0 & 1 & 2 & 0 & 1 & 1 & 0 & 1 & 0 & 0 & 1 & 0 \\
\hline 4 & 1 & 0 & 2 & 3 & 0 & 1 & 1 & 0 & 1 & 0 & 0 & 1 & 0 \\
\hline 4 & 1 & 0 & 1 & 4 & 0 & 1 & 1 & 0 & 1 & 0 & 0 & 0 & 1 \\
\hline
\end{tabular}


Table F.1

\begin{tabular}{|c|c|c|c|c|c|c|c|c|c|c|c|c|c|}
\hline PROV & BMP & RENT & FEXP & FIN & PLANDC & LABI & CDT & GFA & FLC & LEDUH & LEDUCH & LEDUC & LEDUU \\
\hline 4 & 1 & 5 & 2 & 3 & 0 & 1 & 1 & 0 & 1 & 0 & 0 & 1 & 0 \\
\hline 4 & 1 & 0 & 1 & 3 & 0 & 1 & 1 & 0 & 1 & 0 & 0 & 0 & 1 \\
\hline 4 & 0 & 0 & 3 & 2 & 0 & 1 & 0 & 0 & 1 & 0 & 1 & 0 & 0 \\
\hline 4 & 1 & 0 & 2 & 4 & 0 & 1 & 1 & 0 & 1 & 0 & 0 & 1 & 0 \\
\hline 4 & 1 & 0 & 1 & 3 & 0 & 0 & 1 & 0 & 1 & 0 & 0 & 1 & 0 \\
\hline 4 & 1 & 0 & 2 & 4 & 0 & 0 & 1 & 0 & 1 & 0 & 0 & 0 & 1 \\
\hline 4 & 0 & 600 & 4 & 2 & 0 & 0 & 1 & 0 & 1 & 1 & 0 & 0 & 0 \\
\hline 4 & 1 & 0 & 2 & 3 & 0 & 0 & 1 & 0 & 1 & 0 & 1 & 0 & 0 \\
\hline 4 & 0 & 0 & 1 & 4 & 0 & 1 & 1 & 0 & 1 & 0 & 0 & 1 & 0 \\
\hline 4 & 1 & 0 & 2 & 3 & 1 & 1 & 1 & 0 & 1 & 0 & 0 & 0 & 1 \\
\hline 4 & 0 & 0 & 1 & 4 & 1 & 1 & 1 & 0 & 1 & 0 & 0 & 1 & 0 \\
\hline 4 & 0 & 680 & 4 & 1 & 0 & 0 & 1 & 0 & 1 & 0 & 0 & 0 & 0 \\
\hline 4 & 1 & 220 & 4 & 3 & 0 & 1 & 1 & 1 & 1 & 0 & 1 & 0 & 0 \\
\hline 4 & 0 & 400 & 4 & 1 & 1 & 1 & 1 & 1 & 1 & 1 & 0 & 0 & 0 \\
\hline 4 & 1 & 0 & 2 & 3 & 0 & 0 & 0 & 0 & 1 & 0 & 1 & 0 & 0 \\
\hline 4 & 1 & 0 & 4 & 4 & 0 & 1 & 0 & 1 & 1 & 0 & 0 & 0 & 1 \\
\hline 4 & 0 & 200 & 4 & 4 & 0 & 0 & 1 & 0 & 1 & 0 & 0 & 0 & 1 \\
\hline 5 & 1 & 0 & 1 & 3 & 0 & 1 & 0 & 0 & 1 & 0 & 0 & 0 & 1 \\
\hline 5 & 0 & 1000 & 3 & 2 & 0 & 0 & 0 & 0 & 1 & 1 & 0 & 0 & 0 \\
\hline 5 & 0 & 1200 & 3 & 1 & 0 & 0 & 1 & 0 & 1 & 1 & 0 & 0 & 0 \\
\hline 5 & 0 & 5000 & 4 & 2 & 0 & 0 & 0 & 0 & 0 & 1 & 0 & 0 & 0 \\
\hline 5 & 0 & 2340 & 4 & 2 & 1 & 0 & 0 & 0 & 0 & 1 & 0 & 0 & 0 \\
\hline 5 & 0 & 345 & 4 & 1 & 0 & 0 & 1 & 0 & 0 & 0 & 1 & 0 & 0 \\
\hline 5 & 0 & 1500 & 2 & 3 & 0 & 0 & 0 & 0 & 1 & 1 & 0 & 0 & 0 \\
\hline 5 & 1 & 0 & 2 & 3 & 0 & 1 & 1 & 0 & 1 & 0 & 0 & 1 & 0 \\
\hline 5 & 1 & 0 & 2 & 3 & 1 & 1 & 1 & 0 & 1 & 0 & 0 & 0 & 1 \\
\hline 5 & 1 & 0 & 2 & 4 & 0 & 1 & 1 & 0 & 1 & 0 & 0 & 1 & 0 \\
\hline 5 & 1 & 0 & 2 & 3 & 0 & 1 & 0 & 0 & 1 & 0 & 0 & 1 & 0 \\
\hline 5 & 1 & 80 & 1 & 3 & 0 & 1 & 1 & 0 & 1 & 0 & 0 & 0 & 1 \\
\hline 5 & 1 & 0 & 1 & 4 & 0 & 1 & 1 & 0 & 1 & 1 & 0 & 0 & 0 \\
\hline 5 & 0 & 1600 & 4 & 1 & 0 & 1 & 0 & 0 & 0 & 0 & 1 & 0 & 0 \\
\hline
\end{tabular}


Table F.1

\begin{tabular}{|c|c|c|c|c|c|c|c|c|c|c|c|c|c|}
\hline PROV & BMP & RENT & FEXP & FIN & PLANDC & LABI & CDT & GFA & FLC & LEDUH & LEDUCH & LEDUC & LEDUU \\
\hline 5 & 0 & 5900 & 3 & 2 & 0 & 1 & 0 & 0 & 1 & 1 & 0 & 0 & 0 \\
\hline 5 & 0 & 1400 & 4 & 1 & 0 & 0 & 0 & 0 & 1 & 0 & 1 & 0 & 0 \\
\hline 5 & 0 & 350 & 3 & 1 & 0 & 0 & 0 & 0 & 0 & 0 & 0 & 0 & 1 \\
\hline 5 & 1 & 0 & 2 & 3 & 0 & 1 & 1 & 0 & 1 & 0 & 0 & 1 & 0 \\
\hline 5 & 0 & 1555 & 4 & 1 & 0 & 0 & 0 & 0 & 1 & 0 & 1 & 0 & 0 \\
\hline 5 & 1 & 0 & 3 & 3 & 0 & 0 & 1 & 1 & 1 & 0 & 0 & 1 & 0 \\
\hline 5 & 1 & 0 & 2 & 4 & 0 & 1 & 0 & 0 & 1 & 0 & 0 & 0 & 1 \\
\hline 5 & 0 & 1500 & 2 & 3 & 0 & 1 & 0 & 0 & 1 & 1 & 0 & 0 & 0 \\
\hline 5 & 0 & 250 & 3 & 3 & 0 & 0 & 0 & 0 & 1 & 0 & 0 & 0 & 1 \\
\hline 5 & 1 & 0 & 4 & 1 & 0 & 1 & 1 & 1 & 1 & 0 & 0 & 1 & 0 \\
\hline 5 & 0 & 0 & 3 & 4 & 0 & 0 & 0 & 0 & 1 & 0 & 0 & 0 & 1 \\
\hline 6 & 1 & 420 & 4 & 3 & 0 & 1 & 1 & 0 & 1 & 0 & 0 & 0 & 1 \\
\hline 6 & 1 & 0 & 4 & 4 & 0 & 0 & 1 & 0 & 1 & 0 & 0 & 0 & 1 \\
\hline 6 & 1 & 0 & 2 & 3 & 1 & 1 & 1 & 1 & 1 & 0 & 0 & 1 & 0 \\
\hline 6 & 1 & 0 & 1 & 4 & 0 & 1 & 1 & 0 & 1 & 0 & 0 & 0 & 1 \\
\hline 6 & 0 & 4 & 2 & 2 & 0 & 1 & 0 & 0 & 0 & 1 & 0 & 0 & 0 \\
\hline 6 & 1 & 0 & 1 & 3 & 0 & 1 & 1 & 0 & 0 & 0 & 1 & 0 & 0 \\
\hline 6 & 1 & 30 & 2 & 3 & 0 & 1 & 1 & 1 & 1 & 0 & 0 & 1 & 0 \\
\hline 6 & 1 & 60 & 2 & 4 & 1 & 0 & 1 & 0 & 1 & 0 & 0 & 1 & 0 \\
\hline 6 & 1 & 0 & 1 & 4 & 0 & 1 & 1 & 0 & 1 & 0 & 0 & 0 & 1 \\
\hline 6 & 1 & 0 & 2 & 4 & 0 & 1 & 1 & 0 & 1 & 0 & 0 & 0 & 1 \\
\hline 6 & 1 & 0 & 1 & 3 & 0 & 1 & 1 & 1 & 0 & 0 & 0 & 0 & 1 \\
\hline 6 & 1 & 0 & 3 & 3 & 1 & 1 & 1 & 0 & 0 & 0 & 0 & 1 & 0 \\
\hline 6 & 0 & 1000 & 3 & 1 & 0 & 0 & 0 & 0 & 0 & 0 & 1 & 0 & 0 \\
\hline 6 & 0 & 215 & 4 & 2 & 0 & 0 & 0 & 0 & 0 & 1 & 0 & 0 & 0 \\
\hline 6 & 1 & 0 & 3 & 4 & 0 & 1 & 1 & 1 & 1 & 0 & 0 & 1 & 0 \\
\hline 6 & 1 & 0 & 2 & 3 & 0 & 1 & 1 & 0 & 1 & 0 & 0 & 1 & 0 \\
\hline 6 & 1 & 0 & 1 & 4 & 0 & 1 & 1 & 0 & 1 & 0 & 0 & 1 & 0 \\
\hline 6 & 1 & 0 & 2 & 3 & 0 & 1 & 1 & 1 & 0 & 0 & 1 & 0 & 0 \\
\hline 6 & 1 & 0 & 3 & 4 & 0 & 1 & 1 & 0 & 1 & 0 & 0 & 1 & 0 \\
\hline 6 & 1 & 0 & 2 & 2 & 1 & 1 & 1 & 0 & 1 & 0 & 1 & 0 & 0 \\
\hline
\end{tabular}


Table F.1

\begin{tabular}{|c|c|c|c|c|c|c|c|c|c|c|c|c|c|}
\hline PROV & BMP & RENT & FEXP & FIN & PLANDC & LABI & CDT & GFA & FLC & LEDUH & LEDUCH & LEDUC & LEDUU \\
\hline 6 & 1 & 0 & 1 & 3 & 0 & 1 & 1 & 0 & 1 & 0 & 1 & 0 & 0 \\
\hline 6 & 0 & 100 & 3 & 1 & 0 & 0 & 0 & 0 & 1 & 1 & 0 & 0 & 0 \\
\hline 6 & 1 & 0 & 2 & 3 & 0 & 0 & 1 & 0 & 1 & 0 & 0 & 0 & 1 \\
\hline 6 & 0 & 1150 & 3 & 2 & 0 & 1 & 0 & 1 & 1 & 1 & 0 & 0 & 0 \\
\hline 6 & 0 & 5520 & 3 & 2 & 0 & 0 & 0 & 1 & 1 & 1 & 0 & 0 & 0 \\
\hline 6 & 1 & 0 & 1 & 3 & 0 & 1 & 1 & 1 & 1 & 0 & 0 & 1 & 0 \\
\hline 6 & 1 & 0 & 2 & 3 & 0 & 1 & 1 & 0 & 1 & 0 & 0 & 0 & 1 \\
\hline 6 & 1 & 0 & 1 & 4 & 0 & 1 & 1 & 0 & 1 & 0 & 0 & 0 & 1 \\
\hline 6 & 1 & 0 & 2 & 4 & 0 & 1 & 1 & 1 & 1 & 0 & 0 & 1 & 0 \\
\hline 6 & 0 & 1000 & 3 & 2 & 0 & 0 & 0 & 0 & 1 & 1 & 0 & 0 & 0 \\
\hline 6 & 1 & 0 & 1 & 3 & 1 & 1 & 1 & 0 & 1 & 0 & 1 & 0 & 0 \\
\hline 7 & 0 & 5400 & 4 & 3 & 1 & 0 & 0 & 0 & 0 & 1 & 0 & 0 & 0 \\
\hline 7 & 1 & 0 & 4 & 2 & 0 & 0 & 0 & 0 & 0 & 0 & 0 & 1 & 0 \\
\hline 7 & 0 & 15000 & 3 & 2 & 0 & 1 & 0 & 0 & 0 & 1 & 0 & 0 & 0 \\
\hline 7 & 1 & 0 & 3 & 2 & 0 & 0 & 1 & 0 & 1 & 0 & 0 & 0 & 1 \\
\hline 7 & 0 & 0 & 4 & 3 & 1 & 0 & 0 & 0 & 1 & 1 & 0 & 0 & 0 \\
\hline 7 & 0 & 0 & 3 & 4 & 0 & 0 & 1 & 0 & 1 & 1 & 0 & 0 & 0 \\
\hline 7 & 1 & 0 & 2 & 4 & 0 & 1 & 1 & 0 & 1 & 0 & 0 & 0 & 1 \\
\hline 7 & 0 & 0 & 2 & 3 & 0 & 0 & 1 & 0 & 0 & 1 & 0 & 0 & 0 \\
\hline 7 & 0 & 3000 & 2 & 4 & 0 & 0 & 0 & 0 & 1 & 0 & 1 & 0 & 0 \\
\hline 7 & 0 & 1100 & 4 & 1 & 0 & 0 & 1 & 1 & 1 & 0 & 0 & 0 & 0 \\
\hline 7 & 0 & 170 & 4 & 3 & 0 & 0 & 1 & 1 & 0 & 0 & 1 & 0 & 0 \\
\hline 7 & 1 & 0 & 4 & 2 & 0 & 0 & 0 & 0 & 1 & 0 & 0 & 0 & 1 \\
\hline 7 & 1 & 0 & 4 & 1 & 0 & 0 & 0 & 1 & 1 & 0 & 1 & 0 & 0 \\
\hline 7 & 0 & 100 & 3 & 2 & 0 & 0 & 0 & 0 & 1 & 0 & 1 & 0 & 0 \\
\hline 7 & 0 & 4000 & 3 & 2 & 0 & 0 & 0 & 0 & 0 & 1 & 0 & 0 & 0 \\
\hline 7 & 0 & 500 & 2 & 1 & 0 & 0 & 0 & 0 & 0 & 1 & 0 & 0 & 0 \\
\hline 7 & 0 & 710 & 3 & 3 & 0 & 0 & 0 & 0 & 1 & 1 & 0 & 0 & 0 \\
\hline 7 & 0 & 1850 & 4 & 1 & 0 & 0 & 0 & 0 & 0 & 0 & 1 & 0 & 0 \\
\hline 7 & 1 & 0 & 2 & 4 & 0 & 1 & 1 & 1 & 1 & 0 & 0 & 1 & 0 \\
\hline 7 & 0 & 0 & 3 & 1 & 0 & 0 & 0 & 0 & 1 & 1 & 0 & 0 & 0 \\
\hline
\end{tabular}


Table F.1

\begin{tabular}{|c|c|c|c|c|c|c|c|c|c|c|c|c|c|}
\hline PROV & BMP & RENT & FEXP & FIN & PLANDC & LABI & CDT & GFA & FLC & LEDUH & LEDUCH & LEDUC & LEDUU \\
\hline 7 & 0 & 410 & 4 & 2 & 0 & 0 & 0 & 0 & 0 & 0 & 1 & 0 & 0 \\
\hline 7 & 1 & 1 & 3 & 2 & 0 & 0 & 0 & 1 & 1 & 0 & 0 & 1 & 0 \\
\hline 7 & 0 & 2500 & 4 & 3 & 0 & 0 & 0 & 0 & 1 & 0 & 0 & 1 & 0 \\
\hline 7 & 0 & 800 & 3 & 2 & 0 & 1 & 0 & 0 & 1 & 1 & 0 & 0 & 0 \\
\hline 7 & 1 & 0 & 2 & 4 & 0 & 1 & 1 & 1 & 1 & 0 & 0 & 0 & 1 \\
\hline 7 & 1 & 0 & 2 & 3 & 0 & 1 & 1 & 0 & 1 & 0 & 0 & 0 & 1 \\
\hline 7 & 1 & 120 & 1 & 4 & 0 & 1 & 1 & 0 & 0 & 0 & 1 & 0 & 0 \\
\hline 7 & 1 & 0 & 2 & 4 & 0 & 1 & 1 & 0 & 1 & 0 & 0 & 1 & 0 \\
\hline 7 & 0 & 3600 & 3 & 2 & 0 & 0 & 0 & 0 & 0 & 0 & 0 & 1 & 0 \\
\hline 7 & 1 & 0 & 2 & 3 & 0 & 1 & 1 & 0 & 1 & 0 & 1 & 0 & 0 \\
\hline 7 & 0 & 0 & 3 & 4 & 0 & 1 & 1 & 0 & 1 & 0 & 0 & 0 & 1 \\
\hline 7 & 1 & 0 & 4 & 4 & 0 & 1 & 1 & 1 & 0 & 0 & 0 & 0 & 1 \\
\hline 7 & 1 & 0 & 4 & 4 & 0 & 1 & 1 & 1 & 0 & 0 & 1 & 0 & 0 \\
\hline 7 & 1 & 0 & 4 & 4 & 0 & 0 & 1 & 1 & 1 & 0 & 0 & 0 & 1 \\
\hline 7 & 1 & 605 & 4 & 2 & 0 & 1 & 1 & 1 & 1 & 0 & 0 & 0 & 1 \\
\hline 7 & 1 & 0 & 4 & 4 & 0 & 0 & 0 & 1 & 1 & 0 & 1 & 0 & 0 \\
\hline 7 & 1 & 0 & 3 & 2 & 0 & 1 & 1 & 1 & 1 & 0 & 0 & 0 & 1 \\
\hline 7 & 1 & 0 & 1 & 2 & 0 & 1 & 1 & 1 & 0 & 0 & 0 & 0 & 1 \\
\hline 7 & 1 & 0 & 4 & 4 & 0 & 0 & 1 & 1 & 0 & 0 & 0 & 0 & 1 \\
\hline 7 & 0 & 0 & 3 & 1 & 0 & 0 & 0 & 0 & 1 & 0 & 1 & 0 & 0 \\
\hline 7 & 1 & 0 & 4 & 4 & 0 & 1 & 1 & 1 & 1 & 0 & 1 & 0 & 0 \\
\hline 7 & 1 & 80 & 4 & 1 & 0 & 1 & 1 & 1 & 1 & 0 & 0 & 0 & 1 \\
\hline 7 & 0 & 0 & 3 & 3 & 0 & 0 & 0 & 0 & 1 & 1 & 0 & 0 & 0 \\
\hline 8 & 1 & 0 & 4 & 4 & 0 & 0 & 1 & 0 & 1 & 0 & 0 & 0 & 1 \\
\hline 8 & 1 & 0 & 2 & 3 & 0 & 1 & 1 & 0 & 1 & 0 & 0 & 1 & 0 \\
\hline 8 & 1 & 0 & 1 & 2 & 0 & 1 & 1 & 0 & 1 & 0 & 0 & 0 & 1 \\
\hline 8 & 0 & 320 & 3 & 2 & 0 & 0 & 0 & 0 & 0 & 0 & 1 & 0 & 0 \\
\hline 8 & 1 & 1100 & 4 & 1 & 1 & 0 & 0 & 0 & 0 & 0 & 1 & 0 & 0 \\
\hline 8 & 0 & 2990 & 3 & 1 & 0 & 1 & 0 & 1 & 1 & 1 & 0 & 0 & 0 \\
\hline 8 & 0 & 948 & 4 & 2 & 0 & 0 & 0 & 0 & 1 & 1 & 0 & 0 & 0 \\
\hline 8 & 1 & 328 & 3 & 2 & 0 & 0 & 0 & 0 & 1 & 1 & 0 & 0 & 0 \\
\hline
\end{tabular}


Table F.1

\begin{tabular}{|c|c|c|c|c|c|c|c|c|c|c|c|c|c|}
\hline PROV & BMP & RENT & FEXP & FIN & PLANDC & LABI & CDT & GFA & FLC & LEDUH & LEDUCH & LEDUC & LEDUU \\
\hline 8 & 0 & 1840 & 4 & 3 & 0 & 1 & 0 & 1 & 1 & 0 & 1 & 0 & 0 \\
\hline 8 & 1 & 0 & 1 & 4 & 0 & 1 & 1 & 0 & 1 & 0 & 0 & 1 & 0 \\
\hline 8 & 1 & 0 & 2 & 4 & 0 & 1 & 1 & 1 & 1 & 0 & 0 & 0 & 1 \\
\hline 8 & 0 & 0 & 2 & 3 & 0 & 1 & 1 & 0 & 0 & 0 & 0 & 0 & 1 \\
\hline 8 & 0 & 0 & 1 & 3 & 0 & 1 & 1 & 1 & 1 & 0 & 0 & 0 & 1 \\
\hline 8 & 1 & 0 & 1 & 3 & 0 & 1 & 1 & 1 & 1 & 0 & 0 & 0 & 1 \\
\hline 8 & 1 & 300 & 2 & 2 & 0 & 1 & 1 & 1 & 1 & 0 & 0 & 0 & 1 \\
\hline 8 & 1 & 0 & 2 & 4 & 0 & 1 & 1 & 0 & 1 & 0 & 0 & 1 & 0 \\
\hline 8 & 1 & 0 & 1 & 3 & 0 & 1 & 1 & 0 & 1 & 0 & 0 & 0 & 1 \\
\hline 8 & 1 & 0 & 2 & 3 & 0 & 1 & 1 & 0 & 1 & 0 & 0 & 1 & 0 \\
\hline 8 & 1 & 200 & 1 & 4 & 0 & 1 & 1 & 0 & 0 & 0 & 0 & 1 & 0 \\
\hline 8 & 1 & 0 & 2 & 2 & 0 & 1 & 1 & 0 & 0 & 0 & 0 & 0 & 1 \\
\hline 8 & 1 & 0 & 2 & 4 & 0 & 1 & 1 & 1 & 1 & 0 & 0 & 0 & 1 \\
\hline 8 & 1 & 0 & 1 & 4 & 0 & 1 & 1 & 0 & 1 & 0 & 0 & 0 & 1 \\
\hline 8 & 1 & 0 & 2 & 3 & 0 & 1 & 1 & 0 & 1 & 0 & 0 & 0 & 1 \\
\hline 8 & 0 & 0 & 3 & 2 & 0 & 0 & 0 & 1 & 1 & 0 & 0 & 1 & 0 \\
\hline 8 & 0 & 600 & 3 & 1 & 0 & 0 & 0 & 1 & 1 & 0 & 0 & 1 & 0 \\
\hline 8 & 1 & 0 & 1 & 4 & 0 & 1 & 1 & 1 & 1 & 0 & 0 & 1 & 0 \\
\hline 8 & 1 & 0 & 2 & 3 & 0 & 1 & 1 & 0 & 1 & 0 & 0 & 0 & 1 \\
\hline 8 & 0 & 1500 & 3 & 1 & 1 & 0 & 0 & 0 & 0 & 0 & 0 & 0 & 0 \\
\hline 8 & 0 & 2520 & 4 & 2 & 0 & 0 & 0 & 0 & 0 & 0 & 1 & 0 & 0 \\
\hline 8 & 1 & 0 & 1 & 4 & 0 & 1 & 1 & 0 & 0 & 0 & 0 & 1 & 0 \\
\hline 8 & 1 & 0 & 2 & 3 & 0 & 1 & 1 & 0 & 0 & 0 & 0 & 0 & 1 \\
\hline 8 & 1 & 0 & 2 & 3 & 0 & 1 & 1 & 1 & 0 & 0 & 0 & 0 & 1 \\
\hline 8 & 0 & 500 & 3 & 2 & 1 & 0 & 0 & 1 & 0 & 1 & 0 & 0 & 0 \\
\hline 8 & 0 & 1800 & 3 & 1 & 0 & 0 & 0 & 0 & 0 & 0 & 1 & 0 & 0 \\
\hline 9 & 1 & 1300 & 1 & 4 & 0 & 0 & 0 & 1 & 1 & 0 & 0 & 0 & 1 \\
\hline 9 & 1 & 6 & 2 & 4 & 0 & 1 & 1 & 0 & 1 & 0 & 0 & 1 & 0 \\
\hline 9 & 1 & 0 & 1 & 4 & 0 & 1 & 1 & 0 & 1 & 0 & 0 & 0 & 1 \\
\hline 9 & 1 & 0 & 2 & 3 & 0 & 1 & 1 & 0 & 1 & 0 & 0 & 0 & 1 \\
\hline 9 & 0 & 18 & 1 & 3 & 0 & 1 & 1 & 0 & 1 & 0 & 1 & 0 & 0 \\
\hline
\end{tabular}


Table F.1

\begin{tabular}{|c|c|c|c|c|c|c|c|c|c|c|c|c|c|}
\hline PROV & BMP & RENT & FEXP & FIN & PLANDC & LABI & CDT & GFA & FLC & LEDUH & LEDUCH & LEDUC & LEDUU \\
\hline 9 & 1 & 0 & 2 & 2 & 0 & 1 & 1 & 1 & 1 & 0 & 0 & 0 & 1 \\
\hline 9 & 1 & 0 & 3 & 1 & 0 & 0 & 0 & 1 & 0 & 0 & 0 & 0 & 1 \\
\hline 9 & 0 & 4500 & 4 & 2 & 0 & 0 & 0 & 1 & 0 & 1 & 0 & 0 & 0 \\
\hline 9 & 0 & 0 & 3 & 3 & 0 & 1 & 0 & 1 & 0 & 1 & 0 & 0 & 0 \\
\hline 9 & 1 & 0 & 4 & 4 & 0 & 1 & 1 & 1 & 0 & 0 & 0 & 1 & 0 \\
\hline 9 & 0 & 234 & 3 & 1 & 0 & 1 & 0 & 0 & 1 & 1 & 0 & 0 & 0 \\
\hline 9 & 0 & 568 & 4 & 2 & 0 & 0 & 0 & 0 & 1 & 0 & 1 & 0 & 0 \\
\hline 9 & 0 & 504 & 3 & 1 & 0 & 0 & 0 & 0 & 0 & 0 & 1 & 0 & 0 \\
\hline 9 & 1 & 0 & 4 & 2 & 0 & 0 & 0 & 0 & 1 & 1 & 0 & 0 & 0 \\
\hline 9 & 0 & 220 & 3 & 3 & 0 & 0 & 0 & 0 & 0 & 0 & 0 & 1 & 0 \\
\hline 9 & 1 & 0 & 1 & 4 & 0 & 1 & 1 & 0 & 1 & 0 & 0 & 0 & 1 \\
\hline 9 & 1 & 2000 & 2 & 3 & 0 & 1 & 1 & 0 & 1 & 0 & 0 & 0 & 1 \\
\hline 9 & 0 & 1700 & 3 & 2 & 0 & 0 & 0 & 0 & 1 & 0 & 0 & 1 & 0 \\
\hline 9 & 1 & 0 & 2 & 3 & 0 & 1 & 1 & 0 & 0 & 0 & 0 & 0 & 1 \\
\hline 9 & 1 & 0 & 1 & 4 & 1 & 1 & 1 & 0 & 0 & 0 & 0 & 0 & 1 \\
\hline 9 & 1 & 0 & 2 & 3 & 1 & 1 & 1 & 0 & 0 & 0 & 0 & 1 & 0 \\
\hline 9 & 1 & 0 & 2 & 2 & 0 & 1 & 1 & 0 & 1 & 0 & 0 & 0 & 1 \\
\hline 9 & 1 & 0 & 1 & 3 & 0 & 1 & 0 & 0 & 1 & 0 & 0 & 0 & 1 \\
\hline 9 & 1 & 0 & 2 & 4 & 0 & 1 & 1 & 0 & 1 & 0 & 0 & 1 & 0 \\
\hline 9 & 1 & 0 & 1 & 3 & 0 & 1 & 1 & 0 & 1 & 0 & 0 & 0 & 1 \\
\hline 9 & 1 & 0 & 2 & 4 & 0 & 1 & 1 & 0 & 1 & 0 & 1 & 0 & 0 \\
\hline 9 & 1 & 0 & 1 & 4 & 0 & 1 & 1 & 0 & 0 & 0 & 1 & 0 & 0 \\
\hline 9 & 1 & 0 & 1 & 4 & 0 & 1 & 1 & 0 & 0 & 0 & 0 & 1 & 0 \\
\hline 9 & 1 & 120 & 2 & 4 & 1 & 1 & 1 & 1 & 1 & 0 & 0 & 1 & 0 \\
\hline 9 & 1 & 0 & 2 & 3 & 0 & 1 & 1 & 1 & 0 & 0 & 0 & 0 & 1 \\
\hline 9 & 0 & 0 & 1 & 3 & 0 & 0 & 0 & 0 & 1 & 0 & 0 & 0 & 0 \\
\hline 9 & 0 & 500 & 3 & 2 & 1 & 0 & 0 & 0 & 1 & 0 & 1 & 0 & 0 \\
\hline 9 & 1 & 30 & 2 & 2 & 0 & 0 & 0 & 0 & 0 & 0 & 1 & 0 & 0 \\
\hline 9 & 1 & 0 & 3 & 3 & 0 & 0 & 1 & 0 & 1 & 0 & 0 & 1 & 0 \\
\hline 9 & 0 & 0 & 4 & 4 & 1 & 0 & 0 & 0 & 0 & 0 & 0 & 0 & 1 \\
\hline
\end{tabular}




\section{Table F. 2}

\begin{tabular}{|c|c|c|c|c|c|c|c|c|c|c|}
\hline PROV & AGE35 & AGE3645 & FEXP5 & FEXP610 & FEXP1120 & FEXP20 & ENTLVST & ENTHORT & ENTFCROP & ENTMXFAR \\
\hline 1 & 0 & 0 & 0 & 0 & 0 & 1 & 1 & 0 & 0 & 0 \\
\hline 1 & 0 & 0 & 0 & 1 & 0 & 0 & 1 & 0 & 0 & 0 \\
\hline 1 & 0 & 0 & 0 & 0 & 0 & 1 & 1 & 0 & 0 & 0 \\
\hline 1 & 0 & 0 & 0 & 1 & 0 & 0 & 1 & 0 & 0 & 0 \\
\hline 1 & 1 & 0 & 0 & 0 & 0 & 1 & 0 & 0 & 1 & 0 \\
\hline 1 & 0 & 1 & 1 & 0 & 0 & 0 & 0 & 0 & 0 & 1 \\
\hline 1 & 1 & 0 & 1 & 0 & 0 & 0 & 0 & 0 & 1 & 0 \\
\hline 1 & 0 & 1 & 0 & 1 & 0 & 0 & 0 & 1 & 0 & 0 \\
\hline 1 & 0 & 0 & 0 & 0 & 1 & 0 & 0 & 0 & 0 & 0 \\
\hline 1 & 1 & 0 & 0 & 0 & 0 & 1 & 1 & 0 & 0 & 0 \\
\hline 1 & 1 & 0 & 0 & 0 & 1 & 0 & 1 & 0 & 0 & 0 \\
\hline 1 & 0 & 0 & 1 & 0 & 0 & 0 & 0 & 1 & 0 & 0 \\
\hline 1 & 0 & 0 & 0 & 0 & 1 & 0 & 0 & 0 & 0 & 0 \\
\hline 1 & 0 & 0 & 0 & 0 & 0 & 1 & 0 & 1 & 0 & 0 \\
\hline 1 & 0 & 1 & 0 & 0 & 0 & 1 & 1 & 0 & 0 & 0 \\
\hline 1 & 0 & 1 & 0 & 0 & 1 & 0 & 0 & 1 & 0 & 0 \\
\hline 1 & 0 & 1 & 0 & 0 & 1 & 0 & 0 & 1 & 0 & 0 \\
\hline 1 & 0 & 1 & 0 & 0 & 1 & 0 & 0 & 0 & 1 & 0 \\
\hline 1 & 0 & 0 & 1 & 0 & 0 & 0 & 1 & 0 & 0 & 0 \\
\hline 1 & 0 & 1 & 0 & 1 & 0 & 0 & 1 & 0 & 0 & 0 \\
\hline 1 & 0 & 0 & 0 & 1 & 0 & 0 & 0 & 1 & 0 & 0 \\
\hline 1 & 0 & 1 & 0 & 0 & 1 & 0 & 0 & 1 & 0 & 0 \\
\hline 1 & 0 & 0 & 0 & 1 & 0 & 0 & 0 & 1 & 0 & 0 \\
\hline 1 & 0 & 1 & 0 & 0 & 1 & 0 & 0 & 0 & 0 & 1 \\
\hline 1 & 0 & 0 & 0 & 0 & 0 & 1 & 0 & 0 & 0 & 1 \\
\hline 1 & 0 & 0 & 0 & 1 & 0 & 0 & 0 & 0 & 0 & 1 \\
\hline 1 & 0 & 0 & 1 & 0 & 0 & 0 & 1 & 0 & 0 & 0 \\
\hline 1 & 0 & 0 & 0 & 1 & 0 & 0 & 1 & 0 & 0 & 0 \\
\hline 1 & 0 & 1 & 0 & 0 & 1 & 0 & 1 & 0 & 0 & 0 \\
\hline 1 & 0 & 1 & 0 & 0 & 0 & 1 & 1 & 0 & 0 & 0 \\
\hline 1 & 0 & 0 & 0 & 0 & 1 & 0 & 0 & 0 & 0 & 1 \\
\hline
\end{tabular}


Table F. 2

\begin{tabular}{|c|c|c|c|c|c|c|c|c|c|c|}
\hline PROV & AGE35 & AGE3645 & FEXP5 & FEXP610 & FEXP1120 & FEXP20 & ENTLVST & ENTHORT & ENTFCROP & ENTMXFAR \\
\hline 1 & 0 & 1 & 0 & 0 & 1 & 0 & 1 & 0 & 0 & 0 \\
\hline 1 & 0 & 0 & 0 & 0 & 1 & 0 & 1 & 0 & 0 & 0 \\
\hline 1 & 0 & 1 & 0 & 1 & 0 & 0 & 0 & 1 & 0 & 0 \\
\hline 1 & 1 & 0 & 1 & 0 & 0 & 0 & 1 & 0 & 0 & 0 \\
\hline 1 & 0 & 0 & 1 & 0 & 0 & 0 & 1 & 0 & 0 & 0 \\
\hline 1 & 0 & 0 & 0 & 0 & 0 & 1 & 0 & 0 & 0 & 1 \\
\hline 2 & 0 & 0 & 1 & 0 & 0 & 0 & 1 & 0 & 0 & 0 \\
\hline 2 & 0 & 1 & 0 & 1 & 0 & 0 & 1 & 0 & 0 & 0 \\
\hline 2 & 0 & 1 & 0 & 1 & 0 & 0 & 1 & 0 & 0 & 0 \\
\hline 2 & 0 & 1 & 1 & 0 & 0 & 0 & 0 & 1 & 0 & 0 \\
\hline 2 & 0 & 1 & 0 & 0 & 0 & 1 & 1 & 0 & 0 & 0 \\
\hline 2 & 0 & 1 & 0 & 0 & 1 & 0 & 0 & 0 & 1 & 0 \\
\hline 2 & 0 & 1 & 0 & 0 & 1 & 0 & 0 & 0 & 1 & 0 \\
\hline 2 & 0 & 1 & 1 & 0 & 0 & 0 & 1 & 0 & 0 & 0 \\
\hline 2 & 0 & 1 & 0 & 1 & 0 & 0 & 0 & 0 & 1 & 0 \\
\hline 2 & 0 & 1 & 0 & 0 & 1 & 0 & 0 & 0 & 0 & 1 \\
\hline 2 & 0 & 0 & 0 & 0 & 0 & 1 & 0 & 0 & 0 & 1 \\
\hline 2 & 0 & 0 & 0 & 1 & 0 & 0 & 1 & 0 & 0 & 0 \\
\hline 2 & 0 & 1 & 0 & 1 & 0 & 0 & 0 & 0 & 1 & 0 \\
\hline 2 & 0 & 1 & 1 & 0 & 0 & 0 & 1 & 0 & 0 & 0 \\
\hline 2 & 0 & 0 & 1 & 0 & 0 & 0 & 1 & 0 & 0 & 0 \\
\hline 2 & 0 & 0 & 0 & 0 & 1 & 0 & 1 & 0 & 0 & 0 \\
\hline 2 & 1 & 0 & 0 & 0 & 0 & 1 & 1 & 0 & 0 & 0 \\
\hline 2 & 0 & 0 & 0 & 0 & 1 & 0 & 0 & 0 & 1 & 0 \\
\hline 2 & 0 & 1 & 0 & 0 & 0 & 1 & 0 & 0 & 1 & 0 \\
\hline 2 & 0 & 0 & 0 & 0 & 1 & 0 & 0 & 0 & 0 & 1 \\
\hline 2 & 0 & 0 & 0 & 1 & 0 & 0 & 0 & 0 & 0 & 1 \\
\hline 2 & 0 & 0 & 0 & 1 & 0 & 0 & 1 & 0 & 0 & 0 \\
\hline 2 & 0 & 0 & 1 & 0 & 0 & 0 & 0 & 1 & 0 & 0 \\
\hline 2 & 1 & 0 & 0 & 0 & 0 & 1 & 1 & 0 & 0 & 0 \\
\hline 2 & 0 & 1 & 0 & 0 & 0 & 1 & 1 & 0 & 0 & 0 \\
\hline
\end{tabular}


Table F. 2

\begin{tabular}{|c|c|c|c|c|c|c|c|c|c|c|}
\hline PROV & AGE35 & AGE3645 & FEXP5 & FEXP610 & FEXP1120 & FEXP20 & ENTLVST & ENTHORT & ENTFCROP & ENTMXFAR \\
\hline 2 & 0 & 1 & 0 & 0 & 1 & 0 & 1 & 0 & 0 & 0 \\
\hline 2 & 0 & 0 & 0 & 1 & 0 & 0 & 0 & 1 & 0 & 0 \\
\hline 2 & 0 & 0 & 1 & 0 & 0 & 0 & 0 & 0 & 1 & 0 \\
\hline 2 & 0 & 1 & 1 & 0 & 0 & 0 & 1 & 0 & 0 & 0 \\
\hline 2 & 0 & 0 & 1 & 0 & 0 & 0 & 0 & 0 & 1 & 0 \\
\hline 2 & 1 & 0 & 0 & 1 & 0 & 0 & 0 & 1 & 0 & 0 \\
\hline 2 & 0 & 0 & 1 & 0 & 0 & 0 & 0 & 1 & 0 & 0 \\
\hline 2 & 1 & 0 & 0 & 1 & 0 & 0 & 0 & 0 & 1 & 0 \\
\hline 2 & 0 & 1 & 0 & 1 & 0 & 0 & 0 & 0 & 0 & 1 \\
\hline 2 & 0 & 1 & 0 & 0 & 1 & 0 & 0 & 0 & 0 & 1 \\
\hline 2 & 0 & 1 & 0 & 1 & 0 & 0 & 0 & 0 & 0 & 1 \\
\hline 2 & 0 & 0 & 0 & 0 & 1 & 0 & 0 & 0 & 1 & 0 \\
\hline 2 & 0 & 0 & 0 & 0 & 1 & 0 & 1 & 0 & 0 & 0 \\
\hline 2 & 1 & 0 & 1 & 0 & 0 & 0 & 1 & 0 & 0 & 0 \\
\hline 2 & 0 & 1 & 0 & 1 & 0 & 0 & 0 & 1 & 0 & 0 \\
\hline 2 & 0 & 0 & 0 & 1 & 0 & 0 & 1 & 0 & 0 & 0 \\
\hline 2 & 0 & 0 & 0 & 0 & 0 & 1 & 1 & 0 & 0 & 0 \\
\hline 2 & 0 & 0 & 0 & 0 & 1 & 0 & 1 & 0 & 0 & 0 \\
\hline 2 & 0 & 0 & 0 & 0 & 1 & 0 & 1 & 0 & 0 & 0 \\
\hline 2 & 0 & 0 & 0 & 0 & 0 & 1 & 0 & 0 & 1 & 0 \\
\hline 2 & 0 & 0 & 0 & 0 & 1 & 0 & 0 & 0 & 1 & 0 \\
\hline 2 & 0 & 0 & 0 & 1 & 0 & 0 & 0 & 0 & 1 & 0 \\
\hline 2 & 0 & 0 & 0 & 1 & 0 & 0 & 1 & 0 & 0 & 0 \\
\hline 2 & 0 & 0 & 1 & 0 & 0 & 0 & 0 & 0 & 1 & 0 \\
\hline 2 & 0 & 0 & 0 & 1 & 0 & 0 & 0 & 0 & 0 & 1 \\
\hline 2 & 0 & 0 & 0 & 1 & 0 & 0 & 0 & 1 & 0 & 0 \\
\hline 2 & 0 & 0 & 1 & 0 & 0 & 0 & 1 & 0 & 0 & 0 \\
\hline 2 & 0 & 0 & 0 & 1 & 0 & 0 & 0 & 0 & 1 & 0 \\
\hline 2 & 0 & 0 & 1 & 0 & 0 & 0 & 1 & 0 & 0 & 0 \\
\hline 2 & 0 & 1 & 0 & 0 & 1 & 0 & 0 & 1 & 0 & 0 \\
\hline 2 & 0 & 0 & 0 & 0 & 1 & 0 & 0 & 0 & 1 & 0 \\
\hline
\end{tabular}


Table F. 2

\begin{tabular}{|c|c|c|c|c|c|c|c|c|c|c|}
\hline PROV & AGE35 & AGE3645 & FEXP5 & FEXP610 & FEXP1120 & FEXP20 & ENTLVST & ENTHORT & ENTFCROP & ENTMXFAR \\
\hline 2 & 0 & 0 & 0 & 1 & 0 & 0 & 0 & 0 & 0 & 1 \\
\hline 2 & 1 & 0 & 1 & 0 & 0 & 0 & 0 & 0 & 1 & 0 \\
\hline 2 & 0 & 0 & 1 & 0 & 0 & 0 & 0 & 1 & 0 & 0 \\
\hline 2 & 1 & 0 & 0 & 0 & 0 & 1 & 1 & 0 & 0 & 0 \\
\hline 2 & 0 & 0 & 0 & 0 & 1 & 0 & 1 & 0 & 0 & 0 \\
\hline 2 & 0 & 0 & 0 & 0 & 0 & 1 & 1 & 0 & 0 & 0 \\
\hline 2 & 0 & 0 & 0 & 0 & 0 & 1 & 0 & 0 & 1 & 0 \\
\hline 3 & 0 & 1 & 0 & 0 & 0 & 1 & 0 & 0 & 1 & 0 \\
\hline 3 & 0 & 0 & 1 & 0 & 0 & 0 & 0 & 1 & 0 & 0 \\
\hline 3 & 0 & 0 & 0 & 1 & 0 & 0 & 1 & 0 & 0 & 0 \\
\hline 3 & 0 & 1 & 0 & 1 & 0 & 0 & 0 & 0 & 1 & 0 \\
\hline 3 & 0 & 0 & 1 & 0 & 0 & 0 & 0 & 0 & 0 & 1 \\
\hline 3 & 0 & 0 & 0 & 0 & 0 & 1 & 0 & 0 & 0 & 1 \\
\hline 3 & 1 & 0 & 0 & 0 & 1 & 0 & 0 & 0 & 0 & 1 \\
\hline 3 & 0 & 0 & 1 & 0 & 0 & 0 & 1 & 0 & 0 & 0 \\
\hline 3 & 1 & 0 & 0 & 1 & 0 & 0 & 1 & 0 & 0 & 0 \\
\hline 3 & 0 & 0 & 0 & 0 & 0 & 1 & 1 & 0 & 0 & 0 \\
\hline 3 & 0 & 1 & 0 & 1 & 0 & 0 & 0 & 1 & 0 & 0 \\
\hline 3 & 0 & 1 & 1 & 0 & 0 & 0 & 0 & 1 & 0 & 0 \\
\hline 3 & 1 & 0 & 0 & 1 & 0 & 0 & 1 & 0 & 0 & 0 \\
\hline 3 & 0 & 0 & 0 & 1 & 0 & 0 & 0 & 1 & 0 & 0 \\
\hline 3 & 0 & 0 & 0 & 1 & 0 & 0 & 0 & 0 & 1 & 0 \\
\hline 3 & 0 & 0 & 1 & 0 & 0 & 0 & 0 & 0 & 1 & 0 \\
\hline 3 & 0 & 0 & 1 & 0 & 0 & 0 & 0 & 1 & 0 & 0 \\
\hline 3 & 0 & 0 & 0 & 0 & 1 & 0 & 1 & 0 & 0 & 0 \\
\hline 3 & 0 & 0 & 0 & 0 & 1 & 0 & 0 & 0 & 0 & 1 \\
\hline 3 & 0 & 0 & 0 & 1 & 0 & 0 & 1 & 0 & 0 & 0 \\
\hline 3 & 0 & 1 & 1 & 0 & 0 & 0 & 0 & 1 & 0 & 0 \\
\hline 3 & 0 & 0 & 0 & 1 & 0 & 0 & 0 & 1 & 0 & 0 \\
\hline 3 & 0 & 0 & 1 & 0 & 0 & 0 & 1 & 0 & 0 & 0 \\
\hline 3 & 0 & 1 & 0 & 0 & 0 & 1 & 1 & 0 & 0 & 0 \\
\hline
\end{tabular}


Table F. 2

\begin{tabular}{|c|c|c|c|c|c|c|c|c|c|c|}
\hline PROV & AGE35 & AGE3645 & FEXP5 & FEXP610 & FEXP1120 & FEXP20 & ENTLVST & ENTHORT & ENTFCROP & ENTMXFAR \\
\hline 3 & 1 & 0 & 0 & 0 & 0 & 1 & 1 & 0 & 0 & 0 \\
\hline 4 & 0 & 0 & 1 & 0 & 0 & 0 & 0 & 0 & 1 & 0 \\
\hline 4 & 0 & 0 & 0 & 0 & 0 & 1 & 0 & 0 & 1 & 0 \\
\hline 4 & 0 & 1 & 0 & 0 & 1 & 0 & 0 & 0 & 1 & 0 \\
\hline 4 & 0 & 0 & 0 & 0 & 1 & 0 & 1 & 0 & 0 & 0 \\
\hline 4 & 1 & 0 & 0 & 0 & 0 & 1 & 1 & 0 & 0 & 0 \\
\hline 4 & 0 & 1 & 0 & 0 & 0 & 1 & 0 & 0 & 0 & 1 \\
\hline 4 & 0 & 0 & 0 & 0 & 0 & 1 & 0 & 0 & 0 & 1 \\
\hline 4 & 0 & 0 & 1 & 0 & 0 & 0 & 0 & 0 & 0 & 1 \\
\hline 4 & 0 & 0 & 0 & 0 & 0 & 1 & 1 & 0 & 0 & 0 \\
\hline 4 & 0 & 0 & 0 & 0 & 1 & 0 & 0 & 1 & 0 & 0 \\
\hline 4 & 0 & 1 & 0 & 0 & 0 & 1 & 0 & 0 & 1 & 0 \\
\hline 4 & 0 & 0 & 0 & 0 & 1 & 0 & 0 & 0 & 0 & 1 \\
\hline 4 & 0 & 0 & 0 & 0 & 1 & 0 & 0 & 1 & 0 & 0 \\
\hline 4 & 1 & 0 & 0 & 0 & 1 & 0 & 0 & 0 & 0 & 1 \\
\hline 4 & 0 & 0 & 0 & 0 & 0 & 1 & 1 & 0 & 0 & 0 \\
\hline 4 & 0 & 1 & 0 & 1 & 0 & 0 & 1 & 0 & 0 & 0 \\
\hline 4 & 0 & 0 & 1 & 0 & 0 & 0 & 0 & 1 & 0 & 0 \\
\hline 4 & 0 & 1 & 1 & 0 & 0 & 0 & 1 & 0 & 0 & 0 \\
\hline 4 & 0 & 0 & 0 & 0 & 1 & 0 & 1 & 0 & 0 & 0 \\
\hline 4 & 1 & 0 & 0 & 1 & 0 & 0 & 0 & 1 & 0 & 0 \\
\hline 4 & 0 & 0 & 1 & 0 & 0 & 0 & 0 & 0 & 0 & 1 \\
\hline 4 & 1 & 0 & 0 & 1 & 0 & 0 & 0 & 1 & 0 & 0 \\
\hline 4 & 0 & 0 & 0 & 1 & 0 & 0 & 0 & 0 & 1 & 0 \\
\hline 4 & 0 & 0 & 1 & 0 & 0 & 0 & 0 & 0 & 1 & 0 \\
\hline 4 & 0 & 0 & 0 & 1 & 0 & 0 & 0 & 0 & 1 & 0 \\
\hline 4 & 0 & 0 & 1 & 0 & 0 & 0 & 0 & 0 & 1 & 0 \\
\hline 4 & 0 & 0 & 0 & 1 & 0 & 0 & 1 & 0 & 0 & 0 \\
\hline 4 & 0 & 0 & 1 & 0 & 0 & 0 & 1 & 0 & 0 & 0 \\
\hline 4 & 1 & 0 & 0 & 0 & 1 & 0 & 0 & 1 & 0 & 0 \\
\hline 4 & 1 & 0 & 0 & 1 & 0 & 0 & 1 & 0 & 0 & 0 \\
\hline
\end{tabular}


Table F. 2

\begin{tabular}{|c|c|c|c|c|c|c|c|c|c|c|}
\hline PROV & AGE35 & AGE3645 & FEXP5 & FEXP610 & FEXP1120 & FEXP20 & ENTLVST & ENTHORT & ENTFCROP & ENTMXFAR \\
\hline 4 & 1 & 0 & 1 & 0 & 0 & 0 & 0 & 0 & 1 & 0 \\
\hline 4 & 1 & 0 & 0 & 1 & 0 & 0 & 0 & 1 & 0 & 0 \\
\hline 4 & 0 & 1 & 0 & 0 & 0 & 1 & 1 & 0 & 0 & 0 \\
\hline 4 & 0 & 0 & 0 & 1 & 0 & 0 & 0 & 0 & 1 & 0 \\
\hline 4 & 0 & 0 & 1 & 0 & 0 & 0 & 1 & 0 & 0 & 0 \\
\hline 4 & 0 & 0 & 0 & 1 & 0 & 0 & 0 & 0 & 0 & 1 \\
\hline 4 & 0 & 1 & 1 & 0 & 0 & 0 & 0 & 1 & 0 & 0 \\
\hline 4 & 0 & 1 & 0 & 0 & 0 & 1 & 0 & 0 & 1 & 0 \\
\hline 4 & 0 & 0 & 0 & 0 & 0 & 1 & 1 & 0 & 0 & 0 \\
\hline 4 & 1 & 0 & 0 & 0 & 0 & 1 & 1 & 0 & 0 & 0 \\
\hline 4 & 0 & 1 & 0 & 1 & 0 & 0 & 1 & 0 & 0 & 0 \\
\hline 4 & 0 & 1 & 0 & 0 & 0 & 1 & 0 & 1 & 0 & 0 \\
\hline 4 & 0 & 0 & 0 & 0 & 0 & 1 & 0 & 1 & 0 & 0 \\
\hline 5 & 0 & 1 & 1 & 0 & 0 & 0 & 0 & 0 & 0 & 0 \\
\hline 5 & 0 & 0 & 0 & 0 & 1 & 0 & 1 & 0 & 0 & 0 \\
\hline 5 & 0 & 1 & 0 & 0 & 1 & 0 & 0 & 1 & 0 & 0 \\
\hline 5 & 0 & 0 & 0 & 0 & 0 & 1 & 0 & 0 & 1 & 0 \\
\hline 5 & 0 & 1 & 0 & 0 & 0 & 1 & 0 & 0 & 0 & 1 \\
\hline 5 & 0 & 0 & 0 & 0 & 0 & 1 & 1 & 0 & 0 & 0 \\
\hline 5 & 0 & 0 & 0 & 1 & 0 & 0 & 1 & 0 & 0 & 0 \\
\hline 5 & 1 & 0 & 0 & 1 & 0 & 0 & 0 & 1 & 0 & 0 \\
\hline 5 & 0 & 0 & 0 & 1 & 0 & 0 & 1 & 0 & 0 & 0 \\
\hline 5 & 0 & 1 & 0 & 1 & 0 & 0 & 0 & 1 & 0 & 0 \\
\hline 5 & 0 & 0 & 0 & 1 & 0 & 0 & 1 & 0 & 0 & 0 \\
\hline 5 & 1 & 0 & 1 & 0 & 0 & 0 & 0 & 1 & 0 & 0 \\
\hline 5 & 0 & 0 & 1 & 0 & 0 & 0 & 0 & 0 & 1 & 0 \\
\hline 5 & 0 & 1 & 0 & 0 & 0 & 1 & 0 & 0 & 0 & 1 \\
\hline 5 & 0 & 1 & 0 & 0 & 1 & 0 & 1 & 0 & 0 & 0 \\
\hline 5 & 0 & 1 & 0 & 0 & 0 & 1 & 1 & 0 & 0 & 0 \\
\hline 5 & 0 & 1 & 0 & 0 & 1 & 0 & 1 & 0 & 0 & 0 \\
\hline 5 & 1 & 0 & 0 & 1 & 0 & 0 & 0 & 0 & 1 & 0 \\
\hline
\end{tabular}


Table F. 2

\begin{tabular}{|c|c|c|c|c|c|c|c|c|c|c|}
\hline PROV & AGE35 & AGE3645 & FEXP5 & FEXP610 & FEXP1120 & FEXP20 & ENTLVST & ENTHORT & ENTFCROP & ENTMXFAR \\
\hline 5 & 0 & 0 & 0 & 0 & 0 & 1 & 0 & 0 & 0 & 1 \\
\hline 5 & 0 & 0 & 0 & 0 & 1 & 0 & 0 & 1 & 0 & 0 \\
\hline 5 & 0 & 0 & 0 & 1 & 0 & 0 & 0 & 1 & 0 & 0 \\
\hline 5 & 0 & 0 & 0 & 1 & 0 & 0 & 0 & 1 & 0 & 0 \\
\hline 5 & 0 & 0 & 0 & 0 & 1 & 0 & 0 & 0 & 1 & 0 \\
\hline 5 & 1 & 0 & 0 & 0 & 0 & 1 & 0 & 0 & 1 & 0 \\
\hline 5 & 0 & 1 & 0 & 0 & 1 & 0 & 0 & 1 & 0 & 0 \\
\hline 6 & 0 & 0 & 0 & 0 & 0 & 1 & 0 & 0 & 0 & 1 \\
\hline 6 & 0 & 0 & 0 & 0 & 0 & 1 & 0 & 0 & 0 & 1 \\
\hline 6 & 0 & 1 & 0 & 1 & 0 & 0 & 0 & 1 & 0 & 0 \\
\hline 6 & 0 & 1 & 1 & 0 & 0 & 0 & 0 & 1 & 0 & 0 \\
\hline 6 & 0 & 0 & 0 & 1 & 0 & 0 & 0 & 1 & 0 & 0 \\
\hline 6 & 1 & 0 & 1 & 0 & 0 & 0 & 1 & 0 & 0 & 0 \\
\hline 6 & 0 & 1 & 0 & 1 & 0 & 0 & 0 & 1 & 0 & 0 \\
\hline 6 & 1 & 0 & 0 & 1 & 0 & 0 & 0 & 1 & 0 & 0 \\
\hline 6 & 0 & 1 & 1 & 0 & 0 & 0 & 0 & 0 & 1 & 0 \\
\hline 6 & 0 & 0 & 0 & 1 & 0 & 0 & 0 & 1 & 0 & 0 \\
\hline 6 & 0 & 1 & 1 & 0 & 0 & 0 & 0 & 1 & 0 & 0 \\
\hline 6 & 0 & 0 & 0 & 0 & 1 & 0 & 1 & 0 & 0 & 0 \\
\hline 6 & 0 & 0 & 0 & 0 & 1 & 0 & 1 & 0 & 0 & 0 \\
\hline 6 & 1 & 0 & 0 & 0 & 0 & 1 & 0 & 0 & 1 & 0 \\
\hline 6 & 0 & 0 & 0 & 0 & 1 & 0 & 0 & 0 & 0 & 1 \\
\hline 6 & 0 & 0 & 0 & 1 & 0 & 0 & 0 & 0 & 0 & 1 \\
\hline 6 & 0 & 0 & 1 & 0 & 0 & 0 & 0 & 1 & 0 & 0 \\
\hline 6 & 0 & 0 & 0 & 1 & 0 & 0 & 1 & 0 & 0 & 0 \\
\hline 6 & 0 & 0 & 0 & 0 & 1 & 0 & 0 & 1 & 0 & 0 \\
\hline 6 & 0 & 0 & 0 & 1 & 0 & 0 & 0 & 0 & 0 & 1 \\
\hline 6 & 0 & 0 & 1 & 0 & 0 & 0 & 1 & 1 & 0 & 0 \\
\hline 6 & 0 & 1 & 0 & 0 & 1 & 0 & 0 & 0 & 0 & 1 \\
\hline 6 & 0 & 0 & 0 & 1 & 0 & 0 & 1 & 0 & 0 & 0 \\
\hline 6 & 0 & 0 & 0 & 0 & 1 & 0 & 1 & 0 & 0 & 0 \\
\hline
\end{tabular}


Table F. 2

\begin{tabular}{|c|c|c|c|c|c|c|c|c|c|c|}
\hline PROV & AGE35 & AGE3645 & FEXP5 & FEXP610 & FEXP1120 & FEXP20 & ENTLVST & ENTHORT & ENTFCROP & ENTMXFAR \\
\hline 6 & 0 & 1 & 0 & 0 & 1 & 0 & 1 & 0 & 0 & 0 \\
\hline 6 & 0 & 1 & 1 & 0 & 0 & 0 & 0 & 0 & 1 & 0 \\
\hline 6 & 1 & 0 & 0 & 1 & 0 & 0 & 1 & 0 & 0 & 0 \\
\hline 6 & 0 & 0 & 1 & 0 & 0 & 0 & 0 & 0 & 1 & 0 \\
\hline 6 & 1 & 0 & 0 & 1 & 0 & 0 & 0 & 1 & 0 & 0 \\
\hline 6 & 0 & 0 & 0 & 0 & 1 & 0 & 1 & 0 & 0 & 0 \\
\hline 6 & 1 & 0 & 1 & 0 & 0 & 0 & 0 & 1 & 0 & 0 \\
\hline 7 & 0 & 0 & 0 & 0 & 0 & 1 & 0 & 0 & 1 & 0 \\
\hline 7 & 0 & 0 & 0 & 0 & 0 & 1 & 1 & 0 & 0 & 0 \\
\hline 7 & 0 & 0 & 0 & 0 & 1 & 0 & 1 & 0 & 0 & 0 \\
\hline 7 & 0 & 0 & 0 & 0 & 1 & 0 & 0 & 0 & 1 & 0 \\
\hline 7 & 0 & 1 & 0 & 0 & 0 & 1 & 1 & 0 & 0 & 0 \\
\hline 7 & 0 & 1 & 0 & 0 & 1 & 0 & 1 & 0 & 0 & 0 \\
\hline 7 & 0 & 1 & 0 & 1 & 0 & 0 & 0 & 1 & 0 & 0 \\
\hline 7 & 0 & 1 & 0 & 1 & 0 & 0 & 1 & 0 & 0 & 0 \\
\hline 7 & 0 & 0 & 0 & 1 & 0 & 0 & 1 & 0 & 0 & 0 \\
\hline 7 & 0 & 0 & 0 & 0 & 0 & 1 & 1 & 0 & 0 & 0 \\
\hline 7 & 0 & 0 & 0 & 0 & 0 & 1 & 0 & 0 & 0 & 1 \\
\hline 7 & 0 & 1 & 0 & 0 & 0 & 1 & 1 & 0 & 0 & 0 \\
\hline 7 & 1 & 0 & 0 & 0 & 0 & 1 & 0 & 0 & 0 & 1 \\
\hline 7 & 0 & 1 & 0 & 0 & 1 & 0 & 0 & 0 & 0 & 1 \\
\hline 7 & 0 & 1 & 0 & 0 & 1 & 0 & 0 & 1 & 0 & 0 \\
\hline 7 & 0 & 1 & 0 & 1 & 0 & 0 & 0 & 0 & 1 & 0 \\
\hline 7 & 0 & 1 & 0 & 0 & 1 & 0 & 0 & 0 & 0 & 1 \\
\hline 7 & 0 & 0 & 0 & 0 & 0 & 1 & 1 & 0 & 0 & 0 \\
\hline 7 & 0 & 1 & 0 & 1 & 0 & 0 & 0 & 1 & 0 & 0 \\
\hline 7 & 0 & 1 & 0 & 0 & 1 & 0 & 0 & 1 & 0 & 0 \\
\hline 7 & 0 & 1 & 0 & 0 & 0 & 1 & 1 & 0 & 0 & 0 \\
\hline 7 & 0 & 0 & 0 & 0 & 1 & 0 & 0 & 1 & 0 & 0 \\
\hline 7 & 0 & 1 & 0 & 0 & 0 & 1 & 1 & 0 & 0 & 0 \\
\hline 7 & 0 & 0 & 0 & 0 & 1 & 0 & 1 & 0 & 0 & 0 \\
\hline
\end{tabular}


Table F. 2

\begin{tabular}{|c|c|c|c|c|c|c|c|c|c|c|}
\hline PROV & AGE35 & AGE3645 & FEXP5 & FEXP610 & FEXP1120 & FEXP20 & ENTLVST & ENTHORT & ENTFCROP & ENTMXFAR \\
\hline 7 & 1 & 0 & 0 & 1 & 0 & 0 & 0 & 1 & 0 & 0 \\
\hline 7 & 0 & 0 & 0 & 1 & 0 & 0 & 0 & 0 & 1 & 0 \\
\hline 7 & 0 & 0 & 1 & 0 & 0 & 0 & 0 & 1 & 0 & 0 \\
\hline 7 & 0 & 1 & 0 & 1 & 0 & 0 & 1 & 0 & 0 & 0 \\
\hline 7 & 0 & 0 & 0 & 0 & 1 & 0 & 1 & 0 & 0 & 0 \\
\hline 7 & 0 & 0 & 0 & 1 & 0 & 0 & 0 & 0 & 1 & 0 \\
\hline 7 & 0 & 0 & 0 & 0 & 1 & 0 & 1 & 0 & 0 & 0 \\
\hline 7 & 0 & 0 & 0 & 0 & 0 & 1 & 1 & 0 & 0 & 0 \\
\hline 7 & 0 & 0 & 0 & 0 & 0 & 1 & 0 & 0 & 1 & 0 \\
\hline 7 & 0 & 0 & 0 & 0 & 0 & 1 & 0 & 0 & 1 & 0 \\
\hline 7 & 0 & 0 & 0 & 0 & 0 & 1 & 0 & 0 & 1 & 0 \\
\hline 7 & 0 & 0 & 0 & 0 & 0 & 1 & 0 & 1 & 0 & 0 \\
\hline 7 & 1 & 0 & 0 & 0 & 1 & 0 & 1 & 0 & 0 & 0 \\
\hline 7 & 0 & 0 & 1 & 0 & 0 & 0 & 0 & 1 & 0 & 0 \\
\hline 7 & 1 & 0 & 0 & 0 & 0 & 1 & 0 & 0 & 1 & 0 \\
\hline 7 & 0 & 1 & 0 & 0 & 1 & 0 & 0 & 0 & 1 & 0 \\
\hline 7 & 1 & 0 & 0 & 0 & 0 & 1 & 1 & 0 & 0 & 0 \\
\hline 7 & 0 & 0 & 0 & 0 & 0 & 1 & 0 & 1 & 0 & 0 \\
\hline 7 & 0 & 0 & 0 & 0 & 1 & 0 & 1 & 0 & 0 & 0 \\
\hline 8 & 1 & 0 & 0 & 0 & 0 & 1 & 0 & 0 & 0 & 1 \\
\hline 8 & 0 & 1 & 0 & 1 & 0 & 0 & 0 & 0 & 0 & 1 \\
\hline 8 & 0 & 1 & 1 & 0 & 0 & 0 & 0 & 0 & 0 & 1 \\
\hline 8 & 0 & 0 & 0 & 0 & 1 & 0 & 1 & 0 & 0 & 0 \\
\hline 8 & 1 & 0 & 0 & 0 & 0 & 1 & 1 & 0 & 0 & 0 \\
\hline 8 & 0 & 0 & 0 & 0 & 1 & 0 & 0 & 0 & 1 & 0 \\
\hline 8 & 0 & 0 & 0 & 0 & 0 & 1 & 0 & 0 & 1 & 0 \\
\hline 8 & 0 & 0 & 0 & 0 & 1 & 0 & 0 & 0 & 0 & 1 \\
\hline 8 & 0 & 0 & 0 & 0 & 0 & 1 & 0 & 0 & 0 & 1 \\
\hline 8 & 0 & 1 & 1 & 0 & 0 & 0 & 0 & 1 & 0 & 0 \\
\hline 8 & 0 & 1 & 0 & 1 & 0 & 0 & 0 & 1 & 0 & 0 \\
\hline 8 & 0 & 1 & 0 & 1 & 0 & 0 & 1 & 0 & 0 & 0 \\
\hline
\end{tabular}


Table F. 2

\begin{tabular}{|c|c|c|c|c|c|c|c|c|c|c|}
\hline PROV & AGE35 & AGE3645 & FEXP5 & FEXP610 & FEXP1120 & FEXP20 & ENTLVST & ENTHORT & ENTFCROP & ENTMXFAR \\
\hline 8 & 0 & 0 & 1 & 0 & 0 & 0 & 0 & 0 & 1 & 0 \\
\hline 8 & 0 & 1 & 1 & 0 & 0 & 0 & 0 & 1 & 0 & 0 \\
\hline 8 & 0 & 1 & 0 & 1 & 0 & 0 & 0 & 1 & 0 & 0 \\
\hline 8 & 1 & 0 & 0 & 1 & 0 & 0 & 0 & 1 & 0 & 0 \\
\hline 8 & 0 & 0 & 1 & 0 & 0 & 0 & 0 & 0 & 1 & 0 \\
\hline 8 & 1 & 0 & 0 & 1 & 0 & 0 & 1 & 0 & 0 & 0 \\
\hline 8 & 0 & 1 & 1 & 0 & 0 & 0 & 0 & 1 & 0 & 0 \\
\hline 8 & 0 & 0 & 0 & 1 & 0 & 0 & 0 & 1 & 0 & 0 \\
\hline 8 & 1 & 0 & 0 & 1 & 0 & 0 & 0 & 0 & 1 & 0 \\
\hline 8 & 0 & 1 & 1 & 0 & 0 & 0 & 0 & 1 & 0 & 0 \\
\hline 8 & 0 & 0 & 0 & 1 & 0 & 0 & 0 & 1 & 0 & 0 \\
\hline 8 & 0 & 0 & 0 & 0 & 1 & 0 & 0 & 0 & 0 & 1 \\
\hline 8 & 0 & 0 & 0 & 0 & 1 & 0 & 1 & 0 & 0 & 0 \\
\hline 8 & 1 & 0 & 1 & 0 & 0 & 0 & 1 & 0 & 0 & 0 \\
\hline 8 & 0 & 1 & 0 & 1 & 0 & 0 & 0 & 1 & 0 & 0 \\
\hline 8 & 0 & 1 & 0 & 0 & 1 & 0 & 0 & 0 & 1 & 0 \\
\hline 8 & 0 & 1 & 0 & 0 & 0 & 1 & 0 & 0 & 1 & 0 \\
\hline 8 & 0 & 0 & 1 & 0 & 0 & 0 & 0 & 0 & 0 & 1 \\
\hline 8 & 0 & 0 & 0 & 1 & 0 & 0 & 1 & 0 & 0 & 0 \\
\hline 8 & 0 & 0 & 0 & 1 & 0 & 0 & 1 & 0 & 0 & 0 \\
\hline 8 & 0 & 1 & 0 & 0 & 1 & 0 & 0 & 1 & 0 & 0 \\
\hline 8 & 1 & 0 & 0 & 0 & 1 & 0 & 1 & 0 & 0 & 0 \\
\hline 9 & 0 & 0 & 1 & 0 & 0 & 0 & 0 & 0 & 0 & 1 \\
\hline 9 & 0 & 0 & 0 & 1 & 0 & 0 & 0 & 1 & 0 & 0 \\
\hline 9 & 0 & 1 & 1 & 0 & 0 & 0 & 1 & 0 & 0 & 0 \\
\hline 9 & 1 & 0 & 0 & 1 & 0 & 0 & 0 & 1 & 0 & 0 \\
\hline 9 & 0 & 0 & 1 & 0 & 0 & 0 & 1 & 0 & 0 & 0 \\
\hline 9 & 0 & 0 & 0 & 1 & 0 & 0 & 1 & 0 & 0 & 0 \\
\hline 9 & 0 & 1 & 0 & 0 & 1 & 0 & 1 & 0 & 0 & 0 \\
\hline 9 & 0 & 1 & 0 & 0 & 0 & 1 & 0 & 0 & 1 & 0 \\
\hline 9 & 0 & 0 & 0 & 0 & 1 & 0 & 0 & 0 & 1 & 0 \\
\hline
\end{tabular}


Table F. 2

\begin{tabular}{ccccccccccc}
\hline PROV & AGE35 & AGE3645 & FEXP5 & FEXP610 & FEXP1120 & FEXP20 & ENTLVST & ENTHORT & ENTFCROP & ENTMXFAR \\
\hline 9 & 0 & 0 & 0 & 0 & 0 & 1 & 0 & 0 & 1 & 0 \\
9 & 1 & 0 & 0 & 0 & 1 & 0 & 0 & 0 & 1 & 0 \\
9 & 0 & 0 & 0 & 0 & 0 & 1 & 0 & 0 & 0 & 1 \\
9 & 1 & 0 & 0 & 0 & 1 & 0 & 0 & 1 & 0 & 0 \\
9 & 0 & 1 & 0 & 0 & 0 & 1 & 0 & 1 & 0 & 0 \\
9 & 0 & 1 & 0 & 0 & 1 & 0 & 0 & 0 & 1 & 0 \\
9 & 0 & 0 & 1 & 0 & 0 & 0 & 0 & 1 & 0 & 0 \\
9 & 0 & 0 & 0 & 1 & 0 & 0 & 1 & 0 & 0 & 0 \\
9 & 0 & 0 & 0 & 0 & 1 & 0 & 0 & 0 & 1 & 0 \\
9 & 1 & 0 & 0 & 1 & 0 & 0 & 0 & 1 & 0 & 0 \\
9 & 0 & 0 & 1 & 0 & 0 & 0 & 0 & 0 & 0 & 0 \\
9 & 0 & 0 & 0 & 1 & 0 & 0 & 0 & 1 & 0 & 0 \\
9 & 0 & 0 & 0 & 1 & 0 & 0 & 0 & 0 & 0 & 0 \\
9 & 1 & 0 & 1 & 0 & 0 & 0 & 1 & 0 & 0 & 0 \\
9 & 0 & 0 & 0 & 1 & 0 & 0 & 0 & 1 & 0 & 0 \\
9 & 1 & 0 & 1 & 0 & 0 & 0 & 1 & 0 & 0 & 0 \\
9 & 0 & 1 & 0 & 1 & 0 & 0 & 0 & 0 & 1 & 0 \\
9 & 0 & 1 & 1 & 0 & 0 & 0 & 0 & 1 & 0 & 0 \\
9 & 0 & 0 & 1 & 0 & 0 & 0 & 0 & 1 & 0 & 0 \\
9 & 0 & 1 & 0 & 1 & 0 & 0 & 0 & 0 & 1 & 0 \\
9 & 1 & 0 & 0 & 1 & 0 & 0 & 0 & 1 & 0 & 0 \\
9 & 0 & 1 & 1 & 0 & 0 & 0 & 0 & 0 & 0 & 0 \\
9 & 0 & 1 & 0 & 0 & 1 & 0 & 0 & 1 & 0 & 0 \\
9 & 0 & 0 & 0 & 1 & 0 & 0 & 0 & 1 & 0 & 0 \\
9 & 1 & 0 & 0 & 0 & 1 & 0 & 1 & 0 & 0 & 0 \\
9 & 0 & 0 & 0 & 0 & 0 & 1 & 0 & 0 & 1 & 0
\end{tabular}


Table F.3

\begin{tabular}{|c|c|c|c|c|c|c|c|c|c|}
\hline PROV & FIN100 & FIN1025 & FIN2550 & FIN500 & AGE46 & FHUOS & FHUOM & FHUOL & RESIDUAL \\
\hline 1 & 0 & 0 & 0 & 0 & 1 & 1 & 0 & 0 & 0 \\
\hline 1 & 0 & 0 & 0 & 0 & 1 & 1 & 0 & 0 & 0 \\
\hline 1 & 1 & 0 & 0 & 1 & 1 & 1 & 0 & 0 & 0 \\
\hline 1 & 0 & 0 & 0 & 1 & 1 & 0 & 1 & 0 & 0 \\
\hline 1 & 1 & 0 & 1 & 0 & 1 & 1 & 0 & 0 & 0 \\
\hline 1 & 1 & 0 & 1 & 0 & 1 & 1 & 0 & 0 & 0 \\
\hline 1 & 1 & 0 & 0 & 1 & 1 & 1 & 0 & 0 & 1 \\
\hline 1 & 0 & 0 & 0 & 1 & 1 & 0 & 1 & 0 & 0 \\
\hline 1 & 1 & 0 & 0 & 0 & 0 & 1 & 0 & 0 & 0 \\
\hline 1 & 0 & 1 & 0 & 0 & 0 & 0 & 1 & 0 & 0 \\
\hline 1 & 0 & 0 & 1 & 0 & 0 & 0 & 1 & 0 & 0 \\
\hline 1 & 0 & 0 & 0 & 1 & 1 & 0 & 0 & 1 & 0 \\
\hline 1 & 1 & 0 & 0 & 0 & 1 & 1 & 0 & 0 & 0 \\
\hline 1 & 0 & 1 & 0 & 0 & 1 & 1 & 0 & 0 & 0 \\
\hline 1 & 0 & 1 & 0 & 0 & 0 & 0 & 1 & 0 & 0 \\
\hline 1 & 1 & 0 & 0 & 0 & 0 & 0 & 1 & 0 & 0 \\
\hline 1 & 0 & 0 & 1 & 0 & 0 & 0 & 1 & 0 & 0 \\
\hline 1 & 0 & 1 & 0 & 0 & 0 & 1 & 0 & 0 & 0 \\
\hline 1 & 0 & 0 & 0 & 1 & 1 & 0 & 1 & 0 & 0 \\
\hline 1 & 0 & 0 & 0 & 1 & 1 & 0 & 0 & 1 & 0 \\
\hline 1 & 0 & 0 & 0 & 1 & 1 & 1 & 0 & 0 & 0 \\
\hline 1 & 0 & 1 & 0 & 0 & 0 & 0 & 1 & 0 & 0 \\
\hline 1 & 0 & 0 & 1 & 0 & 1 & 0 & 0 & 1 & 0 \\
\hline 1 & 0 & 1 & 0 & 0 & 0 & 1 & 0 & 0 & 0 \\
\hline 1 & 0 & 1 & 0 & 0 & 1 & 1 & 0 & 0 & 0 \\
\hline 1 & 0 & 0 & 0 & 1 & 1 & 0 & 1 & 0 & 0 \\
\hline 1 & 0 & 0 & 1 & 0 & 1 & 0 & 1 & 0 & -1 \\
\hline 1 & 0 & 0 & 1 & 0 & 1 & 0 & 0 & 1 & 0 \\
\hline 1 & 1 & 0 & 0 & 0 & 0 & 1 & 0 & 0 & 0 \\
\hline 1 & 0 & 1 & 0 & 0 & 0 & 0 & 1 & 0 & 0 \\
\hline 1 & 1 & 0 & 0 & 0 & 1 & 1 & 0 & 0 & 0 \\
\hline
\end{tabular}




\begin{tabular}{|c|c|c|c|c|c|c|c|c|c|}
\hline PROV & FIN100 & FIN1025 & FIN2550 & FIN500 & AGE46 & FHUOS & FHUOM & FHUOL & RESIDUAL \\
\hline 1 & 1 & 0 & 0 & 0 & 0 & 1 & 0 & 0 & 0 \\
\hline 1 & 0 & 1 & 0 & 0 & 1 & 1 & 0 & 0 & 0 \\
\hline 1 & 0 & 0 & 1 & 0 & 1 & 0 & 1 & 0 & 0 \\
\hline 1 & 0 & 0 & 0 & 1 & 1 & 0 & 1 & 0 & 0 \\
\hline 1 & 1 & 0 & 0 & 0 & 1 & 1 & 0 & 0 & 0 \\
\hline 1 & 1 & 0 & 0 & 0 & 1 & 0 & 1 & 0 & 0 \\
\hline 2 & 0 & 0 & 1 & 0 & 1 & 0 & 1 & 0 & 0 \\
\hline 2 & 0 & 0 & 0 & 1 & 0 & 0 & 1 & 0 & 0 \\
\hline 2 & 0 & 0 & 0 & 1 & 0 & 1 & 0 & 0 & -1 \\
\hline 2 & 0 & 0 & 1 & 0 & 0 & 0 & 1 & 0 & 0 \\
\hline 2 & 0 & 1 & 0 & 0 & 0 & 1 & 0 & 0 & 0 \\
\hline 2 & 0 & 1 & 0 & 0 & 0 & 1 & 0 & 0 & 0 \\
\hline 2 & 1 & 0 & 0 & 0 & 0 & 1 & 0 & 0 & 0 \\
\hline 2 & 0 & 0 & 1 & 0 & 0 & 0 & 1 & 0 & 0 \\
\hline 2 & 0 & 0 & 0 & 1 & 0 & 0 & 1 & 0 & 0 \\
\hline 2 & 0 & 1 & 0 & 0 & 0 & 1 & 0 & 0 & 0 \\
\hline 2 & 1 & 0 & 0 & 0 & 1 & 1 & 0 & 0 & 0 \\
\hline 2 & 0 & 1 & 0 & 0 & 1 & 1 & 0 & 0 & 0 \\
\hline 2 & 0 & 0 & 1 & 0 & 0 & 0 & 1 & 0 & 0 \\
\hline 2 & 0 & 0 & 1 & 0 & 0 & 0 & 0 & 1 & 0 \\
\hline 2 & 0 & 0 & 0 & 1 & 1 & 0 & 1 & 0 & 0 \\
\hline 2 & 1 & 0 & 0 & 0 & 0 & 1 & 0 & 0 & 0 \\
\hline 2 & 0 & 1 & 0 & 0 & 0 & 1 & 0 & 0 & 0 \\
\hline 2 & 0 & 0 & 1 & 0 & 1 & 1 & 0 & 0 & 0 \\
\hline 2 & 1 & 0 & 0 & 0 & 0 & 1 & 0 & 0 & 0 \\
\hline 2 & 0 & 1 & 0 & 0 & 0 & 1 & 0 & 0 & 0 \\
\hline 2 & 0 & 1 & 0 & 0 & 1 & 0 & 1 & 0 & 0 \\
\hline 2 & 0 & 0 & 0 & 1 & 1 & 0 & 0 & 1 & -1 \\
\hline 2 & 0 & 0 & 0 & 1 & 1 & 0 & 0 & 1 & 0 \\
\hline 2 & 0 & 1 & 0 & 0 & 0 & 0 & 1 & 0 & 0 \\
\hline 2 & 0 & 1 & 0 & 0 & 0 & 1 & 0 & 0 & 0 \\
\hline
\end{tabular}


Table F.3

\begin{tabular}{|c|c|c|c|c|c|c|c|c|c|}
\hline PROV & FIN100 & FIN1025 & FIN2550 & FIN500 & AGE46 & FHUOS & FHUOM & FHUOL & RESIDUAL \\
\hline 2 & 1 & 0 & 0 & 0 & 0 & 1 & 0 & 0 & 0 \\
\hline 2 & 0 & 0 & 0 & 1 & 1 & 1 & 0 & 0 & 0 \\
\hline 2 & 0 & 0 & 1 & 0 & 0 & 0 & 1 & 0 & 0 \\
\hline 2 & 0 & 0 & 0 & 1 & 1 & 0 & 1 & 0 & 0 \\
\hline 2 & 0 & 0 & 1 & 0 & 1 & 0 & 1 & 0 & 0 \\
\hline 2 & 0 & 0 & 1 & 0 & 1 & 0 & 1 & 0 & 0 \\
\hline 2 & 0 & 0 & 0 & 1 & 1 & 0 & 0 & 1 & 0 \\
\hline 2 & 0 & 0 & 1 & 0 & 1 & 0 & 0 & 1 & 0 \\
\hline 2 & 0 & 0 & 0 & 1 & 0 & 0 & 1 & 0 & 0 \\
\hline 2 & 1 & 0 & 0 & 0 & 0 & 0 & 1 & 0 & 0 \\
\hline 2 & 0 & 0 & 1 & 0 & 0 & 0 & 1 & 0 & 0 \\
\hline 2 & 1 & 0 & 0 & 0 & 1 & 0 & 0 & 1 & 0 \\
\hline 2 & 0 & 1 & 0 & 0 & 1 & 0 & 1 & 0 & 0 \\
\hline 2 & 0 & 0 & 0 & 1 & 1 & 0 & 1 & 0 & 0 \\
\hline 2 & 0 & 0 & 1 & 0 & 1 & 0 & 1 & 0 & 0 \\
\hline 2 & 0 & 0 & 0 & 1 & 1 & 0 & 1 & 0 & 0 \\
\hline 2 & 1 & 0 & 0 & 0 & 0 & 1 & 0 & 0 & 0 \\
\hline 2 & 0 & 1 & 0 & 0 & 1 & 1 & 0 & 0 & 0 \\
\hline 2 & 0 & 1 & 0 & 0 & 1 & 1 & 0 & 0 & 0 \\
\hline 2 & 1 & 0 & 0 & 0 & 0 & 1 & 0 & 0 & 0 \\
\hline 2 & 1 & 0 & 0 & 0 & 1 & 0 & 0 & 1 & 0 \\
\hline 2 & 0 & 0 & 1 & 0 & 1 & 0 & 1 & 0 & 0 \\
\hline 2 & 0 & 0 & 0 & 1 & 1 & 0 & 1 & 0 & 0 \\
\hline 2 & 0 & 0 & 1 & 0 & 1 & 0 & 1 & 0 & 0 \\
\hline 2 & 0 & 0 & 0 & 1 & 1 & 0 & 1 & 0 & 0 \\
\hline 2 & 0 & 0 & 0 & 1 & 1 & 0 & 1 & 0 & 0 \\
\hline 2 & 0 & 0 & 1 & 0 & 1 & 0 & 1 & 0 & 0 \\
\hline 2 & 0 & 0 & 0 & 1 & 1 & 0 & 1 & 0 & 0 \\
\hline 2 & 0 & 0 & 1 & 0 & 1 & 0 & 1 & 0 & 0 \\
\hline 2 & 1 & 0 & 0 & 0 & 0 & 1 & 0 & 0 & 0 \\
\hline 2 & 0 & 0 & 0 & 1 & 1 & 1 & 0 & 0 & 0 \\
\hline
\end{tabular}


Table F.3

\begin{tabular}{|c|c|c|c|c|c|c|c|c|c|}
\hline PROV & FIN100 & FIN1025 & FIN2550 & FIN500 & AGE46 & FHUOS & FHUOM & FHUOL & RESIDUAL \\
\hline 2 & 0 & 0 & 1 & 0 & 1 & 0 & 1 & 0 & 0 \\
\hline 2 & 0 & 0 & 1 & 0 & 1 & 0 & 1 & 0 & 0 \\
\hline 2 & 0 & 0 & 0 & 1 & 1 & 0 & 0 & 1 & 0 \\
\hline 2 & 0 & 1 & 0 & 0 & 0 & 0 & 1 & 0 & 0 \\
\hline 2 & 0 & 0 & 1 & 0 & 1 & 0 & 1 & 0 & 0 \\
\hline 2 & 0 & 0 & 0 & 1 & 1 & 1 & 0 & 0 & 0 \\
\hline 2 & 0 & 0 & 0 & 1 & 1 & 0 & 1 & 0 & 0 \\
\hline 3 & 1 & 0 & 0 & 0 & 0 & 1 & 0 & 0 & 0 \\
\hline 3 & 0 & 0 & 1 & 0 & 1 & 0 & 0 & 1 & 0 \\
\hline 3 & 0 & 0 & 1 & 0 & 1 & 0 & 0 & 1 & 0 \\
\hline 3 & 0 & 0 & 0 & 1 & 0 & 1 & 0 & 0 & -1 \\
\hline 3 & 0 & 0 & 0 & 1 & 1 & 0 & 0 & 1 & 0 \\
\hline 3 & 1 & 0 & 0 & 0 & 1 & 0 & 1 & 0 & 0 \\
\hline 3 & 1 & 0 & 0 & 0 & 0 & 1 & 0 & 0 & 1 \\
\hline 3 & 0 & 0 & 1 & 0 & 1 & 0 & 0 & 1 & 0 \\
\hline 3 & 0 & 0 & 1 & 0 & 1 & 0 & 0 & 1 & 0 \\
\hline 3 & 1 & 0 & 0 & 0 & 1 & 0 & 1 & 0 & 0 \\
\hline 3 & 0 & 0 & 0 & 1 & 1 & 0 & 1 & 0 & 0 \\
\hline 3 & 0 & 0 & 0 & 1 & 1 & 0 & 1 & 0 & 0 \\
\hline 3 & 0 & 0 & 1 & 0 & 1 & 0 & 1 & 0 & 0 \\
\hline 3 & 0 & 0 & 0 & 1 & 1 & 0 & 1 & 0 & 0 \\
\hline 3 & 0 & 0 & 1 & 0 & 1 & 0 & 1 & 0 & 0 \\
\hline 3 & 0 & 0 & 0 & 1 & 1 & 0 & 1 & 0 & 0 \\
\hline 3 & 0 & 0 & 1 & 0 & 1 & 0 & 1 & 0 & 0 \\
\hline 3 & 1 & 0 & 0 & 0 & 0 & 1 & 0 & 0 & 0 \\
\hline 3 & 1 & 0 & 0 & 0 & 1 & 1 & 0 & 0 & 0 \\
\hline 3 & 0 & 0 & 1 & 0 & 1 & 0 & 0 & 1 & 0 \\
\hline 3 & 0 & 0 & 0 & 1 & 1 & 0 & 0 & 1 & 0 \\
\hline 3 & 0 & 0 & 1 & 0 & 1 & 0 & 1 & 0 & 0 \\
\hline 3 & 0 & 0 & 0 & 1 & 1 & 0 & 1 & 0 & 0 \\
\hline 3 & 0 & 1 & 0 & 0 & 0 & 1 & 0 & 0 & 0 \\
\hline
\end{tabular}


Table F.3

\begin{tabular}{|c|c|c|c|c|c|c|c|c|c|}
\hline PROV & FIN100 & FIN1025 & FIN2550 & FIN500 & AGE46 & FHUOS & FHUOM & FHUOL & RESIDUAL \\
\hline 3 & 0 & 1 & 0 & 0 & 0 & 1 & 0 & 0 & 0 \\
\hline 4 & 0 & 0 & 0 & 1 & 1 & 1 & 0 & 0 & -1 \\
\hline 4 & 0 & 0 & 0 & 0 & 0 & 0 & 1 & 0 & 0 \\
\hline 4 & 0 & 0 & 0 & 0 & 0 & 1 & 0 & 0 & 0 \\
\hline 4 & 0 & 0 & 0 & 0 & 1 & 0 & 1 & 0 & 0 \\
\hline 4 & 0 & 0 & 0 & 1 & 0 & 1 & 0 & 0 & 0 \\
\hline 4 & 0 & 0 & 0 & 1 & 0 & 0 & 1 & 0 & 0 \\
\hline 4 & 1 & 0 & 0 & 0 & 1 & 1 & 0 & 0 & -1 \\
\hline 4 & 0 & 0 & 0 & 1 & 1 & 0 & 1 & 0 & 0 \\
\hline 4 & 0 & 0 & 0 & 1 & 1 & 0 & 1 & 0 & 0 \\
\hline 4 & 0 & 0 & 0 & 1 & 1 & 1 & 0 & 0 & 0 \\
\hline 4 & 0 & 0 & 0 & 1 & 0 & 1 & 0 & 0 & 0 \\
\hline 4 & 0 & 0 & 0 & 0 & 1 & 0 & 1 & 0 & -1 \\
\hline 4 & 1 & 0 & 0 & 0 & 1 & 1 & 0 & 0 & 0 \\
\hline 4 & 1 & 0 & 1 & 0 & 1 & 0 & 1 & 0 & 0 \\
\hline 4 & 0 & 0 & 0 & 1 & 1 & 1 & 0 & 0 & 0 \\
\hline 4 & 0 & 0 & 0 & 1 & 1 & 0 & 1 & 0 & 0 \\
\hline 4 & 0 & 0 & 0 & 1 & 1 & 0 & 0 & 1 & 0 \\
\hline 4 & 0 & 0 & 0 & 1 & 1 & 1 & 0 & 0 & 0 \\
\hline 4 & 0 & 0 & 1 & 0 & 1 & 1 & 0 & 0 & 0 \\
\hline 4 & 0 & 0 & 0 & 1 & 1 & 0 & 0 & 1 & 0 \\
\hline 4 & 0 & 0 & 1 & 0 & 1 & 0 & 1 & 0 & 0 \\
\hline 4 & 0 & 0 & 0 & 1 & 1 & 0 & 0 & 1 & 0 \\
\hline 4 & 0 & 0 & 1 & 0 & 1 & 0 & 0 & 1 & 0 \\
\hline 4 & 0 & 1 & 0 & 0 & 1 & 0 & 0 & 1 & -1 \\
\hline 4 & 0 & 0 & 1 & 0 & 1 & 0 & 1 & 0 & 0 \\
\hline 4 & 0 & 0 & 0 & 1 & 1 & 0 & 1 & 0 & 0 \\
\hline 4 & 0 & 0 & 1 & 0 & 1 & 0 & 0 & 1 & 0 \\
\hline 4 & 0 & 0 & 1 & 0 & 1 & 0 & 0 & 1 & 0 \\
\hline 4 & 0 & 1 & 0 & 0 & 0 & 0 & 1 & 0 & 0 \\
\hline 4 & 0 & 0 & 0 & 1 & 0 & 0 & 1 & 0 & 0 \\
\hline
\end{tabular}


Table F.3

\begin{tabular}{|c|c|c|c|c|c|c|c|c|c|}
\hline PROV & FIN100 & FIN1025 & FIN2550 & FIN500 & AGE46 & FHUOS & FHUOM & FHUOL & RESIDUAL \\
\hline 4 & 0 & 0 & 1 & 0 & 0 & 0 & 0 & 1 & 0 \\
\hline 4 & 0 & 0 & 0 & 1 & 0 & 0 & 1 & 0 & 0 \\
\hline 4 & 0 & 1 & 0 & 0 & 0 & 1 & 0 & 0 & 0 \\
\hline 4 & 0 & 0 & 1 & 0 & 1 & 0 & 1 & 0 & 0 \\
\hline 4 & 0 & 0 & 0 & 1 & 1 & 0 & 1 & 0 & -1 \\
\hline 4 & 0 & 0 & 1 & 0 & 1 & 0 & 1 & 0 & 0 \\
\hline 4 & 0 & 0 & 0 & 1 & 0 & 0 & 1 & 0 & -1 \\
\hline 4 & 1 & 0 & 0 & 0 & 0 & 0 & 1 & 0 & 0 \\
\hline 4 & 0 & 0 & 1 & 0 & 1 & 0 & 1 & 0 & 0 \\
\hline 4 & 1 & 0 & 0 & 0 & 0 & 1 & 0 & 0 & 0 \\
\hline 4 & 0 & 0 & 1 & 0 & 0 & 0 & 1 & 0 & 0 \\
\hline 4 & 0 & 0 & 0 & 1 & 1 & 1 & 0 & 0 & 0 \\
\hline 4 & 0 & 0 & 0 & 1 & 1 & 1 & 0 & 0 & -1 \\
\hline 5 & 0 & 0 & 1 & 0 & 0 & 1 & 0 & 0 & 0 \\
\hline 5 & 0 & 1 & 0 & 0 & 0 & 0 & 0 & 1 & 0 \\
\hline 5 & 1 & 0 & 0 & 0 & 0 & 1 & 0 & 0 & 0 \\
\hline 5 & 0 & 1 & 0 & 0 & 0 & 1 & 0 & 0 & 0 \\
\hline 5 & 0 & 1 & 0 & 0 & 0 & 1 & 0 & 0 & 0 \\
\hline 5 & 1 & 0 & 0 & 0 & 1 & 0 & 1 & 0 & 0 \\
\hline 5 & 0 & 0 & 1 & 0 & 1 & 1 & 0 & 0 & 0 \\
\hline 5 & 0 & 0 & 1 & 0 & 1 & 0 & 1 & 0 & 0 \\
\hline 5 & 0 & 0 & 1 & 0 & 1 & 0 & 1 & 0 & 0 \\
\hline 5 & 0 & 0 & 0 & 1 & 1 & 0 & 1 & 0 & 0 \\
\hline 5 & 0 & 0 & 1 & 0 & 1 & 0 & 1 & 0 & 0 \\
\hline 5 & 0 & 0 & 1 & 0 & 1 & 0 & 1 & 0 & 0 \\
\hline 5 & 0 & 0 & 0 & 1 & 1 & 0 & 1 & 0 & 0 \\
\hline 5 & 1 & 0 & 0 & 0 & 0 & 1 & 0 & 0 & 0 \\
\hline 5 & 0 & 1 & 0 & 0 & 0 & 1 & 0 & 0 & 0 \\
\hline 5 & 1 & 0 & 0 & 0 & 0 & 1 & 0 & 0 & 0 \\
\hline 5 & 1 & 0 & 0 & 0 & 0 & 1 & 0 & 0 & 0 \\
\hline 5 & 0 & 0 & 1 & 0 & 1 & 0 & 1 & 0 & 0 \\
\hline
\end{tabular}


Table F.3

\begin{tabular}{|c|c|c|c|c|c|c|c|c|c|}
\hline PROV & FIN100 & FIN1025 & FIN2550 & FIN500 & AGE46 & FHUOS & FHUOM & FHUOL & RESIDUAL \\
\hline 5 & 1 & 0 & 0 & 0 & 1 & 0 & 1 & 0 & 0 \\
\hline 5 & 0 & 0 & 1 & 0 & 1 & 0 & 1 & 0 & 0 \\
\hline 5 & 0 & 0 & 0 & 1 & 1 & 0 & 1 & 0 & 0 \\
\hline 5 & 0 & 0 & 1 & 0 & 1 & 1 & 0 & 0 & 0 \\
\hline 5 & 0 & 0 & 1 & 0 & 1 & 1 & 0 & 0 & 0 \\
\hline 5 & 1 & 0 & 0 & 0 & 1 & 1 & 0 & 0 & 0 \\
\hline 5 & 0 & 0 & 0 & 0 & 0 & 1 & 0 & 0 & 0 \\
\hline 6 & 0 & 0 & 1 & 0 & 1 & 0 & 1 & 0 & 0 \\
\hline 6 & 0 & 0 & 0 & 1 & 1 & 0 & 0 & 1 & 0 \\
\hline 6 & 0 & 0 & 1 & 0 & 0 & 0 & 0 & 1 & 0 \\
\hline 6 & 0 & 0 & 0 & 1 & 0 & 0 & 0 & 1 & 0 \\
\hline 6 & 0 & 1 & 0 & 0 & 1 & 1 & 0 & 0 & 0 \\
\hline 6 & 0 & 0 & 1 & 0 & 1 & 0 & 1 & 0 & 0 \\
\hline 6 & 0 & 0 & 1 & 0 & 1 & 0 & 0 & 1 & 0 \\
\hline 6 & 0 & 0 & 0 & 1 & 0 & 0 & 1 & 0 & 0 \\
\hline 6 & 0 & 0 & 0 & 1 & 1 & 0 & 0 & 1 & 0 \\
\hline 6 & 0 & 0 & 0 & 1 & 1 & 0 & 0 & 1 & 0 \\
\hline 6 & 0 & 0 & 1 & 0 & 1 & 0 & 1 & 0 & 0 \\
\hline 6 & 0 & 0 & 1 & 0 & 1 & 0 & 1 & 0 & 0 \\
\hline 6 & 1 & 0 & 0 & 0 & 1 & 0 & 1 & 0 & 0 \\
\hline 6 & 0 & 1 & 0 & 0 & 0 & 0 & 1 & 0 & 0 \\
\hline 6 & 0 & 0 & 0 & 1 & 1 & 0 & 1 & 0 & 0 \\
\hline 6 & 0 & 0 & 1 & 0 & 1 & 0 & 1 & 0 & 0 \\
\hline 6 & 0 & 0 & 0 & 1 & 1 & 0 & 0 & 1 & 0 \\
\hline 6 & 0 & 0 & 1 & 0 & 1 & 0 & 0 & 1 & 0 \\
\hline 6 & 0 & 0 & 0 & 1 & 1 & 0 & 1 & 0 & 0 \\
\hline 6 & 0 & 1 & 0 & 0 & 1 & 0 & 1 & 0 & 0 \\
\hline 6 & 0 & 0 & 1 & 0 & 1 & 0 & 1 & 0 & 0 \\
\hline 6 & 1 & 0 & 0 & 0 & 0 & 0 & 1 & 0 & 0 \\
\hline 6 & 0 & 0 & 1 & 0 & 1 & 0 & 0 & 1 & 0 \\
\hline 6 & 0 & 1 & 0 & 0 & 1 & 1 & 0 & 0 & 0 \\
\hline
\end{tabular}


Table F.3

\begin{tabular}{|c|c|c|c|c|c|c|c|c|c|}
\hline PROV & FIN100 & FIN1025 & FIN2550 & FIN500 & AGE46 & FHUOS & FHUOM & FHUOL & RESIDUAL \\
\hline 6 & 0 & 1 & 0 & 0 & 0 & 1 & 0 & 0 & 0 \\
\hline 6 & 0 & 0 & 1 & 0 & 0 & 0 & 1 & 0 & 0 \\
\hline 6 & 0 & 0 & 1 & 0 & 1 & 0 & 0 & 1 & 0 \\
\hline 6 & 0 & 0 & 0 & 1 & 1 & 0 & 1 & 0 & 0 \\
\hline 6 & 0 & 0 & 0 & 1 & 1 & 0 & 1 & 0 & 0 \\
\hline 6 & 0 & 1 & 0 & 0 & 1 & 1 & 0 & 0 & 0 \\
\hline 6 & 0 & 0 & 1 & 0 & 1 & 0 & 1 & 0 & 0 \\
\hline 7 & 0 & 0 & 0 & 0 & 1 & 0 & 0 & 1 & 0 \\
\hline 7 & 0 & 1 & 1 & 0 & 1 & 0 & 1 & 0 & 0 \\
\hline 7 & 0 & 1 & 0 & 0 & 1 & 1 & 0 & 0 & 0 \\
\hline 7 & 0 & 1 & 0 & 0 & 1 & 0 & 0 & 1 & 1 \\
\hline 7 & 0 & 0 & 1 & 0 & 0 & 0 & 0 & 1 & 0 \\
\hline 7 & 0 & 0 & 0 & 1 & 0 & 1 & 0 & 0 & 0 \\
\hline 7 & 0 & 0 & 0 & 1 & 0 & 0 & 0 & 1 & 0 \\
\hline 7 & 0 & 0 & 1 & 0 & 0 & 0 & 1 & 0 & 0 \\
\hline 7 & 0 & 0 & 0 & 0 & 1 & 0 & 0 & 1 & 0 \\
\hline 7 & 1 & 0 & 0 & 0 & 1 & 1 & 0 & 0 & 0 \\
\hline 7 & 0 & 0 & 1 & 0 & 1 & 1 & 0 & 0 & -1 \\
\hline 7 & 0 & 1 & 1 & 0 & 1 & 0 & 0 & 1 & 0 \\
\hline 7 & 1 & 0 & 0 & 0 & 0 & 1 & 0 & 0 & 1 \\
\hline 7 & 0 & 1 & 0 & 0 & 0 & 0 & 1 & 0 & 0 \\
\hline 7 & 0 & 1 & 0 & 0 & 0 & 1 & 0 & 0 & 0 \\
\hline 7 & 1 & 0 & 0 & 0 & 0 & 1 & 0 & 0 & 0 \\
\hline 7 & 0 & 0 & 1 & 0 & 0 & 0 & 0 & 1 & 0 \\
\hline 7 & 1 & 0 & 0 & 0 & 0 & 1 & 0 & 0 & 0 \\
\hline 7 & 0 & 0 & 0 & 1 & 0 & 0 & 1 & 0 & 0 \\
\hline 7 & 1 & 0 & 0 & 0 & 0 & 0 & 1 & 0 & 0 \\
\hline 7 & 0 & 1 & 0 & 0 & 0 & 0 & 1 & 0 & 0 \\
\hline 7 & 0 & 1 & 0 & 0 & 0 & 1 & 0 & 0 & 0 \\
\hline 7 & 0 & 0 & 1 & 0 & 0 & 0 & 1 & 0 & 0 \\
\hline 7 & 0 & 1 & 0 & 0 & 1 & 0 & 1 & 0 & 0 \\
\hline
\end{tabular}


Table F.3

\begin{tabular}{|c|c|c|c|c|c|c|c|c|c|}
\hline PROV & FIN100 & FIN1025 & FIN2550 & FIN500 & AGE46 & FHUOS & FHUOM & FHUOL & RESIDUAL \\
\hline 7 & 0 & 0 & 0 & 1 & 1 & 0 & 1 & 0 & 0 \\
\hline 7 & 0 & 0 & 1 & 0 & 1 & 0 & 0 & 1 & 0 \\
\hline 7 & 0 & 0 & 0 & 1 & 1 & 0 & 1 & 0 & 0 \\
\hline 7 & 0 & 0 & 0 & 1 & 1 & 0 & 0 & 1 & 0 \\
\hline 7 & 0 & 1 & 0 & 0 & 1 & 0 & 1 & 0 & 0 \\
\hline 7 & 0 & 0 & 1 & 0 & 1 & 0 & 1 & 0 & 0 \\
\hline 7 & 0 & 0 & 0 & 1 & 1 & 0 & 1 & 0 & -1 \\
\hline 7 & 0 & 0 & 0 & 1 & 1 & 1 & 0 & 0 & 0 \\
\hline 7 & 0 & 0 & 0 & 1 & 1 & 0 & 1 & 0 & 0 \\
\hline 7 & 0 & 0 & 0 & 1 & 1 & 1 & 0 & 0 & 0 \\
\hline 7 & 0 & 1 & 0 & 0 & 1 & 1 & 0 & 0 & 0 \\
\hline 7 & 0 & 0 & 0 & 1 & 1 & 1 & 0 & 0 & 0 \\
\hline 7 & 0 & 1 & 0 & 0 & 0 & 1 & 0 & 0 & 1 \\
\hline 7 & 0 & 1 & 0 & 0 & 1 & 1 & 0 & 0 & 0 \\
\hline 7 & 0 & 0 & 0 & 1 & 0 & 1 & 0 & 0 & 0 \\
\hline 7 & 1 & 0 & 0 & 0 & 0 & 1 & 0 & 0 & 0 \\
\hline 7 & 0 & 0 & 0 & 1 & 1 & 1 & 0 & 0 & 0 \\
\hline 7 & 1 & 0 & 0 & 0 & 1 & 1 & 0 & 0 & 0 \\
\hline 7 & 0 & 0 & 0 & 0 & 1 & 0 & 1 & 0 & 0 \\
\hline 8 & 0 & 0 & 0 & 1 & 1 & 0 & 1 & 0 & 0 \\
\hline 8 & 0 & 0 & 1 & 0 & 0 & 0 & 1 & 0 & 0 \\
\hline 8 & 0 & 1 & 0 & 0 & 0 & 0 & 1 & 0 & 0 \\
\hline 8 & 0 & 1 & 0 & 0 & 0 & 0 & 1 & 0 & 0 \\
\hline 8 & 1 & 0 & 0 & 0 & 0 & 0 & 1 & 0 & 1 \\
\hline 8 & 1 & 0 & 0 & 0 & 1 & 1 & 0 & 0 & 0 \\
\hline 8 & 0 & 1 & 0 & 0 & 1 & 1 & 0 & 0 & 0 \\
\hline 8 & 0 & 1 & 1 & 0 & 1 & 1 & 0 & 0 & 1 \\
\hline 8 & 0 & 0 & 1 & 0 & 0 & 1 & 0 & 0 & 0 \\
\hline 8 & 0 & 0 & 0 & 1 & 0 & 0 & 1 & 0 & 0 \\
\hline 8 & 0 & 0 & 0 & 1 & 0 & 0 & 1 & 0 & 0 \\
\hline 8 & 0 & 0 & 0 & 0 & 0 & 0 & 0 & 1 & 0 \\
\hline
\end{tabular}


Table F.3

\begin{tabular}{|c|c|c|c|c|c|c|c|c|c|}
\hline PROV & FIN100 & FIN1025 & FIN2550 & FIN500 & AGE46 & FHUOS & FHUOM & FHUOL & RESIDUAL \\
\hline 8 & 0 & 0 & 1 & 0 & 1 & 0 & 0 & 1 & -1 \\
\hline 8 & 0 & 0 & 1 & 0 & 1 & 0 & 1 & 0 & 0 \\
\hline 8 & 0 & 1 & 0 & 0 & 1 & 0 & 0 & 1 & 0 \\
\hline 8 & 0 & 0 & 0 & 1 & 1 & 0 & 1 & 0 & 0 \\
\hline 8 & 0 & 0 & 1 & 0 & 1 & 0 & 0 & 1 & 0 \\
\hline 8 & 0 & 0 & 1 & 0 & 1 & 0 & 0 & 1 & 0 \\
\hline 8 & 0 & 0 & 0 & 1 & 1 & 0 & 1 & 0 & 0 \\
\hline 8 & 0 & 1 & 0 & 0 & 1 & 0 & 0 & 1 & 0 \\
\hline 8 & 0 & 0 & 0 & 1 & 0 & 0 & 1 & 0 & 0 \\
\hline 8 & 0 & 0 & 0 & 1 & 1 & 0 & 1 & 0 & 0 \\
\hline 8 & 0 & 0 & 1 & 0 & 1 & 0 & 1 & 0 & 0 \\
\hline 8 & 0 & 1 & 0 & 0 & 0 & 0 & 1 & 0 & -1 \\
\hline 8 & 1 & 0 & 0 & 0 & 0 & 0 & 1 & 0 & 0 \\
\hline 8 & 0 & 0 & 0 & 1 & 1 & 0 & 1 & 0 & 0 \\
\hline 8 & 0 & 0 & 1 & 0 & 1 & 0 & 0 & 1 & 0 \\
\hline 8 & 1 & 0 & 0 & 0 & 0 & 1 & 0 & 0 & 0 \\
\hline 8 & 0 & 1 & 0 & 0 & 0 & 1 & 0 & 0 & 0 \\
\hline 8 & 0 & 0 & 0 & 1 & 1 & 0 & 0 & 1 & 0 \\
\hline 8 & 0 & 0 & 1 & 0 & 1 & 0 & 1 & 0 & 0 \\
\hline 8 & 0 & 0 & 1 & 0 & 1 & 0 & 1 & 0 & 0 \\
\hline 8 & 0 & 1 & 0 & 0 & 0 & 0 & 1 & 0 & 0 \\
\hline 8 & 1 & 0 & 0 & 0 & 0 & 0 & 1 & 0 & 0 \\
\hline 9 & 0 & 0 & 0 & 1 & 1 & 0 & 1 & 0 & 0 \\
\hline 9 & 0 & 0 & 0 & 1 & 1 & 0 & 0 & 1 & 0 \\
\hline 9 & 0 & 0 & 0 & 1 & 1 & 0 & 0 & 1 & 0 \\
\hline 9 & 0 & 0 & 1 & 0 & 1 & 0 & 1 & 0 & 0 \\
\hline 9 & 0 & 0 & 0 & 0 & 1 & 0 & 0 & 1 & 0 \\
\hline 9 & 0 & 1 & 0 & 1 & 1 & 0 & 1 & 0 & 0 \\
\hline 9 & 1 & 0 & 0 & 0 & 0 & 0 & 1 & 0 & 1 \\
\hline 9 & 0 & 1 & 0 & 0 & 0 & 1 & 0 & 0 & 0 \\
\hline 9 & 0 & 0 & 0 & 0 & 1 & 0 & 1 & 0 & 0 \\
\hline
\end{tabular}


Table F.3

\begin{tabular}{|c|c|c|c|c|c|c|c|c|c|}
\hline PROV & FIN100 & FIN1025 & FIN2550 & FIN500 & AGE46 & FHUOS & FHUOM & FHUOL & RESIDUAL \\
\hline 9 & 0 & 0 & 0 & 1 & 1 & 0 & 1 & 0 & 0 \\
\hline 9 & 1 & 0 & 0 & 0 & 0 & 1 & 0 & 0 & 0 \\
\hline 9 & 0 & 1 & 0 & 0 & 0 & 1 & 0 & 0 & 0 \\
\hline 9 & 1 & 0 & 0 & 0 & 0 & 1 & 0 & 0 & 0 \\
\hline 9 & 0 & 1 & 0 & 0 & 0 & 0 & 1 & 0 & 1 \\
\hline 9 & 0 & 0 & 1 & 0 & 0 & 1 & 0 & 0 & 0 \\
\hline 9 & 0 & 0 & 0 & 1 & 1 & 0 & 0 & 1 & 0 \\
\hline 9 & 0 & 0 & 1 & 0 & 1 & 0 & 1 & 0 & 0 \\
\hline 9 & 0 & 1 & 0 & 0 & 1 & 0 & 1 & 0 & 0 \\
\hline 9 & 0 & 0 & 1 & 0 & 1 & 0 & 1 & 0 & 0 \\
\hline 9 & 0 & 0 & 0 & 1 & 1 & 0 & 0 & 1 & 0 \\
\hline 9 & 0 & 0 & 1 & 0 & 1 & 0 & 0 & 1 & 0 \\
\hline 9 & 0 & 1 & 0 & 0 & 1 & 1 & 0 & 0 & 0 \\
\hline 9 & 0 & 0 & 1 & 0 & 1 & 0 & 1 & 0 & 0 \\
\hline 9 & 0 & 0 & 0 & 1 & 1 & 0 & 1 & 0 & 0 \\
\hline 9 & 0 & 0 & 1 & 0 & 1 & 0 & 1 & 0 & 0 \\
\hline 9 & 0 & 0 & 0 & 1 & 1 & 0 & 0 & 1 & 0 \\
\hline 9 & 0 & 0 & 0 & 1 & 1 & 0 & 1 & 0 & 0 \\
\hline 9 & 0 & 0 & 0 & 1 & 1 & 0 & 1 & 0 & 0 \\
\hline 9 & 0 & 0 & 0 & 1 & 1 & 0 & 1 & 0 & 0 \\
\hline 9 & 0 & 0 & 1 & 0 & 1 & 0 & 1 & 0 & 0 \\
\hline 9 & 0 & 0 & 1 & 0 & 0 & 1 & 0 & 0 & 0 \\
\hline 9 & 0 & 1 & 0 & 0 & 0 & 0 & 1 & 0 & 0 \\
\hline 9 & 0 & 1 & 0 & 0 & 1 & 0 & 1 & 0 & 0 \\
\hline 9 & 0 & 0 & 1 & 0 & 1 & 0 & 1 & 0 & 0 \\
\hline 9 & 0 & 0 & 0 & 0 & 1 & 1 & 0 & 0 & 0 \\
\hline
\end{tabular}


Table F.4

\begin{tabular}{cccccc} 
PROV & FIN250 & FEXP11 & AGE36 & LEDC & FHUOLA \\
\hline 1 & 0 & 1 & 1 & 1 & 0 \\
1 & 0 & 0 & 1 & 0 & 0 \\
1 & 1 & 1 & 1 & 1 & 0 \\
1 & 1 & 0 & 1 & 1 & 1 \\
1 & 1 & 1 & 1 & 1 & 0 \\
1 & 1 & 0 & 1 & 1 & 0 \\
1 & 1 & 0 & 1 & 0 & 0 \\
1 & 1 & 0 & 1 & 1 & 1 \\
1 & 0 & 1 & 0 & 0 & 0 \\
1 & 0 & 1 & 0 & 1 & 1 \\
1 & 1 & 1 & 0 & 1 & 1 \\
1 & 1 & 0 & 1 & 1 & 1 \\
1 & 0 & 1 & 1 & 0 & 0 \\
1 & 0 & 1 & 1 & 0 & 0 \\
1 & 0 & 1 & 1 & 0 & 1 \\
1 & 0 & 1 & 1 & 0 & 1 \\
1 & 1 & 1 & 1 & 0 & 1 \\
1 & 0 & 1 & 1 & 0 & 0 \\
1 & 1 & 0 & 1 & 1 & 1 \\
1 & 1 & 0 & 1 & 1 & 1 \\
1 & 1 & 0 & 1 & 1 & 0 \\
1 & 0 & 1 & 1 & 0 & 1 \\
1 & 1 & 0 & 1 & 1 & 1 \\
1 & 0 & 1 & 1 & 0 & 0 \\
1 & 0 & 1 & 1 & 0 & 0 \\
1 & 1 & 0 & 1 & 1 & 1 \\
1 & 1 & 0 & 1 & 1 & 1 \\
1 & 1 & 0 & 1 & 0 & 1 \\
1 & 0 & 1 & 1 & 0 & 0 \\
1 & 0 & 1 & 1 & 0 & 1 \\
1 & 0 & 1 & 1 & 0 & 0 \\
& 1 & & & &
\end{tabular}


Table F.4

\begin{tabular}{cccccc} 
PROV & FIN250 & FEXP11 & AGE36 & LEDC & FHUOLA \\
\hline 1 & 0 & 1 & 1 & 1 & 0 \\
1 & 0 & 1 & 1 & 0 & 0 \\
1 & 1 & 0 & 1 & 1 & 1 \\
1 & 1 & 0 & 1 & 1 & 1 \\
1 & 0 & 0 & 1 & 0 & 0 \\
1 & 0 & 1 & 1 & 0 & 1 \\
2 & 1 & 0 & 1 & 1 & 1 \\
2 & 1 & 0 & 1 & 1 & 1 \\
2 & 1 & 0 & 1 & 1 & 0 \\
2 & 1 & 0 & 1 & 1 & 1 \\
2 & 0 & 1 & 1 & 0 & 0 \\
2 & 0 & 1 & 1 & 0 & 0 \\
2 & 0 & 1 & 1 & 0 & 0 \\
2 & 1 & 0 & 1 & 1 & 1 \\
2 & 1 & 0 & 1 & 1 & 1 \\
2 & 0 & 1 & 1 & 0 & 0 \\
2 & 0 & 1 & 1 & 0 & 0 \\
2 & 0 & 0 & 1 & 0 & 0 \\
2 & 1 & 0 & 1 & 1 & 1 \\
2 & 1 & 0 & 1 & 0 & 1 \\
2 & 1 & 0 & 1 & 1 & 1 \\
2 & 0 & 1 & 0 & 0 & 0 \\
2 & 0 & 1 & 0 & 0 & 0 \\
2 & 1 & 1 & 1 & 0 & 0 \\
2 & 0 & 1 & 1 & 0 & 0 \\
2 & 0 & 1 & 0 & 0 & 0 \\
2 & 0 & 0 & 1 & 1 & 1 \\
2 & 1 & 0 & 1 & 1 & 1 \\
2 & 1 & 0 & 1 & 1 & 1 \\
2 & 0 & 1 & 0 & 0 & 1 \\
2 & 0 & 1 & 1 & 0 & 0 \\
& & & & &
\end{tabular}


Table F.4

\begin{tabular}{cccccc} 
PROV & FIN250 & FEXP11 & AGE36 & LEDC & FHUOLA \\
\hline 2 & 0 & 1 & 1 & 0 & 0 \\
2 & 1 & 0 & 1 & 0 & 0 \\
2 & 1 & 0 & 0 & 1 & 1 \\
2 & 1 & 0 & 1 & 1 & 1 \\
2 & 1 & 0 & 1 & 1 & 1 \\
2 & 1 & 0 & 1 & 1 & 1 \\
2 & 1 & 0 & 1 & 1 & 1 \\
2 & 1 & 0 & 1 & 1 & 1 \\
2 & 1 & 0 & 1 & 1 & 1 \\
2 & 0 & 1 & 1 & 0 & 1 \\
2 & 1 & 0 & 1 & 0 & 1 \\
2 & 0 & 1 & 1 & 0 & 1 \\
2 & 0 & 1 & 1 & 0 & 1 \\
2 & 1 & 0 & 1 & 0 & 1 \\
2 & 1 & 0 & 1 & 1 & 1 \\
2 & 1 & 0 & 1 & 1 & 1 \\
2 & 0 & 1 & 0 & 0 & 0 \\
2 & 0 & 1 & 1 & 0 & 0 \\
2 & 0 & 1 & 1 & 0 & 0 \\
2 & 0 & 1 & 0 & 0 & 0 \\
2 & 0 & 1 & 1 & 0 & 1 \\
2 & 1 & 0 & 1 & 1 & 1 \\
2 & 1 & 0 & 1 & 0 & 1 \\
2 & 1 & 0 & 1 & 1 & 1 \\
2 & 1 & 0 & 1 & 1 & 1 \\
2 & 1 & 0 & 1 & 1 & 1 \\
2 & 1 & 0 & 1 & 1 & 1 \\
2 & 1 & 0 & 1 & 1 & 1 \\
2 & 1 & 0 & 1 & 1 & 1 \\
2 & 0 & 1 & 1 & 0 & 0 \\
2 & 1 & 1 & 1 & 0 & 0 \\
& & & & &
\end{tabular}


Table F.4

\begin{tabular}{cccccc} 
PROV & FIN250 & FEXP11 & AGE36 & LEDC & FHUOLA \\
\hline 2 & 1 & 0 & 1 & 0 & 1 \\
2 & 1 & 0 & 1 & 0 & 1 \\
2 & 1 & 0 & 1 & 0 & 1 \\
2 & 0 & 1 & 0 & 0 & 1 \\
2 & 1 & 1 & 1 & 0 & 1 \\
2 & 1 & 1 & 1 & 0 & 0 \\
2 & 1 & 1 & 1 & 1 & 1 \\
3 & 0 & 1 & 1 & 0 & 0 \\
3 & 1 & 0 & 1 & 1 & 1 \\
3 & 1 & 0 & 1 & 0 & 1 \\
3 & 1 & 0 & 1 & 1 & 0 \\
3 & 1 & 0 & 1 & 1 & 1 \\
3 & 0 & 1 & 1 & 0 & 1 \\
3 & 0 & 1 & 0 & 1 & 0 \\
3 & 1 & 0 & 1 & 0 & 1 \\
3 & 1 & 0 & 1 & 1 & 1 \\
3 & 0 & 1 & 1 & 0 & 1 \\
3 & 1 & 0 & 1 & 1 & 1 \\
3 & 1 & 0 & 1 & 1 & 1 \\
3 & 1 & 0 & 1 & 1 & 1 \\
3 & 1 & 0 & 1 & 1 & 1 \\
3 & 1 & 0 & 1 & 1 & 1 \\
3 & 1 & 0 & 1 & 1 & 1 \\
3 & 1 & 0 & 1 & 1 & 1 \\
3 & 0 & 1 & 0 & 0 & 0 \\
3 & 0 & 1 & 1 & 0 & 0 \\
3 & 1 & 0 & 1 & 1 & 1 \\
3 & 1 & 0 & 1 & 1 & 1 \\
3 & 1 & 0 & 1 & 1 & 1 \\
3 & 1 & 0 & 1 & 1 & 1 \\
3 & 0 & 1 & 1 & 0 & 0 \\
& & & & &
\end{tabular}


Table F.4

\begin{tabular}{cccccc} 
PROV & FIN250 & FEXP11 & AGE36 & LEDC & FHUOLA \\
\hline 3 & 0 & 1 & 0 & 0 & 0 \\
4 & 1 & 0 & 1 & 0 & 0 \\
4 & 0 & 1 & 0 & 1 & 1 \\
4 & 0 & 1 & 1 & 1 & 0 \\
4 & 0 & 1 & 1 & 0 & 1 \\
4 & 1 & 1 & 0 & 1 & 0 \\
4 & 1 & 1 & 1 & 1 & 1 \\
4 & 0 & 1 & 1 & 1 & 0 \\
4 & 1 & 0 & 1 & 0 & 1 \\
4 & 1 & 1 & 1 & 1 & 1 \\
4 & 1 & 1 & 1 & 0 & 0 \\
4 & 1 & 1 & 1 & 1 & 0 \\
4 & 0 & 1 & 1 & 1 & 1 \\
4 & 0 & 1 & 1 & 1 & 0 \\
4 & 1 & 1 & 1 & 1 & 1 \\
4 & 1 & 1 & 1 & 0 & 0 \\
4 & 1 & 0 & 1 & 1 & 1 \\
4 & 1 & 0 & 1 & 1 & 1 \\
4 & 1 & 0 & 1 & 1 & 0 \\
4 & 1 & 1 & 1 & 1 & 0 \\
4 & 1 & 0 & 1 & 1 & 1 \\
4 & 1 & 0 & 1 & 1 & 1 \\
4 & 1 & 0 & 1 & 1 & 1 \\
4 & 1 & 0 & 1 & 1 & 1 \\
4 & 0 & 0 & 1 & 1 & 1 \\
4 & 1 & 0 & 1 & 1 & 1 \\
4 & 1 & 0 & 1 & 1 & 1 \\
4 & 1 & 0 & 1 & 1 & 1 \\
4 & 1 & 0 & 1 & 1 & 1 \\
4 & 0 & 1 & 0 & 0 & 1 \\
4 & 1 & 0 & 0 & 1 & 1 \\
& 1 & & & &
\end{tabular}


Table F.4

\begin{tabular}{cccccc} 
PROV & FIN250 & FEXP11 & AGE36 & LEDC & FHUOLA \\
\hline 4 & 1 & 0 & 0 & 1 & 1 \\
4 & 1 & 0 & 0 & 1 & 1 \\
4 & 0 & 1 & 1 & 0 & 0 \\
4 & 1 & 0 & 1 & 0 & 1 \\
4 & 1 & 0 & 1 & 1 & 1 \\
4 & 1 & 0 & 1 & 1 & 1 \\
4 & 1 & 0 & 1 & 1 & 1 \\
4 & 0 & 1 & 1 & 0 & 1 \\
4 & 1 & 1 & 1 & 0 & 1 \\
4 & 0 & 1 & 0 & 0 & 0 \\
4 & 1 & 0 & 1 & 0 & 1 \\
4 & 1 & 1 & 1 & 1 & 0 \\
4 & 1 & 1 & 1 & 1 & 0 \\
5 & 1 & 0 & 1 & 1 & 0 \\
5 & 0 & 1 & 0 & 0 & 1 \\
5 & 0 & 1 & 1 & 0 & 0 \\
5 & 0 & 1 & 0 & 0 & 0 \\
5 & 0 & 1 & 1 & 0 & 0 \\
5 & 0 & 1 & 1 & 0 & 1 \\
5 & 1 & 0 & 1 & 0 & 0 \\
5 & 1 & 0 & 1 & 1 & 1 \\
5 & 1 & 0 & 1 & 1 & 1 \\
5 & 1 & 0 & 1 & 1 & 1 \\
5 & 1 & 0 & 1 & 1 & 1 \\
5 & 1 & 0 & 1 & 1 & 1 \\
5 & 1 & 0 & 1 & 0 & 1 \\
5 & 0 & 1 & 1 & 0 & 0 \\
5 & 0 & 1 & 1 & 0 & 0 \\
5 & 0 & 1 & 1 & 0 & 0 \\
5 & 0 & 1 & 1 & 1 & 0 \\
5 & 1 & 0 & 1 & 1 & 1 \\
& 1 & & & &
\end{tabular}


Table F.4

\begin{tabular}{cccccc} 
PROV & FIN250 & FEXP11 & AGE36 & LEDC & FHUOLA \\
\hline 5 & 0 & 1 & 1 & 0 & 1 \\
5 & 1 & 1 & 1 & 1 & 1 \\
5 & 1 & 0 & 1 & 1 & 1 \\
5 & 1 & 0 & 1 & 0 & 0 \\
5 & 1 & 1 & 1 & 1 & 0 \\
5 & 0 & 1 & 1 & 1 & 0 \\
5 & 0 & 1 & 1 & 1 & 0 \\
6 & 1 & 1 & 1 & 1 & 1 \\
6 & 1 & 1 & 1 & 1 & 1 \\
6 & 1 & 0 & 1 & 1 & 1 \\
6 & 1 & 0 & 1 & 1 & 1 \\
6 & 0 & 0 & 1 & 0 & 0 \\
6 & 1 & 0 & 1 & 0 & 1 \\
6 & 1 & 0 & 1 & 1 & 1 \\
6 & 1 & 0 & 0 & 1 & 1 \\
6 & 1 & 0 & 1 & 1 & 1 \\
6 & 1 & 0 & 1 & 1 & 1 \\
6 & 1 & 0 & 1 & 1 & 1 \\
6 & 1 & 1 & 1 & 1 & 1 \\
6 & 0 & 1 & 1 & 0 & 1 \\
6 & 0 & 1 & 0 & 0 & 1 \\
6 & 1 & 1 & 1 & 1 & 1 \\
6 & 1 & 0 & 1 & 1 & 1 \\
6 & 1 & 0 & 1 & 1 & 1 \\
6 & 1 & 0 & 1 & 0 & 1 \\
6 & 1 & 1 & 1 & 1 & 1 \\
6 & 0 & 0 & 1 & 0 & 1 \\
6 & 1 & 0 & 1 & 0 & 1 \\
6 & 0 & 1 & 1 & 0 & 1 \\
6 & 1 & 0 & 1 & 1 & 1 \\
6 & 0 & 1 & 1 & 0 & 0 \\
& 1 & & & &
\end{tabular}


Table F.4

\begin{tabular}{cccccc}
\hline PROV & FIN250 & FEXP11 & AGE36 & LEDC & FHUOLA \\
\hline 6 & 0 & 1 & 1 & 0 & 0 \\
6 & 1 & 0 & 1 & 1 & 1 \\
6 & 1 & 0 & 1 & 1 & 1 \\
6 & 1 & 0 & 1 & 1 & 1 \\
6 & 1 & 0 & 1 & 1 & 1 \\
6 & 0 & 1 & 1 & 0 & 0 \\
6 & 1 & 0 & 1 & 0 & 1 \\
7 & 0 & 1 & 1 & 0 & 1 \\
7 & 1 & 1 & 1 & 1 & 1 \\
7 & 0 & 1 & 1 & 0 & 0 \\
7 & 0 & 1 & 1 & 1 & 1 \\
7 & 1 & 1 & 1 & 0 & 1 \\
7 & 1 & 1 & 1 & 0 & 0 \\
7 & 1 & 0 & 1 & 1 & 1 \\
7 & 1 & 0 & 1 & 0 & 1 \\
7 & 0 & 0 & 1 & 0 & 1 \\
7 & 0 & 1 & 1 & 0 & 0 \\
7 & 1 & 1 & 1 & 0 & 0 \\
7 & 1 & 1 & 1 & 1 & 1 \\
7 & 0 & 1 & 0 & 0 & 0 \\
7 & 0 & 1 & 1 & 0 & 1 \\
7 & 0 & 1 & 1 & 0 & 0 \\
7 & 0 & 0 & 1 & 0 & 0 \\
7 & 1 & 1 & 1 & 0 & 1 \\
7 & 0 & 1 & 0 & 0 & 0 \\
7 & 1 & 0 & 1 & 1 & 1 \\
7 & 0 & 1 & 1 & 0 & 1 \\
7 & 0 & 1 & 1 & 0 & 1 \\
7 & 0 & 1 & 0 & 1 & 0 \\
7 & 1 & 1 & 1 & 1 & 1 \\
7 & 0 & 1 & 1 & 0 & 1 \\
& & & & &
\end{tabular}


Table F.4

\begin{tabular}{cccccc} 
PROV & FIN250 & FEXP11 & AGE36 & LEDC & FHUOLA \\
\hline 7 & 1 & 0 & 1 & 1 & 1 \\
7 & 1 & 0 & 1 & 1 & 1 \\
7 & 1 & 0 & 1 & 0 & 1 \\
7 & 1 & 0 & 1 & 1 & 1 \\
7 & 0 & 1 & 1 & 1 & 1 \\
7 & 1 & 0 & 1 & 0 & 1 \\
7 & 1 & 1 & 1 & 1 & 1 \\
7 & 1 & 1 & 1 & 1 & 0 \\
7 & 1 & 1 & 1 & 0 & 1 \\
7 & 1 & 1 & 1 & 1 & 0 \\
7 & 0 & 1 & 1 & 1 & 0 \\
7 & 1 & 1 & 1 & 0 & 0 \\
7 & 0 & 1 & 0 & 1 & 0 \\
7 & 0 & 0 & 1 & 1 & 0 \\
7 & 1 & 1 & 0 & 1 & 0 \\
7 & 0 & 1 & 1 & 0 & 0 \\
7 & 1 & 1 & 1 & 0 & 0 \\
7 & 0 & 1 & 1 & 1 & 0 \\
7 & 0 & 1 & 1 & 0 & 1 \\
8 & 1 & 1 & 1 & 1 & 1 \\
8 & 1 & 0 & 1 & 1 & 1 \\
8 & 0 & 0 & 1 & 1 & 1 \\
8 & 0 & 1 & 0 & 0 & 1 \\
8 & 0 & 1 & 0 & 0 & 1 \\
8 & 0 & 1 & 1 & 0 & 0 \\
8 & 0 & 1 & 1 & 0 & 0 \\
8 & 1 & 1 & 1 & 0 & 0 \\
8 & 1 & 1 & 0 & 0 & 0 \\
8 & 1 & 0 & 1 & 1 & 1 \\
8 & 1 & 0 & 1 & 1 & 1 \\
8 & 0 & 0 & 1 & 1 & 1 \\
& 0 & & & &
\end{tabular}


Table F.4

\begin{tabular}{cccccc} 
PROV & FIN250 & FEXP11 & AGE36 & LEDC & FHUOLA \\
\hline 8 & 1 & 0 & 1 & 1 & 1 \\
8 & 1 & 0 & 1 & 1 & 1 \\
8 & 0 & 0 & 1 & 1 & 1 \\
8 & 1 & 0 & 1 & 1 & 1 \\
8 & 1 & 0 & 1 & 1 & 1 \\
8 & 1 & 0 & 1 & 1 & 1 \\
8 & 1 & 0 & 1 & 1 & 1 \\
8 & 0 & 0 & 1 & 1 & 1 \\
8 & 1 & 0 & 0 & 1 & 1 \\
8 & 1 & 0 & 1 & 1 & 1 \\
8 & 1 & 0 & 1 & 1 & 1 \\
8 & 0 & 1 & 0 & 1 & 1 \\
8 & 0 & 1 & 0 & 1 & 1 \\
8 & 1 & 0 & 1 & 1 & 1 \\
8 & 1 & 0 & 1 & 1 & 1 \\
8 & 0 & 1 & 1 & 0 & 0 \\
8 & 0 & 1 & 1 & 0 & 0 \\
8 & 1 & 0 & 1 & 1 & 1 \\
8 & 1 & 0 & 1 & 1 & 1 \\
8 & 1 & 0 & 1 & 1 & 1 \\
8 & 0 & 1 & 1 & 0 & 1 \\
8 & 0 & 1 & 0 & 0 & 1 \\
9 & 1 & 0 & 1 & 1 & 1 \\
9 & 1 & 0 & 1 & 1 & 1 \\
9 & 1 & 0 & 1 & 1 & 1 \\
9 & 1 & 0 & 1 & 1 & 1 \\
9 & 0 & 0 & 1 & 0 & 1 \\
9 & 1 & 0 & 1 & 1 & 1 \\
9 & 0 & 1 & 1 & 1 & 1 \\
9 & 0 & 1 & 1 & 0 & 0 \\
9 & 0 & 1 & 1 & 0 & 1 \\
& 1 & & & &
\end{tabular}


Table F.4

\begin{tabular}{cccccc} 
PROV & FIN250 & FEXP11 & AGE36 & LEDC & FHUOLA \\
\hline 9 & 1 & 1 & 1 & 1 & 1 \\
9 & 0 & 1 & 0 & 0 & 0 \\
9 & 0 & 1 & 0 & 0 & 0 \\
9 & 0 & 1 & 0 & 0 & 0 \\
9 & 0 & 1 & 1 & 0 & 1 \\
9 & 1 & 1 & 1 & 1 & 0 \\
9 & 1 & 0 & 1 & 1 & 1 \\
9 & 1 & 0 & 1 & 1 & 1 \\
9 & 0 & 1 & 1 & 1 & 1 \\
9 & 1 & 0 & 1 & 1 & 1 \\
9 & 1 & 0 & 1 & 1 & 1 \\
9 & 1 & 0 & 1 & 1 & 1 \\
9 & 0 & 0 & 1 & 1 & 0 \\
9 & 1 & 0 & 1 & 1 & 1 \\
9 & 1 & 0 & 1 & 1 & 1 \\
9 & 1 & 0 & 1 & 1 & 1 \\
9 & 1 & 0 & 1 & 0 & 1 \\
9 & 1 & 0 & 1 & 0 & 1 \\
9 & 1 & 0 & 1 & 1 & 1 \\
9 & 1 & 0 & 1 & 1 & 1 \\
9 & 1 & 0 & 1 & 1 & 1 \\
9 & 1 & 0 & 1 & 0 & 0 \\
9 & 0 & 1 & 1 & 0 & 1 \\
9 & 0 & 0 & 1 & 0 & 1 \\
9 & 1 & 1 & 1 & 1 & 1 \\
9 & 0 & 1 & 1 & 1 & 0
\end{tabular}

